\title{
ESTUDO DA DINÂMICA E CONFORMAÇÃO DE POLÍMEROS UTILIZANDO-SE TÉCNICAS AVANÇADAS DE RMN NO ESTADO SÓLIDO
} (EXCHANGE E DOUBLE QUANTUM)

\author{
FÁBIO BECKER GUEDES
}

\section{USPAFSC/SBI [1110111III 8-2-001424}

Tese apresentada ao Instituto de Física de São Carlos, da Universidade de São Paulo, para Đotenção do título de Doutor em Ciênciass: Física Aplicada.

Orientador: Prof. Dr. Tito José Bonagamba SÃO CARLOS 


\section{Becker-Guedes, Fábio}

Estudo da Dinâmica e Conformação de Polímeros Utilizando-se Técnicas Avançadas de RMN no Estado Sólido (Exchange e Double Quantum).--São Carlos, 2001.

$163 \mathrm{p}$. $\ldots$

Tese (Doutorado)--Instituto de Física de São Carlos, 2001

Orientador: Prof. Dr. Tito José Bonagamba

1.Ressonância Magnética Nuclear. 2.Polímeros. I. Título. 


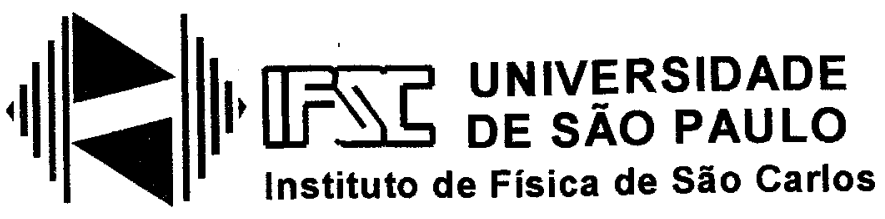

MEMBROS DA COMISSÃO JULGADORA DA TESE DE DOUTORADO DE FÁBIO BECKER GLEDES, APRESENTADA AO INSTITUTO DE FÍSICA dE SÃo CARLOS, UNIVERSIDAdE DE SÃo PAULO, EM 29-11-2001.

\section{COMISSÃO JULGADORA:}

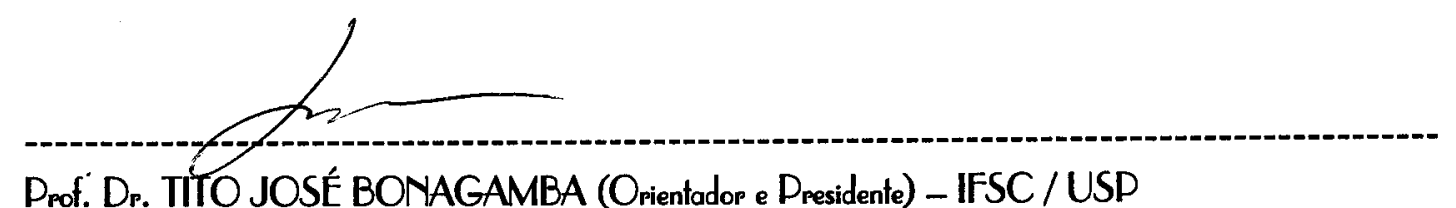

Drof. Dr. TITO JOSÉ BONAGAMBA (Orientador e Presidente) - IFSC / USP

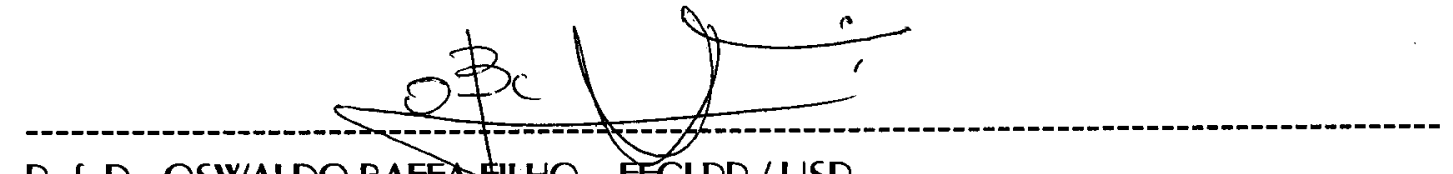

Prof. Dr. OSWALDO BAFFA FIUHO _ FFCLRD / USP

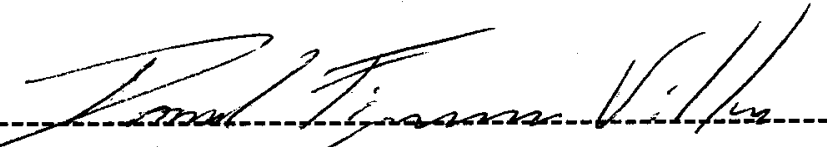

Drof. Dr. JOSÉ DANIEL DE FIGUEROA VILLAR - IME

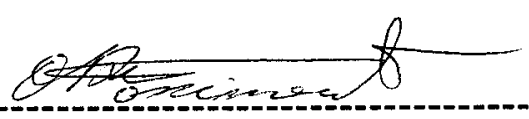

Drof. Dr. OTACIRO RANGEL NASCIMENTO - IFSC / USP

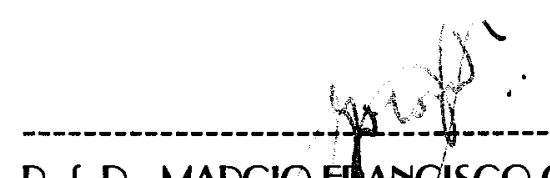

Prof. Dr. MARCIO FRANCISCO COLOMBO - UNESD / S.J.Rio Preto 
Para minha mãe ARLETE. 
"Terão verdadeiramente clareza de pensamento aqueles que tratarem as coisas simples com a merecida importância, e as coisas importantes com a devida simplicidade." (Hammed - A Imensidão dos Sentidos, 2000) 


\section{AGRADECIMENTOS}

O lugar de honra desta lista de agradecimentos deve pertencer, sem sombra de dúvidas, ao meu orientador Prof. Tito José Bonagamba. Sua participação no andamento deste projeto não se restringiu ao lado científico - que teve uma imensa colaboração de sua parte - mas sempre incluiu a questão humana e pessoal. Por isso e muito mais, muito obrigado. Através da sua disponibilidade em me receber em Amherst nos EUA, por ocasião de um pós-doutoramento, tive a oportunidade de conviver e trabalhar por 6 meses com o Prof. Klaus Schmidt-Rohr no Polymer Science and Engineering Department / University of Massachusetts. Ao Prof. Schmidt-Rohr deixo o meu agradecimento pela acolhida que recebi nos 6 meses em que pude participar de sua equipe e, também, pelas suas contribuições para este trabalho. Para não se injusto, eu não poderia deixar de citar entre os primeiros Eduardo Ribeiro de Azevedo, colega de laboratório, que tornou-se muito mais que isso. As discussões pertinentes a esse trabalho e outros relacionados foram sempre muito produtivas, contribuindo sobremaneira para minha formação nessa área. A você Eduardo, meu agradecimento. Gostaria de agradecer sinceramente ao Prof. Horácio Carlos Panepucci por me receber como seu aluno durante os estágios de meu orientador no exterior durante determinados períodos desta tese. Como sem uma máquina de RMN funcionando este trabalho nunca seria realizado e como o nosso espectrômetro teimava em não querer cooperar, devo citar aqui o nome de Edson Luiz Gea Vidoto, técnico de nível superior de nosso grupo que sempre conseguiu dar um "jeitinho" para que a pesquisa não parasse. Muito obrigado Edson. Pelas diversas "pequenas" contribuições, que foram sempre indispensáveis para o todo de um projeto como este, agradeço aos técnicos do Grupo de Ressonância: João Gomes 
da Silva, José Carlos Gazziro, Mateus José Martins e Odir Adolfo Canevarollo e às secretárias: Isabel Possatto e Leila Lamon. Também contribuíram para este trabalho todo o pessoal da biblioteca do IFSC com o seu esforço em oferecer uma nova biblioteca de física, com instalações e atendimento de altíssima qualidade. A todos vocês muito obrigado. Agradeço também aòs professores e colegas do Grupo de Ressonância que sempre fizeram valer a sua presença nessa área comum que escolhemos. Não poderia deixar de agradecer a todas as outras pessoas, não citadas nominalmente aqui, que direta ou indiretamente contribuiram para que este trabalho fosse realizado. Finalmente agradeço a FAPESP, CAPES, FINEP e CNPq pelo financiamento deste projeto.

Além do apoio para o projeto especificamente científico, existe aquele que não constitui-se de uma contribuição direta para a realização deste trabalho, mas que foi de fundamental importância, ao passo que deu-me condições para concretizá-lo. Inicialmente, quero agradecer enfaticamente à Jane, à Vitória e à Júlia, pelo apoio carinhoso durante minha estadia nos EUA. Entre os diversos amigos e pessoas da família que gostaria de agradecer, tenho que citar as figuras marcantes de meu pai Amadeu, minha irmã Fátima, e meus quatro avós: José, Dulcínia, Waldemar e Margarete. A todos vocês muito obrigado pelo apoio e pela presença constantes. Do fundo do meu coração, agradeço à minha mãe por ter aberto os meus olhos para o caminho da física dez anos atrás. Agradeço também aos amigos do grupo Ana Nery: Ariuska, Beto, Éder, Jair, Judite, Mara, Marcus, Sebastiana e Sílvia. Por vocês me ajudarem a lembrar que aquilo que a ciência atual ainda não pode explicar também merece ser estudado e vivido, o meu muito obrigado. À minha esposa Claudia, que durante estes quatro anos conseguiu a façanha de estar sempre ao meu lado - até mesmo quando a ciência teve que nos separar por alguns meses. À você, minha luz, 
meu amoroso agradecimento pela sua presença na minha vida.

Por fim, acima de tudo, agradeço a Deus, por amar incondicionalmente e com a mesma intensidade todas as pessoas que se envolveram de uma forma ou de outra neste trabalho, dando-as condições para fazerem a sua parte. 


\section{Sumário}

Lista de Figuras....................................................................................... ii

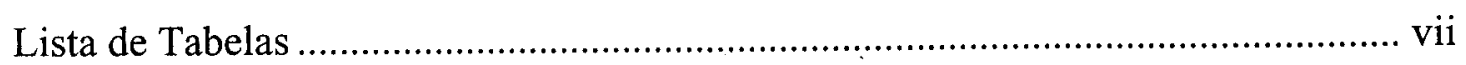

Lista de Abreviaturas e Siglas ...................................................................... viii

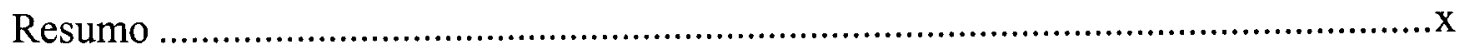

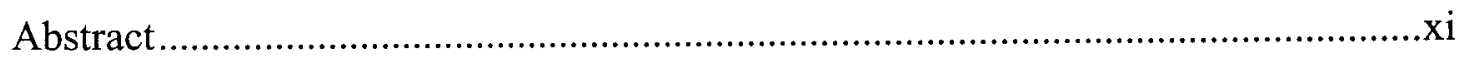

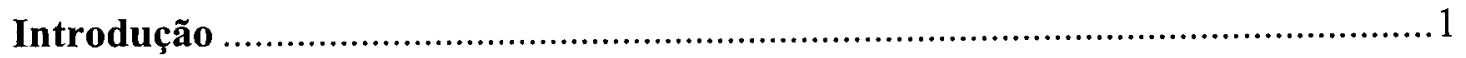

Capítulo I: Técnicas de Exchange para Análise da Dinâmica Molecular .............8

1.1 Exchange Convencional e o Estudo de Movimentos Moleculares Lentos........9

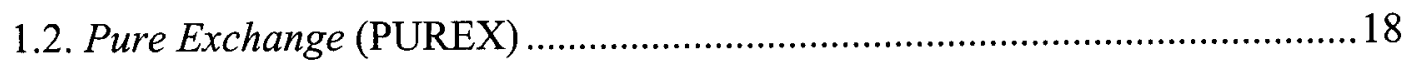

1.3. Centerband-Only Detection of Exchange (CODEX) ................................26

Capítulo II: Técnica Double Quantum para Análise da Estrutura Molecular....34

2.1. Determinação de Ângulos de Torção por RMN ...........................................34

2.2. Princípios do Experimento Double Quantum ................................................37

2.3. Modulação do Sinal Devido ao Double Quantum ........................................40

2.4. Manifestação do Ângulo de Torção na Forma do Espectro DQ.....................55

2.5. Detalhes da Seqüência de Pulsos ............................................................59

2.6. Experimento DQ com Desacoplamento Homonuclear ${ }^{13} \mathrm{C}-{ }^{13} \mathrm{C} \ldots \ldots \ldots \ldots \ldots \ldots \ldots . . . .61$

2.7. Exemplos de Aplicação da Técnica .............................................................64

2.7.1. POE Amorfo: DQ e as Predições do Modelo RIS ....................................65

2.7.2. POE Cristalino: Aplicação da Técnica DQ com Dec ${ }^{13} \mathrm{C}-{ }^{13} \mathrm{C}$...................69

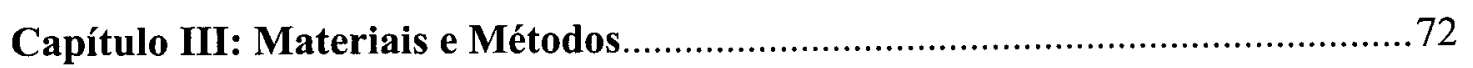

3.1. Características Gerais dos Polímeros.......................................................73

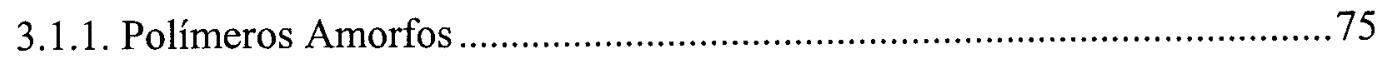

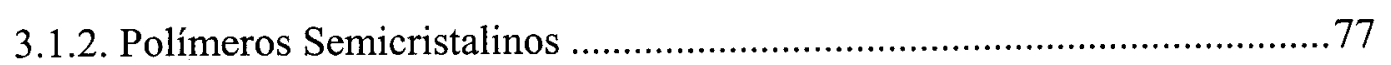

3.1.3. Configurações Rotacionais em Polímeros .............................................78 
3.2. Resumo Sobre as Técnicas de Relaxação Dinâmica .81

3.2.1. Mecanismos Moleculares de Relaxação ................................................83

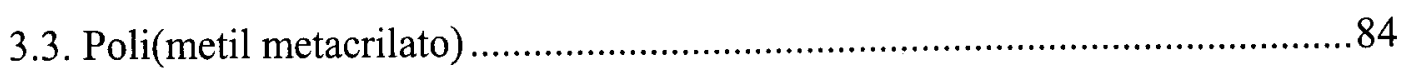

3.3.1. Poli(alquil metacrilato)s e Poli(acrilatos $\alpha$-substituído)s ........................89

3.3.2. Polímeros Estudados Neste Trabalho ...................................................91

3.4. Princípios das Simulações das Curvas de Exchange ....................................94

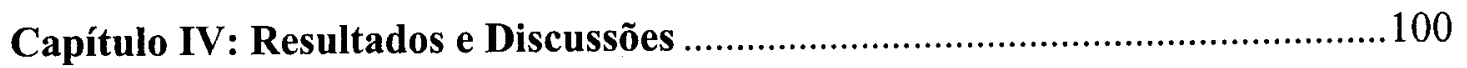

4.1. Dinâmica Lenta em PRMAs e PM $\alpha$ As ................................................... 101

4.1.1. Aplicações da Técnica CODEX .........................................................103

4.1.2. Reavaliação dos Dados Obtidos para os PRMAs em Função de $N t_{\mathrm{r}}$...... 115

4.1:3. Estudo das Curvas PUREX em Função de $2 \tau$......................................137

4.2. Resultados Experimentais Obtidos no Estudo da Técnica DQ....................147

4.2.1. Experimentos de DQ no POE/PNP e no PET .......................................147

4.2.2. Experimentos DQ em Complexos de POE com Sais de Metais

Alcalinos

Capítulo V: Conclusões e Perspectivas 154

Referências .159 


\section{Lista de Figuras}

Figura 1.1: Representação do poli(metil metacrilato) (PMMA) e os eixos principais do tensor de deslocamento químico do ${ }^{13} \mathrm{C}$ do grupo carboxil

Figura 1.2: Espectro de pó simulado do ${ }^{13} \mathrm{C}$ do grupo carboxil no PMMA com os respectivos parâmetros tensoriais.

Figura 1.3: Diagrama que mostra a ocorrência de movimentos lentos de exchange entre dois picos

Figura 1.4: Princípio de um experimento de exchange para detectar reorientações por movimento

Figura 1.5: Reorientação molecular manifestando-se no sinal de exchange 1D ........16

Figura 1.6: Espectros de exchange 2D para quatro ângulos de reorientação ..............18

Figura 1.7: Espectros de exchange 2D para o DMS ..................................................20

Figura 1.8: Seqüências de pulsos necessárias para obtenção do sinal PUREX 1D ....21

Figura 1.9: Seqüências de pulsos necessárias para obtenção do sinal CODEX .........27

Figura 1.10: Reintrodução do deslocamento químico anisotrópico depois de um período de rotação do rotor

Figura 1.11: Reintrodução do deslocamento químico anisotrópico por um pulso $\pi$ para se observar o movimento durante $t_{\mathrm{m}}$ no experimento CODEX ......29

Figura 1.12: Exemplo da geração de um espectro apenas dos segmentos móveis ....31

Figura 1.13: Exemplo de aplicação da técnica CODEX para o estudo

da amplitude de movimentos moleculares lentos.

Figura 2.1: Comparação entre os espectros 2D obtidos pelas técnicas de double quantum e de exchange......

Figura 2.2: Esquema da seqüência de pulsos básica necessária para a geração da coerência de double quantum

Figura 2.3: Representação do subespaço tridimensional de operadores

Figura 2.4: Representação dos subespaços tridimensionais de operadores em evolução sob a hamiltoniana $H_{B}$. 
Figura 2.5: Representação gráfica da evolução dos estados iniciais (1)

e (2) do grupo Y na Tabela I devido a $H_{(-C) D}$ e $H_{C D}$

Figura 2.6: Representação gráfica da evolução dos estados iniciais (1)

e (2) do grupo $\mathrm{X}$ na Tabela I devido a $H_{(-C) D}$ e $H_{C D}$.

Figura 2.7: Representação gráfica da evolução dos operadores produto (1)

e (2) do grupo Y na Tabela I sob o trecho $\tau \rightarrow \pi(\mathrm{b}) \rightarrow \tau$

da excitação DQ da seqüência de pulsos da Figura 2.2.

Figura 2.8: Representação gráfica da evolução dos operadores produto (1)

e (2) do grupo X na Tabela I sob um trecho $\tau \rightarrow \pi(\mathrm{b}) \rightarrow \tau$

da excitação DQ.

Figura 2.9: Exemplos de espectros de correlação de coerências double-quantum

e single-quantum para o $\mathrm{POE}$

Figura 2.10: Representações dos sistemas de eixos principais para dois sítios de carbono em uma ligação C-C de uma cadeia polimérica com $\psi=0$ e $\psi \neq 0$

Figura 2.11: Esquema que representa a formação de dois espectros 2D

DQ com ângulos de torção distintos em uma ligação ${ }^{13} \mathrm{C}_{a}-{ }^{13} \mathrm{C}_{b}$

Figura 2.12: Seqüência de pulsos do experimento de double quantum voltado para o estudo de amostras sólidas....

Figura 2.13: Obtenção do desacoplamento homonuclear para o experimento double quantum

Figura 2.14: Espectros double quantum de ${ }^{13} \mathrm{C}$ simulados para o POE enriquecido com pares ${ }^{13} \mathrm{C}-{ }^{13} \mathrm{C}$ sem/com desacoplamento homonuclear

Figura 2.15: Espectros experimentais e simulados de double quantum para (a) POE/HCT e (b) POE/MoS

Figura 2.16: Espectro de double quantum para o POE/RES sem desacoplamento dipolar homonuclear medido em $75,5 \mathrm{MHz}$ para o ${ }^{13} \mathrm{C} \mathrm{a}-23^{\circ} \mathrm{C}$

Figura 2.17: Espectros de double quantum de ${ }^{13} \mathrm{C}$ para o POE/PNP medido em $75,5 \mathrm{MHz}$ a $20^{\circ} \mathrm{C}$.

Figura 3.1: Diagrama da temperatura versus o peso molecular em polímeros amorfos e semicristalinos 
Figura 3.2: Exemplos de ângulos de torção em uma ligação química... .78

Figura 3.3: Possibilidades mais prováveis de transições de conformação em uma cadeia: gtt - ttg e ttt-gtg

Figura 3.4: Isomerismo estrutural em polímeros do tipo $-\mathrm{CXY}-\mathrm{CH}_{2}$

Figura 3.5: Dependência dos parâmetros dinâmico-dinâmicos $G^{\prime}$ e $\Lambda$ com a temperatura para o PMMA a $1 \mathrm{~Hz}$.

Figura 3.6: Representação da rotações e vibrações correspondentes às relaxações observadas no PMMA

Figura 3.7: Diagrama que representa os dois movimentos responsáveis pela relaxação $\beta$ nos PRMAs

Figura 3.8: Explicação para a relaxação $\beta$ no PMMA e polímeros similares .............88

Figura 3.9: Representações químicas do PiBMA e do PnBMA.................................90

Figura 3.10: Poli(alquil metacrilato)s estudados ..............................................92

Figura 3.11: Poli(acrilatos $\alpha$-substituído)s estudados ..........................................93

Figura 3.12: Definição dos ângulos de Euler, do SEP e do SM ...............................95

Figura 3.13: Representação de como os dados são utilizados na simulação da intensidade do sinal de exchange

Figura 3.14: Orientações relativas entre o sistema de eixos principais (A) e o sistema molecular (B) do grupo COO dos PRMAs

Figura 4.1: Funções de correlação dos movimentos lentos dos grupos laterais obtidos através das intensidades CODEX em função de $t_{\mathrm{m}}$ 105

Figura 4.2: Curvas CODEX em função do tempo de reacoplamento $N t_{\mathrm{r}}$ 108

Figura 4.3: Os dois movimentos básicos do grupo lateral COO nos poli(metil metacrilato)s e poli(acrilato $\alpha$-substituído)s

Figura 4.4: Dados experimentais CODEX mostrando a dependência da temperatura dos movimentos lentos

Figura 4.5: Curvas CODEX em função do tempo de reacoplamento $N t_{\mathrm{r}}$ para os poli(acrilatos $\alpha$-substituído)s

Figura 4.6: Simulações totais e suas duas componentes para curvas experimentais CODEX e PUREX para o PMMA 
Figura 4.7: Simulações para a intensidade do sinal CODEX em função de $N t_{\text {r }}$

e $\delta N t_{\mathrm{r}}$ para o PMMA

Figura 4.8: Simulações para a intensidade do sinal PUREX em função de $2 \tau$

e $\delta 2 \tau$ para o PMMA

Figura 4.9: Os três diferentes processos que podem ser observáveis por

$\mathrm{RMN}$ do grupo ${ }^{13} \mathrm{COO}$.

Figura 4.10: Os quatro diferentes processos que podem ser observáveis por RMN dos carbonos da cadeia principal do PRMAs

Figura 4.11: Curvas experimentais PUREX $\left({ }^{13} \mathrm{COO}\right)$ e CODEX

$\left({ }^{13} \mathrm{C}\right.$ quaternário e $\left.{ }^{13} \mathrm{CH}_{2}\right)$.

Figura 4.12: Curva experimental $\operatorname{CODEX}\left({ }^{13} \mathrm{COO}\right)$ e simulação que contém as mesmas componentes utilizadas para o caso PUREX.

Figura 4.13: Curvas experimentais $\operatorname{PUREX}\left({ }^{13} \mathrm{COO}\right)$ e $\operatorname{CODEX}\left({ }^{13} \mathrm{C}\right.$ quaternário

$\mathrm{e}^{13} \mathrm{CH}_{2}$ ) para o PEMA, o PiBMA e o PcHMA

Figura 4.14: Curvas CODEX em função do tempo de reacoplamento $N t_{\mathrm{r}}$ com as simulações definidas na Tabela III

Figura 4.15: Representação das conformações dos grupos laterais dos PRMAs ..... 136

Figura 4.16: Curvas PUREX em função de $2 \tau$ mostrando a dependência dos movimentos lentos com a temperatura para os PRMAs.

Figura 4.17: Espaço necessário para acomodar os grupos laterais do PcHMA e do PMMA

Figura 4.18: Espectros de pó do ${ }^{13} \mathrm{C}$ do grupo COO para os PRMAs. 145

Figura 4.19: Espectros double quantum do POE no POE/PNP e do PET. 148

Figura 4.20: Espectros experimentais de double quantum sem desacoplamento homonuclear e as respectivas simulações para: $(\mathrm{POE})_{3} \mathrm{LiCF}_{3} \mathrm{SO}_{3}$; $(\mathrm{POE})_{3} \mathrm{NaI}$ e (c) $(\mathrm{POE})_{3} \mathrm{LiClO}_{4}$ 


\section{Lista de Tabelas}

Tabela I: Operadores produto relacionados às evoluções sob efeito do acoplamento intermediário

Tabela II: Pesos moleculares e temperaturas das transições vitreas dos polímeros estudados

Tabela III: Porcentagem de cada componente nas simulações do tipo indicado na Figura 4.10 para todos os PRMAs à temperatura ambiente.

Tabela IV: Porcentagem e amplitude de cada componente das simulações dos espectros PUREX dos PRMAs para cada temperatura. 


\section{Lista de Abreviaturas e Siglas}

1D - unidimensional

2D - bidimensional

CODEX - centerband-only detection of exchange (deteç̧ão de exchange apenas da banda central - ou exchange sob MAS)

$C D Q$ - coerência de double quantum

DOQSY - double quantum spectroscopy (espectroscopia double quantum)

DSC - differential scanning calorimetry

FID - free induction decay (decaimento livre de indução), o sinal de RMN

Flip - rotação de $180^{\circ}$ de grupos laterais da cadeia polimérica

HCT - hectorita

IR - infrared spectroscopy

MAS - magic angle spinning (rotação da amostra em torno do ângulo mágico)

PcHMA - poli(ciclohexil metacrilato)

PDMI - poli(dimetil itaconato)

PEMA - poli(etil metacrilato)

PET - poli(etileno teraftalato)

PiBMA - poli(isobutil metacrilato)

$P M$ - peso molecular

PMAA - ácido polimetacrílico

PMEA - poli(metil etacrilato)

PMMA - poli(metil metacrilato)

PM $\alpha$ As - poli(acrilato $\alpha$-substituído)s

PM[TMS]A - poli(metil $\alpha$-trimetilsiloxilacrilato)

PNP - poli(para-nitrofenol)

POE - poli(óxido etileno)

PRMAs - poli(alquil metacrilato)s

PSE - Polymer Science and Engineering Department, Universidade de Massachusetts PUREX - pure exchange (exchange puro - ou sem o sinal de segmentos imóveis) 
RES - resorcinol

$\mathrm{RF}$ - rádio-freqüência

RIS - rotary isomeric state model (modelo de estado isomérico rotacional)

RMN - ressonância magnética nuclear

rms - root mean square (raiz quadrática média)

SEP - sistema de eixos principais

SL - sistema de coordenadas de laboratório

SM - sistema de coordenadas molecular

SR - sistema de coordenadas do rotor

TMS - tetrametilsilano

Twist - pequeno movimento rotacional de grupos laterais em torno da cadeia polimérica

WAXD - wide angle $X$-ray diffraction 


\section{Resumo}

Esta tese baseia-se no estudo da dinâmica e conformação de polímeros no estado sólido utilizando-se técnicas modernas de RMN.

Para o estudo quantitativo da dinâmica molecular lenta dos grupos laterais em uma série de poli(alquil metacrilato)s que apresentam diferentes tamanhos para os seus grupos laterais foram utilizadas duas novas técnicas de exchange: centerband-only detection of exchange (CODEX) e pure exchange (PUREX). Rotações dos grupos ésteres de $180^{\circ}$ (flip) acopladas a movimentos de pequenos ângulos em torno da cadeia principal $\left(<20^{\circ}\right)$, que são associados à relaxação $\beta$ nestes polímeros, são observados distintamente. As porcentagens de grupos laterais que realizam os movimentos de flip foram obtidas com $3 \%$ de precisão. Esses valores decrescem com o tamanho do grupo lateral, indo de 34\% (PMMA) até cerca de 10\% (PcHMA) à temperatura ambiente. No PMAA nenhum movimento lento dos grupos laterais é detectado. A fração de grupos laterais que realizam o flip se mantém constante com o aumento da temperatura para o PMMA até próximo da sua transição vítrea $\left(T_{\mathrm{g}}\right)$, enquanto que para o PEMA, o PiBMA e o PcHMA essa fração aumenta continuamente até próximo da $T_{\mathrm{g}}$ (de $31 \%$ para $80 \%$ para o PEMA). Movimentos independentes de pequena amplitude $\left(<5^{\circ}\right)$ que cooperam para a acomodação dos grupos laterais durante o flip das cadeias vizinhas também foram verificados. O monitoramento do sinal atribuído ao grupo $\mathrm{CH}_{2}$ através da técnica CODEX confirma os resultados obtidos para o movimento da cadeia principal. Além disso, observa-se em alguns poli(acrilatos $\alpha$-substituído)s que o tamanho dos grupos laterais $\alpha$ também têm influência na fração dos grupos ésteres que sofrem reorientação à $25^{\circ} \mathrm{C}$.

Para o estudo da conformação de polímeros foram implementados experimentos Double Quantum, que determinam ângulos de torção entre pares ${ }^{13} \mathrm{C}-{ }^{13} \mathrm{C}$ na cadeia polimérica. Foram realizados experimentos para dois polímeros, poli(óxido etileno) - (POE) e poli(etileno teraftalato) - (PET), enriquecidos em ${ }^{13} \mathrm{C}$ com e sem desacoplamento homonuclear $\left({ }^{13} \mathrm{C}-{ }^{13} \mathrm{C}\right)$ em um espectrômetro Variam Inova 400. 


\section{Abstract}

This work is based on the study of dynamics and conformation of solid-state polymers, using NMR modern techniques.

For the quantitative study of slow sidegroup dynamics in a series of poly(alkyl methacrylate)s and other of poly( $\alpha$-substituted acrylate)s with varying sidegroup sizes two new ${ }^{13} \mathrm{C}$ exchange techniques were used: centerband-only detection of exchange (CODEX) and pure exchange (PUREX). Flips and small-angle motions of the ester groups associated with the $\beta$-relaxation are observed distinctly, and the fraction of slowly flipping groups has been measured with $3 \%$ precision. A decreasing in these values occurs growing the sidegroup size. In PMMA, 34\% of sidegroups flip, while the fraction is c.a. 10\% in PcHMA around room temperature. In PMAA, no slow sidegroup flips are detected. In PMMA, the flipping fraction is temperature-independent between $25^{\circ} \mathrm{C}$ and $96^{\circ} \mathrm{C}$, while in PEMA, PiBMA, and PcHMA it increases continuously between room temperature and $T_{g}$ (from 31 to $80 \%$ for PEMA). Backbone $\mathrm{CH}_{2}$ CODEX data confirm the results obtained for the main chain movements. Flip-independent small amplitude motions $\left(<5^{\circ}\right)$ are also observed. Besides, it is noticed that in some poly( $\alpha$-substituted acrylate)s the $\alpha$ sidegroup size has influence in the fraction of slowly flipping ester groups at $25^{\circ} \mathrm{C}$.

For the study of polymers conformation Double Quantum NMR experiments were used, for torsion angles determination between ${ }^{13} \mathrm{C}-{ }^{13} \mathrm{C}$ pairs through the polymer chain. Experiments for two standards ${ }^{13} \mathrm{C}$ labeled samples: poly(ethylene oxide) - (PEO) and poly(ethylene teraftalate) - (PET) were performed, with and without homonuclear decoupling $\left({ }^{13} \mathrm{C}-{ }^{13} \mathrm{C}\right)$, in a Varian Inova 400 spectrometer. 


\section{Introdução}

Considerando-se a resolução espectral, a Ressonância Magnética Nuclear (RMN) do estado sólido ainda está atrás da RMN de alta resolução em líquidos. Várias técnicas para promediação das interações de spin anisotrópicas foram desenvolvidas, incluindo rotações no espaço usual ${ }^{1,2}$ e rotações no espaço de spins ${ }^{3,4}$ ou combinações dos dois tipos 5,6 . Mesmo assim, a sua eficiência sempre esteve abaixo dos rápidos movimentos moleculares isotrópicos dos líquidos. No entanto, por sua própria natureza, essas interações anisotrópicas contém valiosas informações sobre a estrutura e a dinâmica dos sistemas que se quer estudar. Desde que o comportamento macroscópico dos materiais está diretamente ligado a sua dinâmica e conformação molecular no estado sólido, a possibilidade de se explorar estas propriedades criou novas aplicações para a RMN de materiais no estado sólido. Neste contexto, experimentos de RMN do estado sólido bidimensionais (2D) sempre se mostraram muito superiores às técnicas unidimensionais (1D) no que se refere à estudos dinâmicos e estruturais ${ }^{7}$. Particularmente, técnicas de exchange 2D estáticas mostram-se extremamente úteis tanto na análise de processos dinâmicos $8-11$ como para a obtenção de ângulos de torção no nível de ligações individuais $12-15$. Para se usufruir a boa resolução angular dos experimentos estáticos sem que ocorra um comprometimento devido à falta de resolução espectral, na maioria desses experimentos utiliza-se o enriquecimento isotópico $\left({ }^{13} \mathrm{C}\right.$ ou $\left.{ }^{2} \mathrm{H}\right)$ que permite uma distinção entre os diversos grupos funcionais da amostra (estudos dinâmicos) ou seleciona um determinado par de núcleos interagentes (estudos estruturais). Quando 
não é possível realizar este enriquecimento isotópico, pode-se recorrer à utilização da rotação da amostra em torno do ângulo mágico (MAS) com baixas rotações 16 . Explorando o padrão de bandas laterais no espectro bidimensional de exchange, pode-se melhorar a resolução espectral sem, no entanto, evitar a diminuição da resolução do experimento 17 .

Considerando apenas a dinâmica molecular, a utilização da técnica de exchange para o estudo da reorientação molecular lenta em sólidos é capaz de caracterizar a escala de tempo e a geometria de movimentos entre aproximadamente 1 e $10^{4} \mathrm{~ms}$. No entanto, esta técnica sempre foi limitada para quando a maioria dos segmentos presentes na amostra realizam esses movimentos. Caso contrário, uma intensa linha diagonal torna-se presente no espectro $2 \mathrm{D}$ devida à presença dos segmentos estáticos, que se sobrepõe ao padrão de exchange impedindo, em muitos casos, a sua análise. Uma nova técnica denominada pure exchange (PUREX) 18 foi desenvolvida de modo a superar esta limitação. Seus espectros bidimensionais não apresentam a linha diagonal devida aos segmentos rígidos e, como conseqüência, nem os artefatos provenientes deste indesejado sinal. Sua versão 1D produz um espectro seletivo apenas dos segmentos que realizam exchange, permitindo a deteç̧ão das reorientações lentas de segmentos moleculares com a identificação dos grupos que estão realizando esse movimento, sem a necessidade de se recorrer ao experimento 2D. Com essas características essa técnica de exchange permite determinar tempos e funções de correlação e a geometria do movimento sem a necessidade de utilização de modelos complexos, pois a informação vem diretamente do espectro. Por exemplo, a análise dos movimentos lentos das regiões amorfas de polímeros semicristalinos próximos de sua transição vítrea ${ }^{19}$, ou o estudo detalhado 
do movimento de grupos laterais sem o enriquecimento com ${ }^{13} \mathrm{C}^{20}$.

Geralmente, técnicas de exchange voltadas ao estudo da dinâmica molecular em amostras não enriquecidas apresentam baixas sensibilidade e resolução espectral. Estas limitações são provenientes das largas linhas anisotrópicas ou das bandas laterais bem evidenciadas necessárias em experimentos com MAS. Recentemente, foi apresentada à comunidade científica a técnica centerband-only detection of exchange $(\mathrm{CODEX})^{21}$ que contorna este problema. Nesse experimento 1D, espectros isotrópicos obtidos com desacoplamento heteronuclear e MAS, trazem as informações contidas na parte anisotrópica da interação de deslocamento químico, com a máxima sensibilidade e resolução espectral possíveis num experimento de alta resolução em sólidos. Como para o experimento PUREX 1D, os espectros CODEX também são devidos apenas aos segmentos que realizam os movimentos moleculares lentos, permitindo a sua aplicação em diversos casos.

Estas duas novas técnicas apresentam alto potencial para aplicação em polímeros amorfos ou semicristalinos. Polímeros amorfos apresentam uma fase vítrea delimitada em altas temperaturas pela sua transição vítrea, $T_{\mathrm{g}}$ (que também ocorre na fase amorfa de polímeros semicristalinos $)^{22}$. Em torno dessa temperatura são observadas grandes mudanças nas propriedades físicas do polímero, entre elas: a viscosidade, as relaxações dielétrica e mecânica, a difusão e a reatividade química 22,23 . Todas essas mudanças de comportamento associadas à $T_{\mathrm{g}}$ estão diretamente ligadas à grandes mudanças nos movimentos moleculares, através da relaxação cooperativa de segmentos da cadeia polimérica. A chamada relaxação $\alpha$ ocorre próximo à $T_{g}$, comportando movimentos cooperativos de grandes segmentos da cadeia principal. Porém, outros processos de relaxação também ocorrem abaixo 
da temperatura de transição vítrea, recebendo, em ordem decrescente de temperatura e significância, os nomes de relaxação $\beta, \gamma$ ou $\delta$. Usualmente, o processo de relaxação $\beta$, que ocorre logo abaixo da $T_{g}$, é associado aos movimentos de grupos laterais, podendo, algumas vezes, também ser relacionado a movimentos de pequenas unidades da cadeia principal ${ }^{22}$. A correlação entre os dois principais processos de relaxação ( $\alpha$ e $\beta$ ) surge ao considerar-se que o processo de relaxação $\beta$ é associado a mudanças conformacionais de curto alcance, isto é, mudanças que envolvem pequenas seções da cadeia polimérica (ou oscilações de pequena amplitude na unidade principal); enquanto que a transição vítrea propriamente dita, ou processo de relaxação $\alpha$, envolve o movimento cooperativo de muito mais elementos da cadeia (seis ou mais unidades monoméricas) ${ }^{24}$. Estes processos de relaxação acabam determinando a faixa de temperatura em que um determinado material polimérico pode ser utilizado. Podem, ainda, influenciar uma determinada característica física do polímero, como sua resistência à impactos (abaixo da $T_{g}$ ) e a sua maleabilidade (acima da $T_{g}$ ). Por esse motivo, é muito importante conhecer a origem molecular destes processos, respondendo a perguntas como: esses processos surgem de movimentos localizados ou de grande alcance da cadeia polimérica? eles estão relacionados a movimentos das cadeias laterais? dependem do seu tamanho? estes processos dependem da temperatura? qual é a exata natureza dos movimentos envolvidos (rotações de pequenos/grandes ângulos discretos ou uma distribuição de ângulos de rotação)?

O poli(metil metacrilato) (PMMA), na sua forma mais comum, é um polímero amorfo utilizado, no seu estado vítreo, na fabricação de lanternas de automóveis por sua transparência e resistência à foto-oxidação devido à exposição 
contínua a raios ultra-violetas 25 . A relaxação $\beta$ observada no PMMA é geralmente considerada como o modelo de uma relaxação localizada em polímeros. Estudos de relaxação mecânica e dielétrica outorgam a esse processo de relaxação um mecanismo de dissipação de energia que pode estar ligado às boas propriedades mecânicas do PMMA entre a temperatura ambiente e a sua transição vítrea $\left(T_{\mathrm{g}} \approx 100^{\circ} \mathrm{C}\right)^{26,27}$. Experimentos de RMN de exchange em ${ }^{13} \mathrm{C} \mathrm{e}{ }^{1} \mathrm{H}$ mostraram que a relaxação $\beta$ nestes polímeros está associada a movimentos do grupo $-\mathrm{COOCH}_{3}$ e da ligação $\mathrm{C}-\mathrm{C}$ que conecta este grupo lateral à cadeia principal 28 (para visualização consultar Fig. 3.7, capítulo III). Neste caso, o grupo lateral realiza movimentos de $180^{\circ}$ (flip) acompanhados pela conformação da cadeia principal (twist), como será visto no item 3.3. Os dois movimentos ocorrem cooperativamente já que sem o twist o grupo lateral não conseguiria se reacomodar no espaço assimétrico deixado por ele próprio ao realizar o flip. No entanto, devido às limitações da técnica de exchange convencional discutidas acima, um estudo mais detalhado destes movimentos ainda não havia sido realizado.

O tópico principal desta tese baseia-se no estudo de relaxações locais em polímeros vítreos através do detalhamento do movimento dos grupos laterais envolvidos na transição $\beta$ do PMMA e outros poli(alquil metacrilato)s através das técnicas PUREX e CODEX em função da temperatura. Visando a observação da influência do tamanho do grupo lateral sobre esse processo de relaxação varias amostras foram analisadas. Os diversos grupos laterais (-CH3, - $\mathrm{CH} 2 \mathrm{CH} 3$, - $\mathrm{CH} 2 \mathrm{CH}(\mathrm{CH} 3) 2$ e ciclohexil) acoplados ao carboxil (-COO-) nos poli(alquil metacrilato)s estudados definem, respectivamente: o PMMA, o poli(etil metacrilato) (PEMA), o poli(isobutil metacrilato) (PiBMA) e o poli(ciclohexil metacrilato) 
(PcHMA) (para visualização das fórmulas estruturais consultar Fig. 3.10). Adicionalmente, o efeito nesses movimentos, devido à substituição do outro grupo metil $\left(\alpha-\mathrm{CH}_{3}\right)$ do PMMA por diferentes grupos funcionais, também é observado para três amostras à temperatura ambiente: o poli(metil etacrilato) (PMEA), o poli(dimetil itaconato) (PDMI) e o poli(metil $\alpha$-trimetilsiloxilacrilato), PM[TMS]A (para visualização das fórmulas estruturais consultar Fig. 3.11).

Devido à pequena distância internuclear presente em sistemas com ${ }^{13} \mathrm{C}$ diretamente ligados $\left({ }^{13} \mathrm{C}-{ }^{13} \mathrm{C}\right)$, algumas dificuldades aparecem na utilização da técnica de exchange 2D em estudos estruturais. Muitas vezes os espectros se mostram muito intrincados, devido ao forte acoplamento dipolar homonuclear, exigindo a implementação de desacoplamentos homonuleares ${ }^{13} \mathrm{C}-{ }^{13} \mathrm{C} \quad \mathrm{e}$ heteronucleares ${ }^{13} \mathrm{C}-{ }^{1} \mathrm{H}$ em ambas dimensões espectrais. Além disso, os espectros mostram sempre uma intensa linha diagonal que não contém nenhuma informação conformacional. Não apresentando estes problemas, outra técnica, a correlação bidimensional do acoplamento dipolar e do deslocamento químico anisotrópico, também permite a obtenção de informação estrutural através da determinação de ângulos de torção, mas apenas para o caso do regime de acoplamento intermediário 29,30 . Todas essas limitações podem ser suprimidas com a utilização da técnica de double quantum para a determinação dos ângulos de torção em polímeros desenvolvida recentemente ${ }^{31}$. Em seu espectro 2D, essa técnica correlaciona as freqüências individuais dos carbonos ${ }^{13} \mathrm{C}-{ }^{13} \mathrm{C}$ acoplados dipolarmente com a soma dos seus deslocamentos químicos. Neste caso, o espectro não apresenta o sinal de fundo dos outros ${ }^{13} \mathrm{C}$ em abundância natural na amostra e nem a intensa linha diagonal que domina os espectros de exchange, podendo ser aplicado a 
qualquer par ${ }^{13} \mathrm{C}-{ }^{13} \mathrm{C}$ isotopicamente enriquecido. Além disso, a versão dessa técnica com o desacoplamento homonuclear leva a simplificações espectrais necessárias em alguns $\operatorname{casos}^{32}$.

Neste trabalho também foi realizado o estudo e a implementação da técnica de double quantum no espectrômetro de RMN do Grupo de Ressonância do IFSC. Para que fosse possível avaliar os resultados à medida que as seqüências de pulso fossem desenvolvidas, foram escolhidas duas amostras padrão enriquecidas com pares ${ }^{13} \mathrm{C}^{13} \mathrm{C}$ que já foram estudadas anteriormente 33,34 : o poli(etileno teraftalato) (PET) e um complexo polimérico de poli(óxido etileno) e poli(para nitrofenol) (POE/PNP).

Esta tese está dividida em cinco capítulos. No Capítulo I é feita uma introdução à técnica de exchange e, logo após, são apresentadas as técnicas PUREX e CODEX utilizadas nesse trabalho para o estudo da dinâmica molecular nos metacrilatos. O Capítulo II discute a técnica de double quantum e suas características em detalhes. No Capítulo III estão apresentados os polímeros que fazem parte deste trabalho e como são realizadas as simulações dos seus movimentos moleculares lentos. O Capítulo IV contém os resultados da aplicação das técnicas de PUREX 1D e CODEX para o estudo da relaxação $\beta$ nos metacrilatos e espectros de double quantum - para o PET e o POE/PNP - obtidos no espectrômetro de RMN do Grupo de Ressonância do IFSC. Por fim, o Capítulo V apresenta as conclusões deste trabalho e as perspectivas de trabalhos futuros relacionados aos tópicos abordados nesta tese. 


\section{Técnicas de Exchange para Análise da Dinâmica}

\section{Molecular}

Neste capítulo são discutidas duas novas técnicas de experimentais de RMN do estado sólido apresentadas recentemente: pure exchange NMR (PUREX) ${ }^{1} \mathrm{e}$ centerband-only detection of exchange $(\mathrm{CODEX})^{2,3}$. Sua aplicação refere-se ao estudo da dinâmica molecular de polímeros, área em que técnicas tradicionais de RMN de exchange multidimensional 4,5 já se mostraram muito eficazes. Neste trabalho, estas técnicas foram utilizadas para a caraterização dos movimentos lentos em polímeros da família dos poli(metacrilato)s como será discutido no Capítulo IV.

O fato da dinâmica molecular apresentar drásticos efeitos sobre as propriedades mecânicas de diversos materiais 6 impulsionou o interesse em aumentar as possibilidades de aplicação da técnica de RMN de exchange. As técnicas PUREX e CODEX atingiram este objetivo. Apresentando um ganho de sensibilidade com relação a técnica de exchange convencional, elas permitem um estudo mais detalhado da dinâmica molecular. Principalmente para o caso de polímeros, onde mecanismos de relaxação observados macroscopicamente têm uma ligação direta com a dinâmica molecular do material, sua utilização mostrou-se muito adequada, como será visto no Capítulo IV para o estudo de polímeros da família dos 
polimetacrilatos.

Com o objetivo de facilitar o entendimento dos resultados experimentais do Capítulo IV inicialmente é apresentada a técnica tradicional de exchange. Em seguida, é abordado o seu desenvolvimento resultando nos experimentos PUREX e CODEX, respectivamente.

\subsection{Exchange Convencional e o Estudo de Movimentos Moleculares Lentos}

As interações do spin nuclear apresentam uma dependência com a orientação que se reflete nos espectros de RMN de sólidos. Essa característica permite a medida de orientações moleculares ou reorientações de segmentos. A dependência angular do espectro surge da natureza tensorial das interações e pode ser entendida em termos de considerações geométricas descritas em vários livros de RMN7,8. Como conseqüência, as freqüências anisotrópicas do espectro de RMN revelam as orientações dos segmentos moleculares e não das orientações dos spins nucleares propriamente ditos. $O$ caso de interesse aqui é o da interação de deslocamento químico anisotrópico que reflete a orientação de uma determinada unidade molecular com relação ao campo externo aplicado, $\boldsymbol{B}_{0}$, da seguinte forma:

$$
\omega_{\text {aniso }}(\theta, \phi)=\frac{\delta}{2}\left(3 \cos ^{2} \theta-1-\eta \sin ^{2} \theta \cos (2 \phi)\right)
$$

onde $\delta$ e $\eta$ são, respectivamente, os parâmetros de anisotropia e de assimetria do tensor deslocamento químico, enquanto que $\theta$ e $\phi$ são os ângulos polares do campo $\boldsymbol{B}_{0}$ no sistema de eixos principais ${ }^{*}, \mathrm{SEP}$, do tensor deslocamento químico.

A orientação do tensor, com respeito à unidade molecular, é uma propriedade inerente de cada tipo de grupo funcional refletindo sua simetria local. 
Isso pode ser observado na Figura 1.1 para o poli(metil metacrilato) (PMMA). Em grupos carboxil, por razões de simetria, um dos eixos principais do tensor de deslocamento químico de ${ }^{13} \mathrm{C}$ deve ser perpendicular ao plano OCO. O valor principal do tensor com maior campo de blindagem geralmente é definido como $\omega_{33}$ (ou $\sigma_{33}$ ).
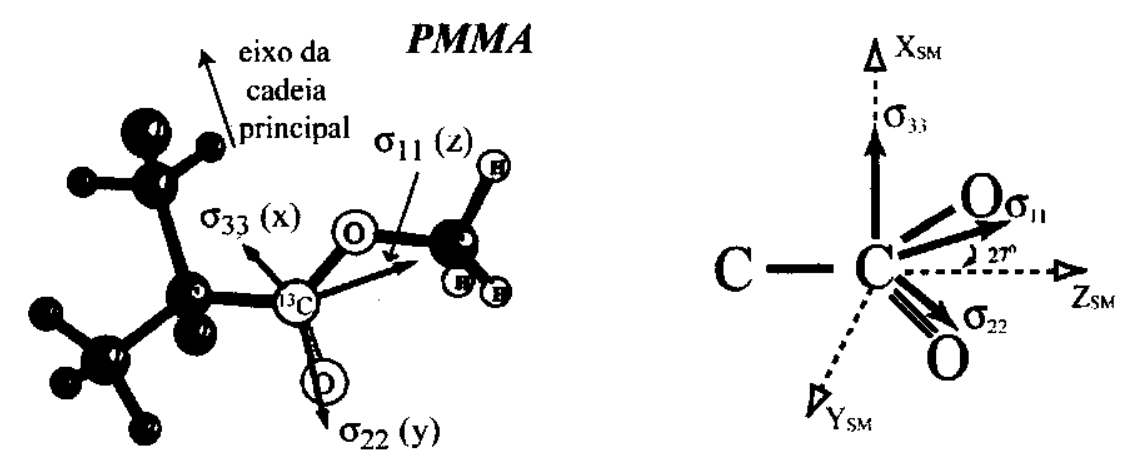

Figura 1.1: Representação do poli(metil metacrilato) (PMMA) e os eixos principais do tensor de deslocamento químico do ${ }^{13} \mathrm{C}$ do grupo carboxil. Nestes grupos laterais $\sigma_{33}$ é perpendicular ao plano $\mathrm{COO}$, também definido pelos eixos $Y_{S M}$ e $Z_{S M}$ do sistema de eixos molecular (SM). $0 \sigma_{11}$ do SEP faz um ângulo de $27^{\circ}$ com $Z_{S M}$, que define o eixo da ligação $\mathrm{C}-\mathrm{C}$ que conecta o grupo lateral à cadeia principal no $\mathrm{PMMA}^{9}$.

Como o tensor deslocamento químico é determinado pela estrutura eletrônica em torno do núcleo sob análise, o SEP fica fixo relativamente ao segmento molecular que realiza o movimento. A dependência das interações com a orientação e os conseqüentes deslocamentos anisotrópicos de freqüência podem ser observadas nos chamados espectros de pó ${ }^{\dagger}$, Figura 1.2.

\footnotetext{
- O SEP é o sistema de eixos no qual a parte simétrica do tensor que representa a interaçăo de interesse é diagonal.

† Essa denominação é utilizada para os espectros, em RMN do estado sólido, de amostras isotrópicas de um material suficientemente rígido. Sua forma depende das várias orientaçð̋es do tensor de deslocamento químico com relaçăo ao campo magnético externo $\boldsymbol{B}_{0}$ em uma amostra policristalina ou em uma amostra que possui blocos nåo orientados de um material polimérico.
} 


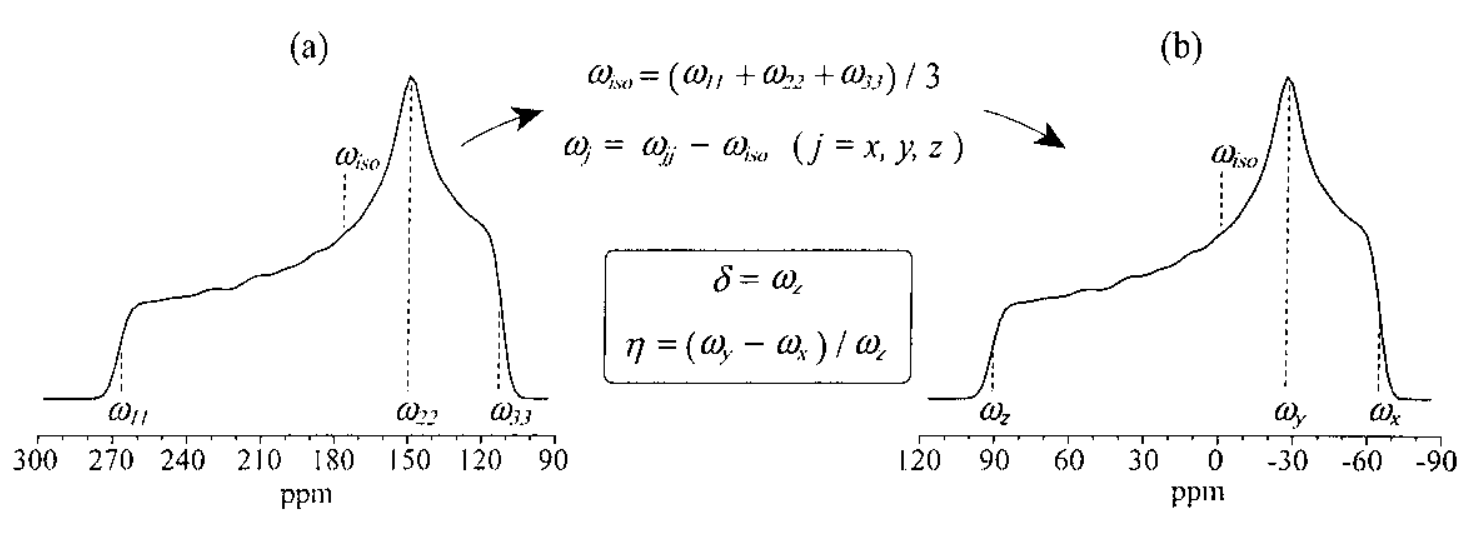

Figura 1.2: Espectro de pó simulado do ${ }^{13} \mathrm{C}$ do grupo carboxil no PMMA com os respectivos parâmetros tensoriais. (a) Valores principais do tensor deslocamento químico, conforme aparecem no espectro. (b) Nova definição dos valores principais considerando-se $\omega_{i s o}$ como referência $(0 \mathrm{ppm})$. As definições dos parâmetros de anisotropia, $\delta$, e de assimetria, $\eta$, são mostradas entre as figuras.

A Figura 1.2, representa o espectro de pó para $0{ }^{13} \mathrm{C}$ do carboxil (COO) do poli(metil-metacrilato) (PMMA) $\left(\mathrm{CH}_{2} \mathrm{CCH}_{3} \mathrm{COOCH}_{3}\right) . \quad \mathrm{A}$ relação entre os parâmetros tensoriais escritos como $\sigma_{\mathrm{ii}}$ (Fig. 1.1) ou $\omega_{\mathrm{ii}}$ (Fig. 1.2) é dada por: $\omega_{\mathrm{ii}}=$ $\gamma \mathrm{B}_{0} \sigma_{\mathrm{ii}}$, onde $\gamma$ é o fator giromagnético do núcleo. Os valores principais do tensor obedecem as seguintes definições:

(i) com deslocamento químico positivo à esquerda, da esquerda para a direita do espectro, observa-se $\omega_{11}, \omega_{22}$ e $\omega_{33}$;

(ii) tomando o deslocamento químico isotrópico, $\omega_{i s o}$, como referência (0 ppm), os valores principais do tensor são $\omega_{y}, \omega_{x}$ e $\omega_{z}$, tal que $\left|\omega_{y}\right| \leq\left|\omega_{x}\right| \leq\left|\omega_{z}\right|$.

A relação entre as notações equivalentes $\omega_{z z}, \omega_{y y}, \omega_{x x}$ e $\omega_{11}, \omega_{22}$ e $\omega_{33}$, deve ser tal que as definições (i) e (ii) sejam sempre válidas. Para o exemplo dado $\omega_{11}=\omega_{z z}, \omega_{22}=\omega_{y y}$ e $\omega_{33}=\omega_{x x}$. No entanto, nem sempre o espectro de RMN apresenta claramente os valores tensoriais como na Figura 1.2. Isso ocorre quando movimentos moleculares passam a promediar a anisotropia da interação nuclear.

Movimentos moleculares são sempre caracterizados por um tempo de correlação $\tau_{c}$. Quando a taxa do movimento molecular excede ou é da ordem da 
largura do espectro, observa-se claramente mudanças no espectro típico de pó. Para o caso de movimentos com $\tau_{\mathrm{c}}^{-1} \ll \delta$ o movimento é suficientemente rápido para que ocorram muitas mudanças de freqüência durante um período de modulação do sinal pela interação, i.e., durante a existência do sinal de $\mathrm{RMN}(\mathrm{FID})^{8}$. Neste caso, a freqüência de precessão efetiva para o caso de $N$ diferentes reorientações moleculares, cada uma com probabilidade de ocupação $p_{i}$, é a média dada por:

$$
\bar{\omega}=\sum_{i=1}^{N} p_{i} \omega_{i}=\gamma \boldsymbol{B}_{0} \sum_{i=1}^{N} p_{i}\left(\sigma_{j}^{S L}\right)_{z z}=\gamma \boldsymbol{B}_{0}(\overline{\boldsymbol{\sigma}})_{z z} \quad ; \quad \overline{\boldsymbol{\sigma}}=\sum_{i=1}^{N} p_{i} \boldsymbol{\sigma}_{i}
$$

onde $\sigma_{j}^{S L}$ são os tensores* que representam as várias orientações expressas no sistema de laboratório e $\bar{\sigma}$ é o tensor promediado. A eq.(1.1) é obtida através das definições de $\delta$ e $\eta$ em termos dos componentes do tensor deslocamento químico no SEP. Da mesma forma, a freqüência promediada pode ser escrita em termos dos parâmetros de $\overline{\boldsymbol{\sigma}}$ :

$$
\bar{\omega}\left(\theta_{a}, \phi_{a}\right)=\frac{\bar{\delta}}{2}\left(3 \cos ^{2} \theta_{a}-1-\bar{\eta} \sin ^{2} \theta_{a} \cos \left(2 \phi_{a}\right)\right)
$$

aqui, $\theta_{a}$ e $\phi_{a}$ são as coordenadas polares do campo magnético $\boldsymbol{B}_{0}$ no SEP do tensor promediado $\bar{\sigma}$. A orientação do sistema de eixos principais na molécula assim como os valores de $\bar{\delta}$ e $\bar{\eta}$ estão relacionados à simetria do movimento 10 . Assim, apesar da notação adotada, os parâmetros de anisotropia e de assimetria promediados não são, em geral, iguais as médias $\sum p_{i} \delta_{i}$ e $\sum p_{i} \eta_{i}$ como é o caso de $\overline{\boldsymbol{\sigma}}$, eq.(1.3). O resultado é que para o caso de saltos entre sítios tetraédricos equivalentes, ou para qualquer movimento isotrópico, a anisotropia é eliminada pois $\bar{\delta}=0$, com $\bar{\eta}$

\footnotetext{
'Através de $\omega_{\alpha}=-\omega_{0} \sigma_{\alpha}(\alpha=x, y, x)$ são válidas as mesmas considerações feitas acima para os parâmetros $\omega_{\alpha}$.
} 
tornando-se irrelevante. Para o caso de rotações uniaxiais livres ou para saltos entre $N$ sítios $(N>2)$ em sistemas com simetria $C_{N}$, o tensor promediado tem simetria axial, i.e., $\bar{\eta}=0$, tendo o seu eixo principal ( $\mathrm{z}$ ) ao longo do eixo de simetria.

Por fim, as informações presentes nas formas de linhas promediadas estão todas contidas nos dois parâmetros: $\bar{\eta}$ e $\bar{\delta} / \delta$. No entanto, diferentes tipos de movimentos podem produzir formas de linha idênticas, o mesmo podendo acontecer com uma variação da probabilidade de ocupação ou uma mudança dos ângulos de reorientação. Esse último efeito é quase que totalmente superado com a técnica de RMN bidimensional denominada exchange 2D. Com esta técnica, os efeitos geométricos e de ocupação são quase que totalmente separados: os primeiros determinam a posição dos sinais ou os padrões que formam o espectro $2 \mathrm{D}$ e o segundo influencia as intensidades relativas de cada um destes padrões de exchange.

Experimentos bidimensionais (2D) em RMN de estado sólido em geral correlacionam as frequiências $\omega_{1}$ e $\omega_{2}$ de um determinado isocromata no ponto de coordenadas $\left(\omega_{1}, \omega_{2}\right)^{11-14}$. Nesse ponto, a intensidade espectral $S\left(\omega_{1}, \omega_{2}\right)$ é a probabilidade de se encontrar freqüências $\omega_{1}$, em um período inicial, e $\omega_{2}$, posteriormente a um tempo de mistura, $t_{\mathrm{m}}$, de um experimento $2 \mathrm{D}$, Figura 1.3. 
(a)

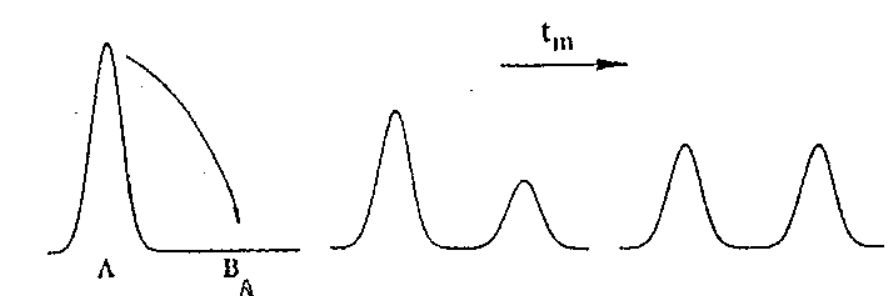

(b)

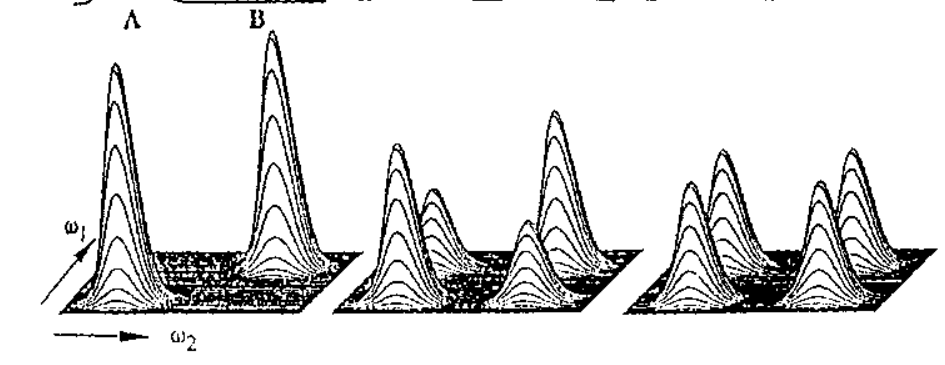

(c)
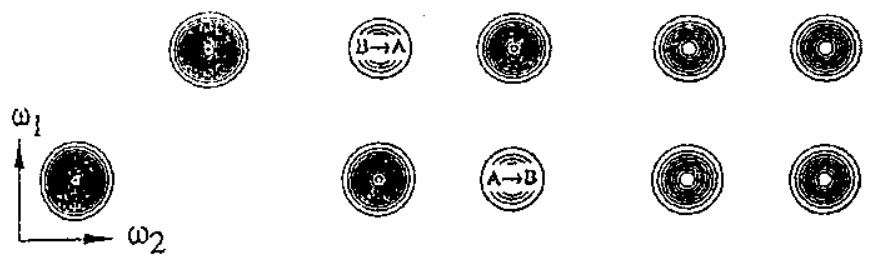

Figura 1.3: Diagrama que mostra a ocorrência de movimentos lentos de exchange entre dois picos: (a) resultado de um experimento de exchange 1D; (b) resultado de um experimento de exchange $2 \mathrm{D}$ e (c) mesmo que o anterior visto de cima com indicação de como os novos picos se formam.

De maneira equivalente, uma fatia unidimensional (1D) de um conjunto de dados $2 \mathrm{D}$ para $\omega_{1}$ constante $\left(=w_{1}\right)$ corresponde ao espectro $1 \mathrm{D} S\left(\omega_{2} ; w_{1}\right)$ que é obtido por um experimento unidimensional, onde somente a magnetização com $\omega_{1}=$ $w_{1}$ é selecionada através de excitação seletiva ${ }^{15}$, por exemplo. Para o experimento 2D, os dados são obtidos no domínio do tempo seguindo períodos bem definidos chamados de: preparação, evolução $\left(t_{1}\right)$, mistura $\left(t_{\mathrm{m}}\right)$ e deteç̧ão $\left(t_{2}\right)$. As mudanças de magnetização durante o período $t_{1}$, que é incrementado em experimentos sucessivos, são detectados indiretamente como modulações do sinal nuclear observado durante o período $t_{2}$. É durante o período de mistura que ocorre a reorientação - ou mudança nos ângulos $\theta$ e $\phi$ - fazendo com que o sistema passe de um estado inicial a um estado final que são descritos pelas freqüências $\omega\left(\theta_{l}, \varphi_{l}\right)$ e $\omega\left(\theta_{2}, \varphi_{2}\right)$, respectivamente, Figura 1.4. 
Para serem observados, os movimentos moleculares precisam ter tempos de correlação maiores que $1 \mathrm{~ms}$. Movimentos mais rápidos passam a ser da ordem dos períodos de evolução, $t_{1}$ e $t_{2}$, significando que tanto antes como depois de $t_{\mathrm{m}}$ apenas uma frequiência promediada é observada, $\bar{\omega}\left(\theta_{a}, \varphi_{a}\right)$, como na eq.(1.3). Por outro lado, os movimentos devem ter tempos de correlação da ordem de, no máximo, alguns segundos para serem observados. Movimentos extremamente lentos exigiriam tempos de mistura muito longos para o experimento, trazendo uma limitação prática para a sua observação já que neste caso, devido à relaxação longitudinal do sistema de spins, o sinal fica drasticamente reduzido. Ë importante lembrar que mesmo durante $t_{\mathrm{m}}$, quando a magnetização está ao longo da direção $\mathrm{z}$, a relaxação longitudinal está ocorrendo, produzindo o efeito discutido acima. Além disso, altos valores de $t_{\mathrm{m}}$ aumentam a probabilidade da ocorrência da difusão de spins ${ }^{16}$, que pode ser considerada um exchange sem movimento. A difusão de spins acontece devido ao acoplamento dipolar entre dois núcleos de ${ }^{13} \mathrm{C}$. O hamiltoniano dipolar possui um termo que torna possível a ocorrência de uma troca entre os estados de dois spins que estejam acoplados. Isso pode introduzir erros de interpretação no resultado de experimentos de exchange pois esse efeito é observado como se cada spin individualmente tivesse modificado a sua orientação. $O$ resultado da difusão de spins nas curvas de exchange é mais notoriamente observado em amostras enriquecidas devido à pequena distância entre os pares ${ }^{13} \mathrm{C}-{ }^{13} \mathrm{C}$, como será observado no Capítulo IV. 


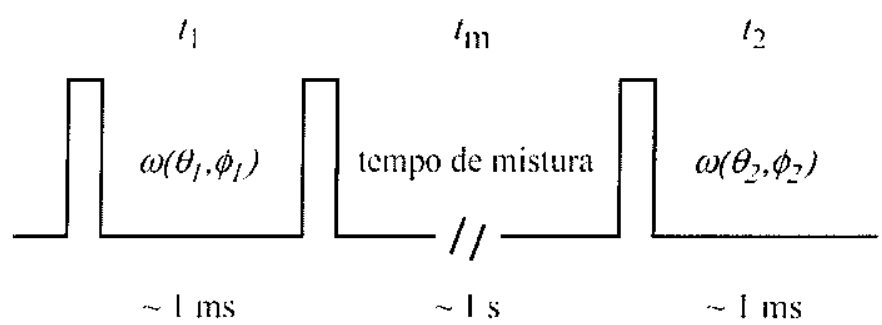

Figura 1.4: Princípio de um experimento de exchange para detectar reorientações por movimentos lentos (períodos de $1 \mathrm{~ms}$ a $10 \mathrm{~s}$ ). A freqüência com a sua dependência angular é medida em dois pontos distintos no tempo, que são separados pelo tempo de mistura. Os tempos característicos para cada etapa estão definidos na figura.

Como discutido acima, a orientação de um determinado segmento molecular relativamente ao campo $\boldsymbol{B}_{0}$ também se reflete na freqüência. Dessa forma, uma mudança de orientação molecular causa uma mudança na freqüência que, em princípio, também pode ser detectada em um experimento de exchange. A Figura 1.5 demonstra esse efeito em um espectro de exchange 1D.

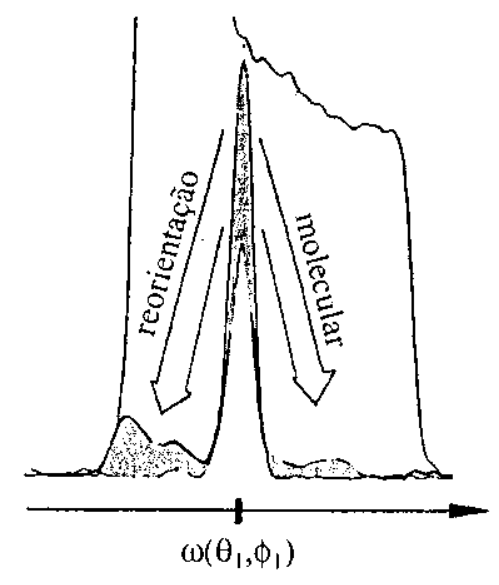

Figura 1.5: Reorientação molecular manifestando-se no sinal de exchange 1D com excitação seletiva de uma freqüência $\omega\left(\theta_{l}, \varphi_{1}\right)$ de um largo espectro de pó (não mostrado por completo na figura). Depois do tempo de mistura a banda selecionada se distribui em freqüências $\omega\left(\theta_{2}, \varphi_{2}\right)$.

Com excitação seletiva 15 , pode-se observar uma banda estreita de freqüências em um espectro de pó em torno da freqüência $\omega\left(\theta_{l}, \varphi_{I}\right)$. Reorientações durante $t_{\mathrm{m}}$ envolvem mudanças de $\theta$ e $\phi$, que são detectadas como mudanças na 
freqüência $\omega\left(\theta_{l}, \varphi_{l}\right)$. Então, surgem sinais espectrais com freqüências $\omega\left(\theta_{2}, \varphi_{2}\right)$ fora da banda excitada. Neste caso, a intensidade de exchange cobre uma larga faixa de freqüências, já que o espectro de pó $1 \mathrm{D}$ é contínuo ao invés de ser formado de picos discretos. Assim, o padrão de exchange 1D após uma excitação seletiva hipotética de uma determinada faixa do espectro de pó, passa a exibir algumas características peculiares. No entanto, o espectro de pó (obtido normalmente, sem excitação seletiva) não apresenta mudanças, posto que os segmentos com outras orientações relativamente ao campo $\boldsymbol{B}_{0}$, responsáveis pelas freqüências não excitadas inicialmente, também realizam exchange, com a mesma taxa; repondo, com isso, as contribuições para a intensidade de $\omega\left(\theta_{l}, \varphi_{l}\right)$ no espectro. Resumindo, sem uma excitação seletiva de segmentos moleculares com determinadas orientações com relação a $\boldsymbol{B}_{0}$ não se pode observar exchange através de um espectro $1 \mathrm{D}$, já que o espectro de pó sempre obedece à eq. 1.1. (que está relacionada à distribuição geométrica das diversas orientações nucleares possíveis em uma amostra policristalina) mantendo a sua forma.

Para retirar proveito da técnica de exchange é necessário observar-se as características dos espectros bidimensionais como ilustra a Figura 1.6. A figura é uma simulação de espectros de exchange 2D para o caso de reorientações lentas entre dois sítios para quatro ângulos de reorientação distintos: $0^{\circ}, 30^{\circ}, 60^{\circ}$ e $90^{\circ}$. No primeiro caso, como não há reorientação, $\omega\left(\theta_{2}, \varphi_{2}\right)=\omega\left(\theta_{1}, \varphi_{l}\right)$, surge um padrão espectral ao longo da diagonal. Para ângulos de reorientação não nulos, $\omega\left(\theta_{2}, \varphi_{2}\right) \neq \omega\left(\theta_{l}, \varphi_{l}\right)$, surgem padrões fora da diagonal. Na figura estão representados os espectros como gráficos de contorno e em perspectiva. Adicionalmente, as projeções $1 \mathrm{D}$ ao longo de $\omega_{1}$ e $\omega_{2}$ para os espectros 2D mais distintos (reorientações 
de $0^{\circ}$ e $90^{\circ}$ ) também estão mostradas. Percebe-se claramente da figura que os espectros de pó (projeções) continuam iguais, independentemente se está ocorrendo ou não exchange, como comentado na discussão da Figura 1.5 para o caso sem excitação seletiva.
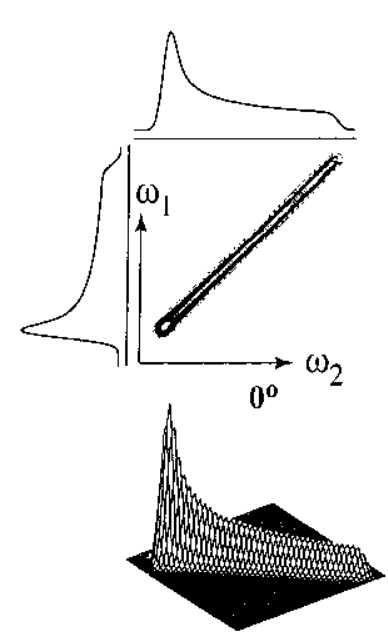

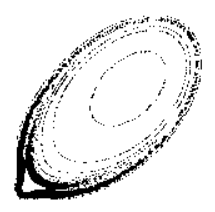

$30^{\circ}$

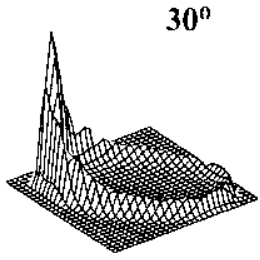

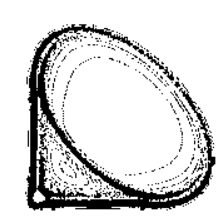

$60^{\circ}$

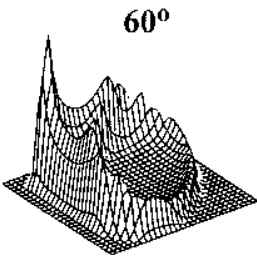

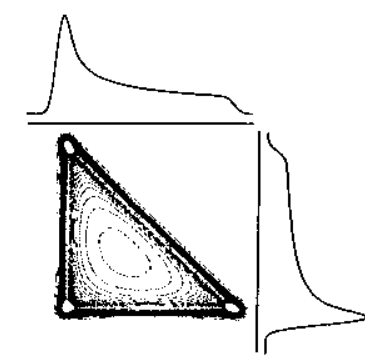

$90^{\circ}$

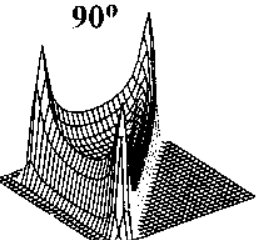

Figura 1.6: Espectros de exchange $2 \mathrm{D}$ para quatro ângulos de reorientação distintos: $0^{\circ}, 30^{\circ}, 60^{\circ}$ e $90^{\circ}$. Um padrão diagonal é observado quando não ocorre movimento. Ângulos distintos de reorientação apresentam características peculiares no espectro $2 \mathrm{D}$, no entanto, as projeções $1 \mathrm{D}$ ao longo de $\omega_{1}$ e $\omega_{2}$ não se modificam.

\subsection{Pure Exchange (PUREX)}

A dinâmica molecular tem drásticos efeitos sobre as propriedades mecânicas em diversos materiais ${ }^{17}$. Mecanismos de relaxação observados macroscopicamente em polímeros como a transição vítrea 18 e fenômenos de transporte em zeólitas ${ }^{19}$ são dois exemplos que têm grande ligação com o comportamento dinâmico do material ao nível molecular. A RMN dispõe de diversas técnicas para a caracterização desses processos em detalhes, especificadamente através dos experimentos multidimensionais de exchange discutidos no item anterior. Sua importância fica evidente, por exemplo, quanto tenta-se relacionar os movimentos moleculares lentos com mecanismos de relaxação observados macroscopicamente em polímeros, 
incluindo sua transição vítrea (relacionada à chamada relaxação $\alpha$ ) ou a relaxação $\beta$, que ocorre em temperaturas um pouco abaixo dessa última e é estudada neste trabalho (Capítulos III e IV) ${ }^{20}$.

Recentemente, surgiu uma técnica de exchange desenvolvida com o intuito de melhorar o desempenho de experimentos de RMN de exchange convencionais. Essa técnica é chamada de pure-exchange NMR (PUREX) ${ }^{1}$. Seu desenvolvimento foi motivado a partir da observação de que muitos espectros de RMN de exchange são difíceis de serem analisados porque a maior parte do sinal observado é proveniente de segmentos que não se reorientam na amostra analisada. Esse problema fica proeminente nos espectros bidimensionais de exchange de amostras com muitos segmentos rígidos (como polímeros semicristalinos) ou com movimentos fora da escala de tempo do experimento, já que tais espectros apresentam uma intensa linha diagonal que muitas vezes "mascara" o sinal dos segmentos móveis que se quer interpretar - observar a Figura 1.6. Além disso, independentemente de haver segmentos imóveis na amostra, uma parte do sinal sempre aparece ao longo da diagonal do espectro de exchange 2D. Este sinal corresponde aos segmentos que realizam o movimento e depois retornam ao sítio original durante o tempo de mistura.

PUREX é um experimento de exchange convencional, sendo que o seu sinal é modulado por uma função do tipo $\sin ^{2}\left(\left(\omega_{1}-\omega_{2}\right) \tau / 2\right)$, onde $\omega_{1}$ e $\omega_{2}$ representam as freqüências de um sítio específico antes e depois de $t_{\mathrm{m}}$, respectivamente. Com isso, quando o sinal é proveniente de segmentos não móveis tem-se que $\omega_{1}=\omega_{2}$ e a função de modulação anula-se, eliminando as sua contribuição para o espectro observado. O mesmo acontece com os segmentos que realizam o movimento, mas 
voltam à posição original antes do fim de $t_{\mathrm{m}}$. A Figura 1.7 mostra a comparação entre um espectro de exchange convencional e um espectro PUREX 2D para a dimetil sulfona (DMS) que, à temperatura ambiente, realiza reorientações moleculares entre dois sítios na escala de tempo de $10 \mathrm{~ms}$. O DMS $\left(\mathrm{O}_{2} \mathrm{~S}\left(\mathrm{CH}_{3}\right)_{2}\right)$ é um cristal molecular no qual todos os seus segmentos são móveis. Portanto, a intensa linha diagonal observada, que corresponde à $50 \%$ do espectro, é devida unicamente aos segmentos que retornam à sua posição original antes do fim de $t_{\mathrm{m}}$, Fig 1.7(a). Essa linha diagonal não aparece no espectro PUREX 2D, Fig. 1.7(b). Além disso, o experimento PUREX elimina também os artefatos visíveis na Figura 1.7(a) associados à diagonal do espectro, posto que o espectro é de fato modulado por $\sin ^{2}\left(\left(\omega_{1}-\omega_{2}\right) \tau / 2\right)$ e não apenas multiplicado por essa função - isso significa que $\omega_{1}$ e $\omega_{2}$, na função de modulação, são as freqüências de precessão dos spins. Os artefatos observados na Figura 1.7(a) são provenientes do truncamento do intenso sinal diagonal ao longo de $t_{1}$. A Figura 1.7(c) mostra a simulação do espectro PUREX (ou a simulação do espectro de exchange sem o sinal diagonal).

(a)

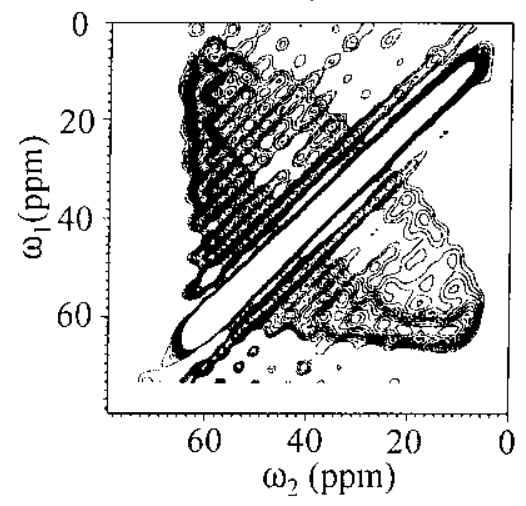

(b)

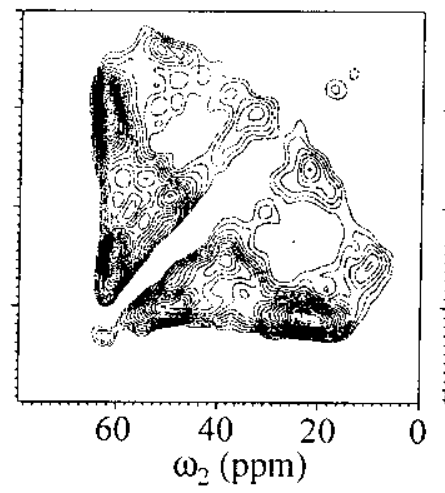

(c)

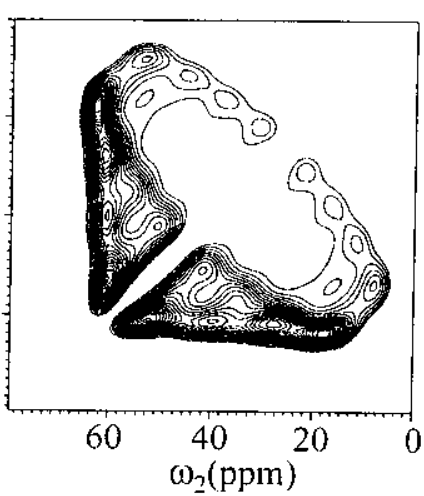

Figura 1.7: Espectros de exchange 2D para o DMS. (a) Espectro obtido com o experimento de exchange convencional, (b) espectro obtido com o experimento PUREX 2D e (c) simulação do espectro de exchange sem o sinal diagonal. Além do sinal diagonal o experimento PUREX elimina os artefatos relacionados a essa contribuição. 
Para criar a modulação do espectro, são acrescentados dois períodos de evolução $\tau$, um antes e outro depois do tempo de mistura, $t_{\mathrm{m}}$ da Figura 1.4. É através dessas duas evoluções adicionais que surge um fator multiplicativo no sinal de exchange que depende de $\omega_{1}$ e $\omega_{2}$ na forma do quadrado do seno da diferença dessas freqüências. Adicionalmente, no experimento PUREX o período $t_{1}$ (Fig. 1.4) responsável pela segunda dimensão do espectro 2D - não é mais indispensável, posto que a informação sobre o movimento é guardada nos períodos de evolução $\tau$. Ou seja, um espectro PUREX 1D traz a informação sobre o movimento através da modulação do sinal de exchange pela função $\sin ^{2}\left(\left(\omega_{1}-\omega_{2}\right) \tau / 2\right)$, o que é impossível de se obter através da técnica de exchange convencional em espectros unidimensionais, como discutido no item anterior. A Figura 1.8 mostra a seqüência de pulsos necessária para a realização do experimento PUREX 1D.

(a) modulado

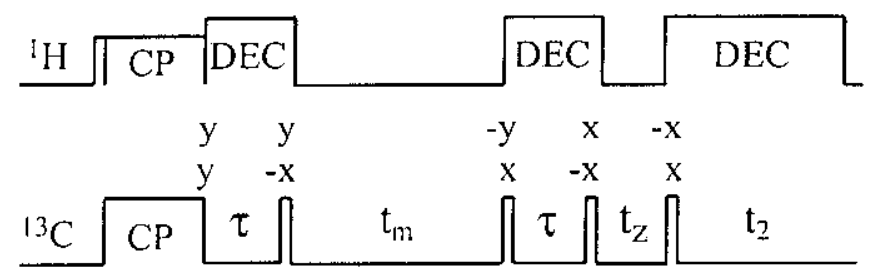

(b) referência

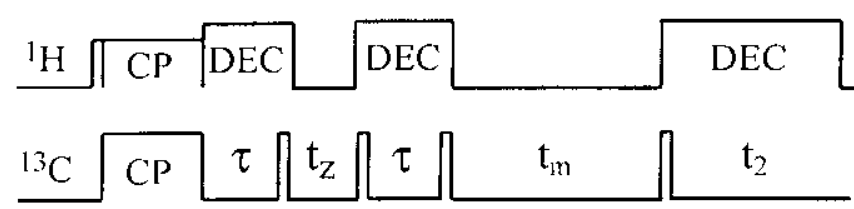

Figura 1.8: Seqüências de pulsos necessárias para obtenção do sinal PUREX 1D. (a) Seqüência de pulsos para o sinal de exchange modulado por $\cos \left[\left(\omega_{1} \tau-\omega_{2} \tau\right)\right], S$. (b) Seqüência de pulsos para o sinal de referência, $S_{0}$. Mudase de (a) para (b) apenas invertendo-se os períodos $t_{\mathrm{m}}$ e $t_{\mathrm{z}}$ no que diz respeito à sua duração. Dessa forma os fatores de relaxação durante as seqüências são sempre os mesmos. O ciclo de fases indicado em (a) deve ser aplicado em duas aquisições sucessivas. Com isso e manipulando-se os sinais de (a) e de (b), o sinal PUREX modulado por $\operatorname{sen}^{2}\left[\left(\omega_{1}-\omega_{2}\right) \tau / 2\right]$ pode ser obtido como explicado no texto. Este sinal é livre da interferência da relaxação e dos segmentos não móveis. $\mathrm{CP}=$ polarização cruzada e $\mathrm{DEC}=$ desacoplamento dipolar heteronuclear. 
As evoluções dos operadores de spin durante os intervalos $\tau$ são as responsáveis pela modulação necessária ao experimento PUREX como discutido acima e descrito na literatura. No entanto, o sinal PUREX surge da manipulação dos sinais resultantes das duas seqüências da Figura 1.8. De certa forma, a mesma seqüência de pulsos é utilizada na aquisição dos espectros modulado e não modulado. Isto é obtido invertendo-se as posições dos intervalos de tempo $t_{\mathrm{m}}$ e $t_{\mathrm{z}}$.

No esquema da Figura 1.8(a), é adquirido um sinal com o $t_{\mathrm{m}}$ adequado para caracterizar o movimento molecular (em geral da ordem de segundos) enquanto que o intervalo de tempo $t_{z}$ é muito mais curto $(\sim 1 \mathrm{~ms})$. A fase do receptor é escolhida de forma que seja somada em aquisições sucessivas as componentes $\operatorname{sen}\left(\omega_{1} \tau\right) \operatorname{sen}\left(\omega_{2} \tau\right)$ e $\cos \left(\omega_{1} \tau\right) \cos \left(\omega_{2} \tau\right)$ da magnetização, resultando no sinal $S=S\left(t_{\mathrm{m}}, 2 \tau\right)$. Com isso, temse um sinal modulado por $\cos \left(\omega_{1} \tau-\omega_{2} \tau\right)$.

Abaixo está mostrada a evolução do sistema através da notação de operadores de spin a partir da magnetização $I_{y}$ criada pela polarização cruzada. A evolução é obtida de acordo com as fases dos pulsos indicadas na Figura 1.8(a) para duas aquisições sucessivas. Assim, com o receptor em $I_{\mathrm{y}}$, ao final de duas aquisições obtém-se o sinal modulado por $\cos \left(\omega_{2} \tau\right) \cos \left(\omega_{1} \tau\right)+\operatorname{sen}\left(\omega_{2} \tau\right) \operatorname{sen}\left(\omega_{1} \tau\right)=$ $\cos \left(\omega_{1} \tau-\omega_{2} \tau\right)$ 


$$
\begin{gathered}
I_{\mathrm{y}} \\
\left.\downarrow \tau \text { (evolução em } \omega_{1}\right) \\
I_{\mathrm{y}} \cos \left(\omega_{1} \tau\right)-I_{\mathrm{x}} \cos \left(\omega_{1} \tau\right) \\
\downarrow 90^{\circ}-\mathrm{x} \\
-I_{\mathrm{z}} \cos \left(\omega_{1} \tau\right)+I_{\mathrm{x}} \cos \left(\omega_{1} \tau\right) \\
\downarrow I_{\mathrm{In}} \\
-I_{\mathrm{z}} \cos \left(\omega_{1} \tau\right) \\
\downarrow 90^{\circ} \mathrm{x} \\
I_{\mathrm{y}} \cos \left(\omega_{1} \tau\right) \\
\downarrow \tau\left(\text { evolução em } \omega_{\mathrm{y}}\right) \\
-\left[I_{\mathrm{z}} \cos \left(\omega_{2} \tau\right)-I_{\mathrm{x}} \sin \left(\omega_{2} \tau\right)\right] \cos \left(\omega_{1} \tau\right) \\
\downarrow 90^{\circ}-\mathrm{x} \\
\left.I_{\mathrm{x}} \sin \left(\omega_{2} \tau\right)\right] \cos \left(\omega_{1} \tau\right) \\
\downarrow t_{\mathrm{z}} \\
I_{\mathrm{y}} \cos \left(\omega_{2} \tau\right) \cos \left(\omega_{1} \tau\right) \\
-I_{\mathrm{z}} \cos \left(\omega_{2} \tau\right) \cos \left(\omega_{1} \tau\right) \\
\downarrow 90^{\circ} \mathrm{x}
\end{gathered}
$$

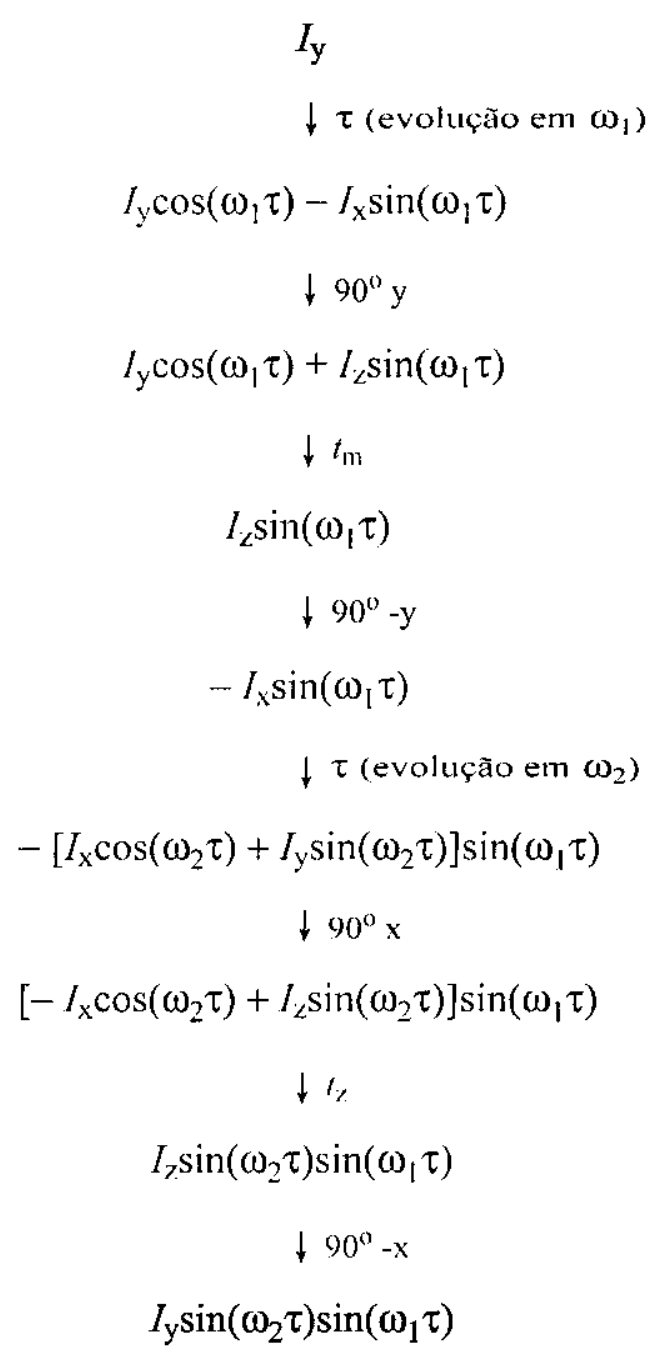

Por outro lado, para se obter o sinal de referência ou não modulado, Figura 1.8(b), utiliza-se um $t_{\mathrm{m}}$ curto (com o valor utilizado para $t_{\mathrm{z}}$ anteriormente) onde não há tempo para ocorrer movimento molecular. Neste caso $\omega_{2}=\omega_{1} \mathrm{e}$ $\cos \left(\omega_{1} \tau\right) \cos \left(\omega_{1} \tau\right)+\operatorname{sen}\left(\omega_{1} \tau\right) \operatorname{sen}\left(\omega_{1} \tau\right)=\cos \left(\omega_{1} \tau-\omega_{1} \tau\right)=1$. Ao mesmo tempo, faz-se com que $t_{\mathrm{z}}$ tenha o antigo valor de $t_{\mathrm{m}}$ de maneira que a soma $t_{\mathrm{z}}+t_{\mathrm{m}}$ seja constante nos dois experimentos, e os efeitos de relaxação sejam iguais para o sinal modulado e o sinal de referência. Assim, neste segundo experimento, o sinal é modulado por $\cos \left(\omega_{1} \tau-\omega_{1} \tau\right)=1$, resultando no sinal $S_{0}=S(0,2 \tau)$. Com isso, tem-se dois experimentos distintos que apresentam os mesmos fatores de relaxação e que, portanto, podem ser comparados: um que resulta em um sinal de exchange modulado 
por $\cos \left(\omega_{1} \tau-\omega_{2} \tau\right)(S)$ e outro que é um sinal de referência $\left(S_{0}\right)$. A posterior subtração do sinal modulado do sinal de referência resulta na modulação final $\sin ^{2}\left[\left(\omega_{1}-\omega_{2}\right) \tau / 2\right]$ necessária para produzir o espectro PUREX normalizado, $\Delta S / S_{0}=\left(S_{0}-S\right) / S_{0}$

A evolução do sinal PUREX pode ser acompanhada de duas maneiras: (i) em função do tempo de mistura, $t_{\mathrm{m}}$, ou (ii) em função dos intervalos de modulação, $\tau$. As medidas da intensidade do sinal PUREX feitas em função de $t_{\mathrm{m}}$ permitem a determinação da função de correlação e do tempo de correlação, $\tau_{\mathfrak{c}}$, relacionados à dinâmica do movimento. As medidas feitas em função de $2 \tau$ possibilitam a obtenção da amplitude ou ângulos de reorientação envolvidos no movimento.

Através do sinal PUREX também é possível se obter a fração dos sítios móveis $\left(f_{\mathrm{m}}\right)$ envolvidos na dinâmica molecular lenta do polímero. A informação sobre $f_{\mathrm{m}}$ é obtida a partir da intensidade do sinal de exchange para tempos, $t_{\mathrm{m}}$ e $\tau$, longos $\left(E_{\infty}\right)$, que também depende do número de sítios com orientações não equivalentes acessíveis no movimento. Por exemplo, para movimentos de $180^{\circ}$ de grupos laterais (flips), que envolve movimentos entre duas posições ou dois sítios, $M=2$.

Como uma fração de, pelo menos, $1 / M$ dos núcleos que realizam o movimento é sempre encontrada no sítio original selecionado, $E_{\infty}$ é dado por:

$$
E_{\infty}=\Delta S\left(t_{m}>\tau_{c}, \delta \tau>>1\right) / S_{0}=f_{m}(1-1 / M)
$$

onde $\delta$ é o parâmetro de anisotropia do deslocamento químico.

Com a eq.(1.4) o exemplo acima para o movimento de flip de grupos laterais 
resulta em $f_{\mathrm{m}}=2 E_{\infty}$, i.e., a fração dos sítios móveis é sempre duas vezes o nível observado para $E_{\infty}$. No caso de movimentos de reorientações aleatórias, onde há a probabilidade de que o movimento envolva a participação de um grande número de sítios, $M \gg>1$, e, se todos os segmentos participam do movimento de difusão rotacional, ou seja, se $f_{\mathrm{m}}=1$, tem-se que $E_{\infty} \approx 1$.

A eq. (1.4) indica que a avaliação da fração dos sítios que realizam o movimento, $f_{\mathrm{m}}$, depende do conhecimento prévio do número de sítios envolvidos nesse movimento, $M$. No caso dos polímeros estudados neste trabalho, é sabido que o movimento principal relacionado à sua relaxação $\beta$ envolve flips dos grupos laterais. Para este caso, portanto, $M=2$, e a fração móvel pode ser determinada através da observação de $E_{\infty}$. Em sistemas em que não se sabe preliminarmente o valor de $M$ ou de $f_{\mathrm{m}}$ o número de sítios envolvidos no movimento pode ser obtido por uma outra técnica de exchange denominada four-time $\operatorname{CODEX}^{3}$ (o experimento CODEX será discutido no próximo item). Basicamente, ela consiste da aplicação de dois experimentos CODEX em seqüência, de forma que na primeira parte é selecionado apenas o sinal dos segmentos móveis e, na segunda parte, pode-se observar o sinal de exchange $E_{\infty}$ já com $f_{\mathrm{m}}=1$ - pois apenas o sinal dos segmentos móveis vão para o segundo experimento PUREX. Dessa forma, com o sinal resultante, pode-se obter $M$ através da eq.(1.4).

individual do espectro. As seqüências de pulsos necessárias para a realização dos experimentos CODEX estão apresentadas na Figura 1.9. 


\subsection{Centerband-Only Detection of Exchange (CODEX)}

Quando foi apresentada a técnica PUREX foi discutida a importância das novas técnicas de RMN de exchange para facilitar a análise do comportamento dinâmico do material ao nível molecular. No entanto, a sensibilidade e resolução destes experimentos é limitada pelo fato das linhas espectrais serem alargadas pela anisotropia de deslocamento químico ou pela necessidade de se utilizar as intensas bandas laterais geradas em experimentos de rotação lenta da amostra em torno do ângulo mágico (MAS).

A partir dessa dificuldade surgiu uma nova técnica de RMN destinada ao estudo e caracterização de reorientações lentas de segmentos moleculares em cadeias poliméricas com a mais alta sensibilidade e resolução possíveis. Esta técnica é denominada Centerband-Only Detection of Exchange, CODEX 2,3 e possibilita o estudo de movimentos na faixa de 1 a $10^{4} \mathrm{~ms}$, através de espectros de RMN obtidos com supressão total de bandas laterais sob MAS. A partir de duas séries de espectros CODEX/MAS unidimensionais pode-se determinar funções de correlação, tempos de correlação, geometria e amplitude do movimento molecular para cada linha individual do espectro. As seqüências de pulsos necessárias para a realização dos experimentos CODEX estão apresentadas na Figura 1.9. 
(a) modulado

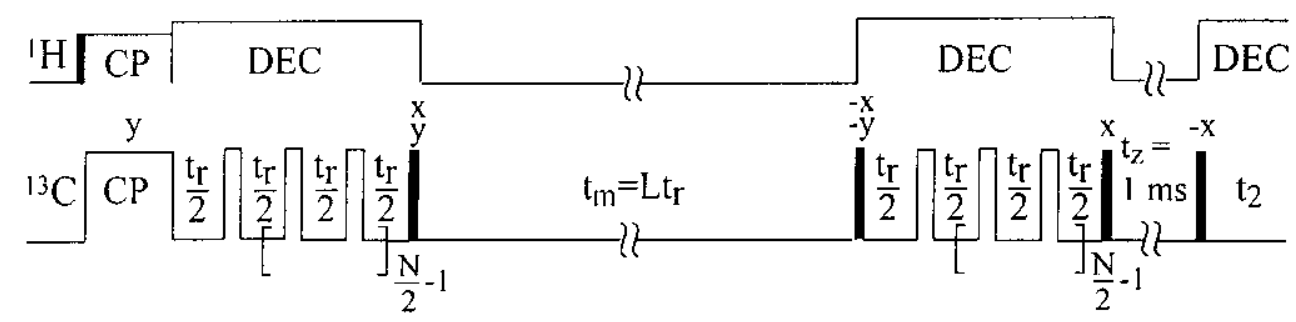

(b) referência

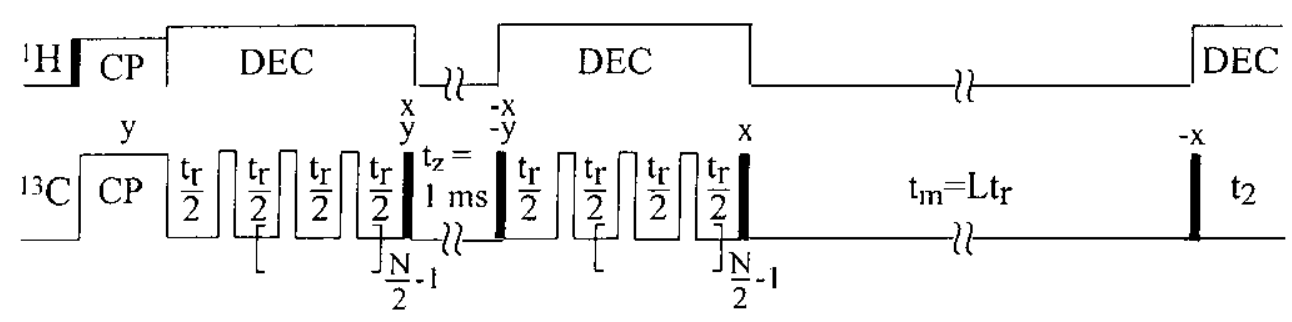

Figura 1.9: Seqüências de pulsos necessárias para obtenção do sinal CODEX. (a) Seqüência de pulsos para o sinal de exchange modulado pelo fator $\left\langle\operatorname{Re}\left\{\exp \left[i \mathrm{~N}\left(\mathrm{~A}_{1}-\mathrm{A}_{2}\right)\right]\right\}\right.$, onde $\mathrm{A} 1$ e $\mathrm{A} 2$ são as fases acumuladas antes e depois do tempo de mistura. (b) Seqüência de pulsos para o sinal de referência. Muda-se de (a) para (b) apenas invertendo-se os periodos $t_{\mathrm{m}} \mathrm{e} t_{\mathrm{z}}$, assim os fatores de relaxação durante as seqüências são sempre os mesmos. Os pulsos de $\pi / 2$ e $\pi$ estão evidenciados em preto e branco, respectivamente. O tempo de mistura deve ser um múltiplo inteiro, $\mathrm{L}$, de períodos de rotação do rotor, $t_{\mathrm{r}} \mathrm{CP}=$ polarização cruzada e $\mathrm{DEC}=$ desacoplamento dipolar. A ciclagem de fases para os pulsos de $\pi / 2$ está indicada na seqüência e é complementada de forma a permitir a remoção de vários artefatos, tais como: relaxação longitudinal durante $t_{\mathrm{m}}$ e problemas instrumentais (linha de base, defeitos de quadratura, etc.). A seqüência TOSS (total suppression of spinning sidebands) ${ }^{21}$ pode ser aplicada antes da detecção para eliminação de eventuais bandas laterais.

$\mathrm{Na}$ primeira metade dos $\mathrm{N}$ períodos de rotação da amostra, $\mathrm{N} t_{\mathrm{r}}$, os spins evoluem sob a ação do deslocamento químico, cuja parte anisotrópica é reintroduzida através da aplicação de dois pulsos de $180^{\circ}$ por período de rotação, $t_{\mathrm{r}} 22$, Figura 1.10 .

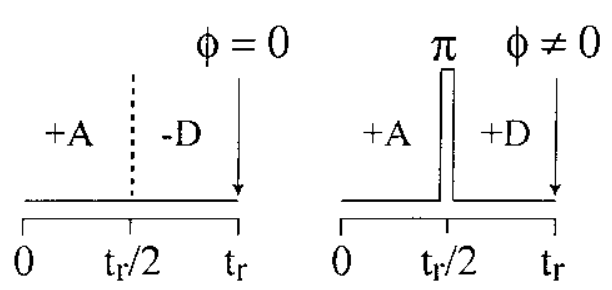

Figura 1.10: Reintrodução do deslocamento químico anisotrópico depois de um período de rotação do rotor, $t_{\mathrm{r}}$. A e D $(|\mathrm{A}|=|\mathrm{D}|)$ representam as fases adquiridas antes e depois de meio período de rotação do rotor, $t_{\mathrm{r}} / 2$, respectivamente. Normalmente o deslocamento químico anisotrópico defasa após uma rotação, $\phi=0$. Com a introdução de um pulso de $\pi$ em meio período de rotação a fase é reintroduzida, $\phi \neq 0$, pois o sinal da fase (D) adquirida no segundo período é invertido. 
Assim, após N/2 períodos de rotação, a magnetização de cada isocromata adquire uma fase $\Phi_{1}$ característica, que depende da orientação do seu respectivo segmento molecular. O mesmo acontece com respeito à fase denominada $\Phi_{2}$ que é adquirida na segunda parte da seqüência de pulsos com N/2 períodos de rotação. A Figura 1.11 explica passo a passo como a reintrodução do deslocamento químico é utilizada para modular a fase do sinal de exchange no experimento CODEX da Fig. 1.9. Considerando-se apenas uma seqüência de pulsos $\pi$ espaçados por um intervalo igual a $t_{\mathrm{r}} / 2$, após $\mathrm{N}$ períodos de rotação do rotor a fase total acumulada é 2NA, Fig. 1.11(a). Retirando-se o pulso $\pi$ localizado em $t_{\mathrm{r}}=\mathrm{N} / 2$ obtém-se que $\Phi_{2}=$ $\Phi_{1}$ e a fase total acumulada é nula, Fig. 1.11(b).

No entanto, se imediatamente após se adquirir a fase $\Phi_{1}$ a magnetização é armazenada na direção $\mathrm{z}$ com a aplicação de um pulso $\pi / 2$, a Figura 1.11(c) passa a representar o mesmo que parte da seqüência de pulsos da Figura 1.9(a). Nessa nova situação a magnetização não executa movimento de precessão e, conseqüentemente, não defasa durante o tempo de mistura subseqüente. Esse tempo de mistura deve ser um múltiplo inteiro, $\mathrm{L}$, de $t_{\mathrm{r}}$, para que o rotor esteja com a mesma fase inicial no segundo ciclo de $\mathrm{N} / 2$ períodos de rotação ${ }^{3}$. Após um segundo pulso de $90^{\circ}$, aplicado com a fase adequada, e outros N/2 períodos de rotação, também com reintrodução do deslocamento químico anisotrópico, a fase adquirida por cada isocromata será $\mathrm{N}\left(\mathrm{A}_{1}\right.$ $\left.A_{2}\right)$ e a magnetização total será modulada pelo fator, $<\operatorname{Re}\left\{\exp \left[i \mathrm{iN}\left(\mathrm{A}_{1}-\mathrm{A}_{2}\right)\right]\right\}>$, onde o símbolo $<>$ indica a média tomada sobre as fases de todos os isocromatas ${ }^{3}$. Não ocorrendo movimentos ao longo dos diversos segmentos da cadeia polimérica durante $t_{\mathrm{m}}, \mathrm{A}_{1}$ será igual a $\mathrm{A}_{2}$ e a deteç̧ão do sinal ocorrerá com todos os spins refocalizados. No entanto, $A_{1}$ será diferente de $A_{2}$ quando ocorrerem movimentos 
moleculares durante o tempo de mistura, visto que o deslocamento químico anisotrópico depende da orientação do sítio nuclear relativamente ao campo externo aplicado. Nesse caso, por causa dessa diferença nas fases de evolução antes e depois do tempo de mistura, a refocalização dos spins não será completa como mostra a Figura 1.11(c).

(a)

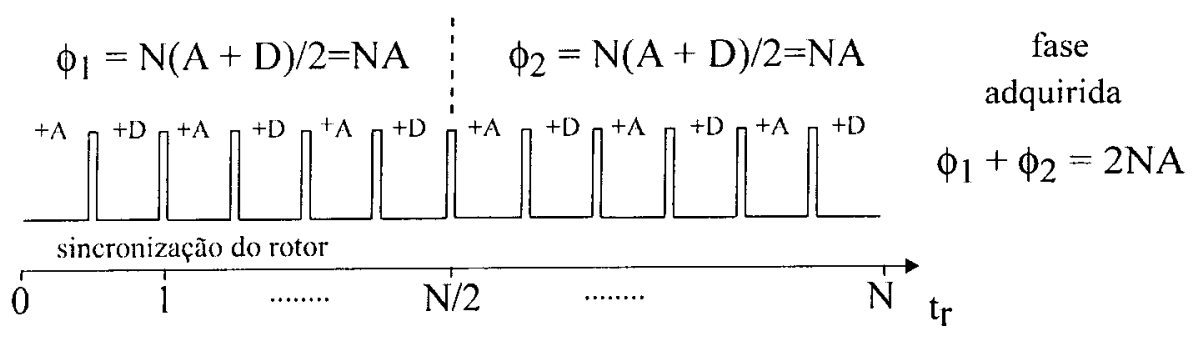

(b)

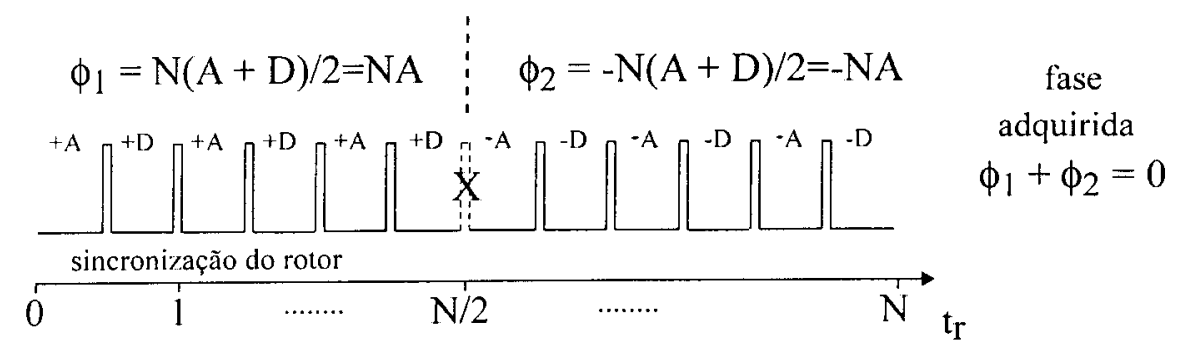

(c)

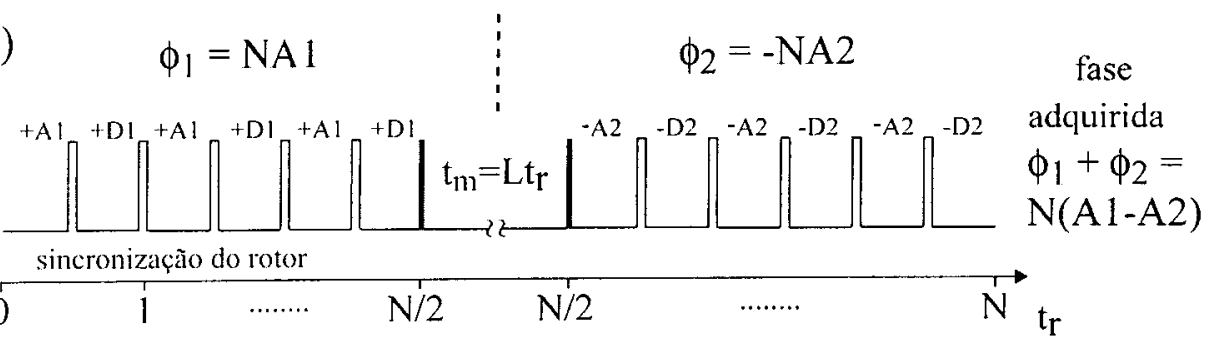

Figura 1.11: Reintrodução do deslocamento químico anisotrópico por um pulso $\pi$ para se observar o movimento durante $t_{\mathrm{m}}$ no experimento CODEX. (a) Série de pulsos $\pi$ em cada meio período do rotor A fase total acumulada depois de $\mathrm{N}$ períodos de rotação é $2 \phi_{1}$. (b) Eliminação de um pulso $\pi$ da seqüência mostrada em (a) na metade dos $\mathrm{N}$ períodos de rotação. A fase total acumulada, neste caso, é nula. (c) Introdução de um tempo de mistura após N/2 períodos de rotação do rotor. Se houver movimento durante $t_{\mathrm{m}}$, a fase total acumulada será $\phi_{1}-\phi_{2}$., caso contrário será nula como em (b). A parte figura (c) está contida na seqüência completa de exchange mostrada na Figura 1.9(a). 
Nota-se dessa discussão que quanto maior o valor de $\mathrm{N}$, maior será a defasagem observada devido ao movimento, i.e., mais intenso se torna o sinal de exchange, exigindo um menor número de médias para a sua aquisição. Por fim, a defasagem dos spins devida ao exchange durante $t_{\mathrm{m}}$ é observada para cada sítio nuclear como um decréscimo na intensidade de cada linha independentemente.

Para se remover os efeitos da relaxação longitudinal $\left(T_{1}\right)$ durante $t_{\mathrm{m}} \mathrm{e}$ transversal $\left(T_{2}\right)$ durante $N t_{\mathrm{r}}$, um espectro de referência $S_{0}=S\left(0, \delta N t_{\mathrm{r}}\right)$ é adquirido, contendo todos os mesmos fatores de relaxação mas nenhum movimento durante $t_{\mathrm{m}}$, de maneira análoga ao realizado para o experimento PUREX. Isso é obtido invertendo-se as durações de $t_{\mathrm{m}}$ e $t_{\mathrm{z}}$, Figura 1.9(b). Para as analises quantitativas, a intensidade CODEX $S=S\left(t_{\mathrm{m}}, \delta N t_{\mathrm{r}}\right.$, ) é subtraída daquela do espectro de referência $S_{0}$ para se obter apenas a intensidade dos segmentos que realizam o movimento (pure exchange) $\Delta S=S_{0}-S$.

Um exemplo que mostra os espectros $S_{0}, S$ e $\Delta S$ de um experimento CODEX é mostrado na Figura 1.12 para o PMMA. Para a análise dos resultados, como aqueles apresentados no Capítulo IV, a intensidade do sinal diferença, $\Delta S$, do grupo COO é plotada após a sua normalização por $S_{0}$. Como discutido anteriormente, o mesmo tipo de manipulação dos espectros é feita para se obter o sinal final PUREX. No entanto, como o experimento PUREX é estático, os espectros da Figura 1.12 seriam do tipo de pó, para cada linha observada. 


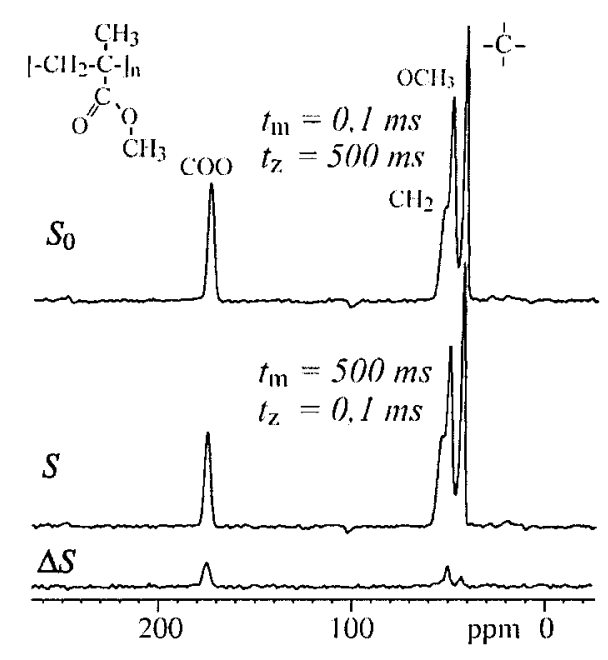

Figura 1.12: Exemplo da geração de um espectro apenas dos segmentos móveis $(\Delta S)$ a partir de um espectro CODEX ( $S$ ) e um espectro de referência sem exchange ( $S_{0}$ ) através de $\Delta S=S_{0}-S$. O espectro foi obtido para o PMMA com $t_{\mathrm{m}}=500 \mathrm{~ms}$ e $N t_{\mathrm{r}}=800 \mu \mathrm{s}$. A intensidade do sinal de exchange é baixa porque somente $34 \%$ de todos os grupos laterais estão realizando o movimento de flip, descrito no Capítulo III. O sinal do grupo $\alpha-\mathrm{CH}_{3}$, que é ligado diretamente à cadeia principal, não é observado no espectro por causa da rápida relaxação longitudinal, devido aos seus rápidos movimentos rotacionais durante $t_{\mathrm{m}}$.

Espectros virtualmente sem bandas laterais melhoram a resolução do sinal com a utilização de altas freqüências de rotação $\left(v_{\mathrm{r}}\right)$, porque o defasamento dos spins é uma função somente do tempo total $N t_{\mathrm{r}}$. Ao se combinar medidas em diferentes velocidades de rotação, a intensidade de exchange $\Delta S / S_{0}$ pode ser obtida para praticamente qualquer tempo $N t_{\mathrm{r}}$ desejado, apesar de que este tem que ser constituído somente de valores inteiros de um específico período de rotação, $t_{\mathrm{r}}$. Além disso, dificuldades surgem ao se tentar utilizar tempos $N t_{\mathrm{r}}$ muito curtos posto que, neste caso, são necessárias altas velocidades de rotação $\left(v_{\mathrm{r}}=1 / t_{\mathrm{r}}\right)$. Para se suprimir as bandas laterais durante a detecção, pode-se utilizar previamente à aquisição do sinal a seqüência TOSS (total suppression of spinning sidebands) 2,3,21.

Assim como para o experimento PUREX, o sinal pode ser adquirido de duas maneiras: (a) em função do tempo de mistura, $t_{\mathrm{m}}$, ou (b) em função do tempo de evolução dos spins ao longo da seqüência de pulsos $\pi$ sincronizados com a 
freqüência de rotação da amostra, $N t_{\mathrm{r}}$. As medidas feitas em função de $t_{\mathrm{m}}$ permitem a determinação da função e do tempo de correlação, pois dependendo de cada valor utilizado para o tempo de mistura pode-se observar movimentos moleculares com diferentes tempos de correlação. Por outro lado, as medidas feitas em função de $N t_{\mathrm{r}}$ possibilitam o cálculo da amplitude do movimento já que é durante os períodos de evolução que surge a dependência angular do sinal de exchange. Através do sinal CODEX também é possível se obter a fração dos sítios móveis $\left(f_{\mathrm{m}}\right)$ envolvidos nos movimentos lentos, conforme dado pela equação 1.4 e discutido para o sinal PUREX.

De acordo com o que será discutido nos Capítulos III e IV, a curva da intensidade de exchange contra $N t_{\mathrm{r}}$ para os poli(alquil metacrilato)s é composta basicamente de duas componentes: uma referente ao movimento de flip de $180^{\circ}$ do grupo lateral $(\gamma)$ e outra que surge do movimento de rotação de pequenos ângulos em torno da cadeia principal $(\alpha)$, como mostra a Figura 1.13(a). Na Figura 1.13(b) estão alguns exemplos de comportamento das curvas CODEX em função de $N t_{\mathrm{r}}$ para o flip e para diferentes valores das rotações de pequenos ângulos. A Figura 1.13(c) mostra os dados obtidos para o PEMA com as componentes da simulação que melhor reproduzem a curva observada. 


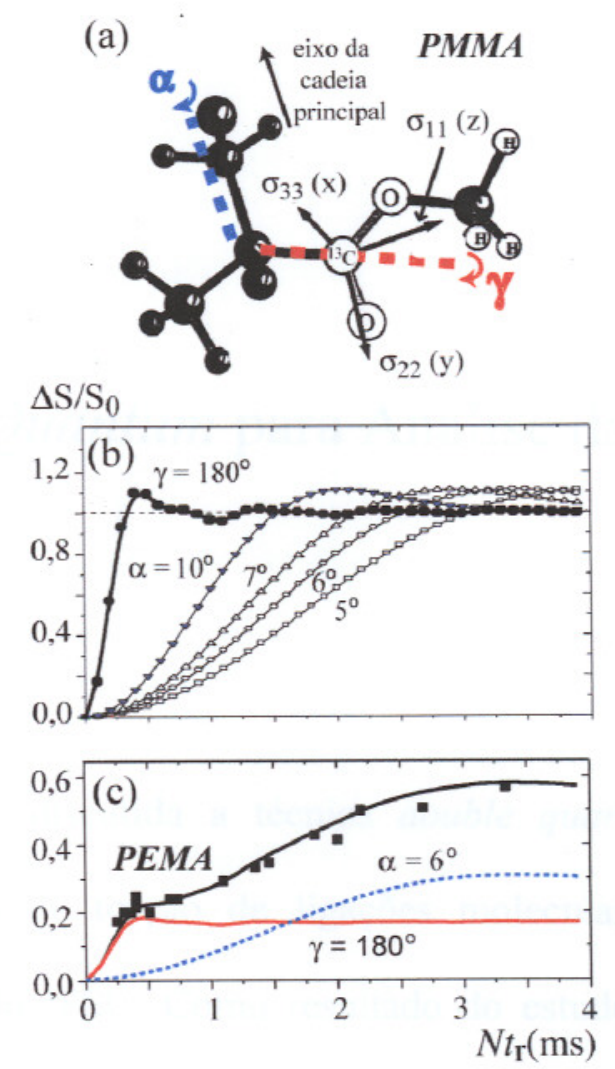

Figura 1.13: Exemplo de aplicação da técnica CODEX para o estudo da amplitude de movimentos moleculares lentos. (a) Eixos de rotação na unidade de repetição do PMMA representando os dois movimentos básicos do grupo lateral COO no PMMA e nos poli(metil metacrilato)s em geral. Rotações em torno da ligação C-C que conecta o grupo lateral à cadeia principal são indicadas por um ângulo $\gamma$. Rotações em torno do eixo da cadeia local são caracterizadas pelo ângulo $\alpha$. (b) Simulações da dependência da intensidade das curvas CODEX com o movimento. (c) Dados obtidos para o PEMA com as componentes da melhor simulação que descreve a curva experimental. 


\section{Técnica Double Quantum para Análise da Estrutura}

\section{Molecular}

Neste capítulo é discutida a técnica double quantum 1,2 utilizada para determinação de ângulos de torção de ligações moleculares, implementada no espectrômetro de RMN do IFSC. Como resultado do estudo e da implementação dessa técnica os primeiros espectros de double quantum obtidos nesse espectrômetro são apresentados no Capítulo IV.

\subsection{Determinação de Ângulos de Torção por RMN}

A ressonância magnética nuclear apresenta uma série de técnicas capazes de ajudar na elucidação de conformações moleculares em polímeros não orientados tais como polímeros amorfos. Através de interações anisotrópicas, tais como o acoplamento dipolar e o deslocamento químico, pode-se determinar as configurações moleculares desses materiais. Com o uso de diferentes técnicas de RMN no estado sólido pode-se aferir as orientações segmentares relativas ${ }^{3-12}$ ou as distâncias internucleares ${ }^{13-18}$ ao nível das ligações químicas individuais. No caso do estudo de ângulos de torção e suas distribuições recorre-se a um espectro de RMN 2D aonde correlaciona-se as orientações dos tensores correspondentes às interações, sem a 
rotação da amostra ( $M A S)$. Para tanto realizam-se experimentos, usualmente em amostras enriquecidas com ${ }^{13} \mathrm{C}$, de exchange $3-8,19$ ou de correlação dos acoplamentos dipolares com os deslocamentos químicos $10-12$.

A técnica de double quantum tem características únicas na determinação da conformação molecular em sólidos não orientados. Ela permite que se obtenha os ângulos $\psi$ de torção das ligações ${ }^{13} \mathrm{C}-{ }^{13} \mathrm{C}$ apresentando grandes vantagens sobre as demais técnicas de RMN para essa caracterização.

A técnica exchange 2D, por exemplo, produz espectros que apresentam certas dificuldades na sua análise quando devidos a um par $(a, b)$ de núcleos ${ }^{13} \mathrm{C}-{ }^{13} \mathrm{C}$ acoplados dipolarmente. Esse enriquecimento em pares é necessário na técnica de exchange para a análise conformacional, posto que é através do fenômeno de difusão de spins entre os dois sítios do par que pode-se observar o padrão de exchange, fora da diagonal, que traz a informação sobre o ângulo de torção. A Figura 2.1 mostra um exemplo retirado da referência ${ }^{2}$, indicando as características dos espectros bidimensionais de double quantum, Fig. 2.1(a) e (b), e exchange, Fig. 2.1(c), (d) e (e); $\operatorname{simulados}^{8}$ para um caso hipotético de desacoplamento hetero e homonuclear com os parâmetros do tensor de deslocamento químico do poli(etileno) 20,21 .

$\mathrm{O}$ primeiro problema desses espectros de exchange $2 \mathrm{D}$ ocorre porque, devido ao acoplamento do par de ${ }^{13} \mathrm{C}-{ }^{13} \mathrm{C}$, o espectro de resultante contém intrinsecamente $50 \%$ da sua intensidade ao longo da diagonal ${ }^{2}$, i.e., sinais em $\left(\omega_{a}, \omega_{a}\right)$ e $\left(\omega_{b}, \omega_{b}\right)$, Fig. 2.1(e) - o que não traz nenhuma informação sobre a conformação e pode mascarar os padrões de exchange, principalmente para conformações trans (exemplificada na Figura 2.1(c)). 
Além do problema da diagonal, a técnica exchange 2D produz espectros muito complexos devido ao forte acoplamento dipolar que surge da pequena distância entre os núcleos ${ }^{13} \mathrm{C}$ na amostra enriquecida. Para contornar essa questão deve-se aplicar um eficiente desacoplamento homonuclear $\left({ }^{13} \mathrm{C}-{ }^{13} \mathrm{C}\right)$ e heteronuclear $\left({ }^{13} \mathrm{C}-{ }^{1} \mathrm{H}\right)$, simultaneamente em ambas as dimensões espectrais, o que é difícil de implementar.

Para se contornar o problema do sinal ao longo da diagonal, pode-se utilizar a técnica de exchange PUREX $2 \mathrm{D}^{22}$. No entanto, com isso a questão dos espectros extremamente complexos é ainda mais difícil de ser contornada, já que, devido ao aumento na complexidade da sequiência de pulsos, a aplicação do desacoplamento ser mais difícil de ser utilizado na prática.

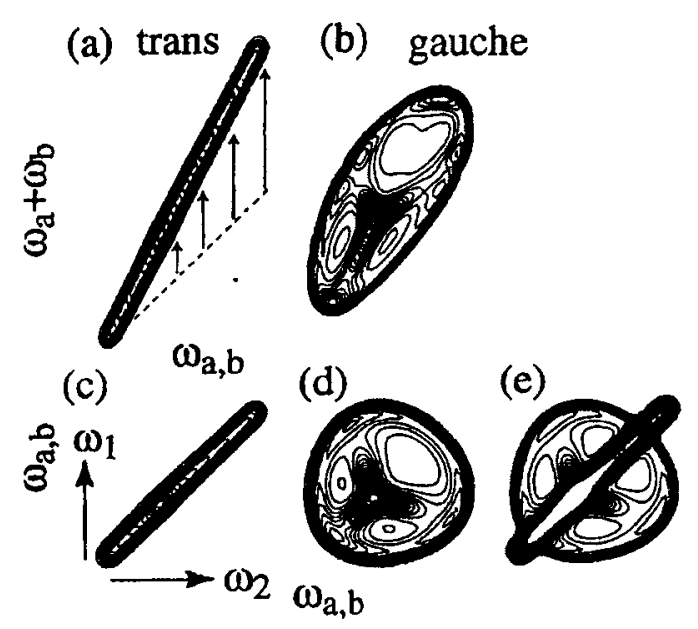

Figura 2.1: Comparação entre os espectros 2D obtidos pelas técnicas de double quantum: (a) e (b); e de exchange: (c), (d) e (e). Os exemplos são simulações calculadas com os parâmetros de deslocamento químico do poli(etileno) considerando-se desacoplamento homo e heteronuclear simultâneos e foram retirados da referência ${ }^{2}$. (a) Espectro DQ para um ângulo de torção $\psi=180^{\circ}$ (trans). (b) Espectro DQ para $\psi= \pm 60^{\circ}$ (gauche). (c) Espectro de exchange com $\psi=180^{\circ}$. Este padrão é indistingüível da parte diagonal intrínseca do espectro de exchange. (d) Espectro de exchange com $\psi= \pm 60^{\circ}$. (e) Espectro de exchange como é observado, incluindo (c) e (d) e o padrão diagonal que domina o espectro e mascara totalmente as contribuições trans.

Outra técnica de RMN utilizada para tratar tais sistemas é a correlação bidimensional do acoplamento dipolar e da anisotropia de deslocamento químico 
para uma ligação ${ }^{13} \mathrm{C}-{ }^{13} \mathrm{C}$. No entanto, com essa técnica pode-se obter somente a informação sobre o ângulo de torção no caso específico de sistemas que estão no regime de acoplamento intermediário 11,12 . Em outras palavras, se o acoplamento dipolar, $\omega_{D}$, é muito maior ou muito menor se comparado a diferença entre os deslocamentos químicos isotrópicos, $\Delta$, dos núcleos pertencentes ao par, o espectro resultante só vai depender da orientação do vetor internuclear ${ }^{13} \mathrm{C}^{13} \mathrm{C}$ nos sistemas de eixos principais dos deslocamentos químicos individuais, não trazendo a informação conformacional desejada.

A técnica de RMN de double quantum aplicada a amostras sólidas traz efetivamente a correlação tensorial entre os segmentos enriquecidos ${ }^{13} \mathrm{C}-{ }^{13} \mathrm{C} . \mathrm{O}$ espectro final bidimensional contém a primeira dimensão espectral, $\omega_{1}$, refletindo o ângulo de torção em termos da soma dos deslocamentos químicos dos sítios acoplados (double quantum), sem qualquer interferência do acoplamento dipolar (independentemente da magnitude do acoplamento). A informação sobre a conformação é aumentada pela correlação com os deslocamentos químicos individuais e o acoplamento dipolar na dimensão $\omega_{2}$ diretamente detectável.

As vantagens desse experimento de double quantum são a inerente remoção do sinal de fundo dos carbonos em abundância natural que domina o espectro em sistemas complexos, além ' da ausência do intenso sinal diagonal presente em espectros de exchange convencionais.

\subsection{Princípios do Experimento Double Quantum}

Algumas complicações espectrais surgem em sistemas de spins com fortes acoplamentos homonucleares. Elas surgem porque as Hamiltonianas dipolar (ou de acoplamento $J$ ) homonuclear e diferença de deslocamento químico não comutam 
entre si 23,24 . A posição das linhas de ressonância e suas intensidades são funções relativamente complexas de $\omega_{D}$ e de $\Delta$ se as magnitudes do acoplamento dipolar, $\omega_{D}$, e da diferença de deslocamento químico, $\Delta$, são similares $\left(\Delta \approx \omega_{D}\right)$. Situações simples são obtidas apenas nos limites de acoplamento fraco, $\Delta \gg \omega_{D}$, e de acoplamento muito forte, $\Delta \ll<\omega_{D}$, já que nesses casos o problema da nãocomutabilidade é resolvido. $\mathrm{O}$ caso em que $\Delta \approx \omega_{D}$ é considerado como o de regime de acoplamento intermediário. Para RMN em líquidos em campos magnéticos altos, o acoplamento $J$ (já que a anisotropia da interação dipolar é promediada para seu valor isotrópico nulo) faz com que o sistema esteja no limite de acoplamento fraco. Em sólidos, o mais comum é a observação do limite de acoplamento forte. Se o núcleo sob análise é o ${ }^{1} \mathrm{H}$, as diferenças de deslocamento químico são muito pequenas (a distribuição de deslocamentos químicos para o ${ }^{1} \mathrm{H}$ é da ordem de $10 \mathrm{ppm}$ ) e o acoplamento dipolar é alto. Para ${ }_{0}{ }^{13} \mathrm{C}$, também em amostras sólidas, maiores diferenças entre os deslocamentos químicos podem ser observadas (distribuição de deslocamentos químicos de $200 \mathrm{ppm}$ ), levando o sistema a um regime de acoplamento intermediário. No entanto, por razões de simetria, algumas vezes a diferença de deslocamento químico desaparece $(\Delta=0)$ e o sistema (assim como o caso geral para ${ }^{1} \mathrm{H}$ ) também se encontra no limite de acoplamento forte.

As expressões para a evolução temporal do operador densidade e para o cálculo do espectro sob acoplamento dipolar nesses dois extremos (caso de líquidos e certos casos de sólidos) são muito similares. Em ambos os casos, o espectro de um segmento com uma ligação ${ }^{13} \mathrm{C}^{13} \mathrm{C}$ fazendo um ângulo $\theta$ com o campo $\boldsymbol{B}_{0}$ exibe dubletos com uma separação dada por ${ }^{1}$ :

$$
2 \omega_{D}=2 q \times 7.6 \mathrm{kHz}\left(3 \cos ^{2} \theta-1\right) / 2 r^{3}
$$


No limite de acoplamento forte, aparece um dubleto com um desdobramento dado pela eq.(2.1) $\operatorname{com} q=3 / 2$, centrado na posição comum aos dois deslocamentos químicos (caso para $\Delta=0$ citado acima). Se esse limite fosse dado pelo acoplamento $J$, o Hamiltoniano seria mais simples ainda e não haveria um desdobramento espectral. No limite de acoplamento fraco, surgem dois dubletos, cada um centrado na posição do deslocamento químico de um dos dois núcleos que estão acoplados. Nesse caso seus desdobramentos também são dados pela eq.(2.1) mas $\operatorname{com} q=1$.

A seqüência de pulsos para o experimento double quantum é constituída basicamente de três partes, Figura 2.2. Inicialmente a magnetização tem que ser colocada no plano transversal. Isso está representado pelo efeito do pulso $a$ na figura, mas essa magnetização pode ser obtida pela polarização cruzada em experimentos de dupla ressonância. Após isso tem-se: (i) o período de excitação da magnetização de double quantum formado por um pulso de $180^{\circ}$ entre dois intervalos de $\tau$ seguido por um pulso de $90^{\circ}, \tau \rightarrow \pi(b) \rightarrow \tau \rightarrow \pi / 2(c)$; (ii) o período de evolução de double quantum durante $t_{1}$ e (iii) o período de reconversão da magnetização $D Q$ em magnetização observável, $\pi / 2(d) \rightarrow \tau \rightarrow \pi(e) \rightarrow \tau$. Após isso o sinal é observado diretamente durante o período $t_{2}$.

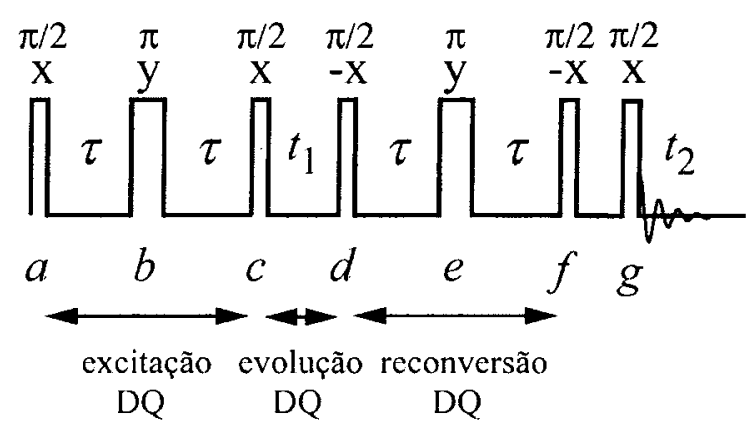

Figura 2.2: Esquema da seqüência de pulsos básica necessária para a geração da coerência de double-quantum e posterior detecção do sinal da coerência de single-quantum com o fator de modulação DQ. 
Para analisar o espectro de double quantum considera-se um par de núcleos

${ }^{13} \mathrm{C}$ diretamente ligados com deslocamentos químicos $\omega_{a}$ e $\omega_{b}$, e com a Hamiltoniana de acoplamento dipolar dada por: $\hbar \omega_{D}\left(3 S_{z} L_{z}-\vec{S} \cdot \vec{L}\right)$. No espectro bidimensional resultante as freqüências individuais $\omega_{a}$ e $\omega_{b}$ dos núcleos acoplados apresentam uma dependência com a orientação, que está mascarada nos seus espectros de pó, na dimensão $\omega_{2}$. Mas essa dependência está correlacionada com a somatória das freqüências individuais $\left(\omega_{a}+\omega_{b}\right)$, que aparece na dimensão $\omega_{1}$ devido a evolução do termo de double quantum, como será explicado nos itens seguintes. Para uma dada orientação do segmento ${ }^{13} \mathrm{C}-{ }^{13} \mathrm{C}$, o experimento de correlação entre os quanta duplo e simples produz intensidades espectrais em $\left(\omega_{a}+\omega_{b}, \omega_{a}\right)$ e $\left(\omega_{a}+\omega_{b}, \omega_{b}\right)$. Isso pode ser observado pela similaridade dos espectros das Figuras 2.1(a) e (c) (ângulo de torção $\psi=180^{\circ}$ ), assim como das Figuras 2.1(b) e (d) (ângulo de torção $\psi= \pm 60^{\circ}$ ); para os experimentos DQ e exchange, respectivamente. Apesar de muito similares, estes espectros têm uma inclinação diferente. Enquanto que o padrão de exchange apresenta-se em torno da diagonal do espectro, o padrão DQ tem uma inclinação espectral 2:1, como indicado na Figura 2.1(a).

É importante observar que os espectros DQ sem desacoplamento homonuclear ${ }^{13} \mathrm{C}-{ }^{13} \mathrm{C}$ apresentam-se alargados devido à interação dipolar entre os núcleos acoplados através da eq.(2.1). Neste caso, pela discussão feita acima, é mais correto dizer que as intensidades espectrais se encontram em $\left(\omega_{a}+\omega_{b}, \omega_{a} \pm \omega_{D}\right) \mathrm{e}$ $\left(\omega_{a}+\omega_{b}, \omega_{b} \pm \omega_{D}\right)$

\subsection{Modulação do Sinal Devido à Coerência de Double Quantum}

A forma do espectro DQ bidimensional depende da orientação relativa entre 
os segmentos contendo ${ }^{13} \mathrm{C}$ e, portanto, do ângulo de torção entre estes segmentos. Para se obter essa dependência deve ser considerado que a coerência de double quantum é gerada a partir da magnetização transversal $\left(I_{y}=S_{y}+L_{y}\right.$ após o pulso $a$, Fig. 2.2) devido à evolução do sistema de spins acoplados dipolarmente sob efeito dos pulsos de radiofreqüência necessários. A seguir ilustra-se a evolução da magnetização representada pelo formalismo de operadores produto 25,26 em um experimento de double quantum, como aquele descrito pela seqüência de pulsos da Figura 2.2.

Considerando-se que $S$ e $L$ são os operadores de spin dos núcleos $a$ e $b$ acoplados dipolarmente $\left({ }^{13} \mathrm{C}_{a}-{ }^{13} \mathrm{C}_{b}\right)$, o hamiltoniano desse sistema pode ser escrito como $^{27}$ :

$$
H^{0}=\hbar \omega_{S} S_{z}+\hbar \omega_{L} L_{z}+\hbar \omega_{D}\left(3 S_{z} L_{z}-\vec{S} \cdot \vec{L}\right)
$$

onde,

$$
\omega_{D}=\frac{\gamma^{2} \hbar}{2} \frac{\left(1-3 \cos ^{2} \theta\right)}{r^{3}}
$$

Para facilitar o acompanhamento da evolução do sistema de spins durante a seqüência de pulsos da Figura 2.2 pode-se separar o hamiltoniano da eq.(2.2) em três partes que comutam. Desta forma, em unidades de $\hbar$, tem-se que:

$$
H^{0}=H_{A}+H_{B}+H_{C}
$$

onde,

$$
\begin{aligned}
& H_{A}=\frac{A}{2}\left(S_{z}+L_{z}\right) ; A=\omega_{S}+\omega_{L} \\
& H_{B}=\frac{B}{2}\left(2 S_{z} L_{z}\right) ; B=\omega_{D}
\end{aligned}
$$




$$
H_{C D}=\frac{C}{2}\left(S_{z}-L_{z}\right)+\frac{D}{2}\left(S^{+} L^{-}+S^{-} L^{+}\right) \quad ; \quad C=\omega_{S}-\omega_{L} \quad \text { e } \quad D=-\omega_{D}
$$

A maneira como o hamiltoniano é reescrito através das equações (2.4) e (2.5) permite que a evolução total do sistema sob $H^{0}$ possa ser considerado como evoluções consecutivas devidas às suas três partes em uma ordem arbitrária, por causa da sua comutabilidade. Desta forma, inicialmente é observado como se dá a evolução do sistema de spins sob cada uma das partes do hamiltoniano total, eq.(2.4).

Os hamiltonianos $H_{A}$ e $H_{B}$ contém partes que resultam em uma evolução do sistema de acordo com o caso comum, como se o acoplamento dipolar estivesse no limite de acoplamento fraco. Considerando-se o spin total $I=S+L$ tem-se que: $I_{\alpha}=S_{\alpha}+L_{\alpha}$ onde $\alpha=x, y, z$. Essa representação descreve as magnetizações transversais ao longo de $x$ e $y$, ou a magnetização longitudinal ao longo de $z$, respectivamente. Com essa notação, são exemplos de evolução do sistema sob $H_{A}$ :

$$
\begin{gathered}
I_{y} \stackrel{H_{A} t}{\longrightarrow} I_{y} \cos \left(\frac{1}{2} A t\right)-I_{x} \sin \left(\frac{1}{2} A t\right) \\
I_{x} \stackrel{H_{A} t}{\longrightarrow} I_{x} \cos \left(\frac{1}{2} A t\right)+I_{y} \sin \left(\frac{1}{2} A t\right)
\end{gathered}
$$

enquanto que exemplos de evolução sob $H_{B}$, lembrando-se que $S_{z}^{2}=L_{z}^{2}=1 / 4$, são:

$$
\begin{gathered}
I_{y} \stackrel{H_{B} t}{\longrightarrow} I_{y} \cos \left(\frac{1}{2} B t\right)-\left(2 S_{z} L_{x}+2 S_{x} L_{z}\right) \sin \left({ }_{2}^{1} B t\right) \\
2 S_{z} L_{x}+2 S_{x} L_{z} \stackrel{H_{B} t}{\longrightarrow}\left(2 S_{z} L_{x}+2 S_{x} L_{z}\right) \cos \left(\frac{1}{2} B t\right)+I_{y} \sin \left(\frac{1}{2} B t\right) \\
I_{x} \stackrel{H_{B} t}{\longrightarrow} I_{x} \cos \left(\frac{1}{2} B t\right)+\left(2 S_{z} L_{y}+2 S_{y} L_{z}\right) \sin \left(\frac{1}{2} B t\right) \\
2 S_{z} L_{y}+2 S_{y} L_{z} \stackrel{H_{B} t}{\longrightarrow}\left(2 S_{z} L_{y}+2 S_{y} L_{z}\right) \cos \left(\frac{1}{2} B t\right)-I_{x} \sin \left(\frac{1}{2} B t\right)
\end{gathered}
$$

As equações (2.6) representam a evolução do deslocamento químico, representada graficamente em eixos cartesianos na Figura 2.3(a). De maneira análoga 
é mostrado o efeito de pulsos de RF ao longo da direção $x$, Fig.2.3(b), e y, Fig. 2.3(c). Em outras palavras, as Figuras 2.3 são representações do subespaço tridimensional de operadores no qual rotações são efetuadas em completa analogia com o espaço físico. Este subespaço tem em sua origem as relações de comutação cíclicas $\left[I_{x}, I_{y}\right]=i I_{z}$.

(a)

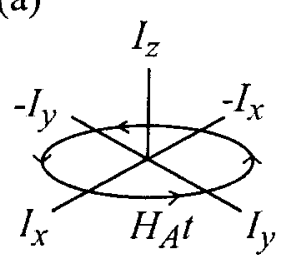

(b)

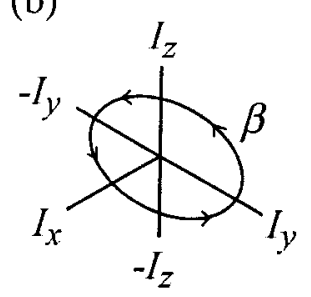

(c)

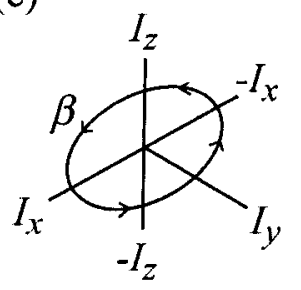

Figura 2.3: Representação do subespaço tridimensional de operadores dado pela relação de comutação cíclica $\left[I_{x} I_{y}\right]=\mathrm{i}_{z}$. (a) Representação das evoluções sob $H_{A}$, eq.(2.6). Efeito de pulsos de RF: (b) ao longo da direção $x \mathrm{e}$ (c) ao longo da direção $y$.

As equações (2.7a) e (2.8a) dizem que sob o hamiltoniano $H_{B}$ a evolução do sistema corresponde a uma conversão de magnetizações em fase para magnetizações anti-fase, conforme a nomenclatura usual para operadores produto 25,26 . Por outro lado, iniciando-se a evolução a partir de magnetizações anti-fase obtém-se magnetizações em fase, conforme mostram as equações (2.7b) e (2.8b). As relações (2.7) e (2.8) estão representadas graficamente em seus respectivos subespaços de operadores nas Figuras 2.4(a) e 2.4(b), respectivamente, de maneira análoga àquela feita na Figura 2.3. As relações de comutação cíclicas relacionadas a estes subespaços são: $\quad\left[2 S_{z} L_{x}+2 S_{x} L_{z}, I_{y}\right]=i 2 S_{z} L_{z}$, para a Fig. 2.4(a), e $\left[I_{x}, 2 S_{z} L_{y}+2 S_{y} L_{z}\right]=i 2 S_{z} L_{z}$, para a Fig. $2.4(\mathrm{~b})$ 
(a)

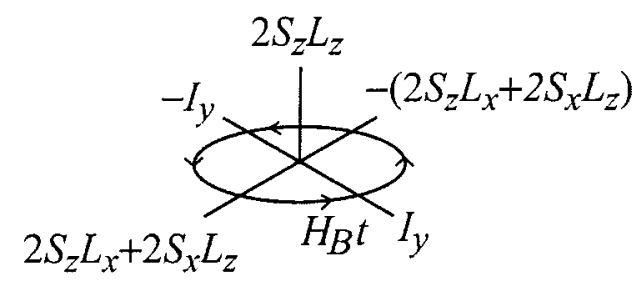

(b)

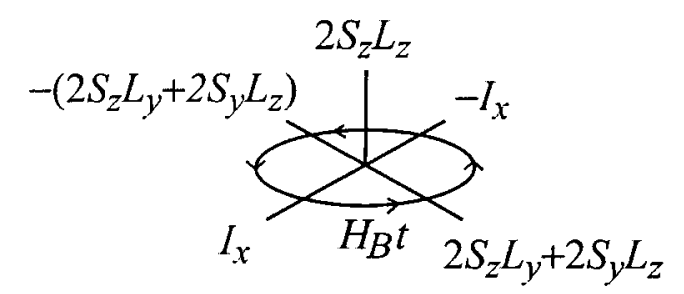

Figura 2.4: Representação dos subespaços tridimensionais de operadores em evolução sob a hamiltoniana $H_{B}$. (a) Subespaço que contém as relações (2.7). (b) Subespaço que contém as relações (2.8).

Por outro lado, a evolução no tempo através da terceira parte do hamiltoniano da eq.(2.4), dada por $H_{C D}$, reflete os efeitos do acoplamento geral (acoplamento forte), e é dada, por 23,28 :

$$
O_{z} \stackrel{H_{C D} t}{\longrightarrow} O_{z} \cos \left(\frac{1}{2} R t\right)+\left(O_{y} \frac{D}{R}+O_{x} \frac{C}{R}\right) \sin \left(\frac{1}{2} R t\right) \quad ; \quad R=\sqrt{C^{2}+D^{2}}
$$

onde os operadores $O_{x}, O_{y}$ e $O_{z}$ estão representados na Tabela I.

Tabela I. Operadores Produto Relacionados às Evoluções sob Efeito do Acoplamento Intermediário, eq.(2.9).

\begin{tabular}{ccccc}
\hline & $O_{z}$ (estados iniciais) & $O_{y}$ & $O_{x}$ \\
\hline grupo Y & (1) & $I_{y}$ & $2 S_{z} L_{x}+2 S_{x} L_{z}$ & $-\left(S_{x}-L_{x}\right)$ \\
& (2) & $2 S_{z} L_{x}+2 S_{x} L_{z}$ & $-I_{y}$ & $-\left(2 S_{z} L_{y}-2 S_{y} L_{z}\right.$; \\
& (3) & $S_{x}-L_{x}$ & $-\left(2 S_{z} L_{y}-2 S_{y} L_{z}\right.$, & $I_{y}$ \\
& (4) & $2 S_{z} L_{y}-2 S_{y} L_{z}$ & $S_{x}-L_{x}$ & $2 S_{z} L_{x}+2 S_{x} L_{z}$ \\
& & & & \\
grupo X & (1) & $I_{x}$ & $-\left(2 S_{z} L_{y}+2 S_{y} L_{z}\right.$, & $S_{y}-L_{y}$ \\
& (2) & $2 S_{z} L_{y}+2 S_{y} L_{z}$ & $I_{x}$ & $2 S_{z} L_{x}-2 S_{x} L_{z}$ \\
& (3) & $S_{y}-L_{y}$ & $2 S_{z} L_{x}-2 S_{x} L_{z}$ & $-I_{x}$ \\
(4) & $2 S_{z} L_{x}-2 S_{x} L_{z}$ & $-\left(S_{y}-L_{y}\right)$ & $-\left(2 S_{z} L_{y}+2 S_{y} L_{z} ;\right.$
\end{tabular}

Na Tabela I a divisão entre grupos Y e X significa que um operador produto pertencente ao grupo $\mathrm{Y}$ sempre evoluirá, de acordo com (2.9), para operadores produto que pertencem a esse grupo $\mathrm{Y}$, o mesmo acontecendo para o grupo $\mathrm{X}$.

Como o hamiltoniano total é dado pela soma dos três hamiltonianos 
analisados acima, eq.(2.4), pode-se obter a evolução sob $H^{0}$ durante um tempo $t$ a partir de aplicações sucessivas das evoluções sob $H_{A}, H_{B}$ e $H_{C D}$. Com essa análise observa-se que apenas a partir de quatro dos oito estados mostrados na Tabela I é que pode-se chegar a magnetizações observáveis. Estes quatro são os estados (1) e (2) dos grupos $\mathrm{Y}$ e X da tabela. A forma como estes quatro operadores produto tornamse magnetizações em fase sob $H^{0}$ pode ser escrita como é mostrado nas expressões (2.10). Nestas expressões $E(t), F(t), G(t)$ e $J(t)$ representam os fatores que surgem devido às evoluções sob cada hamiltoniano durante o tempo $t^{23}$.

$$
\begin{aligned}
& I_{y} \stackrel{H^{0_{t}}}{\longrightarrow} I_{y} E(t)-I_{x} F(t) \quad ; \quad 2 S_{z} L_{x}+2 S_{x} L_{z} \stackrel{H^{0} t}{\longrightarrow} I_{y} G(t)-I_{x} J(t) ; \\
& I_{x} \stackrel{H^{0} t}{\longrightarrow} I_{x} E(t)+I_{y} F(t) \quad \text { e } 2 S_{z} L_{y}+2 S_{y} L_{z} \stackrel{H^{0} t}{\longrightarrow}-I_{x} G(t)-I_{y} J(t)(2.1
\end{aligned}
$$

A evolução da magnetização durante o trecho $\tau \rightarrow \pi \rightarrow \tau$ que aparece em duas partes da seqüência de pulsos da Figura 2.2 (na criação e na reconversão da magnetização de double quatum) é discutida a seguir. A evolução do sistema durante cada um destes períodos pode ser escrita das quatro formas descritas abaixo, utilizando-se o conceito de rotações compostas 25 :
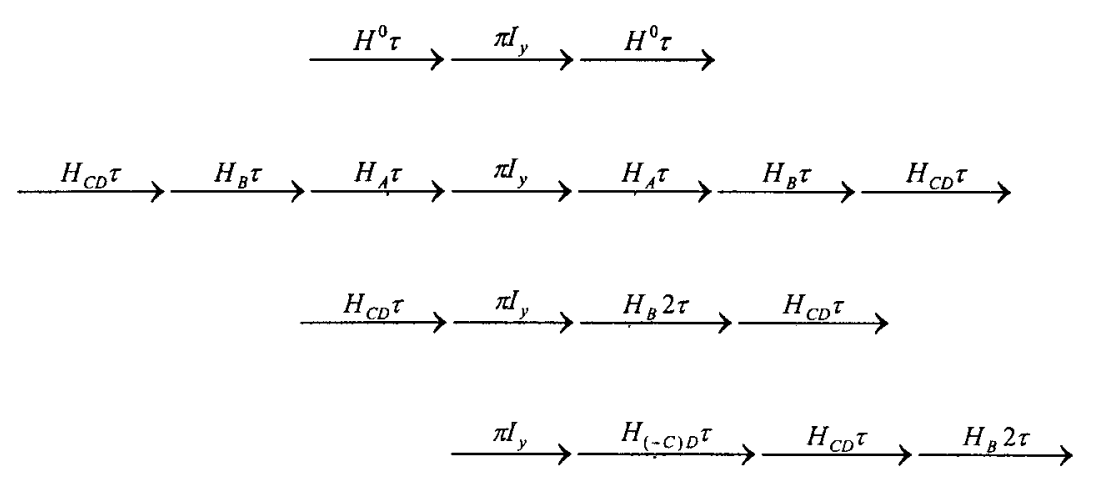
No primeiro passo, (i) $\rightarrow$ (ii), a evolução sob $H^{0}$ foi escrita em termos da evolução sob os três hamiltonianos dados pela eq.(2.4). No segundo passo, (ii) $\rightarrow$ (iii), elimina-se as evoluções sob $H_{A}$, pois seus efeitos antes e depois do pulso $\pi$ se cancelam. Além disso, foi utilizada a comutabilidade dos três hamiltonianos para que as duas evoluções sob $H_{B}$ fossem reunidas em um único termo com um tempo de duração igual a $2 \tau$. Para o terceiro e último passo, (iii) $\rightarrow$ (iv), utiliza-se a propriedade de que o pulso $\pi$ inverte o termo da diferença dos deslocamentos químicos - primeiro termo em $H_{C D}$, eq.(2.5). Assim, coloca-se os dois períodos de evolução sob $H_{C D}$ após o pulso e, invertendo-se o primeiro termo de um deles, designa-se este por $H_{(-C) D}$.

A evolução sob $H_{(-C) D}$ é a mesma que sob $H_{C D}$ dada pela eq.(2.9), a menos do sinal dos termos $O_{x}$ que devem ser invertidos na Tabela I. Com isso, pode-se obter a evolução consecutiva do sistema sob $H_{(-C) D}$ e $H_{C D}$ para os quatro estados iniciais (1) e (2) da Tabela I. As Figuras 2.5(a) e 2.6(a) apresentam esquemas dessa evolução para os dois estados iniciais do grupo $\mathrm{Y}$ e para os dois pertencentes ao grupo $\mathrm{X}$, respectivamente. 
(a)

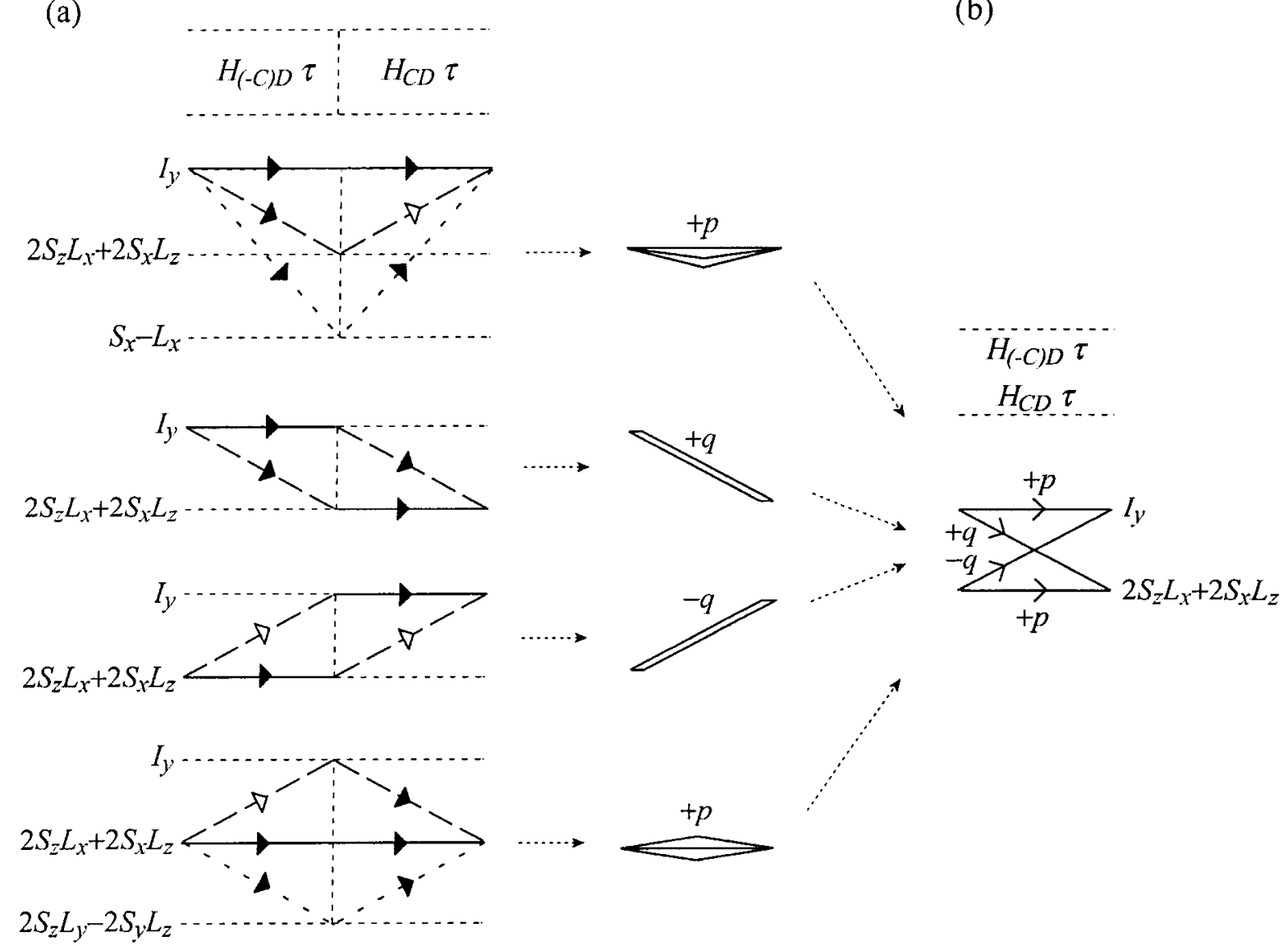

Figura 2.5: Representação gráfica da evolução dos estados iniciais (1) e (2) do grupo Y na Tabela I devido a $H_{(-C) D}$ e $H_{C D}$. (a) Versão detalhada dos caminhos de evolução. As formas das linhas indicam os fatores multiplicativos referentes a cada passo de coerência. Linhas sólidas: $\cos (R t / 2)$. Linhas tracejadas: $(D / R) \operatorname{sen}(R t / 2)$. Linhas pontilhadas: $(C / R) \operatorname{sen}(R t / 2)$. As setas pretas (positivo) e as setas preenchidas com branco (negativo) referem-se aos sinais de cada termo. (b) Versão compacta dos caminhos de evolução mostrados em (a). As definições para $p$ e $q$ são dadas nas equações (2.11a) e (2.11b).

A Figura 2.5(a) mostra as evoluções a partir de $I_{y}$ e de $2 S_{z} L_{x}+2 S_{x} L_{z}$ devido a $H_{(-C D}$ e $H_{C D}$. Esta figura foi dividida em quatro partes: duas mostrando os caminhos que não mudam a magnetização inicial e duas mostrando como $I_{y}$ é convertido em $2 S_{z} L_{x}+2 S_{x} L_{z}$ e vice-versa. O mesmo é mostrado na Figura 2.6(a) a partir de $I_{x}$ e $2 S_{z} L_{y}+2 S_{y} L_{z}$ 
(a)

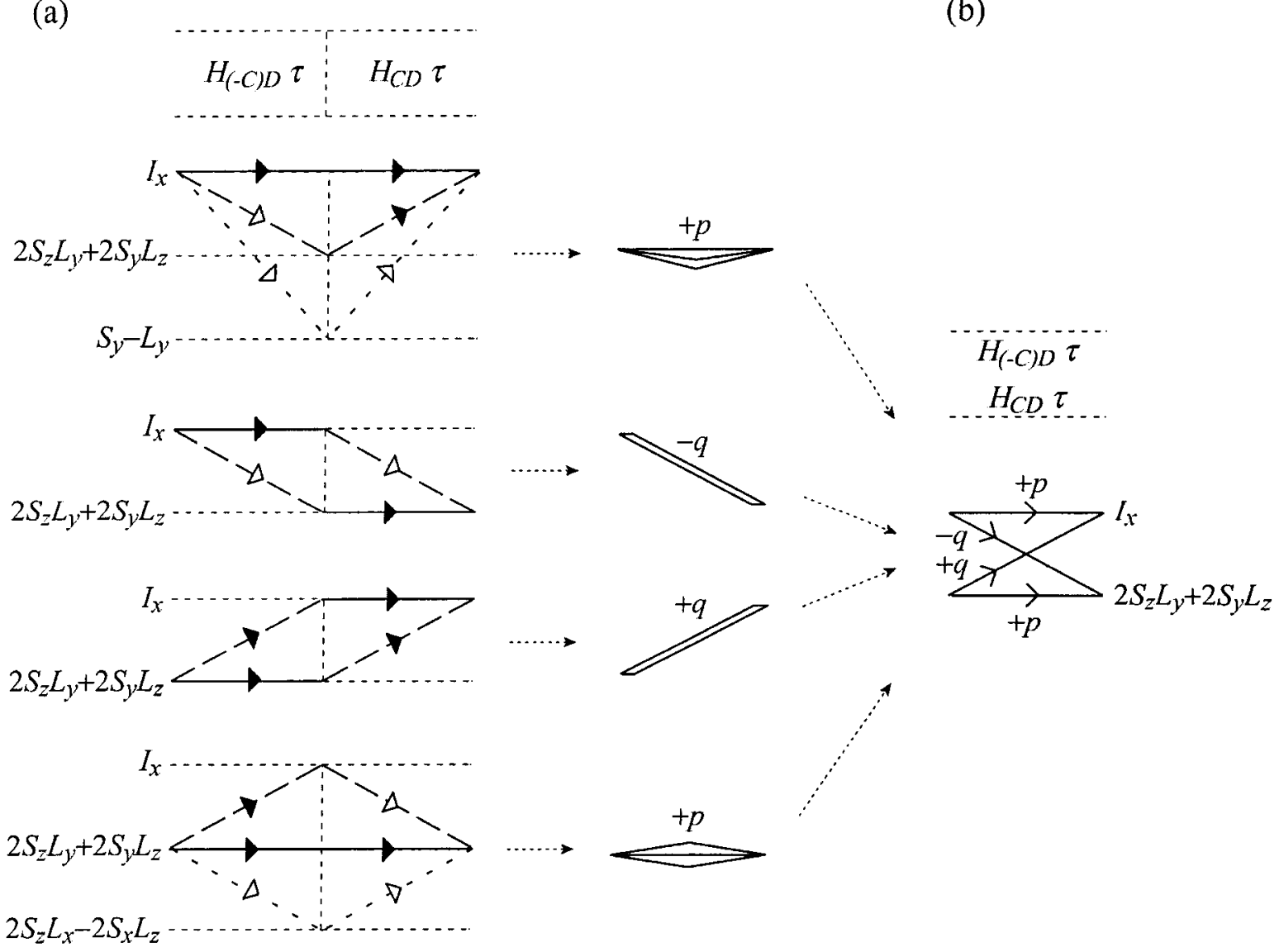

Figura 2.6: Representação gráfica da evolução dos estados iniciais (1) e (2) do grupo X na Tabela I devido a $H_{(-C) D}$ e $H_{C D}$. (a) Versão detalhada dos caminhos de evolução. As formas das linhas indicam os fatores multiplicativos referentes a cada caminho de evolução. Linhas sólidas: $\cos (R t / 2)$. Linhas tracejadas: $(D / R) \operatorname{sen}(R t / 2)$. Linhas pontilhadas: $(C / R) \operatorname{sen}(R t / 2)$. As setas pretas (positivo) e as setas preenchidas com branco (negativo) referem-se aos sinais de cada termo. (b) Versão compacta dos caminhos de evolução mostrados em (a). As definições para $p$ e $q$ são dadas nas equações (2.11a) e (2.11b).

Com isso as seguintes convenções foram adotadas: (1) os caminhos de evolução sólidos introduzem um fator multiplicativo igual a $\cos \left(\frac{1}{2} R t\right) ;(2)$ os caminhos de evolução tracejados referem-se a um fator multiplicativo igual a $\frac{D}{R} \operatorname{sen}\left(\frac{1}{2} R t\right)$; (3) os caminhos de evolução pontilhados introduzem um fator multiplicativo dado por $\frac{C}{R} \operatorname{sen}\left(\frac{1}{2} R t\right) ;(4)$ as setas pretas significam que o sinal dos termos após aquela evolução são positivos e, finalmente, (5) as setas com o interior branco significam que o sinal dos termos após a evolução são negativos. 
As passagens da Figura 2.5(a) para 2.5(b), assim como da Figura 2.6(a) para 2.6(b) são feitas considerando-se apenas os estados iniciais e finais dos caminhos sob $H_{(-C) D}$ e $H_{C D}$. É dessa forma que, para simplificar, define-se $p$ e $q$, resultado das evoluções dadas pela eq.(2.9):

$$
\begin{gathered}
p(\tau)=\left(\frac{C}{R}\right)^{2}+\left(\frac{D}{R}\right)^{2} \cos (R \tau) \\
q(\tau)=\frac{D}{R} \operatorname{sen}(R \tau)
\end{gathered}
$$

Caminhos que ligam os estados iniciais apresentados nas Figuras (2.5) e (2.6) aos respectivos operadores produto na coluna $O_{x}$ da Tabela I, se cancelam. Além disso, os outros estados para os quais o sistema pode evoluir não são importantes neste estudo. Resumindo, os caminhos (1) $\rightarrow(3)$ e (2) $\rightarrow$ (4) além de $(1) \rightarrow(4)$ e (2) $\rightarrow$ (3) (seguindo a notação dos estados iniciais da Tabela I) não são mostrados na evolução devido a $H_{(-C) D}+H_{C D}$ nas Figuras 2.5 e 2.6. Os primeiros porque contém coeficientes de evolução total nulo e os últimos porque resultam em termos que não são observáveis no final da seqüência de pulsos da Figura 2.2.

Segue abaixo um exemplo do resultado de uma das evoluções mostradas na Figura 2.5(b):

$$
I_{y} \stackrel{H_{(-c) D}}{\longrightarrow} \stackrel{H_{C D}}{\longrightarrow} p(\tau) I_{y}+q(\tau)\left(2 S_{z} L_{x}+2 S_{x} L_{z}\right)
$$

Agora, pode-se obter o resultado da evolução total durante períodos do tipo $\tau \rightarrow \pi \rightarrow \tau$ dado pela forma (iv) discutida acima: $\stackrel{\pi I_{y}}{\longrightarrow} \stackrel{H_{(-C) D^{\tau}}}{\longrightarrow} \stackrel{H_{C 0} \tau}{\longrightarrow} \stackrel{H_{B} 2 \tau}{\longrightarrow}$, como mostra a Figura 2.7(a) para os dois principais estados do grupo Y. Neste caso, as três colunas referem-se aos efeitos seqüenciais: do pulso $\pi_{y}$ e das evoluções da magnetização sob $H_{(-C) D}+H_{C D}$ e sob $H_{B}$ 
( $\operatorname{com} t=2 \tau$ ), Figuras $2.5 \mathrm{~b}$ e $2.4 \mathrm{a}$.

A Figura 2.7(a) também mostra os fatores que acompanham os operadores produto finais com seus respectivos sinais. Neste caso $p$ e $q$ seguem as mesmas definições dadas pelas equações (2.11), enquanto que $C$ e $S$ significam $\cos (B \tau)$ e $\operatorname{sen}(B \tau)$, respectivamente, como exigem as equações (2.7) aplicadas ao período de evolução $2 \tau$.

(a)

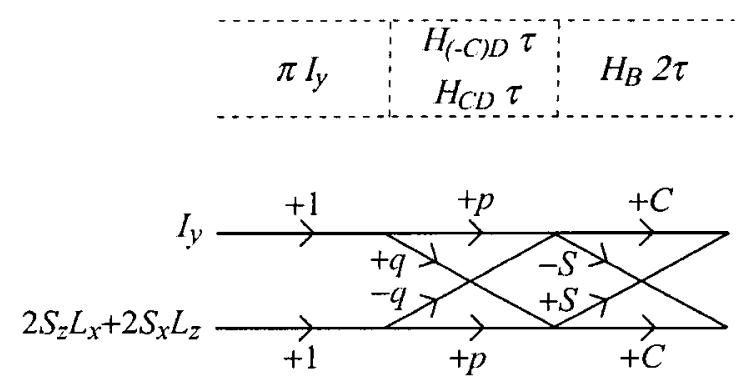

(b)

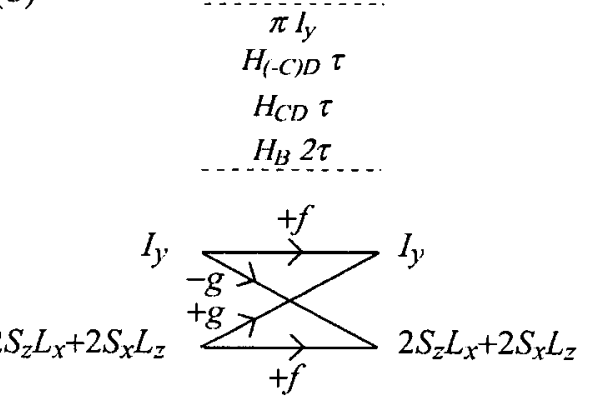

Figura 2.7: Representação gráfica da evolução dos operadores produto (1) e (2) do grupo Y na Tabela I sob o trecho $\tau \rightarrow \pi(b) \rightarrow \tau$ da excitação DQ da seqüência de pulsos da Figura 2.2. (a) Versão que mostra em seqüência os caminhos de evolução da forma (iv) descrita no texto. Aqui $p$ e $q$ também seguem as definições dadas nas equações (2.11) enquanto que $C$ e $S$ significam $\cos (B \tau)$ e $\operatorname{sen}(B \tau)$, respectivamente. (b) Versão compacta dos caminhos de evolução dados em (a). As equações (2.13) definem $f$ e $g$.

A passagem da Figura 2.7(a) para a 2.7(b) é feita de maneira similar à realizada para as Figuras 2.5 e 2.6. Sua função é apenas simplificar a visualização dos efeitos da evolução do sistema. A Figura 2.7(b) resume os fatores presentes nas evoluções durante os períodos $\tau \rightarrow \pi(b)_{y} \rightarrow \tau$ dos dois operadores produto indicados conforme as definições abaixo:

$$
\begin{aligned}
& f(\tau)=p(\tau) \cos (B \tau)+q(\tau) \operatorname{sen}(B \tau) \\
& g(\tau)=p(\tau) \operatorname{sen}(B \tau)-q(\tau) \cos (B \tau)
\end{aligned}
$$

Na Figura 2.8(a) considera-se a evolução a partir dos dois principais operadores produto do Grupo X. Neste caso, as três colunas referem-se aos efeitos 
seqüenciais: do pulso $\pi_{-x}$ e das evoluções da magnetização sob $H_{(-C) D}+H_{C D}$ e sob $H_{B}$

(a)

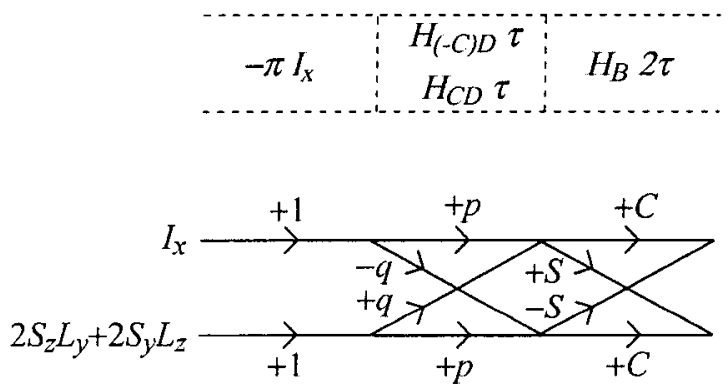

(b)

$-\pi I_{x}$
$H_{(-C) D} \tau$
$H_{C D} \tau$
$H_{B} 2 \tau$

$2 S_{z} L_{y}+2 S_{y} L_{z} \underset{-f^{\prime}}{I_{g^{\prime}}} \stackrel{-f^{\prime}}{f^{\prime}} I_{x}$

Figura 2.8: Representação gráfica da evolução dos operadores produto (1) e (2) do grupo X na Tabela I sob um trecho $\tau \rightarrow \pi$ (b) $\rightarrow \tau$ da excitação DQ da seqüência de pulsos da Figura 2.2. (a) Versão que mostra em sequiência os caminhos de evolução de maneira similar à forma (iv) descrita no texto. Aqui $p$ e $q$ também seguem as definições dadas nas equações (2.11) enquanto que $C$ e $S$ significam $\cos (B \tau)$ e $\operatorname{sen}(B \tau)$, respectivamente. (b) Versão compacta dos caminhos de evolução dados em (a). As equações (2.14) definem $f$ ' e $g$ '.

De maneira similar a 2.7(b), a Figura 2.8(b) apresenta os fatores presentes nas evoluções durante os períodos $\tau \rightarrow \pi(b)_{-x} \rightarrow \tau$ dos estados iniciais indicados, seguindo as definições abaixo:

$$
\begin{aligned}
& f^{\prime}(\tau)=p(\tau) \cos (B \tau)-q(\tau) \operatorname{sen}(B \tau) \\
& g^{\prime}(\tau)=p(\tau) \operatorname{sen}(B \tau)+q(\tau) \cos (B \tau)
\end{aligned}
$$

Como exemplo, duas evoluções obtidas a partir dos diagramas das Figuras 2.7(b) e 2.8(b) são mostradas a seguir:

$$
\begin{gathered}
I_{y} \stackrel{\tau \rightarrow \pi(b) \rightarrow \tau}{\longrightarrow} f(\tau) I_{y}-g(\tau)\left(2 S_{z} L_{x}+2 S_{x} L_{z}\right) \\
I_{x} \stackrel{\tau \rightarrow \pi(b) \rightarrow \tau}{\longrightarrow}-f^{\prime}(\tau) I_{x}+g^{\prime}(\tau)\left(2 S_{z} L_{y}+2 S_{y} L_{z}\right)
\end{gathered}
$$

Com isso, pode-se obter os efeitos da seqüência $\tau \rightarrow \pi(b) \rightarrow \tau$, ou seqüência de eco. Observa-se que para o caso geral estudado - regime de acoplamento intermediário $\left(\Delta\right.$ ou $\left.C \approx \omega_{D}\right)-$ os deslocamentos químicos não são totalmente 
refocalizados por esta seqüência. Os termos $\operatorname{com} p$ e $q$, dados pelas equações (2.10), dependem de $R=\sqrt{C^{2}+D^{2}}$ que contém estes termos explicitamente $\left(C=\omega_{S}-\omega_{L}\right)$.

Após a derivação das equações que mostram a evolução do sistema de spins sob cada termo do hamiltoniano $H^{0}$ podem ser verificados os efeitos da seqüência da Fig.(2.2). O estado inicial $I_{z}$ é convertido pelo pulso $a(\pi / 2)_{x}$ (ou pela polarização cruzada) em $-I_{y}$, que por sua vez evolui conforme a expressão (2.15), multiplicada por -1 , durante $\tau \rightarrow \pi(b) \rightarrow \tau$. O pulso $c(\pi / 2)_{x}$ subseqüente torna $-I_{y}$ em magnetização longitudinal $-I_{z}$ e o termo anti-fase $\left(2 S_{z} L_{x}+2 S_{x} L_{z}\right)$ na coerência de double quantum $-2 C D Q_{y}\left(C D Q_{y}=\left(2 S_{x} L_{y}+2 S_{y} L_{x}\right) / 2\right)^{29}$.

A evolução de termos do tipo $C D Q$ se dá apenas através da soma dos deslocamentos químicos que aparecem na parte $H_{A}$ t do hamiltoniano total $H^{029}$. Uma visão pictórica dessa evolução pode ser obtida através da a Figura 2.3(a), como se esta contivesse os eixos $C D Q_{x}, C D Q_{y},-C D Q_{x}$ e $-C D Q_{y}$ ao invés de $I_{x}, I_{y},-I_{x} \mathrm{e}-I_{y}^{25}$. Portanto, durante o período $t_{1},-C D Q_{y}$ evolui com a freqüência soma $A=\omega_{S}+\omega_{L}$, segundo:

$$
-C D Q_{y} \stackrel{H^{0} t_{3}}{\longrightarrow}-C D Q_{y} \cos \left(\omega_{S}+\omega_{L}\right) t_{1}+C D Q_{x} \operatorname{sen}\left(\omega_{S}+\omega_{L}\right) t_{1}
$$

Assim, imediatamente antes da aplicação do pulso $d$ o estado do sistema é descrito por:

$$
-f(\tau) I_{z}-g(\tau) 2 C D Q_{y} \cos \left(\omega_{S}+\omega_{L}\right) t_{1}+g(\tau) 2 C D Q_{x} \operatorname{sen}\left(\omega_{S}+\omega_{L}\right) t_{1}
$$

Após a aplicação do próximo pulso, o último termo da equação (2.18) transforma-se em $\left(2 S_{x} L_{x}-2 S_{z} L_{z}\right)$, termo que, conforme é feita a aquisição do sinal, não resulta em uma magnetização observável no final da seqüência ${ }^{23}$. Por esta razão 
sua evolução não será acompanhada nos passos seguintes. Considerando-se apenas os dois primeiros termos, logo após a aplicação do pulso $d(\pi / 2)_{-x}$ o sistema passa de (2.18) para:

$$
-f(\tau) I_{y}+g(\tau)\left(2 S_{z} L_{x}+2 S_{x} L_{z}\right) \cos \left(\omega_{S}+\omega_{L}\right) t_{1}
$$

O período de evolução subseqüente é dado por $\tau \rightarrow \pi(e) \rightarrow \tau$, que pode ser obtido novamente através da Figura 2.7(b), resultando, para $I_{y}$ em:

$$
-f(\tau)^{2} I_{y}+f(\tau) g(\tau)\left(2 S_{z} L_{x}+2 S_{x} L_{z}\right)
$$

e levando $2 S_{z} L_{x}+2 S_{x} L_{z}$ a:

$$
\left[g(\tau) f(\tau)\left(2 S_{z} L_{x}+2 S_{x} L_{z}\right)+g(\tau)^{2} I_{y}\right] \cos \left(\omega_{S}+\omega_{L}\right) t_{1}
$$

Em seguida, o pulso $f(\pi / 2)_{-x}$ cria:

$$
\begin{gathered}
f(\tau)^{2} I_{z}+f(\tau) g(\tau) 2 C D Q_{y}+ \\
{\left[g(\tau) f(\tau) 2 C D Q_{y}-g(\tau)^{2} I_{z}\right] \cos \left(\omega_{S}+\omega_{L}\right) t_{1}}
\end{gathered}
$$

Durante o período $t_{z}$ entre os pulsos $f$ e $g$ os termos $C D Q_{y}$ da equações (2.21) evoluem resultando em:

$$
\begin{gathered}
f(\tau)^{2} I_{z}+f(\tau) g(\tau)\left[2 C D Q_{y} \cos \left(\omega_{S}+\omega_{L}\right) t_{z}+2 C D Q_{x} \operatorname{sen}\left(\omega_{S}+\omega_{L}\right) t_{z}\right]+ \\
g(\tau) f(\tau)\left[2 C D Q_{y} \cos \left(\omega_{S}+\omega_{L}\right) t_{z}+2 C D Q_{x} \operatorname{sen}\left(\omega_{S}+\omega_{L}\right) t_{z}\right] \cos \left(\omega_{S}+\omega_{L}\right) t_{1}+ \\
-g(\tau)^{2} I_{z} \cos \left(\omega_{S}+\omega_{L}\right) t_{1}
\end{gathered}
$$

Após a aplicação do pulso $g(\pi / 2)_{x}$ as magnetizações do tipo $C D Q_{x}$ em (2.22) novamente resultam em termos do tipo $\left(2 S_{x} L_{x}-2 S_{z} L_{z}\right)$ que não são 
detectáveis durante o período de aquisição. Considerando apenas os termos observáveis, após o pulso $g$ tem-se, similarmente a (2.20a) e (2.20b):

$$
\begin{gathered}
-f(\tau)^{2} I_{y}+f(\tau) g(\tau)\left(2 S_{z} L_{x}+2 S_{x} L_{z}\right) \cos \left(\omega_{S}+\omega_{L}\right) t_{z}+ \\
{\left[g(\tau) f(\tau)\left(2 S_{z} L_{x}+2 S_{x} L_{z}\right) \cos \left(\omega_{S}+\omega_{L}\right) t_{z}+g(\tau)^{2} I_{y}\right] \cos \left(\omega_{S}+\omega_{L}\right) t_{1}}
\end{gathered}
$$

Considerando-se a evolução das magnetizações dadas por (2.23) sob o hamiltoniano total $H^{0}$ percebe-se que todas elas resultam em sinais observáveis durante $t_{2}$, eq. 2.10. No entanto, apenas o último termo da eq.(2.23) é o que se quer manter. Este termo é o único que contém a informação sobre a evolução do termo de double quantum apenas durante $t_{1}$, definindo a dependência em $\omega_{S}+\omega_{L}$ do segundo eixo no espectro $2 \mathrm{D}$ resultante.

Para que os outros termos sejam eliminados muda-se, a cada duas aquisições, as fases dos pulsos $a, b$ e $c$, entre $x, y, x$ e $y,-x, y$. Ao mesmo tempo, também a cada duas aquisições, muda-se a fase do pulso $g$ entre $x$ e $y$ (intercalandose com a mudança de fase dos 3 primeiros pulsos). Durante este ciclo de fases com 4 aquisições, a fase do receptor deve ser $-y, x,-x, y$.

Seguindo os passos até a eq.(2.23) para cada aquisição no ciclo de fases proposto e, utilizando-se a eq.(2.10) para a evolução dos seus termos sob o hamiltoniano total, obtém-se a eliminação dos três termos indesejáveis da equação

Dessa forma, o espectro bidimensional resultante passa a ser representado por:

$$
S\left(t_{1}, t_{2}\right)=g^{2}(2 \tau) \cos \left[\left(\omega_{S}+\omega_{L}\right) t_{1}\right] f\left(t_{2}\right)
$$


Na Figura 2.9 são mostrados exemplos de espectros DQ conforme exposto na literatura para o poli(óxido etileno) $(\mathrm{POE})^{30}$. Estes espectros foram simulados com base na evolução mostrada acima que traz a correlação de coerências doublequantum e single-quantum $8,31,32$ para o par de núcleos de ${ }^{13} \mathrm{C}^{13} \mathrm{C}$ para duas configurações do POE. Para a geração do double quantum diretamente no domínio das freqüências utiliza-se as fórmulas exatas 23 e os deslocamentos químicos encontrados na literatura 30 . Este exemplo mostra a sensibilidade da técnica observando-se que os dois espectros correspondem a ângulos de torção distintos: um de $180^{\circ}$ (trans) e outro de $70^{\circ}$ (gauche).

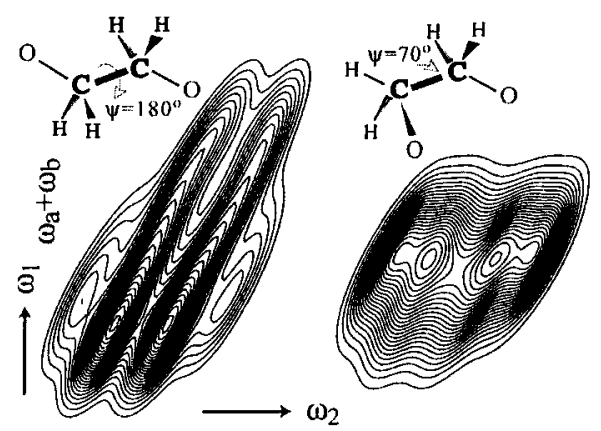

Figura 2.9: Exemplos de espectros de correlação de coerências double-quantum e single-quantum simulados para pares ${ }^{13} \mathrm{C}-{ }^{13} \mathrm{C}$ no poli(óxido etileno) nas configurações trans $\left(180^{\circ}\right)$ e gauche $\left(70^{\circ}\right)$, respectivamente ${ }^{30}$.

\subsection{Manifestação do Ângulo de Torção na Forma do Espectro de Double}

\section{Quantum}

A informação sobre a orientação relativa dos sistemas de eixos principais de dois sítios $a$ e $b$ de ${ }^{13} \mathrm{C}$ acoplados (via interação dipolar) está contida na dependência em $t_{1}$ do espectro expressa na eq.(2.24): $\cos \left(\omega_{a}+\omega_{b}\right) t_{1}$. Para tornar aparente como a eq.(2.24) cria essa dependência do espectro com o ângulo de torção, calcula-se as freqüências $\omega_{a}$ e $\omega_{b}$ através dos tensores de deslocamento químico $\left(\sigma_{a}\right.$ e $\left.\sigma_{b}\right)$ expressos em um sistema de eixos comum. Se a escolha para este sistema de eixos 
for aquele coincidente com o SEP de $\sigma_{a}$ :

$$
\omega_{a}=\vec{b}_{0}^{T}(\theta, \phi) \sigma_{a} \vec{b}_{0}(\theta, \phi) \quad ; \quad \omega_{b}=\vec{b}_{0}^{T}(\theta, \phi) \mathbf{R}_{b \rightarrow a}(\psi) \sigma_{b} \mathbf{R}_{b \rightarrow a}^{T}(\psi) \vec{b}_{0}(\theta, \phi)(2
$$

onde a matriz de rotação do SEP de $\sigma_{\mathrm{a}}$ para o SEP de $\sigma_{\mathrm{b}}$ é:

$$
\mathbf{R}_{b \rightarrow a}(\psi)=\widetilde{\mathbf{R}}^{\mathrm{T}}\left(\alpha_{a}, \beta_{a}, 0\right) \widetilde{\mathbf{R}}\left(\alpha_{b}, \beta_{b},-\psi\right)=\widetilde{\mathbf{R}}\left(0,-\beta_{a},-\alpha_{a}\right) \widetilde{\mathbf{R}}\left(\alpha_{a}, \beta_{a},-\psi\right)
$$

A expressão para $\omega_{a}$ na eq.(2.25) é a relação bem conhecida que dá a freqüência de ressonância em ppm através das coordenadas do tensor deslocamento químico no $\mathrm{SEP}^{1}$. Portanto, $\vec{b}_{0}(\theta, \phi)$ é o vetor unitário ao longo da direção do campo $\mathbf{B}_{0}$, caracterizado pelas coordenadas polares $(\theta, \phi)$ no SEP de $\sigma_{a}$. A expressão para $\omega$ ${ }_{b}$ na eq.(2.25) contém, além disso, as matrizes de rotação do SEP de $a$ para o SEP de b. A eq.(2.26) explicita esta rotação em termos de $\mathbf{R}^{\prime}\left(\alpha_{a}, \beta_{a},-\psi\right)$. Esta é a matriz que realiza a rotação ativa ${ }^{1}$ do tensor deslocamento químico de $b$ através dos ângulos de Euler $\left(\alpha_{a}, \beta_{a},-\psi\right)^{1}$. Seu efeito é o de rodar o eixo $z$ de $\sigma_{b}$ para o vetor internuclear C-C e, posteriormente, efetuar uma rotação em torno deste vetor por um ângulo $(-\psi)$. Dessa forma, $\left(\alpha_{a}, \beta_{a}\right)$ são as coordenadas polares do vetor internuclear no sistema de eixos principais de $\sigma_{a}$.

A Figura 2.10(a) mostra uma ligação C-C entre dois sítios de ${ }^{13} \mathrm{C} a$ e $b$ em uma cadeia polimérica qualquer com um ângulo de torção, $\psi$, nulo. Nela estão representados também os possíveis eixos dos SEP's de $\sigma_{a}$ e de $\sigma_{b}$. Para não sobrecarregar a figura não estão mostrados os ângulos de Euler $\left(\alpha_{a}, \beta_{a}\right)$ que definem a posição do vetor internuclear da ligação química no SEP de $\sigma_{a}$. A Figura

\footnotetext{
${ }^{1}$ Essa notação é utilizada para rotações pseudo-ativas. Estas surgem após uma redefinição de matrizes de rotação passivas - que são rotações do sistema de coordenadas, produzindo novas coordenadas vetoriais.
} 
2.10(b) mostra como poderia ficar o SEP de $\sigma_{b}$ em uma ligação C-C com $\psi \neq 0$. É importante salientar que o eixo $z$ do SEP de $\sigma_{b}$ pode coincidir tanto com a direção de $\sigma_{b, 33}$ como a de $\sigma_{\mathrm{b}, 11}$. Isso depende dos valores principais do tensor $\sigma_{b}$ no polímero observado e da aplicação das definições tensoriais discutidas no Capítulo I. Independentemente disso, pode-se perceber que a rotação do eixo $z$ do SEP de $\sigma_{b}$, dada por $\mathbf{R}^{\prime}\left(\alpha_{a}, \beta_{a},-\psi\right)$, é diferente em (a) e (b) apenas pelos valores distintos de $\psi$ nestas duas situações.

(a)

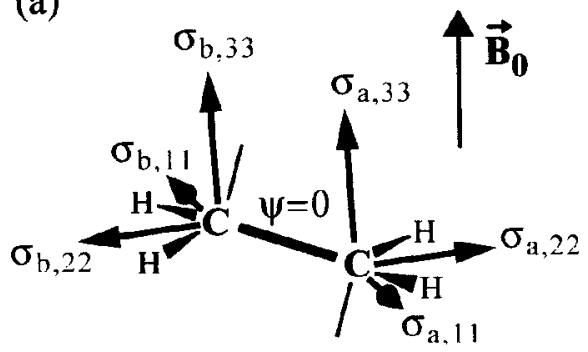

(b)

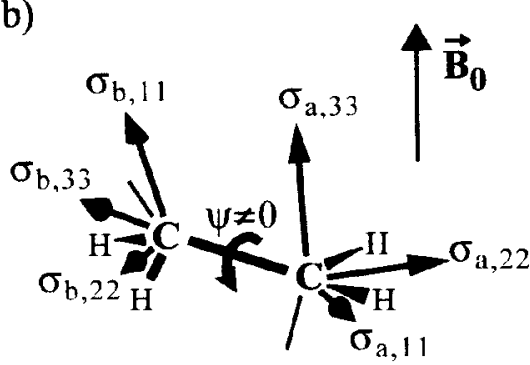

Figura 2.10: Representações dos sistemas de eixos principais para dois sítios de carbono em uma ligação C-C de uma cadeia polimérica com (a) $\psi=0$ e com (b) $\psi \neq 0$.

O espectro de pó, que reflete as freqüências individuais $\omega_{z}$ devido a todas as possíveis orientações do tensor $\sigma_{a}$ com relação a $\mathbf{B}_{\mathbf{0}}$ na amostra, surge da integração sobre os ângulos $\theta$ e $\varphi$ tornando-o independente da orientação absoluta dos segmentos individuais (definidos por ângulos como $\alpha_{a}, \beta_{a}, e \psi$ ). Como visto no Capítulo I, o espectro de pó depende somente dos valores principais de $\sigma_{a}$, ou dos parâmetros $\delta$ e $\eta$ que são seus derivados. O mesmo acontece com o espectro de pó do sítio $b$ que tem como tensor deslocamento químico, $\sigma_{b}$. No entanto, o espectro de pó da soma das freqüências $\omega_{a}$ e $\omega_{b}$, depende dos valores principais do tensor soma $\sigma_{a+b}$

$$
\sigma_{a+b}(\psi)=\sigma_{a}+\widetilde{\mathbf{R}}^{\mathbf{T}}\left(\alpha_{a}, \beta_{a}, 0\right) \widetilde{\mathbf{R}}\left(\alpha_{b}, \beta_{b},-\psi\right) \sigma_{b} \widetilde{\mathbf{R}}^{\mathbf{T}}\left(\alpha_{a}, \beta_{a},-\psi\right) \widetilde{\mathbf{R}}\left(\alpha_{b}, \beta_{b}, 0\right)(2.27)
$$


e, portanto, retém a informação sobre as orientações relativas dos dois sistemas de eixos principais. Dessa forma, dependendo do valor do ângulo de torção, a correlação entre a soma das freqüências e os deslocamentos químicos individuais dará uma forma característica ao espectro bidimensional de double quantum como observado na Figura 2.9.

A Figura 2.11 procura explicar esse efeito mais explicitamente. Nela podese observar, como exemplo, espectros bidimensionais DQ para dois ângulos de torção distintos em uma ligação ${ }^{13} \mathrm{C}_{a}-{ }^{13} \mathrm{C}_{b}$. Esquematicamente são mostradas as projeções $1 \mathrm{D}$ ao longo de $\omega_{1}$ e $\omega_{2}$. Em cada figura, o espectro $1 \mathrm{D}$ em $\omega_{2}$ é uma superposição dos espectros de pó $\left(\omega_{a}\right.$ e $\left.\omega_{b}\right)$ dos sítios $a$ e $b$ do par de carbonos acoplados, sendo que a separação espectral destes sinais em $\omega_{2}$ depende dos parâmetros de anisotropia e de assimetria de cada um deles.
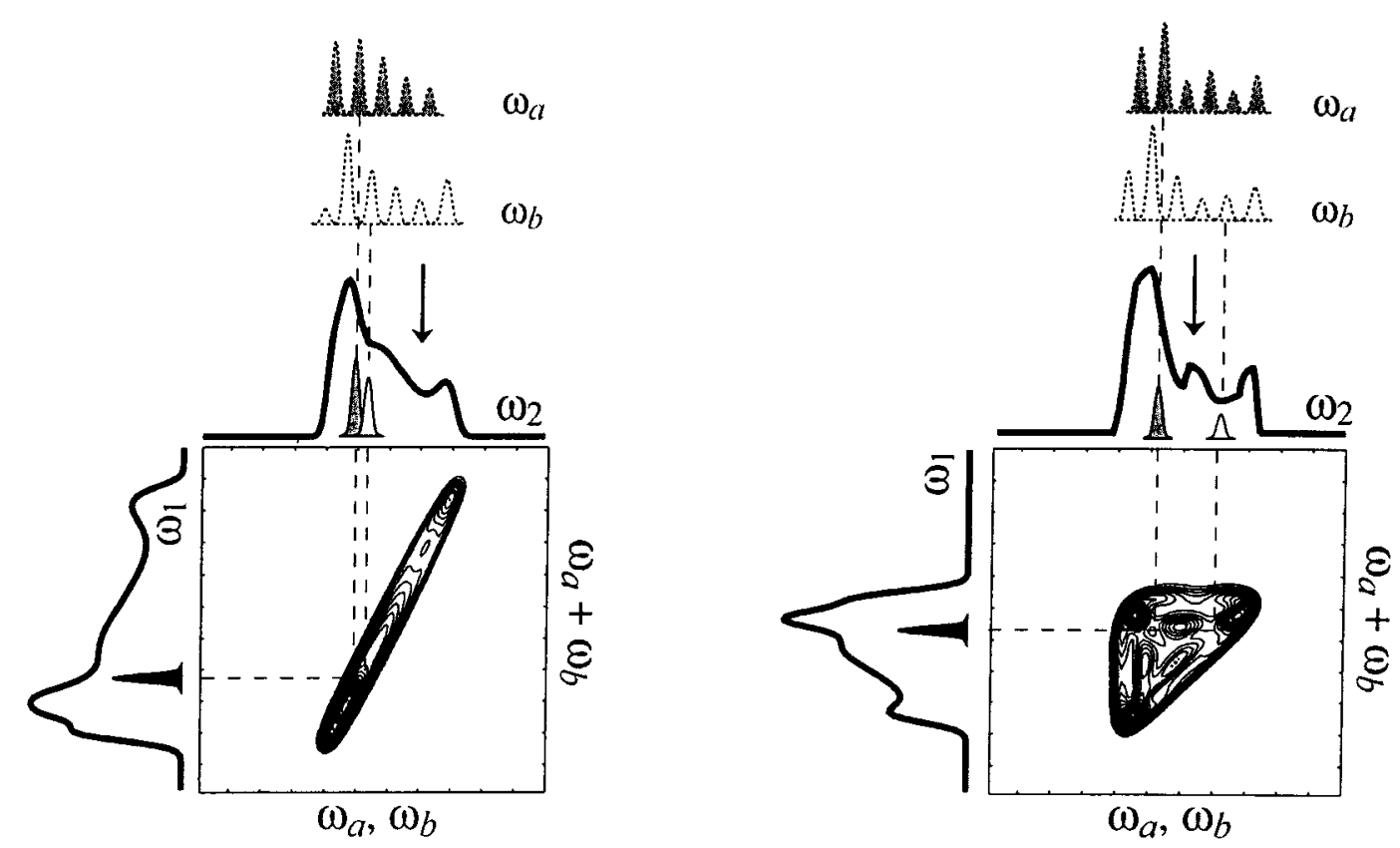

Figura 2.11: Esquema que representa a formação de dois espectros 2D DQ com ângulos de torção distintos em uma ligação ${ }^{13} \mathrm{C}_{a}-{ }^{13} \mathrm{C}_{b}$. As projeções dos espectros ao longo de $\omega_{2} \mathrm{e} \omega_{1}$ são mostradas. Na parte superior observa-se os espectros de pó dos sítios $a \mathrm{e} b, \omega_{a} \mathrm{e} \omega_{b}$, que dão origem às projeç̃os em $\omega_{2}$. Em cada espectro, como exemplo, é mostrado um par de componentes (uma de $\omega_{a}$ e outra de $\omega_{b}$ ) que são de sítios acoplados e que, portanto, dão origem a uma componente da projeção do espectro em $\omega_{1}$. 
Observa-se também que para cada tipo de conformação componentes distintas dos espectros de pó dados por $\omega_{a}$ e $\omega_{b}$ estão acopladas. São os acoplamentos entre estas duas freqüências (uma de $\omega_{a}$ e outra de $\omega_{b}$ ) que formam a componente indicada do espectro unidimensional em $\omega_{1}$, que apresenta uma freqüência dada por $\omega_{a}+\omega_{b}$. Assim, o espectro bidimensional de double quantum resultante apresenta uma forma diretamente relacionada a esses acoplamentos, trazendo a informação sobre o ângulo de torção da ligação química, o que não é possível de se observar nas projeções unidimensionais do espectro. Finalizando, a projeção de um espectro 2D DQ em $\omega_{2}$ apresenta a soma (superposição) dos espectros de pó do ${ }^{13} \mathrm{C}_{a}$ e do ${ }^{13} \mathrm{C}_{b}$, enquanto que a sua projeção em $\omega_{1}$ é o espectro resultante da soma das freqüências de todos os sítios ${ }^{13} \mathrm{C}_{a}-{ }^{13} \mathrm{C}_{b}$ (com diversas orientações com relação a $\mathbf{B}_{0}$ ) acoplados ao longo da amostra.

\subsection{Detalhes da Seqüência de Pulsos}

A Figura 2.12 mostra uma sequiência de pulsos apropriada para experimentos em sólidos. Além das partes básicas necessárias para o experimento double quantum citadas na Figura 2.2, ela apresenta algumas características especiais que envolvem o ciclo de fases adequado. Com isso, além da seleção do sinal DQ, pode-se eliminar artefatos espectrais permitindo uma aquisição mais apropriada do sinal. 


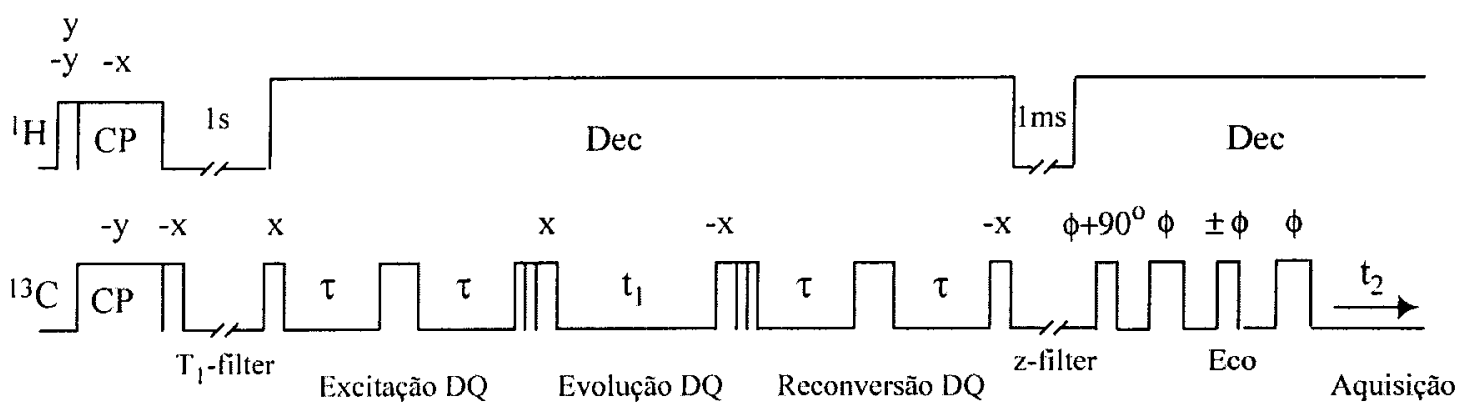

Figura 2.12: Seqüência de pulsos do experimento de double quantum voltado para o estudo de amostras sólidas. Em ordem crescente de largura os três diferentes tipos de pulsos esquematizados representam pulsos de $45^{\circ}, 90^{\circ}$ e $180^{\circ}$.

Os dois primeiros pulsos aplicados ao carbono após a transferência de polarização do ${ }^{1} \mathrm{H}$ para $\mathrm{o}{ }^{13} \mathrm{C}$ são separados por um tempo da ordem de $1 \mathrm{~s}$ e constituem o chamado $T_{1}$-filter, ou filtro de $T_{1} 1$. Esses dois pulsos funcionam como um "filtro" antes do período de excitação de $D Q$ já que selecionam apenas a magnetização proveniente da parte cristalina da amostra. $O T_{1}$ curto da parte cristalina da amostra faz com que a respectiva magnetização relaxe de volta para a direção $z$ durante o intervalo de $1 \mathrm{~s}$. Assim a magnetização da parte amorfa estará oposta à da fase cristalina. Com a mudança de fase do primeiro pulso de ${ }^{1} \mathrm{H}$ para $+y$ as duas magnetizações são colocadas ao longo de $+z$ e não se observa nenhum efeito devido à relaxação. Os sinais armazenados nestes dois ciclos de fase são então subtraídos e o espectro resultante fica apenas com as contribuições da fase cristalina.

Os dois pulsos consecutivos de $45^{\circ}$ antes do pulso de $90^{\circ}$ da excitação de $D Q$ e mais os dois pulsos de $45^{\circ}$ depois do pulso de $90^{\circ}$ da reconversão de $D Q$ servem para eliminar artefatos no espectro final em $\omega_{1}=0$. As fases nestes pulsos devem estar em $-y$ e a cada ciclo um destes pulsos deve ser invertido. Com isso esses pulsos extras realizam a sua função enquanto que os sinais descritos pelos processos (a), (b) e (c) são sempre mantidos. 
Após o período de reconversão de DQ tem-se um z-filter. Sua função é eliminar magnetizações transversais após o pulso de $90^{\circ}$. Como o desacoplamento é desligado por um pequeno período, qualquer magnetização transversal ainda presente irá relaxar através do acoplamento dipolar magnético preparando o sistema para receber os pulsos de leitura.

Por fim, logo após o z-filter, e antes da detecção, utiliza-se uma combinação de eco sólido e eco de Hahn para evitar o problema do tempo morto e introduzir a refocalização de todas as interações. As fases representadas por $\varphi$ em conjunto com um ciclo de fases adequado para o receptor agem de forma a eliminar os termos que surgem da seqüência de pulsos mas que não estão relacionados com o double quantum.

\subsection{Experimento DQ com Desacoplamento Homonuclear ${ }^{13} \mathrm{C}-{ }^{13} \mathrm{C}$}

Dependendo do sistema, os espectros DQ podem ser muito complexos, dificultando a sua análise. Além disso, pode acontecer que o alargamento espectral devido a interação dipolar ${ }^{13} \mathrm{C}-{ }^{13} \mathrm{C}$ diminua a precisão na determinação de ângulos de torção. Nestes casos deve ser aplicada a seqüência de pulsos DQ com desacoplamento homonuclear ${ }^{2}$. Esta seqüência é idêntica àquela mostrada na Figura 2.12 até o momento da aquisição. Só que, então, o sinal é adquirido ponto a ponto, seguindo os ciclos do eco mágico, ou magic-sandwich echo, MSE33. 
A Figura 2.13 mostra como é o funcionamento do eco mágico. Na 2.13(a) é mostrado o seu ciclo de pulsos básico que produz desacoplamento homonuclear mas não heteronuclear. De maneira similar ao campo de RF de spin lock, os pulsos de $n .360^{\circ}$ em $x$ e em $-x$ promediam o deslocamento químico e produzem um hamiltoniano médio de $-H_{\mathrm{xx}} / 2$ (que é transformado em $-H_{\mathrm{zz}} / 2$ pelos pulsos “externos" de $90^{\circ}$ em $y$ e $-y$ ) 8,34 . Os propagadores dos $2 n$ pulsos "internos" de $360^{\circ}$ com duração total de $2 \tau^{\prime}$ se cancelam com o propagador do período $\tau$ ' subseqüente que não contém pulsos para o ${ }^{13} \mathrm{C}$. Na 2.13 (b) os pulsos $x$ internos são divididos em pulsos de $90^{\circ}$ com uma distância entre si igual à duração de pulsos de $360^{\circ}$ para o ${ }^{1} \mathrm{H}$. Com essa configuração e através da irradiação dos hidrogênios para o desacoplamento heteronuclear obtém-se um sinal com desacoplamento total (homonuclear e heteronuclear).

$\mathrm{O}$ esquema do eco mágico exige que sejam adquiridos pelo menos 16 pontos para cada FID, pois para cada ponto há uma fase distinta para os pulsos "internos" e os "externos" na Figura 2.13(a). O ciclo para o primeiro pulso "externo" é: $y, y,-y,-y, y, y,-y,-y,-x,-x, x, x,-x,-x, x, x$. Enquanto que o ciclo para o primeiro pulso "interno" é: $\mathrm{x},-\mathrm{x}, \mathrm{x},-\mathrm{x}, \mathrm{x},-\mathrm{x}, \mathrm{x},-\mathrm{x}, \mathrm{y},-\mathrm{y}, \mathrm{y},-\mathrm{y}, \mathrm{y},-\mathrm{y}, \mathrm{y},-\mathrm{y}$. Estes ciclos de fases são feitos ao mesmo tempo. Da mesma forma, os ciclos para os segundos pulsos seguem o mesmo esquema, mas partindo dos valores iniciais indicados na figura. 
(a)

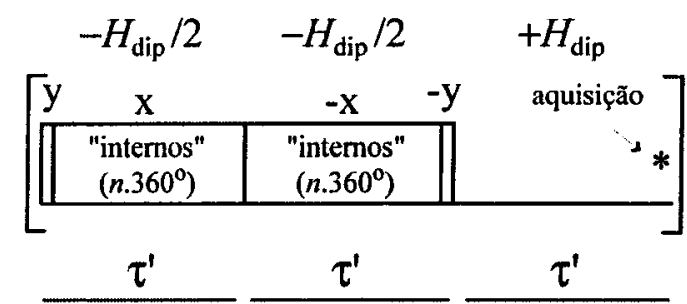

(b)

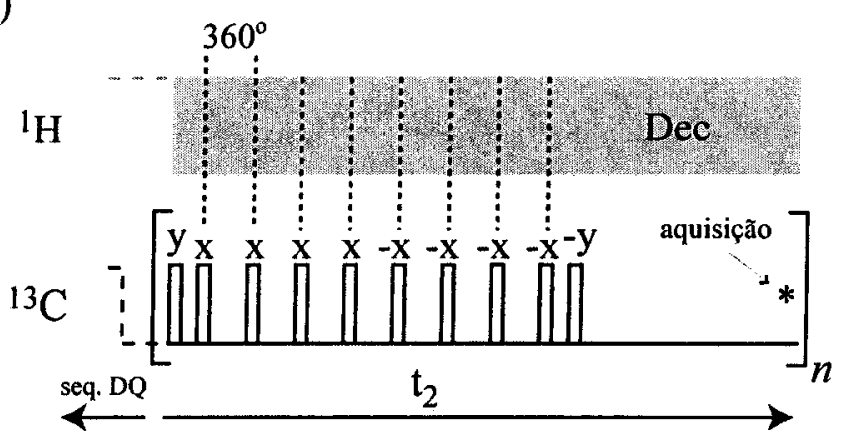

Figura 2.13: Obtenção do desacoplamento homonuclear para o experimento double quantum. (a) Princípio de funcionamento do eco mágico. A aquisição é realizada no ponto indicado pelo asterisco, onde os efeitos do acoplamento dipolar homonuclear são removidos. (b) Aplicação de (a) como no final da sequêencia de pulsos do experimento DQ. Divisão dos pulsos "internos" de $360^{\circ}$ de (a) em quatro de $90^{\circ}$ (com espaçamento de $360^{\circ}$ para ${ }^{1}{ }^{1} \mathrm{H}$ ), permitindo de forma conjunta o desacoplamento dipolar homonuclear e heteronuclear. $O$ número de pontos do FID é dado por $n$.

Para exemplificar como o experimento double quantum com desacoplamento homonuclear modifica o espectro, algumas simulações $8,31,32$ para o POE encontradas na literatura ${ }^{35}$ são mostradas na Figura 2.14. Nessa figura são comparados os espectros com e sem desacoplamento ${ }^{13} \mathrm{C}-{ }^{13} \mathrm{C}$ para os seguintes ângulos de torção: $60^{\circ}, 70^{\circ}, 80^{\circ}, 160^{\circ}, 170^{\circ}$ e $180^{\circ}$. Percebe-se que com o desacoplamento homonuclear é maior a precisão para identificação da distribuição de ângulos trans. 
sem ${ }^{13} \mathrm{C} \mathrm{DEC} \rightarrow \operatorname{com}{ }^{13} \mathrm{C} \mathrm{DEC}$

$\operatorname{sem}^{13} \mathrm{C} \mathrm{DEC} \rightarrow \operatorname{com}{ }^{13} \mathrm{C}$ DEC (d) $70^{\circ}$
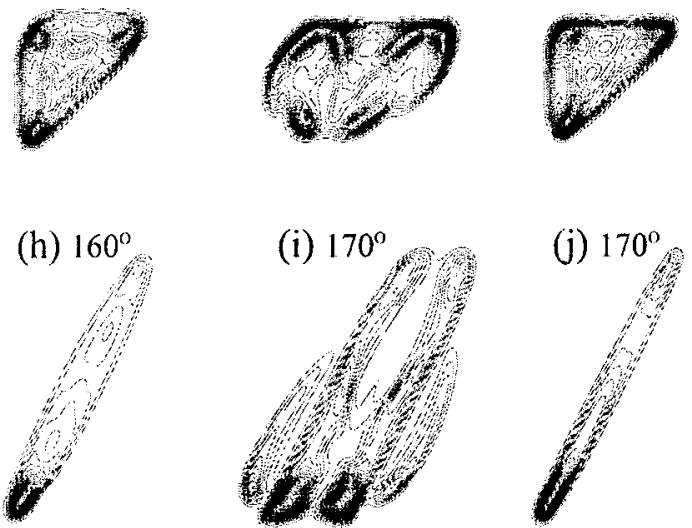

(i) $170^{\circ}$

(c) $70^{\circ}$
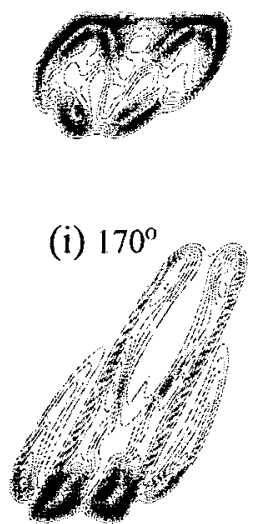

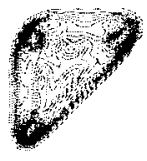

$160^{\circ}$

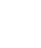

sem ${ }^{13} \mathrm{C}$ DEC $\rightarrow$ com ${ }^{13} \mathrm{C}$ DEC

(e) $80^{\circ}$

(f) $80^{\circ}$

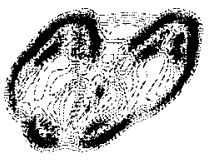

(g) $160^{\circ}$

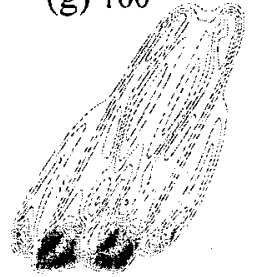

Figura 2.14: Espectros double quantum de ${ }^{13} \mathrm{C}$ simulados para o POE enriquecido com pares ${ }^{13} \mathrm{C}-{ }^{13} \mathrm{C}$ sem/ com desacoplamento homonuclear para ângulos de torção de (a/b) $60^{\circ}$, (c/d) $70^{\circ}$, (e/f) $80^{\circ},(\mathrm{g} / \mathrm{h}) 160^{\circ},(\mathrm{i} / \mathrm{j}) 170^{\circ}$ e (k/l) $180^{\circ 35}$. Pode-se observar a boa precisão para identificação da distribuição de ângulos trans em espectros obtidos com o desacoplamento.

\subsection{Exemplos de Aplicação da Técnica}

A técnica double quantum pode ser aplicada em diversos casos que visam explicitar a conformação de polímeros em condições especiais. Dois desses casos são apresentados resumidamente, como exemplo de utilização da técnica para o estudo do poli(óxido etileno) (POE) em suas fases cristalina e amorfa. Estes dois trabalhos são fruto de uma colaboração entre o professor Tito José Bonagamba do LEAR e pesquisadores do Polymer Science and Engineering Department da Universidade de Massachusetts (EUA).

O POE foi muito estudado há algumas décadas atrás e, por difração de raios X (wide-angle X-ray diffraction, WAXD), espectroscopia Raman e infravermelho (infrared, IR), chegou-se a conclusão que em seu estado cristalino este polímero tem uma estrutura helicoidal que contém sete unidades, em 1,93 nm, que dão duas voltas em um período da fibra (estrutura 72$)^{36,37}$. Nessa hélice a estrutura 
helicoidal $7_{2}$ é distorcida para otimizar as interações intermoleculares. Para o POE $\left[\left(-\mathrm{CH}_{2}-\mathrm{CH}_{2}-\mathrm{O}-\right)_{\mathrm{n}}\right]$, a estrutura cristalina proposta diz que os ângulos de torção para a ligação OC-CO são gauche, com ângulos discretos variando de $49^{\circ}$ a $92^{\circ}$, enquanto que os ângulos de torção para a ligação CO-CC ficam na conformação trans, com ângulos discretos partindo de $180^{\circ}$ até $204^{\circ}$, constituindo-se numa seqüência TTG.

A estrutura da fase amorfa do POE foi estudada através da estatística conformacional. De acordo com o modelo de estado isomérico rotacional (RIS) 38,39 as ligações OC-CO apresentam conformação predominantemente gauche, com aproximadamente $20 \%$ na conformação trans. Por outro lado, a maioria das ligações CC-OC são trans, com aproximadamente $25 \%$ sendo gauche.

\subsubsection{POE Amorfo: DQ e as Predições do Modelo RIS}

Existe um interesse crescente no estudo da intercalação de compostos orgânicos em sólidos hospedeiros de estrutura em camadas, devido às características únicas de condutividade iônica, eletrônica, e de suas propriedades mecânicas e estruturais. Em especial, essas propriedades favoráveis são encontradas em nanocompósitos de poli(óxido etileno) (POE) intercalado em argila - hectorita (HCT) e montmorillonita - ou dicalcogênios de metais de transição - $\mathrm{MoS}_{2}$ e $\mathrm{TiS}_{2}$. Como um dos pré-requisitos para o entendimento das propriedades desses nanocompósitos, o conhecimento das características conformacionais do POE intercalado motivou um estudo através da técnica de double quantum, realizado em 1999 por Harris et al., na sua intercalação na hectorita/ $/ \mathrm{Na}^{+}$e no $\mathrm{Li}_{1} \mathrm{MoS}_{2} \cdot{ }^{30}$

Através de DSC (differential scanning calorimetry) e WAXD (wide-angle $X$-ray diffraction) observou-se que o POE apresenta-se totalmente na fase amorfa sob intercalação nestes compostos. A supressão da fase cristalina e a conformação da 
cadeia polimérica nos nanocompósitos pode ser afetada pelo espaço limitado entre as camadas do material hospedeiro e, também, pela sua interação com as superfícies carregadas das camadas inorgânicas do composto e os cátions intercamadas $\left(\mathrm{Li}^{+}\right.$ou $\mathrm{Na}^{+}$, neste caso). Dados de raios X mostram que sob intercalação a distância entre as camadas aumenta de $0,35 \mathrm{~nm}$ para $1,0 \mathrm{~nm}$ na hectorita e de $0,02 \mathrm{~nm}$ para $0,84 \mathrm{~nm}$ no $\mathrm{MoS}_{2}$ ao acomodar o polímero. Como comparação, a estrutura $7_{2}$ do POE cristalino faz com que o diâmetro da seção transversal da hélice do POE nessa fase seja igual a $0,52 \mathrm{~nm}$.

A seguir são mostrados os espectros de double quantum para o POE com pares enriquecidos ${ }^{13} \mathrm{C}-{ }^{13} \mathrm{C}$ obtido pelos autores do trabalho analisado nas amostras $\mathrm{POE} / \mathrm{HCT}$, Figura 2.15(a), e POE/MoS 2 , Figura 2.15(b), com as respectivas simulações, mostrando uma predominância da configuração gauche, ver Fig. 2.9.

(a)

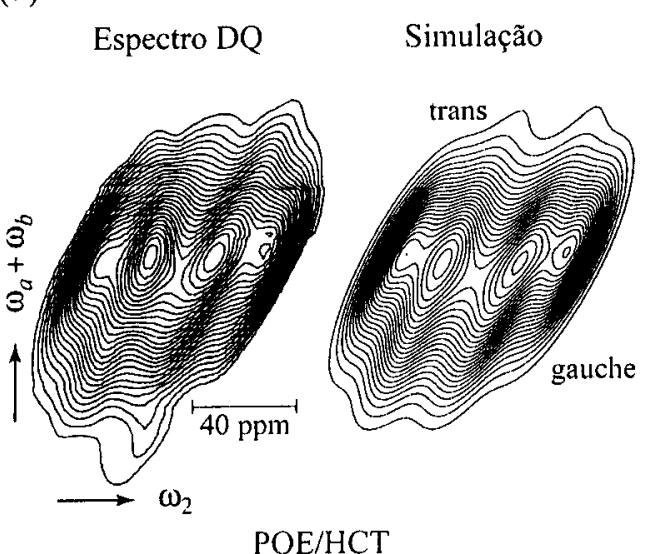

(b)

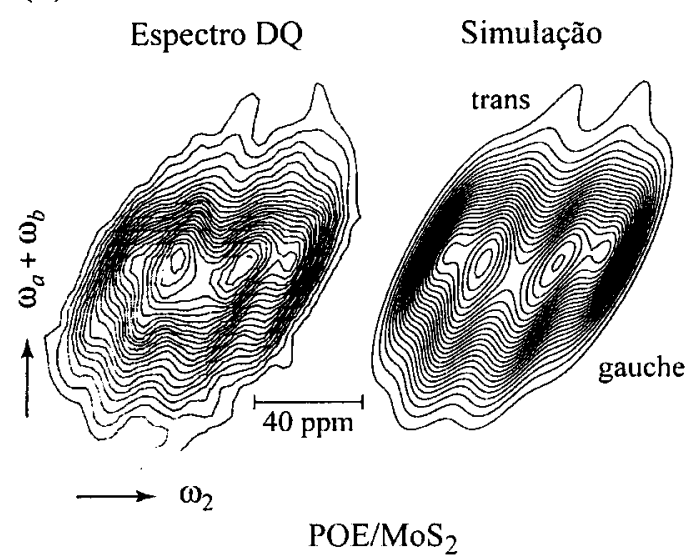

Figura 2.15: Espectros experimentais e simulados de double quantum para (a) $\mathrm{POE} / \mathrm{HCT}$ e (b) $\mathrm{POE} / \mathrm{MoS}_{2}{ }^{30}$. A simulação em (a) utiliza uma porcentagem de conformação trans igual a $8 \%$. A simulação em (b) utiliza uma porcentagem de conformação trans igual a $12 \%$. Nas simulações para os dois compostos os ângulos trans e gauche foram distribuidos por $\pm 10^{\circ}$ em torno de $\Psi=180^{\circ}$ e $70^{\circ}$, respectivamente. $O$ experimentos foram realizados a $-50^{\circ} \mathrm{C}$.

O espectro DQ da argila, mostrado na Figura 2.15(a), apresenta uma razão trans/gauche igual a 8:92 $( \pm 5)$ de acordo com as informações dadas pelos autores 
para a obtenção do espectro simulado. Para o composto POE/MoS 2 , Figura 2.15(b), a razão trans:gauche encontrada pelos autores do trabalho nas simulações é 12:88( \pm 5$)$. Em ambos os casos as simulações foram obtidas com uma média de ângulos gauche e trans iguais a $70 \pm 15^{\circ} \mathrm{e} \sim 180^{\circ}$, respectivamente. Por causa da pequena quantidade de conformação trans, não foi possível estimar a incerteza nos valores do ângulo de torção para essa configuração. Também nos dois casos, foram utilizadas distribuições com larguras iguais a $\pm 10^{\circ}$ em torno do valor médio para as torções trans e gauche centrados em $\psi=180^{\circ}$ e $70^{\circ}$, respectivamente.

Outros estudos já sugeriram a predominância da conformação gauche da ligação OC-CO (favorecendo a possibilidade de uma conformação helicoidal) após a intercalação de POE na hectorita/ $\mathrm{Na}^{+}$, inclusive através de espectros $\mathrm{CP} / \mathrm{MAS}$ de ${ }^{13} \mathrm{C}^{40}$. No entanto, estes resultados não foram conclusivos. A informação sobre a predominância de ligações gauche OC-CO obtidas pelos espectros DQ e as simulações da Figura 2.15 é direta. Além disso, a pequena quantidade trans observada mostra que seções helicoidais muito longas não ocorrem quando o POE está nestes espaços restritos.

O modelo RIS para o POE amorfo diz que a energia da conformação trans é maior que a da conformação gauche para as ligações CO-CC. Além disso, em torno de $25 \%$ dessas ligações têm conformação gauche. No entanto, para as ligações OC$\mathrm{CO}$ a energia da conformação gauche é maior que a da conformação trans e, neste caso, aproximadamente $20 \%$ das ligações apresentam-se com a configuração trans.

Os espectros simulados da Figura 2.15 dão uma população trans de 10 $\pm 5 \%$ para as ligações OC-CO, o que é uma fração menor daquela predita pelo modelo RIS (20\%). Isso deve ser causado pela estreita interação do POE com os íons 
presentes entre as camadas e a interface POE/hospedeiro, ou devido a requerimentos estéricos. Com relação a essa última hipótese é interessante notar que as simulações baseadas no modelo RIS para cadeias de POE confinados em canais de $0,8 \mathrm{~nm}$ de diâmetro resultam em uma fração trans de $50 \%$, ainda que uma conformação helicoidal $7_{2}(100 \%$ gauche) caiba nos canais.

No entanto, o melhor casamento entre as previsões teóricas dadas pelo modelo RIS e os resultados de double quantum levam a consideração de que os ângulos de torção gauche estão se alternando entre gauche ${ }^{+}$e gauche ${ }^{-}$. Neste caso, a cadeia apresenta-se com uma estrutura similar a uma pequena coroa de éteres formada pelos seus oxigênios. Esta conformação é consistente com as fortes interações observadas entre o polímero e os íons entre as camadas. Depois de aproximadamente 5 unidades monoméricas com conformações alternadas $\mathrm{TTG}^{+} \mathrm{e}$ $\mathrm{TTG}^{-}$, tanto uma ligação OC-CO é forçada a uma conformação trans como uma ligação CO-CC é forçada para mudar sua conformação para gauche devido a interações estéricas com outras porções da cadeia. A fração observada de ligações trans OC-CO nos sistemas estudados é apenas 10\%, valor abaixo dos $\sim 25 \%$ necessários devido a estas interações estéricas. Dessa forma, espera-se que o que esteja ocorrendo é que, ao invés da mudança conformacional das ligações OC-CO para trans, uma porcentagem significativa de ligações CO-CC passam para a conformação gauche (maior ganho de energia, como descrito acima).

Este trabalho 30 mostrou como a técnica de double quantum pode auxiliar a identificar as possibilidades de conformação do polímero intercalado, esclarecendo os indícios obtidos por difração de raios $\mathrm{X}$, DSC e outras técnicas de RMN e possibilitando a comparação direta dos ângulos de torção observados com as previsões obtidas através da estatística conformacional do POE. A investigação da 
conformação do POE amorfo através da coerência double quantum representa uma linha de estudos que ainda pode ser muito explorada em outros compostos.

\subsubsection{POE Cristalino: Aplicação da Técnica DQ com Desacoplamento ${ }^{13} \mathrm{C}-{ }^{13} \mathrm{C}$}

Recentemente tem havido muito interesse em complexos de POE com pdihalogenobenzenos e hidroxibenzenos, incluindo resorcinol (RES) e p-nitrofenol (PNP). Resultados de WAXD e IR indicam que o POE têm uma fase cristalina nestes sistemas e que as suas conformações em muitos dos complexos com $p$ dihalogenobenzenos ou RES são muito pouco distorcidas da hélice $7_{2}$ original. A conformação das cadeias nestes sistemas permanecem TTG, apesar da sua periodicidade ser um pouco diferente.

Contrariamente ao complexo POE/RES, a conformação das cadeias no POE/PNP é muito diferente da conformação helicoidal 72 . Difração de raios $\mathrm{X} \mathrm{e}$ espectroscopia por infravermelho indicam que $1 / 3$ da ligações OC-CO estão na conformação trans. Considerou-se que as pontes de hidrogênio entre o hospedeiro e as moléculas do polímero induzem a cadeia a adotar um estrutura TTGTTGTTT TTG'TTG'TTT. Como esta estranha estrutura não tinha sido confirmada até 2000 , neste ano Harris et al. ${ }^{35}$ realizaram um estudo da conformação da ligação OC-CO no POE nos complexos POE/PNP e POE/RES (para comparação), utilizando-se a técnica de double quantum com e sem desacoplamento homonuclear.

Curvas de DSC e medidas de raios X confirmaram, nos compostos estudados, a presença de POE na fase cristalina. Visando a análise da conformação do POE nesta fase através dos experimentos de double quantum, o sinal das regiões amorfas do polímero foram suprimidas através do filtro de $T_{1}$ (item 2.5). $O$ espectro, observado experimentalmente sem desacoplamento homonuclear para os pares ${ }^{13} \mathrm{C}$ - 
${ }^{13} \mathrm{C}$, e o espectro simulado do POE/RES estão mostrados na Figura 2.16.

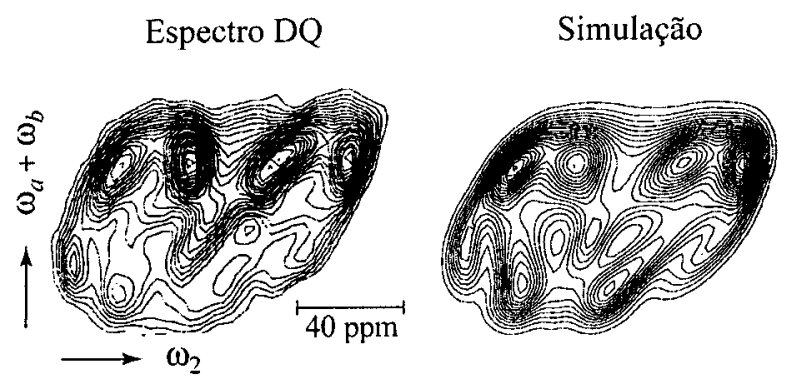

Figura 2.16: Espectro de double quantum para o POE/RES sem desacoplamento dipolar homonuclear medido em $75,5 \mathrm{MHz}$ para o ${ }^{13} \mathrm{C} \mathrm{a}-23^{\circ} \mathrm{C}{ }^{35}$. Ao lado está o espectro simulado com um ângulo médio gauche $\psi=74 \pm 9^{\circ}$ e com uma largura de distribuição dada por $\sigma=7^{\circ}$.

O espectro observado para o POE/RES mostra que todos os ângulos de torção OC-CO são gauche. A simulação indica que o ângulo médio de torção é $\psi=74^{\circ} \pm 9^{\circ}$ com uma distribuição angular de largura $\sigma<10^{\circ}$ (distribuição gaussiana com raiz quadrática média $\sigma$ ). Outros efeitos, como desacoplamento de ${ }^{1} \mathrm{H}$ insuficiente ou movimento lento da cadeia, podem alargar o espectro, refletindo em uma distribuição larga de ângulos de torção nas simulações. Por outro lado, vibrações de torção que são rápidas na escala de tempo de RMN de $\sim 100 \mu$ s são invisíveis a esse experimento.

Os espectros experimentais e simulados para o experimento double quantum com e sem desacoplamento homonuclear para o POE/PNP estão mostrados na Figura 2.17. Os espectros mostram uma grande intensidade "diagonal" (inclinação 2) devido a ligações OC-CO trans. As simulações dos espectros observados foram produzidos considerando-se uma porcentagem de $33 \%$ para a configuração trans e $67 \%$ para a configuração gauche. Tanto os espectros sem desacoplamento como os com desacoplamento homonuclear são consistente com $1 / 3$ das ligações OC-CO no POE/PNP na conformação trans $\left(\psi=180^{\circ}, \sigma<7^{\circ}\right)$ e $2 / 3$ na conformação gauche 
$\left(\psi=70^{\circ} \pm 9^{\circ}, \sigma<10^{\circ}\right)$.

(a)

Espectro DQ

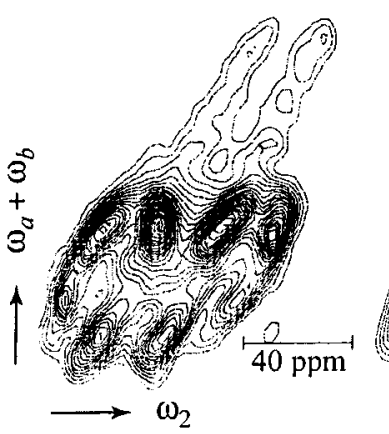

sem ${ }^{13} \mathrm{C}$ DEC (b)

Simulação

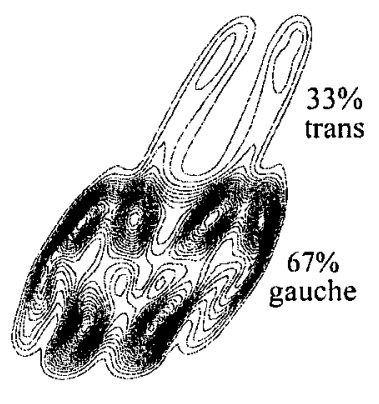

Espectro DQ Simulação

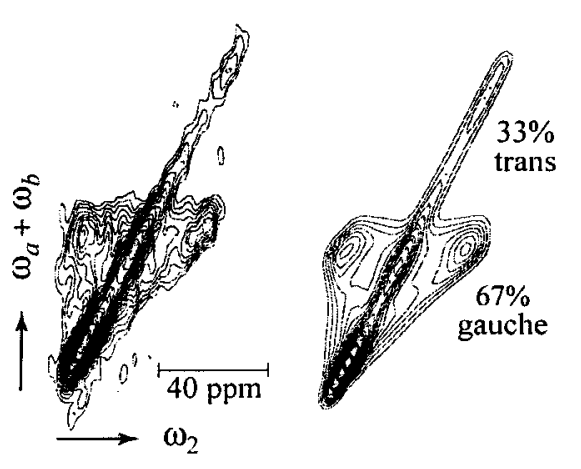

com ${ }^{13} \mathrm{C} \mathrm{DEC}$

Figura 2.17: Espectros de double quantum de ${ }^{13} \mathrm{C}$ para o POE/PNP medido em $75,5 \mathrm{MHz}$ a $20^{\circ} \mathrm{C}{ }^{35}$. (a) Sem desacoplamento homonuclear e (b) com desacoplamento homonuclear. As simulações apresentadas contém uma razão trans/gauche de 1:2. O ângulo gauche médio é $\psi=70 \pm 9^{\circ}$ com uma largura gaussiana de $\sigma=5^{\circ}$. $O$ estreito padrão diagonal indica que a distribuição gaussiana para o ângulo de torção trans $\left(180^{\circ}\right)$ é dado por $\sigma<7^{\circ}$.

Os experimentos com desacoplamento homonuclear foram realizados para uma caracterização mais precisa da distribuição do ângulo de torção trans. A maior precisão na determinação da conformação trans em experimentos com desacoplamento homonuclear pode ser observada nos exemplos de simulações da Figura 2.14.

Neste trabalho ${ }^{30}$, Harris et al. confirmaram com experimentos double quantum que os ângulos de torção OC-CO no POE/RES são todos gauche. Além disso, a constatação dos autores de que $1 / 3$ dos ângulos de torção para o POE/PNP são trans, com $\psi=180 \pm 7^{\circ}$, e $2 / 3$ são gauche, com $\psi=70 \pm 9^{\circ}$ confirmou pela primeira vez a estrutura sugerida anteriormente. 
III

\section{Materiais e Métodos}

Polímeros da família dos alquil metacrilatos, têm sido conhecidos desde 1877 quando o poli(etil metacrilato) $\left(\mathrm{R}=\mathrm{CH}_{2}-\mathrm{CH}_{3}\right)$ foi polimerizado pela primeira vez. Desde então o estudo de suas propriedades tem sido realizado acompanhando as técnicas disponíveis para tal, especialmente após o início da produção industrial do poli(metil metacrilato) $\left(\mathrm{R}=\mathrm{CH}_{3}\right)$ em 1931. Quando preparados na forma convencional, os alquil metacrilatos apresentam-se como polímeros amorfos, no entanto, variando-se a temperatura de polimerização ou utilizando-se catalisadores específicos, muitos deles têm sido preparados em formas cristalizáveis, tendo um alto grau de estereoregularidades sindiotáticas e isotáticas. Além da análise por relaxação mecânica, sua caracterização através de relaxação dielétrica é largamente utilizada devido ao forte momento de dipolo elétrico no grupo éster lateral (-COOR $)^{1}$. Neste capítulo, inicialmente é feita uma pequena introdução aos polímeros ressaltando algumas de suas características básicas, permitindo o entendimento das propriedades dos polímeros estudados. Logo em seguida, após uma breve introdução às técnicas de relaxação dielétrica e mecânica, que usualmente são utilizadas para a caracterização de polímeros, são apresentados os poli(alquil metacrilatos) e suas características. Por fim, são apresentados os princípios de como são feitas as simulações das curvas de exchange em um tópico que terá complementações também ao longo do próximo capítulo. 


\subsection{Características Gerais dos Polímeros}

Polímeros são compostos que contêm moléculas que constituem-se de uma seqüência com um grande número de agrupamentos atômicos acoplados através de ligações químicas. Estes agrupamentos atômicos, que se repetem ao longo da cadeia que forma o material, são as chamadas unidades monoméricas. Em uma primeira observação, as características físicas importantes dos polímeros são determinadas pela estrutura química da sua unidade monomérica. No entanto, polímeros são materiais que, mesmo para uma dada composição química, podem apresentar consideráveis diferenças na sua estrutura física, como por exemplo o tamanho e a orientação das cadeias ou o grau e o caráter de cristalinidade. Esse fato está diretamente ligado à grande sensibilidade dos polímeros ao seu processamento, mais especificamente, ao tamanho das suas cadeias e à sua história térmica. Além disso, independente dessas condições iniciais, tanto a composição química como a estrutura física de um determinado polímero podem mudar com o tempo através de processos de degradação e de relaxação.

Enquanto moléculas simples podem ocorrer em três estados distintos: sólido, líquido e gasoso; possuindo transições estreitas entre estas fases (associadas com o equilíbrio termodinâmico do sistema), as moléculas de polímeros apresentam uma situação muito mais complexa. No caso comum, a divisão entre estas três fases está diretamente ligada à natureza do movimento térmico dos átomos e moléculas que compõem a substância. Enquanto que no estado sólido existem movimentos térmicos mais restritos, no estado gasoso estes movimentos ocorrem com grande intensidade, após a passagem por um estado de movimento intermediário (líquido). 
Já uma definição estrutural para a fase é baseada na diferença no grau de ordenação dos átomos e moléculas No entanto, polímeros não preenchem estas condições de contorno. Primeiramente, polímeros não podem evaporar desde que sofrem a decomposição molecular antes de ferverem. No estado sólido polímeros são, na maioria dos casos, parcial ou totalmente amorfos. Enquanto que um polímero amorfo em seu estado vítreo preenche as especificações de um sólido com respeito à agregação de suas moléculas, ele não apresenta uma fase cristalina. Isso equivale a dizer que ele é classificado como um sólido sem apresentar uma ordenação tridimensional de longo alcance. Os estados mais comuns em que os polímeros podem ser encontrados são: o vítreo, o elastomérico (ou borrachoso) e o semicristalino (ou semi-rígido). Além disso, polímeros com baixo peso molecular podem ser encontrados no estado líquido. $\mathrm{O}$ estado semi-rígido surge em polímeros semicristalinos e não aparece em polímeros amorfos. A Figura 3.1 mostra o comportamento geral de polímeros amorfos e semicristalinos através de um diagrama da temperatura versus o seu peso molecular ${ }^{2}$.

(a)

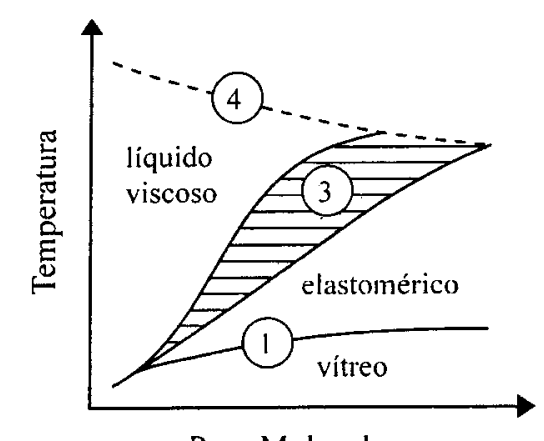

Peso Molecular (b)

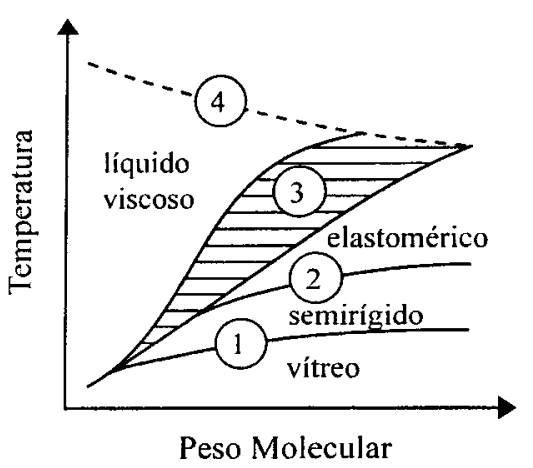

Peso Molecular

Figura 3.1: Diagrama da temperatura versus o peso molecular em polímeros (a) amorfos e (b) semi-cristalinos.

Para a análise de um material polimérico é muito importante o 
conhecimento dos tipos de transições pelas quais ele passa. Quase todas as propriedades dos polímeros são determinadas primariamente por estas transições e as temperaturas em que elas ocorrem. Na Figura 3.1 os números 1 e 2 representam a transição vítrea e o ponto de fusão do material, respectivamente. Enquanto que o número 3 indica a zona de transição difusa entre os estados e o número 4 apresenta onde ocorre a decomposição térmica do material.

\subsubsection{Polímeros Amorfos}

Uma das definições mais aceitas sobre polímeros amorfos é a que são sistemas parcialmente ordenados, formados por blocos de cadeias poliméricas, isto é, apresentam um estrutura sem ordem de longo alcance. Em cada bloco a cadeia polimérica seria ordenada ao mesmo tempo que os blocos apresentam-se emaranhados entre si. Mesmo não estando claro se o elemento básico da estrutura de um sólido amorfo é a molécula ou o bloco pode-se explicar algumas de suas características independentemente de um ou outro caso corresponder à realidade. A transição vítrea $\left(T_{\mathrm{g}}\right)$, por exemplo, que é a principal transição de um polímero amorfo, pode ser explicada quantitativamente por ambas as hipóteses 3 .

Acima da $T_{\mathrm{g}}$ o polímero se comporta quase como um líquido, caracterizando o seu estado elastomérico. O movimento dos segmentos moleculares neste estado é caótico, sendo que em um determinado instante pode-se observar muitos espaços entre agrupamentos destes segmentos. No entanto, os segmentos moleculares variam suas posições por saltos discretos de tal forma que os agrupamentos de moléculas em um instante se movem rapidamente para outra configuração. Como a diferença de densidade entre um cristal e um líquido é devida principalmente aos buracos, em cada temperatura existe um equilíbrio de densidade de buracos refletindo em um 
equilíbrio de volume ${ }^{3}$. Acima da $T_{\mathrm{g}}$ a densidade de buracos aumenta com uma subida de temperatura e diminui ao se abaixar a temperatura. No entanto, abaixo da $T_{\mathrm{g}}$ a densidade de buracos não muda quando a temperatura é modificada.

Na Figura 3.1(a) observa-se que, ao aquecer-se um polímero previamente no estado vítreo, este ganha uma maior mobilidade na região da sua transição vítrea, tornando-se bastante flexível. Ao continuar o aquecimento o comportamento elástico diminui, mas somente em temperaturas algumas dezenas de graus Celsius acima da $T_{\mathrm{g}}$ que uma parte viscosa começa a predominar sobre a conformação elástica.

Em temperaturas abaixo da $T_{\mathrm{g}}$ polímeros vítreos também apresentam transições secundárias. Os efeitos dessas transições são menores e geralmente menos óbvios, apesar de serem importantes para o comportamento mecânico do material pois tendem a diminuir a sua característica quebradiça. Estas transições secundárias, apesar de serem mais sutis, podem ser observadas por RMN através de um estudo da forma de linha e tempos de relaxação em função da temperatura. Enquanto a transição vítrea ocorre em temperaturas em que grandes segmentos da cadeia polimérica estão livres para se moverem, transições secundárias ocorrem em temperaturas em que subgrupos ou cadeias laterais podem oscilar ou mover-se livremente ${ }^{4}$.

É importante notar que o tamanho de grupos laterais pode afetar a temperatura da transição vítrea. De uma maneira geral, quanto mais próximo da cadeia principal fica o grupo lateral, maior é a $T_{\mathrm{g}}$. A mudança na temperatura dessa transição reflete a existência de uma maior barreira de energia para rotações internas, como resultado da grande intensidade das interações não-ligantes; ou um maior volume necessário para comportar a mudança conformacional. Se o grupo lateral de 
um polímero é grande ao ser comparado ao de outro isso não representará, necessariamente, que a $T_{\mathrm{g}}$ do primeiro será maior. Exatamente o oposto é verificado se, apesar do tamanho, ele for suficientemente flexível para adotar com rapidez uma estrutura com baixa energia. Nesse caso, quanto maior for o grupo lateral com seus movimentos rápidos, maior será o volume livre disponível para relaxar a cadeia principal, diminuindo a $T_{\mathrm{g}}^{4}$.

\subsubsection{Polímeros Semicristalinos}

Em alguns polímeros é possível observar-se a existência de uma temperatura de fusão, $T_{\mathrm{m}}$. Acima dessa temperatura o polímero pode ser líquido, viscoelástico ou borrachoso de acordo com o seu peso molecular. Abaixo dela ele tende a ficar semirígido e muito resistente, para altos pesos moleculares, até atingir a $T_{\mathrm{g}}$. Enquanto que para baixos pesos moleculares o polímero tende a se apresentar como uma cera quebradiça nesta região.

A temperatura de fusão é teoricamente a mais alta temperatura em que podem existir pequenos cristais poliméricos. Usualmente, estes pequenos cristais fundem-se em um certo intervalo de temperatura. Porém, transições cristalinas secundárias também podem ocorrer se o material transforma-se de um tipo de cristal para outro em temperaturas abaixo da sua temperatura de fusão. Essas transições podem ser observadas através de medidas de difração por raios-X ou DSC (differential scanning calorimetry) em polímeros semicristalinos.

Mesmo em polímeros cristalinos, nos quais a sua temperatura de fusão é determinante na sua utilização tecnológica, a temperatura da sua transição vítrea também é de grande importância. A razão disso é que entre $T_{\mathrm{g}}$ e $T_{\mathrm{m}}$ o polímero deve estar mais rígido e resistente, justificando a preferência da sua utilização no limite 
inferior da região semi-rígida da Figura 3.1(b).

Abaixo da $T_{\mathrm{g}}$ muitos polímeros tendem a ser quebradiços, principalmente se o seu peso molecular não for muito alto, o que limita as suas aplicações. É possível, no entanto, que um material rígido seja duro sem ser quebradiço devido à presença importante das transições secundárias nesta região.

\subsubsection{Configurações Rotacionais em Polímeros}

O ângulo rotacional de torção ou diédro de cada ligação entre os carbonos de uma cadeia polimérica pode ser igual a $0^{\circ}$, ligação trans (zig-zag planar), ou $\pm 120^{\circ}$, ligação gauche; como indicado na Figura 2.2.

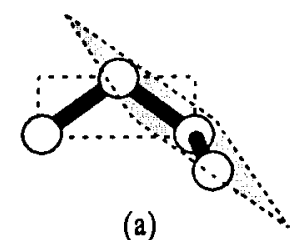

(a)

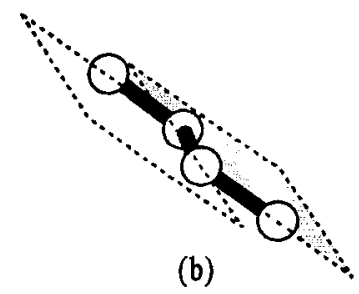

$\bigcirc \quad \mathrm{CH}_{2}$ ligação C-C

(c)

Figura 3.2: Exemplos de ângulos de torção em uma ligação química: (a) uma ligação tipo gauche que faz $120^{\circ}$ entre os planos formados com as ligações adjacentes e (b) uma ligação tipo trans que faz um ângulo nulo entre os dois planos adjacentes. Em (c) está representada a cadeia polimérica com o tipo de conformação das ligações entre os seus carbonos explicitada. As denominações $\mathrm{g}, \mathrm{g}^{-} \mathrm{e}$ t referem-se a ângulos gauche iguais a $120^{\circ} \mathrm{e}-120^{\circ}$ e ângulos trans, respectivamente.

A energia potencial dos estados rotacionais das ligações entre os carbonos apresenta três mínimos, respectivamente em $\phi=0^{\circ},-120^{\circ}$ e $120^{\circ}$. Movimentos da cadeia que dependem da temperatura podem induzir uma transição entre estas 
posições de equilíbrio, sem a necessidade de que ocorram grandes movimentos das macromoléculas do polímero. Esse tipo de rearranjo da cadeia polimérica pode ser observado por RMN por contribuir para a relaxação longitudinal dos carbonos envolvidos.

Através de simulações estatísticas pode-se obter quais transições de conformação são mais importantes. Considerando-se mudanças induzidas até duas ligações vizinhas obteve-se que as ocorrências mais prováveis são as representadas na Figura 3.3 por A e B. Características importantes com relação à sua geometria, comuns a essas duas transições, podem ser verificadas. Em ambos os casos, as duas primeiras e as duas últimas ligações apenas transladam entre si. Ou seja, o estado final de qualquer ligação, exceto a central, é paralelo ao seu estado inicial.

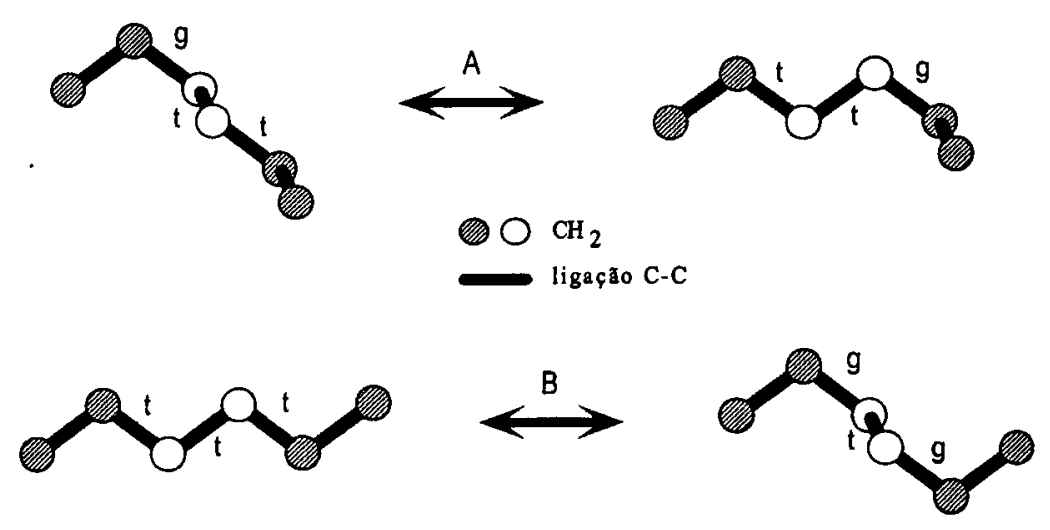

Figura 3.3: Possibilidades mais prováveis de transições de conformação em uma cadeia: gtt - ttg e ttt-gtg.

Levando isso em consideração pode-se observar, para algumas moléculas pequenas, se esse tipo de transição está ocorrendo. Através de excitação seletiva pode-se tentar analisar os carbonos claros da Figura 3.3 separadamente dos carbono 
escuros por RMN. Esse tipo de experimento, quando possível, permite comparar os tempos de relaxação spin-rede $\left(T_{1}\right)$ para estes dois grupos de núcleos. O $\mathrm{T}_{1}$ dos carbonos centrais, por poderem relaxar também através das transições conformacionais, deverá ser mais curto que o dos outros. Por outro lado, os carbonos escuros da figura, por sofrerem apenas uma translação, não têm como relaxar através desse processo ${ }^{5}$.

Além do isomerismo rotacional discutido acima, o isomerismo conformacional é outra característica importante de materiais poliméricos. Muitas vezes a taticidade de um polímero define se ele se apresenta ou não na fase amorfa em condições normais. A Figura 3.4 mostra as três possíveis taticidades para polímeros do tipo $-\mathrm{CXR}-\mathrm{CH}_{2}$. No caso do PMMA: $\mathrm{R}=\mathrm{CH}_{3}$ e $\mathrm{X}=\mathrm{CO}_{2} \mathrm{CH}_{3}$.

Em polímeros sindiotáticos as unidades de repetição adjacentes têm configurações espaciais opostas, Fig 3.4(a). Na forma isotática, apresentam-se os polímeros que têm unidades de repetição sempre na mesma configuração, Fig 3.4(b). Polímeros atáticos são irregulares pois apresentam pequenos trechos da sua cadeia na forma sindiotática e outros na atática, como visto na Figura 3.4(c). 
(a)

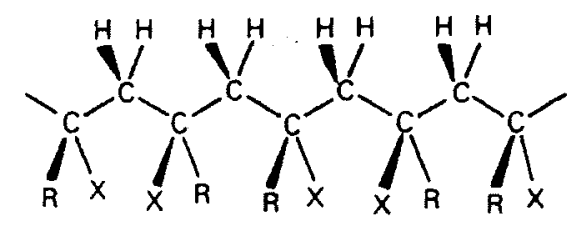

(b)

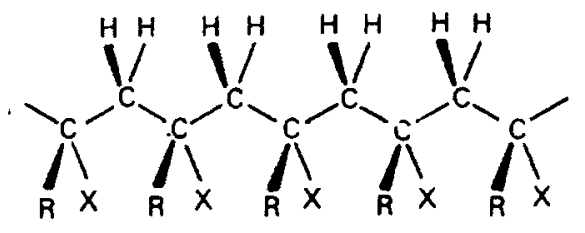

(c)

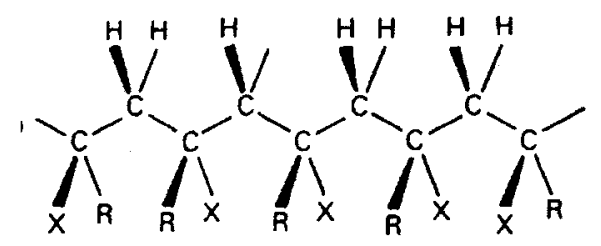

Figura 3.4: Isomerismo estrutural em polímeros do tipo $-\mathrm{CXR}_{-}-\mathrm{CH}_{2}$. Para o $\mathrm{PMMA} \mathrm{R}=\mathrm{CH}_{3}$ e $\mathrm{X}=\mathrm{CO}_{2} \mathrm{CH}_{3}$ : (a) sindiotático; (b) isotático e (c) atático.

\subsection{Resumo Sobre as Técnicas de Relaxação Dinâmica}

Quando uma tensão elétrica senoidal é aplicada a um sólido que exibe relaxação, a tensão de resposta geralmente apresenta uma defasagem com relação à força aplicada por um determinado ângulo de fase $\delta_{\mathrm{G}}$. Esse deslocamento de fase é dado pelo tempo necessário para que ocorram os rearranjos moleculares na amostra. Nos experimentos de relaxação dielétrica, um campo elétrico alternado é aplicado produzindo uma polarização elétrica no material que, no caso de sólidos polares, atrasa o campo elétrico por um ângulo de fase $\delta_{\varepsilon}$. Tanto nos experimentos de relaxação mecânica como dielétrica a dissipação de energia é proporcional ao seno desse ângulo de fase. Portanto, na ausência de efeitos de relaxação, o deslocamento de fase é zero e nenhuma energia é dissipada. A perda mecânica, devida ao movimento de um determinado segmento molecular, muda também a orientação do dipolo elétrico, determinando uma perda dielétrica. Dessa forma, os resultados das 
duas técnicas podem ser relacionados, permitindo uma identificação mais precisa dos movimentos envolvidos na relaxação. No entanto, muitas vezes a perda de energia observada não pode ser corroborada por um modelo molecular quantitativo deixando margens a diversas interpretações. Isso está ligado ao fato de que não há uma teoria molecular que prevê, por exemplo, a freqüência de relaxação mecânica em termos da freqüência na qual uma molécula realiza um movimento de flip (rotação de $180^{\circ}$ ). Adicionalmente, também não existe uma previsão teórica da magnitude da relaxação observada experimentalmente 1 .

O principal objetivo na utilização de técnicas de relaxações dielétrica e mecânica no estudo de polímeros é a determinação de um mecanismo molecular. Uma forma de se fazer isso é quantitativa e envolve medidas dos parâmetros de relaxação (magnitude e freqüência) correlacionando-os posteriormente com predições que levam em conta princípios básicos ou outros resultados experimentais. A outra maneira é qualitativa, envolvendo a medida dos parâmetros de relaxação e a sua dependência com a estrutura para então, por hipótese, postular um mecanismo. $\mathrm{O}$ método qualitativo, sozinho, é geralmente utilizado no caso de polímeros sólidos, apesar de existirem algumas teorias moleculares simples sobre a dinâmica da relaxação primária que permitem uma análise semi-quantitativa.

\subsubsection{Mecanismos Moleculares de Relaxação}

A maioria dos polímeros exibe mais que uma região de relaxação dielétrica ou mecânica. A fim de identificar e comparar adequadamente a posição dos picos de perda em experimentos de relaxação para diferentes polímeros, os picos são usualmente nomeados com as letras gregas $\alpha, \beta, \gamma, \delta$ etc. De acordo com essa 
nomenclatura, o pico $\alpha$ corresponde à relaxação observada na mais alta temperatura (para uma dada freqüência) ou na mais baixa freqüência (em uma dada temperatura). A notação $\beta$ e $\gamma$ se aplica a outras regiões de relaxação em ordem decrescente de temperatura ou crescente de freqüência. Como exemplo, a Figura 3.5 mostra as curvas típicas para o par de parâmetros dinâmico-mecânicos G'e $\Lambda$ para o PMMA, onde observa-se a ocorrência dos processos de relaxação $\alpha$ e $\beta^{1}$.

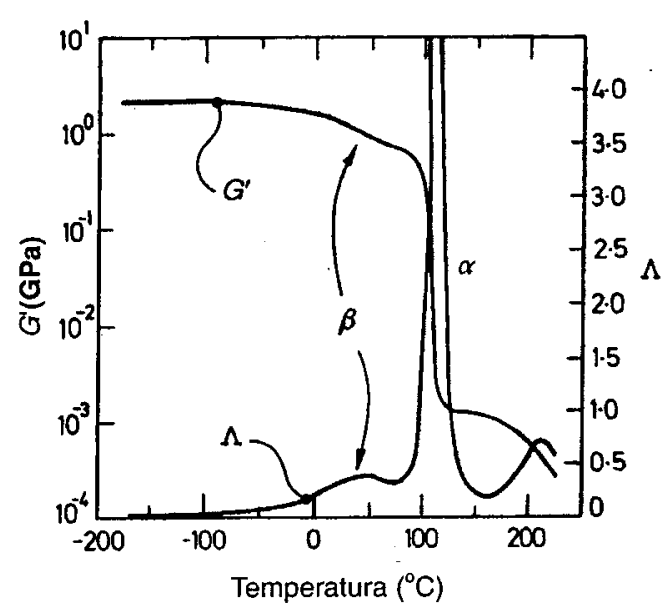

Figura 3.5: Dependência dos parâmetros dinâmico-mecânicos $G^{\prime}$ e $\Lambda$ com a temperatura para o poli(metil metacrilato) para uma freqüência constante próxima de $1 \mathrm{~Hz}$. As curvas mostram claramente as temperaturas para a freqüência especificada em que os processos de relaxação $\alpha$ e $\beta$ são efetivos. Os movimentos lentos dos grupos laterais do PMMA, responsáveis pela sua relaxação $\beta$, podem ser observados à temperatura ambiente.

Associada com a transição vítrea, a relaxação $\alpha$ é a que tem a relaxação mecânica de maior proeminência. Também é chamada de relaxação primária ou relaxação vítreo-borrachosa devido à sua aparição em torno da $T_{\mathrm{g}}$ em polímeros amorfos. Freqüentemente, ela é também a mais evidente relaxação observada dieletricamente. De um ponto de vista molecular, essa transição vítreo-borrachosa resulta de rearranjos conformacionais de larga escala da cadeia principal do polímero. Esses movimentos ocorrem por um mecanismo de rotações restritas em 
torno das ligações químicas da cadeia principal3,6. Adicionalmente, polímeros amorfos usualmente exibem pelo menos mais uma região de relaxação secundária. As regiões de perdas secundárias (relaxações $\beta, \gamma, \delta$ ) resultam de movimentos internos do polímero no estado vítreo. Neste estado, as cadeias principais estão “congeladas", isto é, não estão realizando os movimentos de larga escala responsáveis pela relaxação $\alpha$. Desde que as moléculas da maioria dos polímeros amorfos contém grupos laterais capazes de realizar rotações restritas independentemente da cadeia principal, as relaxações secundárias são geralmente atribuídas a estas rotações. Para polímeros do grupo dos metacrilatos, por exemplo, esses picos $\beta$ de relaxação dielétrica e mecânica são geralmente associados a rotações do grupo lateral -COOR. Isso não quer dizer, no entanto, que em alguns casos movimentos locais limitados da cadeia principal no estado vítreo não possam também ocorrer.

\subsection{Poli(metil metacrilato)}

O poli(metil metacrilato) (PMMA) é um polímero amorfo conhecido também como Plexiglas ${ }^{\circledR}$. Utilizado na indústria para substituir vidros, por ser transparente e altamente resistente, o PMMA apresenta-se extremamente insensível à fotodegradação quando exposto ao sol $^{3}$. Essas características são muito apreciadas pela indústria automobilística que o utiliza na fabricação de lanternas de $\operatorname{carros}^{6}$.

O menor membro da família dos poli(alquil metacrilato)s, o PMMA, é um polímero altamente estudado ${ }^{1}$. Resultados de $\mathrm{RMN}$ em estado sólido sugerem que o PMMA convencional, preparado por iniciação com radicais livres em temperaturas elevadas, tem alto grau de caráter sindiotático $(\approx 60 \%)^{7,8}$ o que foi sustentado por 
medidas de infravermelho 8,9 . Por outro lado, ambas as técnicas mostram que se a temperatura da polimerização com radicais livres é abaixada, a proporção de regiões sindiotáticas na cadeia polimérica aumenta, modificando algumas de suas características. No poli(metil metacrilato) atático estudado neste trabalho, o grau de caráter sindiotático da cadeia polimérica chega a $(\approx 76 \%)$.

No entanto, é outra característica do PMMA, observada por relaxação dielétrica e mecânica, que chama atenção em diversos estudos. O PMMA é um exemplo típico de um polímero amorfo em que ocorrem diversos processos de relaxação molecular. Como usualmente, os quatro processos de relaxação são nomeados a partir daquele de temperatura mais alta (processo de relaxação $\alpha$ ), associado à sua transição vítrea. A relaxação $\beta$ tem componentes principais nos movimentos dos grupos laterais éster. As relaxações $\gamma$ e $\delta$ envolvem movimentos dos grupos metil conectados à cadeia principal (também denominado metil $\alpha$ ) e à cadeia lateral, respectivamente, como mostra a Figura 3.6. Em especial, a relaxação $\beta$, observada no PMMA, é geralmente considerada como o modelo de uma relaxação localizada em polímeros. Estudos de relaxação mecânica e dielétrica outorgam a esse processo de relaxação um mecanismo de dissipação de energia que pode estar ligado às boas propriedades mecânicas do PMMA entre a temperatura ambiente e a sua transição vítrea ${ }^{1}$. 


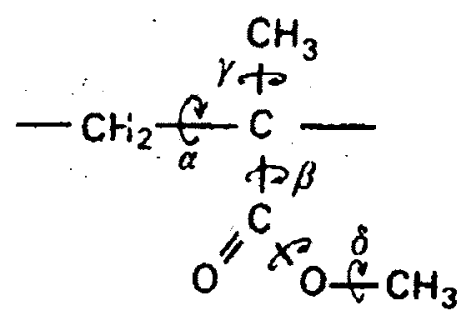

Figura 3.6: Representação das rotações correspondentes às relaxações observadas no PMMA.

Estudos de NMR sempre corroboraram estas informações. Por exemplo, a observação da largura de linha de ressonância em função da temperatura mostra uma relação entre a região do estreitamento da linha com o resultados de estudos mecânicos 1,10 . Essas regiões apresentam-se nas mesmas temperaturas aonde ocorre a diminuição do valor máximo da perda de relaxação mecânica e dielétrica ${ }^{1}$. De maneira similar, os processos de relaxação também apresentam alguma correlação com as regiões de mínimo valor para o tempo de relaxação spin-rede $\left(T_{1}\right)^{11,12}$.

No entanto, não é através do comportamento das linhas de ressonância em função da temperatura em experimentos de polarização cruzada (ou inversãorecuperação para a obtenção do $T_{1}$ ), como nos casos citados acima, que se obtém as mais valiosas informações que a RMN pode trazer sobre o sistema. A elucidação dos dados de relaxação mecânica e dielétrica através de RMN é muito melhor explorada, no PMMA, através da utilização de técnicas de exchange que permite o estudo dos movimentos moleculares lentos do seu grupo lateral. Os movimentos que afetam o espectro de exchange do carbono do grupo carboxil no PMMA, como adiantado no Capítulo I, estão mostrados na Figura 3.7. 

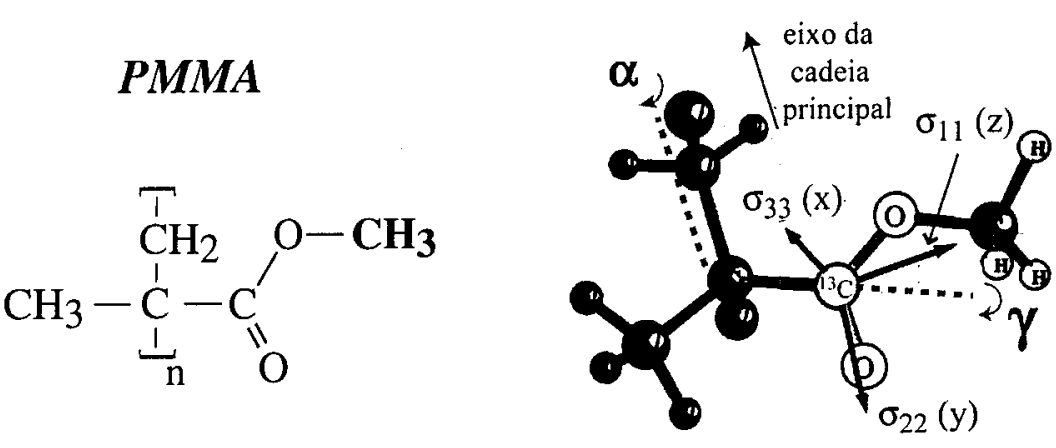

Figura 3.7: Diagrama que exemplifica os dois movimentos responsáveis pela relaxação $\beta$ nos poli(alquil metacrilatos). Aqui é mostrado o PMMA. Os ângulos $\gamma$ e $\alpha$ representam, respectivamente, o flip do grupo lateral $\mathrm{COOCH}_{2} \mathrm{CH}_{3}$ em torno da ligação entre o carbono quaternário da cadeia principal e o carbono do grupo carbonil da cadeia lateral, e o twist que é a rotação desse grupo lateral em torno da cadeia principal ${ }^{13}$. A figura também mostra o sistema de eixos principais do grupo COO.

Rotações em torno da cadeia principal são definidas pelo ângulo $\alpha \mathrm{e}$ rotações do grupo lateral são definidas pelo ângulo $\gamma$. Este dois movimentos são os responsáveis pela relaxação $\beta$ nos poli(alquil metacrilato)s em geral. Ou seja, existem pequenos movimentos da cadeia principal contribuindo para o processo de relaxação $\beta$ e a definição generalizada de que movimentos dessa natureza são relacionados apenas com a relaxação $\alpha$, como indicado na Figura 3.6, deve ser considerada com cautela - e.g. deve-se observar a amplitude do movimento e sua cooperatividade ao longo de toda a cadeia. Assim, mesmo que uma visão localizada das rotações envovidas em cada processo de relaxação esteja $\mathrm{Na}$ figura também é representado o sistema de eixos principais (SEP) do tensor deslocamento químico, que tem como valores principais $\sigma_{11}, \sigma_{22}$ e $\sigma_{33}$.

Os mecanismos que envolvem os movimentos descritos pelos ângulos $\alpha$ e $\gamma$ na Figura 3.7 foram elucidados em 1994 por Spiess e colaboradores, que analisaram os movimentos moleculares por traz da relaxação $\beta$ observada pelas relaxações dielétrica e mecânica dinâmica no PMMA através de técnicas de exchange ${ }^{13}$. Os 
resultados da aplicação de técnicas de relaxação dielétria e mecânical ${ }^{1,4}$ foram comparados utilizando-se métodos complexos de RMN bi e tridimensionais ${ }^{13}$. Por fim, chegou-se à conclusão de que a relaxação $\beta$ no PMMA está associada a uma rotação de $180^{\circ}\left( \pm 20^{\circ}\right)$ (flip) do grupo lateral $\mathrm{COOCH}_{2} \mathrm{CH}_{3}$, em torno da ligação entre o carbono quaternário da cadeia principal e o carbono do grupo carbonil da cadeia lateral, Figura 3.8(a) e (b). Com esse estudo puderam ser realizadas estimativas de que após o flip ocorre um rearranjo espacial que pode ser caracterizado por uma rotação do grupo lateral em torno da cadeia principal da ordem de $20^{\circ}(\mathrm{rms})$. Este efeito adicional está associado ao fato de que, sendo a cadeia lateral assimétrica, após o flip ela não se acomoda na sua vizinhança original. Para ajustar-se ao volume ocupado antes do flip, uma rotação em torno da cadeia principal (twist) é necessária, Figuras 3.8(b) e (c).

(a)

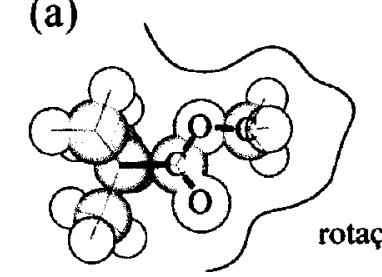

(c)

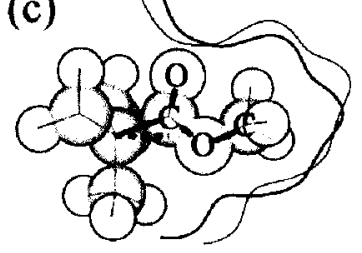

(b)

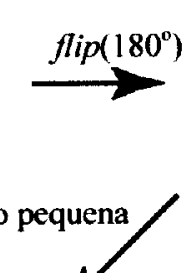

$\operatorname{flip}\left(180^{\circ}\right)$

(d)
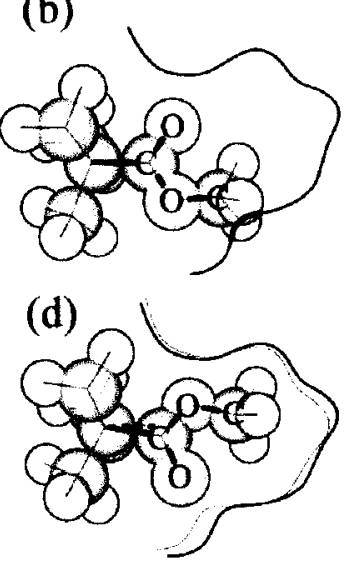

Figura 3.8: Explicação para a relaxação $\beta$ no PMMA e polímeros similares dada por Spiess e colaboradores ${ }^{13}$. (a) posição inicial; (b) rotação de $180^{\circ}$ (fip) do grupo lateral $\mathrm{COOCH}_{2} \mathrm{CH}_{3}$ em torno da ligação entre o carbono quaternário da cadeia principal e o carbono do grupo carbonil da cadeia lateral; (c) rotação do grupo lateral em torno da cadeia principal da ordem de $20^{\circ}$; (d) rotação de $180^{\circ}$ do grupo lateral para voltar a uma posição similar à inicial. 
É importante ressaltar que para se chegar a estes resultados através das técnicas convencionais de exchange, dispendiosos processos de enriquecimento isotópico das amostras tiveram que ser empregados - tanto com ${ }^{13} \mathrm{C}$ como com ${ }^{2} \mathrm{H}$. Nesse sentido estudos mais detalhados destes movimentos podem ser realizados através das novas técnicas de exchange CODEX e PUREX, apresentadas no Capítulo I, que não exigem o enriquecimento da amostra. Maiores detalhes sobre as informações possíveis de se extrair de sistemas do tipo PMMA com a aplicação dessas duas técnicas são discutidas no Capítulo IV.

\subsubsection{Poli(alquil metacrilato)s e Poli(acrilatos $\alpha$-substituído)s}

Considerando-se polímeros em que o grupo metil, em negrito no esquema da Figura 3.7, é substituído por radicais (representados pela letra R) maiores, pode-se comparar o comportamento destes polímeros com o do PMMA. Esse tipo de comparação em função do tamanho do grupo lateral ajudou muito na identificação dos picos de perda de relaxação (medidas de relaxação dielétrica e mecânica) do PMMA ${ }^{1}$. Distintamente, as propriedades dos diversos poli(alquil metacrilato)s (PRMAs) dependem bastante do tamanho do radical R. Alguns ésteres mais conhecidos como o metil, o etil, o n-propil, o n-butil e o ciclohexil apresentam-se vítreos à temperatura ambiente, sendo que outros são borrachosos.

Essa propriedade é refletida pelo decréscimo da $T_{\mathrm{g}}(\mathrm{e}$ picos de relaxação $\alpha$ ) com o aumento do tamanho do grupo lateral - excetuando-se entre os citados acima o caso do ciclohexil - que tem sua transição vítrea muito próxima à do PMMA. Como discutido acima, quando o tamanho do grupo lateral aumenta as cadeias vizinhas são afastadas, diminuindo os obstáculos aos movimentos da cadeia principal ou dos próprios grupos laterais. Isso é confirmado pela observação da diminuição da 
densidade dos polímeros com grupos laterais maiores. Esse fato depende das possibilidades de movimento livre da cadeia lateral o que justifica o caso diferenciado do grupo ciclohexil que é grande mas tem pouca flexibilidade. Porém esta característica só é válida para os poli(n-alquil metacrilatos). Se o grupo n-alquil é substituído pelo correspondente iso-alquil, por exemplo, a $T_{\mathrm{g}}$ acaba se deslocando para temperaturas mais altas. Isso acontece no poli(isobutil metacrilato) (PiBMA) que apresenta uma $T_{\mathrm{g}}$ que é $40^{\circ} \mathrm{C}$ mais alta que o poli(n-butil metacrilato) (PnBMA), Figura 3.9.

(a)

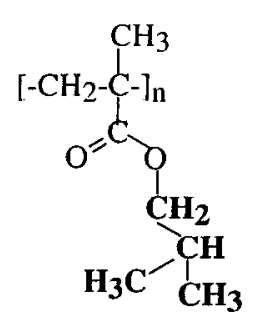

(b)

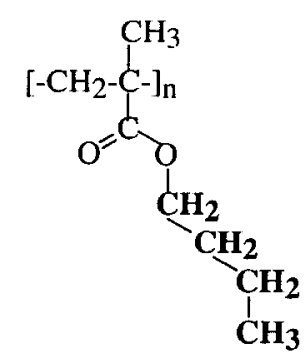

Figura 3.9: Representações químicas (a) do poli(isobutil metacrilato) (PiBMA) e do (b) poli(n-butil metacrilato) (PnBMA).

Foi verificado que isso ocorre desde que o menor e mais rígido grupo isobutil é muito menos efetivo no afastamento das cadeias poliméricas vizinhas que o linear e flexível grupo n-butil. Como as densidades destes dois polímeros são muito similares as forças de restrição coesiva entre cadeias também o são. Nesse caso, o efeito é compensado para o caso do PiBMA por um acréscimo nas obstruções estéricas para rotações intramoleculares produzidas pela maior rigidez do isobutil. O mesmo efeito é observado entre os grupos $\mathrm{n}$-hexil $\left(T_{\mathrm{g}}=-5^{\circ} \mathrm{C}\right)$ e ciclohexil $\left(T_{\mathrm{g}}=104^{\circ} \mathrm{C}\right)$.

Estudos de relaxação dielétrica e mecânica mostram que os poli(alquil 
metacrilato)s tem o mesmo tipo de contribuições que o PMMA no que diz respeito às rotações envolvidas nos processos de relaxação $\alpha, \beta$ e $\gamma$, Figura 3.41.

Outra classe de polímeros de interesse, derivada do PMMA, é a dos chamados poli(acrilatos $\alpha$-substituído)s (PM $\alpha \mathrm{As})$. A substituição do grupo metil ligado à cadeia principal $\left(\alpha-\mathrm{CH}_{3}\right)$ por grupos químicos de diferentes tamanhos também pode afetar o movimento relacionado à relaxação $\beta$ nestes polímeros. Apesar desse mecanismo de relaxação estar relacionado aos movimentos do grupo carboxil (COO), o tamanho do grupo lateral $\alpha$ deve influenciar esses movimentos. Isso porque os diversos grupos laterais ao longo da cadeia de um polímero amorfo fazem parte da circunvizinhança daqueles responsáveis pela relaxação, restringindo ou favorecendo o seu movimento.

\subsubsection{Polímeros Estudados Neste Trabalho}

Os poli(alquil metacrilato)s, PRMAs, estudados neste trabalho, em ordem crescente do tamanho do grupo lateral foram: os poli(metil metacrilato)s atático e isotático (aPMMA e iPMMA), o poli(etil metacrilato) (PEMA), o poli(isobutil metacrilato) (PiBMA) e o poli(ciclohexil metacrilato) (PcHMA), comprados diretamente da empresa Scientific Polymer Products $\left(\mathrm{Sp}^{2}\right)$. A Figura 3.10 apresenta a fórmula estrutural simplificada desses polímeros. Também utilizou-se uma amostra de PEMA enriquecido com ${ }^{13} \mathrm{C}$ obtida pela polimerização com $20 \%$ de monômero enriquecido e $80 \%$ de etil metacrilato não marcado da indústia Merk, que foi feita pelo grupo do Prof. H. W. Spiess conforme procedimento descrito na literatura 14 . Adquirido da empresa $\mathrm{Sp}^{2}$, o ácido polimetacrílico (PMAA), que apresenta um 
hidrogênio no lugar do radical $\mathrm{R}$ dos PRMAs, também foi analisado. Todas as amostras foram comprimidas em forma de cilindro à temperaturas próximas de sua transição vítrea, de forma a se obter o maior fator de preenchimento possível na bobina ou nos rotores da sonda de RMN. Para isso elas eram aquecidas com um soprador térmico (com monitoramento da temperatura feita por termômetros digitais) ao mesmo tempo que eram comprimidas manualmente em um pequeno tubo de vidro com as dimensões internas adequadas. A exceção para esse procedimento foi feita para o PMAA que foi comprimido dentro do rotor na sua forma de pó original. Para o iPMMA foi realizado este procedimento de aquecimento e compressão da amostra e, logo em seguida, o polímero foi rapidamente resfriado no nitrogênio líquido poucas horas antes dos experimentos, de forma a poder ser medido na fase amorfa.
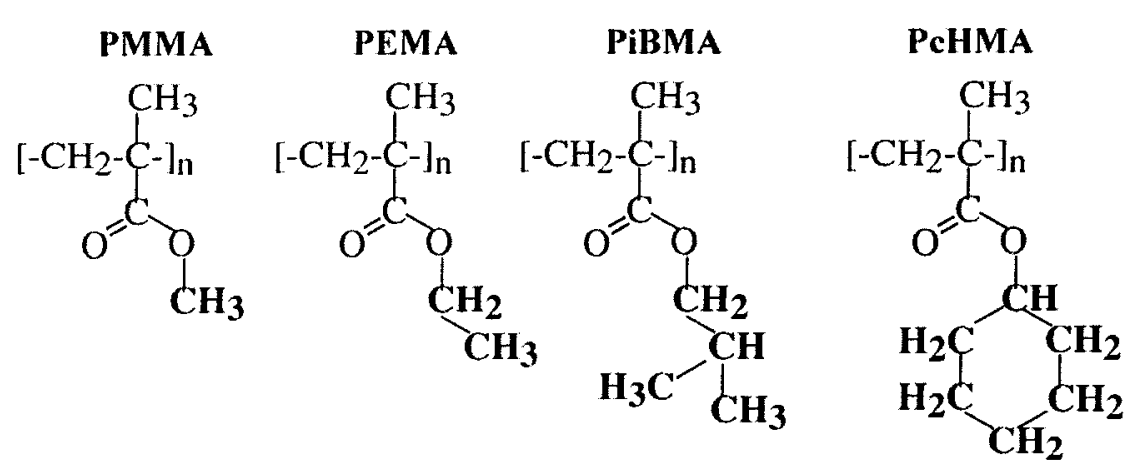

Figura 3.10: Poli(alquil metacrilato)s estudados: poli(metil metacrilato) (PMMA); poli(etil metacrilato) (PEMA); poli(isobutil metacrilato) (PiBMA), e poli(ciclohexil metacrilato) (PcHMA).

Além dos PRMAs, três poli(acrilatos $\alpha$-substituído)s (PM $\alpha$ As) foram 
estudados. Em ordem crescente de seu grupo a lateral eles são: o poli(metil etacrilato) (PMEA), o poli(dimetil itaconato) (PDMI) e o poli(metil $\alpha-$ trimetilsiloxilacrilato) ( PM[TMS]A ). A Figura 3.11 mostra a substituição do $\alpha-\mathrm{CH}_{3}$ do PMMA resultando nos três polímeros acima, através da fórmula estrutural simplificada do PMMA e dos PMaAs. Essas três amostras foram polimerizadas pelo grupo do prof. Jacques Penelle do PSE(UMass) a partir de substituintes adquiridos da indústria Aldrich. O PMEA foi sintetizado por polimerização aniônica ${ }^{15}$ enquanto que o PDMI 16 e o PM[TMS ${ }^{17}$ foram sintetizados utilizando-se a polimerização por radical livre. O mesmo procedimento efetuado para a preparação dos PRMAs para os experimentos de RMN, descrito no parágrafo anterior, foi adotado no caso dos PM $\alpha$ As.<smiles>CCCCCCCCCCCCC(=O)OC</smiles>

Figura 3.11: Poli(acrilatos $\alpha$-substituído)s estudados: poli(metil etacrilato) (PMEA); poli(dimetil itaconato) (PDMI) e poli(metil $\alpha$-trimetilsiloxilacrilato) ( PM[TMS]A ).

A Tabela II mostra os pesos moleculares (PM) e as temperaturas de transição vítrea $\left(T_{\mathrm{g}}\right)$ de todos os poli(alquil metacrilato)s e poli(acrilatos $\alpha$ substituído)s estudados no Capítulo IV. 
Tabela II. Pesos moleculares (PM) e temperaturas das transições vítreas $\left(T_{\mathrm{g}}\right)$ dos polímeros estudados.

\begin{tabular}{ccc}
\hline Polímero & $\sim$ PM & $\boldsymbol{T}_{\boldsymbol{\sigma}}\left({ }^{\circ} \mathrm{C}\right)$ \\
\hline aPMMA & 35.000 & 105 \\
iPMMA & 95.000 & 38 \\
PEMA & 280.000 & 66 \\
PEMA $\left({ }^{13} \mathrm{C}\right)$ & 670.000 & 80 \\
PiBMA & 260.000 & 55 \\
PcHMA & 65.000 & 104 \\
PMEA & 7.000 & 58 \\
PDMI & 125.000 & 100 \\
PM(TMS)A & 170.280 & 102 \\
\hline
\end{tabular}

\subsection{Princípios das Simulações das Curvas de Exchange}

Para simular o comportamento das curvas PUREX em função de $t_{\mathrm{m}}$ ou $2 \tau \mathrm{e}$ das curvas CODEX em função de $t_{\mathrm{m}}$ ou $2 \mathrm{NT}_{\mathrm{r}}$ utiliza-se o mesmo procedimento para simulação dos espectros de exchange descrito por Schmidt-Rohr e Spiess ${ }^{18}$. Adicionalmente, para o caso das curvas PUREX e CODEX devem ser considerados os fatores multiplicativos do sinal de exchange que aparecem devido à evolução do sistema de spins, como discutido no Capítulo I. A seguir é dada uma descrição dos elementos básicos que o programa (desenvolvido em Fortran) precisa para calcular a intensidade de exchange. Os programas com as pequenas modificações que permitem as simulações de espectros tipo PUREX e CODEX podem ser encontrados em deAzevedo(2001) ${ }^{19}$

O programa utiliza-se dos valores principais do tensor deslocamento químico do ${ }^{13} \mathrm{C}$ do grupo químico analisado. Para os poli(alquil metacrilato)s (PRMAs) e os poli(acrilato $\alpha$-substituído)s (PM $\alpha A s$ ) os valores de $\sigma_{11}, \sigma_{22}$ e $\sigma_{33}$ utilizados correspondem a: $268 \mathrm{ppm}, 150 \mathrm{ppm}$ e $112 \mathrm{ppm}$, respectivamente 
para o $\mathrm{COO}$; enquanto que para o $\mathrm{CH}_{2}$ os valores são: $79 \mathrm{ppm}, 48$ ppm e 29 ppm, respectivamente 20 .

Outros dados necessários para se poder simular as curvas de exchange são as orientações relativas entre o sistema de eixos principais do tensor deslocamento químico (SEP) e o sistema molecular de coordenadas adotado (SM). Para tanto utiliza-se a definição de ângulos de Euler $(\alpha, \beta$ e $\gamma)$ dada por Rose ${ }^{21}$. A Figura 3.12(a) mostra, segundo essa definição, as três rotações necessárias para se passar de um sistema de coordenadas A para outro B: (1) rotação de um ângulo $\alpha$ ao longo de $Z_{A}$, colocando $Y_{A}$ em cima da chamada linha nodal; (2) rotação de um ângulo $\beta$ ao longo da linha nodal, transformando $Z_{A}$ em $Z_{B}$ e, por fim, (3) rotação de um de um ângulo $\gamma$ ao longo de $\mathrm{Z}_{\mathrm{B}}$.

(a)

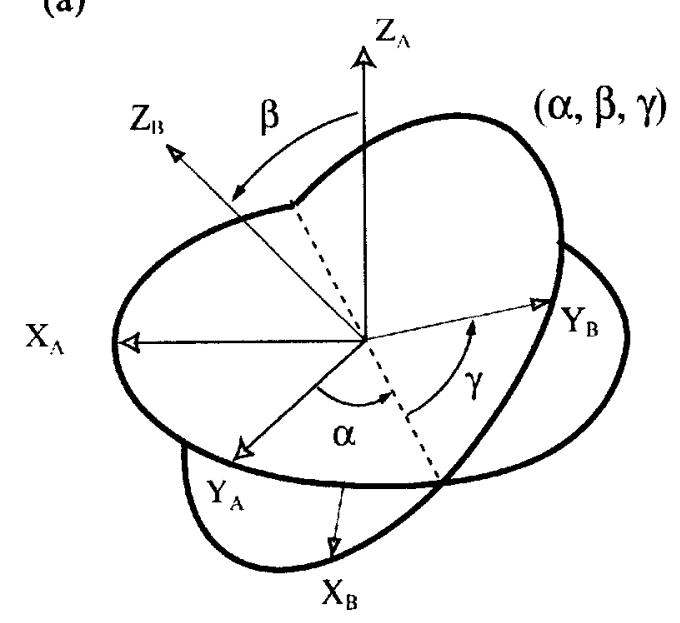

(b)

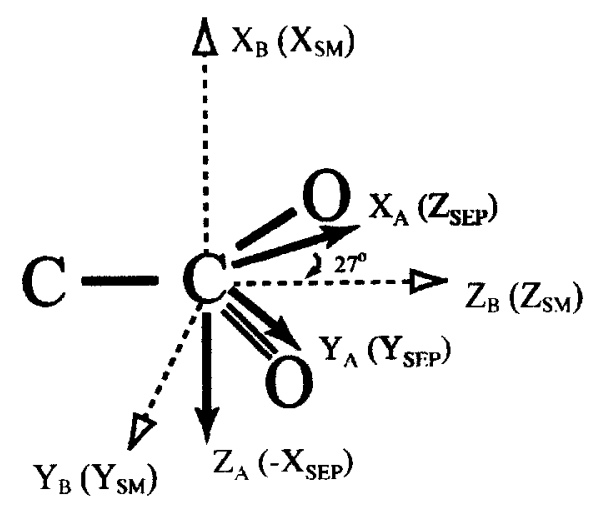

Figura 3.12: (a) Definição dos ângulos de Euler na passagem de um sistema de coordenadas A para outro B. (b) Definição do sistema de eixos principais (SEP) e do sistema molecular de coordenadas (SM) para o grupo carboxil no PMMA. Obtém-se $\alpha, \beta$ e $\gamma$ para as simulações considerando-se o SEP como o sistema de coordenadas A e o SM como o sistema de coordenadas B. 
As orientações do SEP e do SM adotadas nas simulações para o COO no PMMA são mostradas na Figura $3.12(b)$. Em geral, o eixo $X_{S M}$ do sistema de coordenadas molecular é adotado como sendo perpendicular ao plano COO enquanto que $Z_{\mathrm{SM}}$ é localizado ao longo da ligação C-C do grupo lateral. A definição adotada neste trabalho considerou o eixo $\mathrm{Y}_{\mathrm{SEP}}$ do sistema de eixos principais ao longo da direção da ligação dupla $\mathrm{C}=\mathrm{O}$. Com isso, a direção do eixo $\mathrm{X}_{\mathrm{SEP}}$ faz um ângulo de $27^{\circ}$ com relação a $Z_{S M}$. Na Figura $3.12(b) Z_{A}$ foi considerado como sendo $-X_{S E P}$ de forma que o sistema de coordenadas A seguisse uma definição destrógena como na Figura 3.12(a) e a definição para o SEP fosse mantida. Na prática, a escolha arbitrária de como definir o SEP não representa nenhum problema. De fato, as diferentes escolhas dos eixos do SEP presentes na literatura especializada13,22,23 trazem o mesmo resultado se a definição dos ângulos de Euler for feita corretamente como descrito na Figura 3.12(a). Finalizando, a Figura 3.12 mostra que considerando-se o SEP como um sistema de coordenadas A e o SM como um sistema de coordenadas $B$, pode-se facilmente encontrar os ângulos $\alpha, \beta$ e $\gamma$ que definem as orientações relativas destes dois sistemas de coordenadas.

Os espectros de exchange dependem dos ângulos de Euler iniciais $\left(\alpha_{i}, \beta_{i}, \gamma_{i}\right)$ e finais $\left(\alpha_{f}, \beta_{f}, \gamma_{f}\right)$, que são definidos respectivamente antes e depois do movimento molecular. A Figura 3.13 representa como estes dados são utilizados na simulação da intensidade do sinal de exchange em experimentos estáticos como o PUREX. 


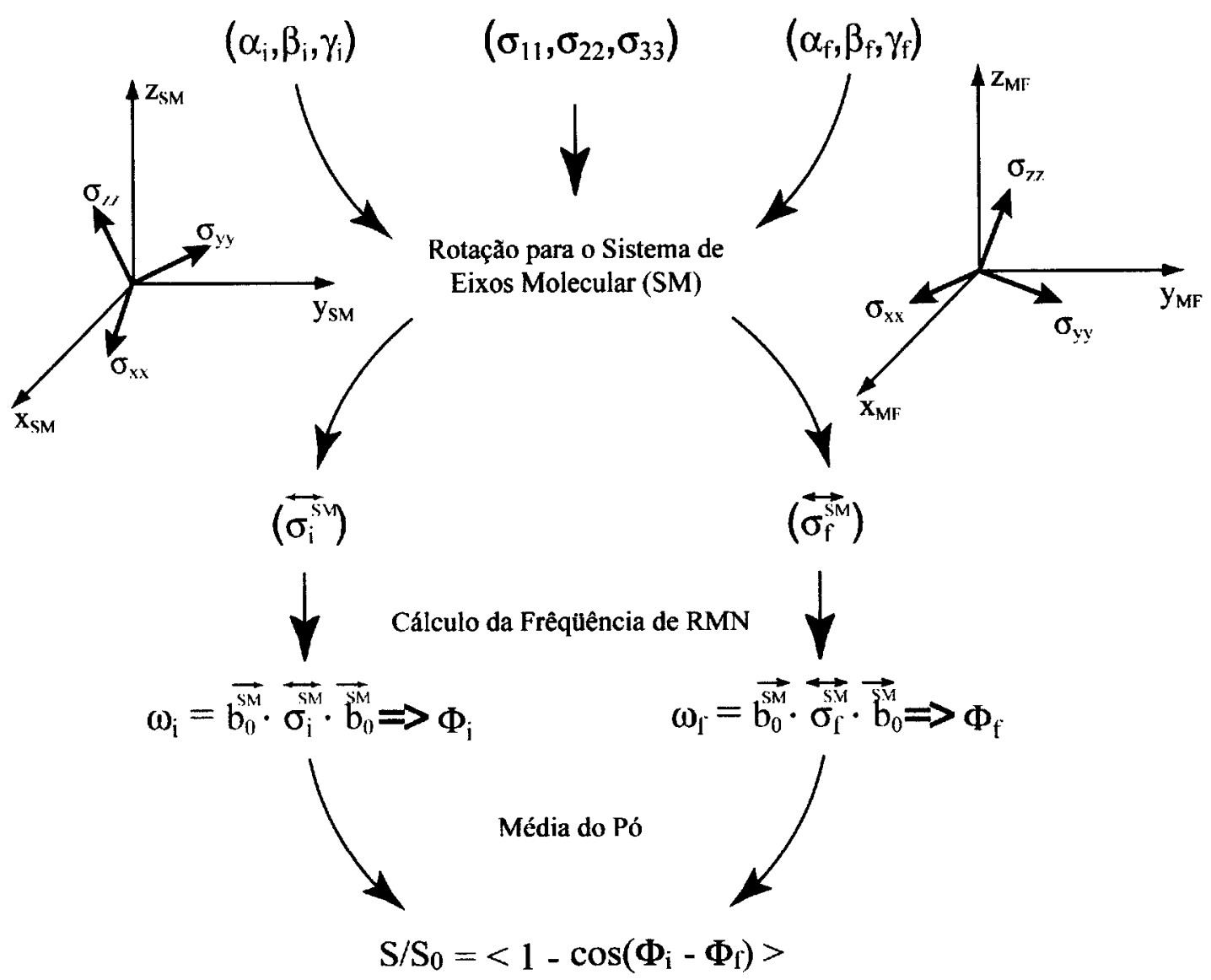

Figura 3.13: Representação de como os dados são utilizados na simulação da intensidade do sinal de exchange em experimentos estático como o PUREX ${ }^{18}$. Para o cálculo de $S / S_{0}$ são necessários os ângulos de Euler iniciais $\left(\alpha_{i}, \beta_{i}, \gamma_{i}\right)$ e finais $\left(\alpha_{f}, \beta_{f}, \gamma_{f}\right)$, além dos valores principais do tensor deslocamento químico $\left(\sigma_{11}, \sigma_{22}, \sigma_{33}\right)$. As cores vermelha e verde foram utilizadas para representar estados antes e depois do processo de exchange, respectivamente. As rotações dos SEPs antes e depois do exchange permitem a obtenção das correspondentes freqüências de RMN para cada configuração molecular, o que resultará na dependência final de $\mathrm{S} / \mathrm{S}_{0} 19$.

Após a definição do SEP e do SM do grupo molecular analisado pode-se considerar as possíveis orientaçães relativas entre estes dois sistemas de coordenadas antes e depois de um determinado movimento molecular. Para isso, faz-se uma rotação do SEP para o SM - tanto na condição inicial como na condição final do sistema. Através dos dados de entrada no programa: $\alpha_{i}, \beta_{i}, \gamma_{i}, \alpha_{f}, \beta_{f}$ e $\gamma_{f}$, calcula-se a matriz de rotação como descrito por Mehring ${ }^{24}$. Com os valores principais do tensor 
deslocamento químico e utilizando-se das matrizes de rotação encontradas, obtém-se os tensores deslocamento químico inicial e final escritos no sistema de coordenadas molecular, $\vec{\sigma}_{\mathrm{i}}^{\mathrm{SM}} \mathrm{e} \vec{\sigma}_{\mathrm{f}}^{\mathrm{SM}}$, conforme descrito por Schmidt-Rohr e Spiess ${ }^{18}$. Nesse ponto, pode ser efetuado o cálculo das freqüências de ressonância, $\omega_{\mathrm{i}}$ e $\omega_{\mathrm{f}}$, a partir da representação do vetor unitário na direção do campo extático, $\overrightarrow{\mathrm{b}}_{0}^{\mathrm{SM}}$, e do tensor deslocamento químico, $\vec{\sigma}^{\mathrm{SM}}$, ambos no sistema de coordenadas molecular. Variando a orientação de $\vec{b}_{0}^{\mathrm{SM}}$, considerando-se todas as possibilidades para as coordenadas polares $\theta$ e $\varphi$ em uma amostra policristalina, chega-se ao espectro final que vai depender das fases relativas $\Phi_{\mathrm{i}}$ e $\Phi_{\mathrm{f}}$ entre os estados inicial e final, ou seja, suas orientações relativas considerando-se antes e depois do processo de exchange.

Experimentos CODEX apresentam mais um passo no procedimento básico descrito na Figura 3.13. Como a amostra está sob MAS os segmentos moleculares estão constantemente mudando de posição com relação a um referencial de laboratório como o campo extático, $\mathbf{B}_{0}$. Neste caso, após a rotação do SEP para o SM deve ser feito outro passo que é a rotação do SM para o SR, o sistema do rotor. Com isso, passa-se de $\vec{\sigma}^{\mathrm{SM}}$ para $\vec{\sigma}^{\mathrm{SR}}$ e de $\overrightarrow{\mathrm{b}}_{0}^{\mathrm{SM}}$ para $\overrightarrow{\mathrm{b}}_{0}^{\mathrm{SR}}$, onde as representações no referencial do rotor, $\ddot{\sigma}^{\mathrm{SR}}$ e $\overrightarrow{\mathrm{b}}_{0}^{\mathrm{SR}}$, contém a dependência temporal que se reflete no espectro devido a aplicação da técnica MAS de rotação da amostra ${ }^{19}$.

A Figura 3.14 mostra como ficam as orientações relativas entre o sistema de eixos principais (indicado pelo índice A) e o sistema molecular (índice B), seguindo as definições da Figura 3.12(b) em três situações distintas do grupo COO nos PRMAs e nos PM $\alpha$ As: 1) antes do movimento molecular, como na Figura 3.12(b); 2) após a ocorrência de um flip e 3) após a realização de um twist. 


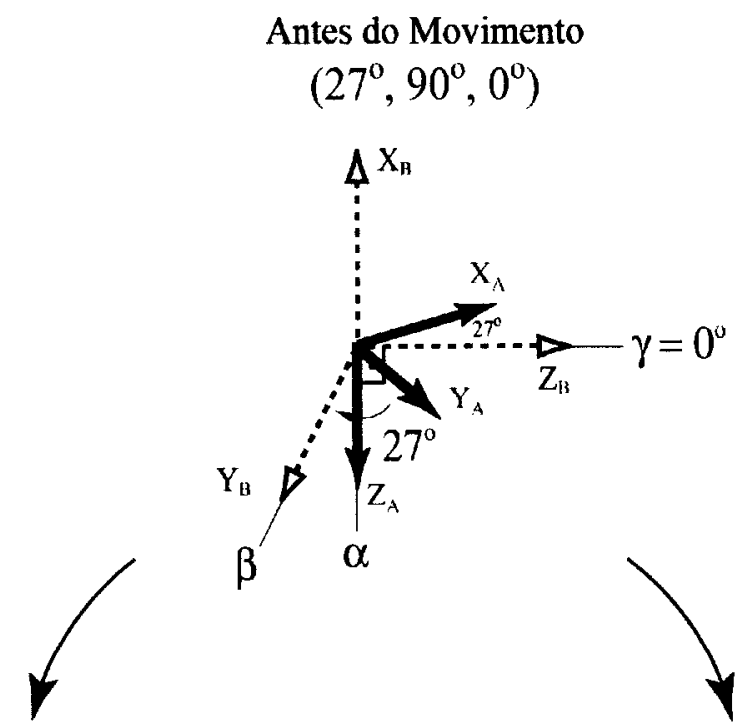

Após um Flip $\left(27^{\circ}, 90^{\circ}, 180^{\circ}\right)$

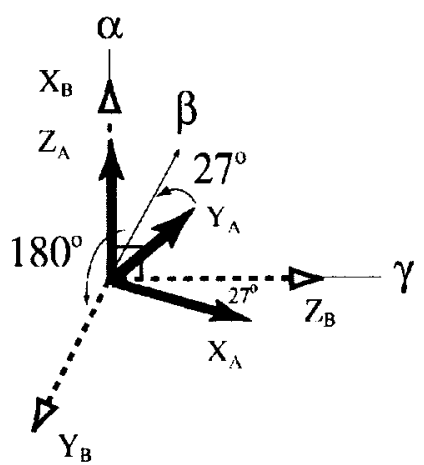

Após um Twist $\left(27^{\circ}+\delta \alpha, 90^{\circ}, 0^{\circ}\right)$

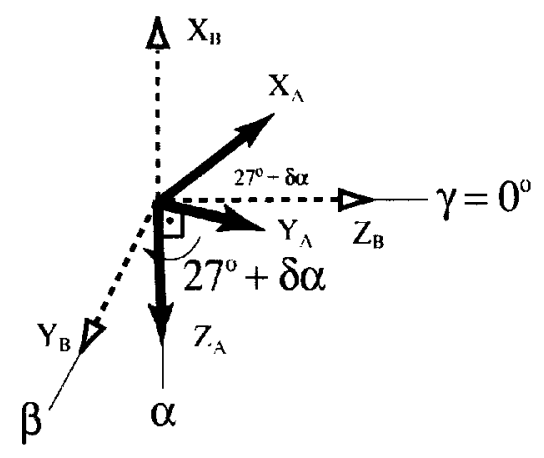

Figura 3.14: Orientações relativas entre o sistema de eixos principais (A) e o sistema molecular (B) do grupo COO nos PRMAs e nos PM $\alpha$ As. As configurações representadas consideram o sistema antes do movimento molecular ou processo de exchange com ângulos de Euler $\left(\alpha_{i}, \beta_{i}, \gamma_{i}\right)$ e após o exchange com ângulos de Euler $\left(\alpha_{f}, \beta_{f}, \gamma_{f}\right)$ em dois casos distintos: após um flip e após um twist do grupo lateral.

A Figura 3.14 também mostra os valores dos ângulos de Euler antes e depois dos dois tipos de movimentos moleculares no caso estudado nesta tese. Um flip é representado por uma mudança do ângulo $\gamma$ de $180^{\circ}$ e um twist é representado por uma mudança de $\delta \alpha$ no valor do ângulo de Euler $\alpha$.

Para facilitar as discussões, as curvas simuladas para estes movimentos para os experimentos PUREX e CODEX serão mostradas no Capítulo IV. 


\section{Resultados e Discussões}

Nesse capítulo são apresentados os resultados da aplicação das técnicas CODEX e PUREX, discutidas no Capítulo I, no estudo da dinâmica lenta do grupo lateral e da cadeia principal em poli(alquil metacrilato)s como função da temperatura e do tamanho desse grupo lateral. Adicionalmente, são apresentados e discutidos experimentos CODEX que permitem a observação do movimento do mesmo grupo lateral em poli(acrilato $\alpha$-substituído)s em função do tamanho do grupo $\alpha$, à temperatura ambiente.

Outro tópico que faz parte deste capítulo refere-se a técnica de double quantum, que permite a análise da conformação de polímeros enriquecidos em pares ${ }^{13} \mathrm{C}-{ }^{13} \mathrm{C}$, como discutido no Capítulo II. Inicialmente, são apresentados os espectros de double quantum em amostras padrão (POE/PNP e PET) que foram obtidos durante a implementação desta técnica no espectrômetro de RMN Variam do grupo de ressonância do IFSC. Posteriormente, são apresentados os resultados do estudo da conformação do POE em três complexos de POE com sais de metais alcalinos, obtidos em um espectrômetro Bruker no Polymer Science and Engineering Department da Universidade de Massachusetts em Amherst (EUA). 


\subsection{Dinâmica Lenta em Poli(metil metacrilato)s e Poli(acrilato $\alpha$-substituído)s}

Como discutido no Capítulo III, os poli(alquil metacrilato)s formam uma importante classe de polímeros vítreos. Suas propriedades mecânicas e dielétricas são altamente afetadas pelo processo de relaxação $\beta$, que é considerada como um exemplo típico de relaxações locais nesses polímeros ${ }^{1}$. Estando de acordo com muitos trabalhos anteriores sobre relaxação dielétrica e mecânica $1-3$, investigações detalhadas através de RMN multidimensional do poli(metil metacrilato) (PMMA) e do poli(etil metacrilato) (PEMA) enriquecidos em ${ }^{13} \mathrm{C}$ mostraram que a relaxação $\beta$ envolve movimentos de $180^{\circ}$ (flip) do grupo lateral conjuntamente com movimentos de pequena a média amplitude em torno do eixo local da cadeia principal, como discutido no Capítulo III 4,5 . Os experimentos de RMN revelaram que somente uma fração dos grupos laterais realizam o movimento de flip, com valor estimado da ordem de $50 \%$ (ou 0,5 na intensidade normalizada do sinal de exchange) para o $\mathrm{PMMA}^{4}$.

Recentemente, foram propostas, as técnicas de RMN de exchange: centerband-only detection of exchange (CODEX) ${ }^{6,7}$ e pure exchange (PUREX) ${ }^{8}$, apresentadas no Capítulo I, que permitem o estudo detalhado e quantitativo de movimentos lentos $\left(0,1 \mathrm{~s}^{-1}\right.$ a $\left.3000 \mathrm{~s}^{-1}\right)$ em polímeros. Utilizando-se estas técnicas pode-se determinar com grande precisão, para cada sítio na unidade de repetição: a fração dos grupos que realizam os movimentos de rotação lenta; a amplitude dos movimentos, incluindo oscilações lentas de pequena amplitude e a função e o tempo de correlação desse movimento. No caso da técnica CODEX, essas possibilidades são estendidas até para polímeros complexos, sem a necessidade do seu enriquecimento isotópico, excedendo o número de informações possíveis de se obter 
da maioria das técnicas já existentes. A relaxação dielétrica, por comparação, usualmente não pode distinguir se a redução do pico de perda dielétrica, após uma diminuição da temperatura (ou um aumento do tamanho do grupo lateral), é devida a movimentos com amplitudes menores ou à menor fração de grupos laterais realizando esse movimento ${ }^{1}$.

A caracterização quantitativa dos movimentos relacionados à relaxação $\beta$ nesses polímeros constitui-se no objetivo desse trabalho. Como os polímeros estudados não são sistemas complexos e o carbono do grupo carbonil (COO) pode ser observado isoladamente mesmo em baixa resolução, a técnica PUREX também pode ser utilizada para a caracterização do seu movimento. Desta forma, esta é uma das primeiras aplicações conjuntas dessas duas novas técnicas de exchange onde pode-se comparar as suas potencialidades na elucidação de determinadas questões relacionadas à dinâmica molecular.

Os experimentos CODEX foram realizados a $75 \mathrm{MHz}$ para o ${ }^{13} \mathrm{C}$ em um espectrômetro Bruker DSX-300 do Polymer Science and Engineering Department da Universidade de Massachusetts em Amherst (EUA). Os dados foram adquiridos em sondas Bruker de 4 ou $7 \mathrm{~mm}$ com MAS e temperatura variável, utilizando-se pulsos de $90^{\circ}$ para ${ }^{13} \mathrm{C}$ e ${ }^{1} \mathrm{H}$ de aproximadamente $3,5 \mu$ s (com a utilização de diferentes potências nos respectivos amplificadores), com desacoplamento de ${ }^{\mathrm{I}} \mathrm{H}$ em $\gamma B_{1} / 2 \pi=80 \mathrm{kHz}$. As velocidades de rotação utilizadas ficaram entre 3,5 e $10,0 \mathrm{kHz}$. O tempo de repetição para a maioria das amostras foi de $1,5 \mathrm{~s}$, enquanto que para $\mathrm{o}$ PMAA foi $2 \mathrm{~s}$. O tempo de polarização cruzada foi 1,5 ms para todas as amostras. Por fim, o número total de médias ficou entre 1280 e 2560, dependendo da amostra, resultando em um tempo típico de medida de $2 \mathrm{~h}$ para cada espectro CODEX. 
Os experimentos PUREX foram realizados a $100,5 \mathrm{MHz}$ para o ${ }^{13} \mathrm{C}$ em um espectrômetro Varian Inova-400. Os dados foram adquiridos com uma sonda Doty de $7 \mathrm{~mm}$ com temperatura variável, utilizando-se pulsos de $90^{\circ}$ para ${ }^{13} \mathrm{C}$ de $4,3 \mu$ s e para o ${ }^{1} \mathrm{H}$ de $4 \mu \mathrm{s}$, com desacoplamento de ${ }^{1} \mathrm{H}$ em $\gamma B_{1} / 2 \pi=70 \mathrm{kHz}$. O tempo de repetição para todas as amostras foi de $2 \mathrm{~s}$. O tempo de polarização cruzada foi 1,6 ms para todas as amostras. Por fim, o número total de médias ficou entre 512 (para baixas temperaturas e valores pequenos de $\tau$ ) e 19456 (para altas temperaturas e grandes valores de $\tau$ ). Com isso, dependendo da amostra e das condições experimentais, cada espectro PUREX pode ter levado de alguns minutos a várias horas para ser produzido.

Os PRMAs estudados são: os poli(metil metacrilato)s atático e isotático (aPMMA e iPMMA), o poli(etil metacrilato) (PEMA), o poli(isobutil metacrilato) (PiBMA) e o poli(ciclohexil metacrilato) (PcHMA). Os três polímeros do tipo PM $\alpha$ A estudados são: o poli(metil etacrilato) (PMEA), o poli(dimetil itaconato) (PDMI) e o poli(metil $\alpha$-trimetilsiloxilacrilato) ( PM[TMS]A ).

\subsubsection{Aplicações da Técnica CODEX}

A Figura 4.1 mostra, para três diferentes PRMAs, a intensidade de exchange devido aos grupos laterais que se reorientaram durante $t_{\mathrm{m}}$. Para cada polímero são mostradas curvas para vários períodos de reacoplamento, $N t_{\mathrm{r}}$. Quando este tempo é mais curto que $1000 \mu \mathrm{s}$, os movimentos de pequenos ângulos não contribuem significativamente para a intensidade de exchange. Isto é confirmado pela concordância entre o que mostram as curvas para $N t_{\mathrm{r}}<1000 \mu \mathrm{s}$, enquanto que para $N t_{\mathrm{r}}>2000 \mu \mathrm{s}$, Figura 4.1(a) e (d), as pequenas mudanças de freqüência devidas aos 
movimentos lentos de pequena amplitude já tiveram tempo para gerar um considerável defasamento e um resultante aumento significativo na intensidade $\Delta S / S_{0}$. Uma análise da dependência da intensidade com $N t_{\mathrm{r}}$ será feita, confirmando essa característica.

Os dados das Figuras 4.1(a) e (b) para o aPMMA e o PEMA, respectivamente, foram obtidas entre $6^{\circ} \mathrm{C}$ e $30^{\circ} \mathrm{C}$. Nesse intervalo de temperaturas, nenhuma mudança significativa é observada nos valores em que as curvas atingem o seu patamar (platô de $E_{\infty}$ ). Isso é de grande interesse, pois revela a fração de segmentos móveis que realizam o movimento de flip. De acordo com a eq.(1.4), como o número de sítios com diferentes orientações para um flip é $N=2$, tem-se que $f_{\mathrm{m}}=2 E_{\infty}$, significando que a fração de elementos que realizam o movimento é duas vezes o nível do platô intermediário observado na figura, como discutido no Capítulo I. A subida inicial, observada na Figura 4.1(a), é ligeiramente menos pronunciada para baixas temperaturas, como esperado para a relaxação $\beta$ que é ativada termicamente. Na Figura 4.1(c), os dados para o PEMA enriquecido em ${ }^{13} \mathrm{C}$ mostram uma inclinação inicial similar àquela para o PEMA não enriquecido da Fig. 4.1(b), mas para $t_{\mathrm{m}}>100 \mathrm{~ms}$, eles começam a mostrar uma subida muito mais pronunciada, não atingindo um patamar para tempos longos. Isso é atribuído ao exchange devido à difusão de spins ${ }^{9}$ do ${ }^{13} \mathrm{C}$, gerado pelos acoplamentos dipolares homonucleares entre os pares ${ }^{13} \mathrm{C}$, comentado no Capítulo I. Por causa do enriquecimento em ${ }^{13} \mathrm{C}$, a distância média entre os grupos ${ }^{13} \mathrm{COO}$ é diminuída e o acoplamento dipolar é aumentado, resultando em um processo de exchange de spin muito mais eficiente do que aquele para amostras não enriquecidas. 

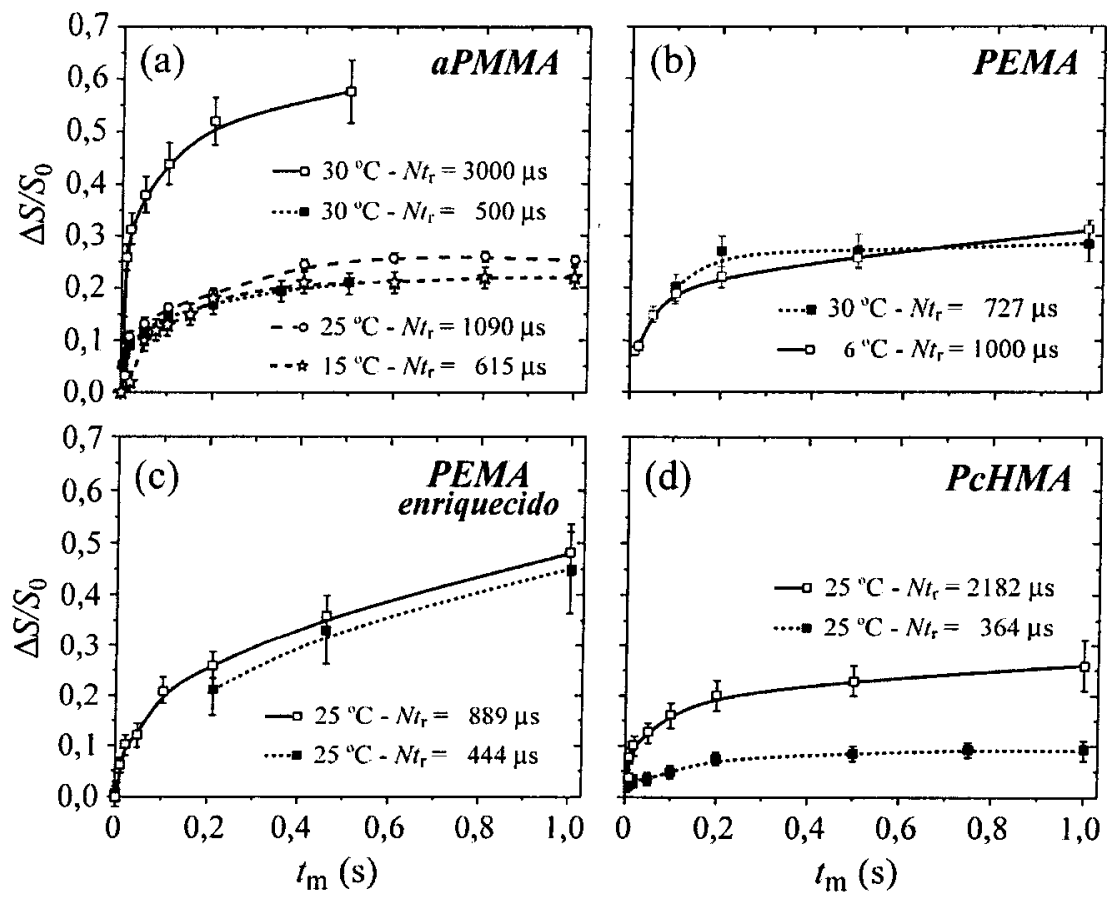

Figura 4.1: Funções de correlação dos movimentos lentos dos grupos laterais obtidos através das intensidades CODEX em função de $t_{\mathrm{m}}$ : dados para (a) PMMA; (b) PEMA; (c) PEMA enriquecido em ${ }^{13} \mathrm{COO}$ que apresenta uma curva até $100 \mathrm{~ms}$ idêntica ao do PEMA não enriquecido, mas após esse valor o efeito da difusão de spins dos ${ }^{13} \mathrm{C}$ resultam em um exchange adicional; (d) PcHMA. A função de correlação é do mesmo tipo que no PMMA e no PEMA, mostrando que o sinal é devido ao mesmo tipo de movimento nos três sistemas. Os dados provam que aproximadamente $10 \%$ dos grupos laterais do ciclohexil estão realizando o flip, apesar do seu grande tamanho. Nos polímeros não enriquecidos, os níveis de intensidade atingem um patamar para longos $t_{\mathrm{m}}$ 's, mostrando que a difusão de spins é pequena $(<5 \%)$ para $t_{\mathrm{m}}<1 \mathrm{~s}$.

Para o PcHMA, que tem a sua curva mostrada na Figura 4.1(d), o platô, ou a fração de grupos laterais que realizam o flip, é significativamente menor que aquela observada para o PMMA ou o PEMA. No entanto, o aumento claro da intensidade de exchange com $t_{\mathrm{m}}$ na curva da Fig. 4.1(d) até atingir um patamar para tempos longos mostra, sem ambigüidade, que aproximadamente $10 \%$ dos grandes grupos laterais ciclohexilester ainda realizam o flip na escala de tempo de $1 \mathrm{~s}$. Para garantir que somente o flip está sendo detectado, foram realizados experimentos com um tempo de reacoplamento $N t_{\mathrm{r}}$ curto, onde somente reorientações de grande amplitude podem produzir uma intensidade de exchange significativa. Tempos de mistura mais longos 
permitem que pares ${ }^{13} \mathrm{C}-{ }^{13} \mathrm{C}$ fracamente acoplados via interação dipolar também possam realizar a difusão de spins. Portanto, como a probabilidade de difusão de spins aumenta com $t_{\mathrm{m}}$, quando este efeito está sendo expressivo, a intensidade de exchange aumenta continuamente para altos valores do tempo de mistura. Considerando as curvas de exchange do PcHMA, a hipótese de que o aumento observado seja um efeito da difusão de spins é excluída., já que esse aumento contínuo da intensidade de exchange com $t_{\mathrm{m}}$ não é visto na Figura 4.1(c). A intensidade adicional para tempo longos, $N t_{\mathrm{r}}=2182 \mu \mathrm{s}$, é atribuída aos movimentos de pequena amplitude, como será observado nas curvas em função de $N t_{\mathrm{r}}$ - a Figura 1.13(b) já adiantou que para baixos valores de $N t_{\mathrm{r}}$ apenas as contribuições de movimentos de grande amplitude são selecionadas na curva de exchange, enquanto que as duas contribuições (de grande e pequena amplitude) aparecem para altos valores de $N t_{\mathrm{r}}$.

A variação da dependência da intensidade de exchange em função de $t_{\mathrm{m}}$ para diversos valores de $N t_{\mathrm{r}}$ na Figura 4.1 sugere que ocorram movimentos tanto de grande amplitude como de pequena amplitude dos grupos laterais. Isso é confirmado através das curvas da intensidade de exchange como função de $N t_{\mathrm{r}}$ para um $t_{\mathrm{m}}=500 \mathrm{~ms}$, sendo que apenas para a amostra de PEMA enriquecido foi utilizado $t_{\mathrm{m}}=100 \mathrm{~ms}$ para se evitar o exchange devido à difusão de spin. Os resultados obtidos para cada polímero, em ordem crescente do tamanho do grupo lateral, estão nas Figuras: 4.2(a) PMMA; 4.2(b) PEMA enriquecido; 4.2(c) PiBMA e 4.2(d) PcHMA, com suas respectivas fórmulas estruturais. 
Na Figura 4.2 também estão sobrepostas as simulações numéricas que mais se adequaram às curvas obtidas experimentalmente. As curvas simuladas são formadas pela contribuição de dois movimentos, o flip de $180^{\circ}$ e a rotação em torno da cadeia principal, Figura 4.3. Em um caso mais realista deveria ser considerado nas simulações uma distribuição de ângulos para a rotação de menor amplitude em torno do valor $\alpha$. No entanto, as curvas CODEX apresentadas não mostram nenhuma diferença significativa ao se considerar um único valor para $\alpha$ ou uma distribuição gaussiana de ângulos em torno de zero (com um valor $r m s$, $\sigma$, similar àquele utilizado para o ângulo simples $\alpha$ ), como será visto adiante. Dessa forma, a não ser pelo fato dela ser mais provável que a ocorrência de um ângulo simples, nenhum dado conclusivo quanto a existência dessa distribuição de ângulos pode ser obtida apenas através dos dados CODEX.

Na Figura 4.2 as simulações foram feitas com $\alpha=6^{\circ}$. Como observado no exemplo da Figura 1.13(b) as simulações são muito sensíveis à movimentos de pequenos ângulos. Assim, apesar de não se poder caracterizar a ocorrência de uma distribuição de ângulos ao de um ângulo simples, é extremamente perceptível a mudança que ocorre ao se considerar um ângulo simples, $\alpha$, de $5^{\circ}$ ou $7^{\circ}$ ao invés dos $6^{\circ}$ utilizados. A Figura 4.2(b) mostra como é a contribuição para o flip e para o twist, como descrito nos Capítulos I e III, considerando-se os movimentos representados na Figura 4.3. 

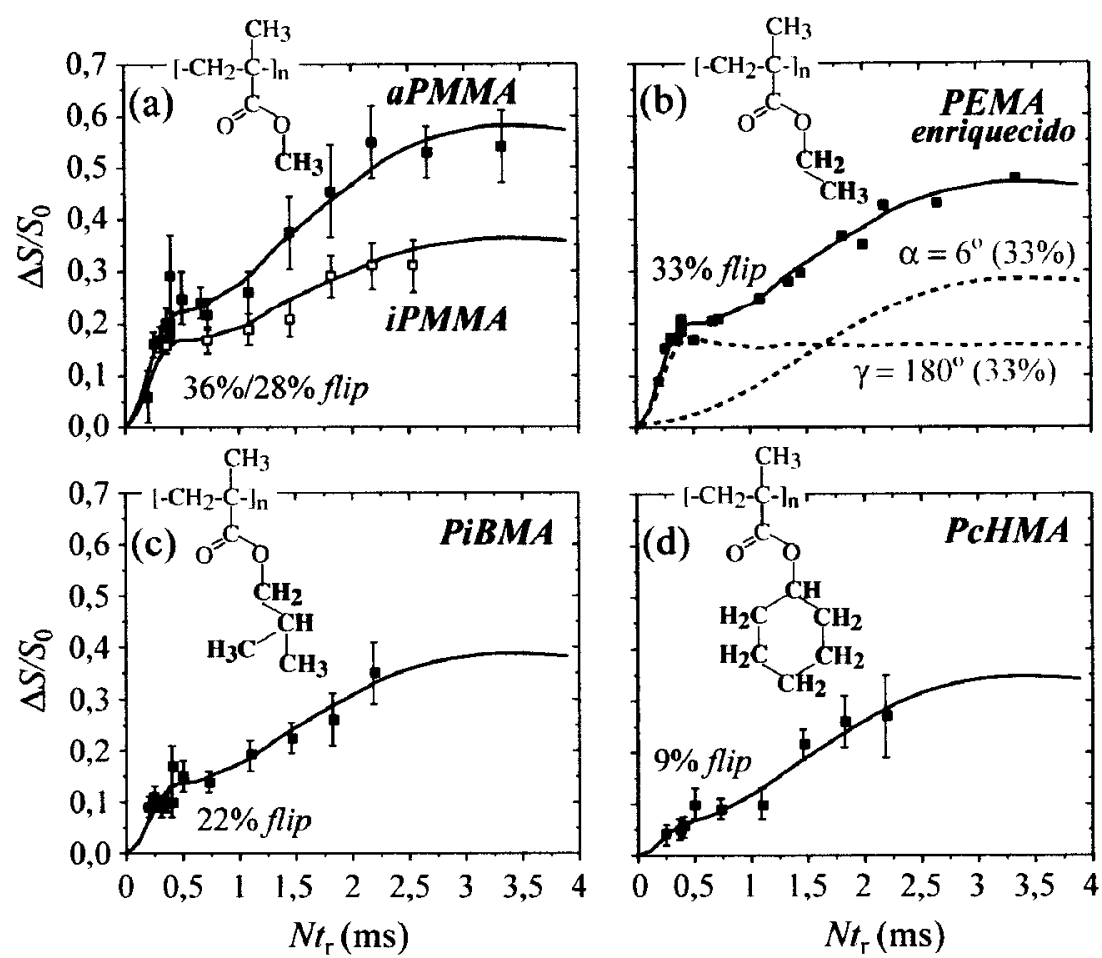

Figura 4.2: Curvas CODEX em função do tempo de reacoplamento $N t_{\mathrm{r}}$ para: (a) aPMMA e iPMMA, (b) PEMA enriquecido, (c) PiBMA e (d) PcHMA à $25^{\circ} \mathrm{C}$. As melhores simulações (linhas) estão sobrepostas aos dados experimentais. O tempo de mistura utilizado foi $500 \mathrm{~ms}$, exceto para o PEMA $\left(t_{\mathrm{m}}=100 \mathrm{~ms}\right)$. As curvas representam a somatória da contribuição de dois movimentos: oflip de $180^{\circ}$ do grupo lateral, que corresponde ao primeiro crescimento da curva, e a rotação de pequenos ângulos em torno da cadeia principal ( $t$ wist), que contribui para a intensidade em altos valores de $N t_{\mathrm{r}}$. Essas duas contribuições são exemplificadas em vermelho e azul, respectivamente, para o PEMA em (b). Todas as curvas foram obtidas dessa mesma maneira, resultando nas porcentagens de grupos laterais que estão realizando o flip indicadas.

A amplitude das reorientações durante $t_{\mathrm{m}}$ é determinada através da variação da duração $N t_{\mathrm{r}}$, que é o período de evolução sob a anisotropia do deslocamento químico reintroduzida. Quanto menor for o ângulo de reorientação, menor é o aumento na intensidade de exchange normalizada $\Delta S / S_{0} \operatorname{com} N t_{\mathrm{r}}$. A simulação para o movimento de twist representada na Figura 4.2(b) refere-se a uma rotação, com um pequeno ângulo $\alpha$, em torno do eixo da cadeia principal (local) que coincide com o eixo normal ao plano que contém o grupo lateral éster, Fig. 4.3. Como observado no Capítulo I e nas curvas simuladas adiante, é uma característica das técnicas CODEX 
(assim como PUREX em função de $2 \tau$ ) a boa resolução para pequenos ângulos de reorientação. As orientações do tensor de deslocamento químico utilizadas para as simulações foram sempre as do PMMA, extraídas da referência ${ }^{4}$. Por outro lado, o movimento de flip em torno da ligação $\mathrm{C}$-C, que conecta o grupo lateral à cadeia principal, leva a grandes mudanças de freqüência e um defasamento mais rápido, Figura 4.2(b). É interessante notar que, devido aos parâmetros tensoriais do PMMA, mudanças de freqüência idênticas ocorrem para rotações em torno da normal ao plano do grupo éster com $\alpha=54^{\circ}$, porque o eixo principal do tensor de deslocamento químico $\sigma_{11}$ faz um ângulo de $54^{\circ} / 2$ com a ligação C-C à cadeia principal.

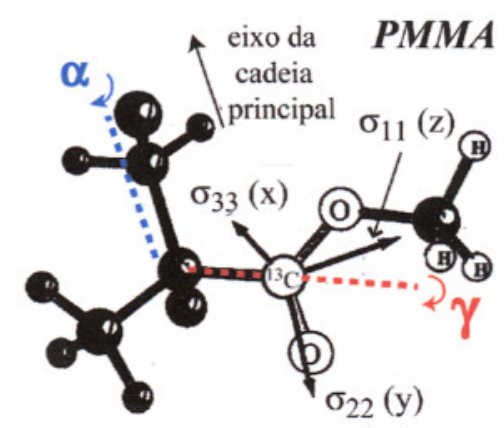

Figura 4.3: Os dois movimentos básicos do grupo lateral COO nos poli(metil metacrilato)s e poli(acrilato $\alpha$ substituído)s e seus eixos de rotação na unidade de repetição do PMMA como considerado nas simulações de exchange. Em vermelho estão indicadas as rotações em torno da ligação C-C que conecta o grupo lateral à cadeia principal e que dependem do ângulo $\gamma$. Em azul estão indicadas as rotações em torno do eixo da cadeia local, que são caracterizadas pelo ângulo $\alpha$.

Comparando-se as curvas para o PMMA atático (aPMMA) e o isotático (iPMMA), percebe-se que o segundo, por ser mais ordenado, apresenta uma porcentagem menor de elementos que realizam o flip. De uma maneira geral, considerando-se todos os PRMAs da Figura 4.2, a porcentagem de elementos que 
realizam o flip é reduzida significativamente com o aumento do tamanho da cadeia lateral à temperatura ambiente, indo de $33 \%$ no aPMMA até os $9 \%$ observado no PcHMA. A região com baixo valores para $N t_{\mathrm{r}}$ (entre 0 e $1 \mathrm{~ms}$ ) nas Figuras 4.2 está associada às medidas CODEX com maiores velocidades de rotação da amostra. Pode-se perceber que essa região inicial das curvas é importantíssima para se obter a informação sobre o flip da cadeia lateral. As medidas em frequiências de rotação mais altas foram realizadas em sondas de RMN CP/MAS com rotores de 4 ao invés de 7 $\mathrm{mm}$, onde as máximas freqüências de rotação foram da ordem de $10 \mathrm{kHz}$. Outro ponto importante das curvas da Figura 4.2 é que a intensidade do sinal CODEX diminui, na região de altos valores de $N t_{\mathrm{r}}$, com o aumento do grupo lateral. Esse efeito não está relacionado com a mudança para valores menores dos ângulos de twist nas simulações, como foi exemplificado no Capítulo I e será visto adiante. Em todas as curvas foi considerado o mesmo ângulo $\alpha=6^{\circ}$, no entanto, como discutido no Capítulo III, os movimentos de flip e de twist estão associados, Fig. 3.7. Assim, a diminuição da porcentagem de flip com o aumento do tamanho do grupo lateral também reduz a contribuição da pequena rotação com $\alpha=6^{\circ}$ para altos valores de $N t_{\mathrm{r}}$

A Figura 4.4 mostra a dependência das curvas CODEX em função de $N t_{r}$ do aPMMA, do PEMA e do PiBMA ao aumentar-se a temperatura. 


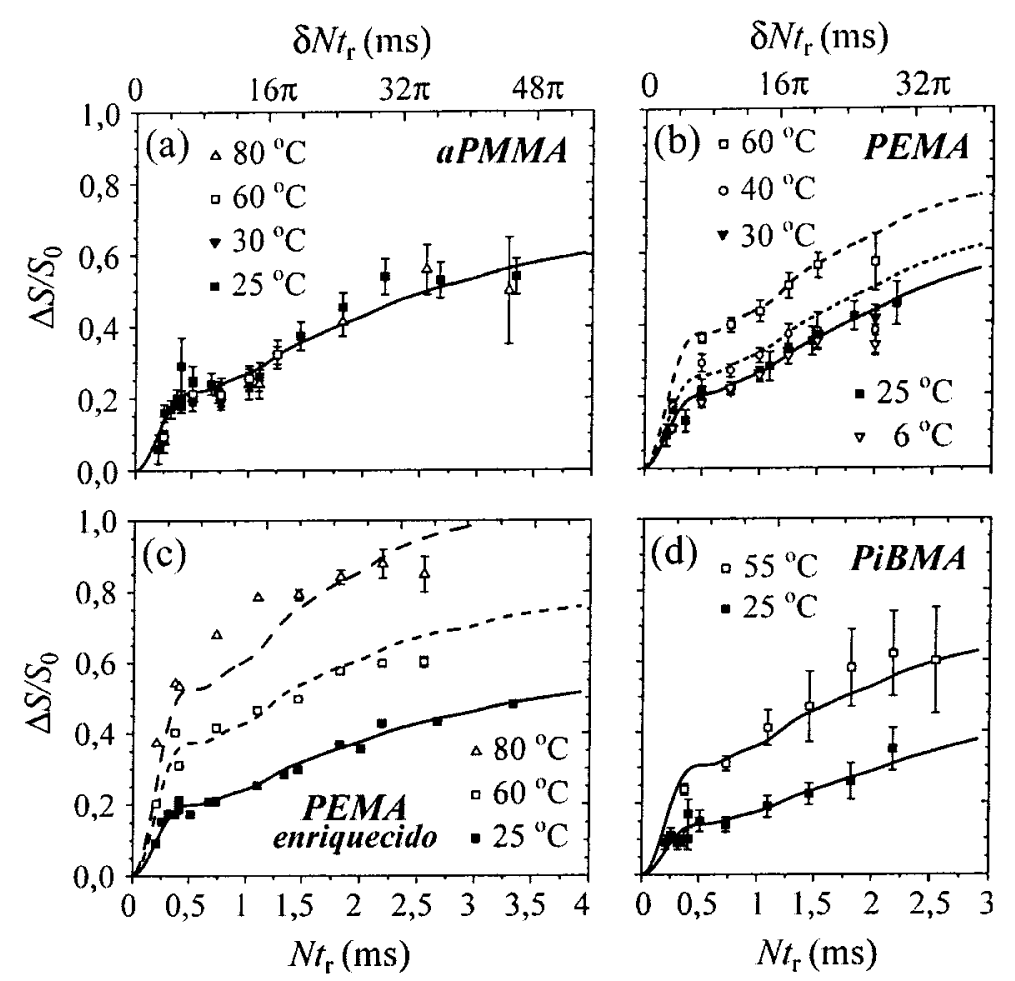

Figura 4.4: Dados experimentais CODEX mostrando a dependência da temperatura dos movimentos lentos, particularmente a fração de grupos laterais móveis para: (a) o PMMA, (b) o PEMA, (c) o PEMA enriquecido para o ${ }^{13} \mathrm{COO}$ e (d) PiBMA. O tempo de mistura utilizado foi sempre $500 \mathrm{~ms}$, exceto para o PEMA enriquecido $\left(t_{\mathrm{m}}=100 \mathrm{~ms}\right)$.

Os dados para o PMMA na Figura 4.4(a) não mostram nenhuma variação detectável em um intervalo de temperatura de $55^{\circ} \mathrm{C}$. Isso indica que a fração móvel não é apenas uma parte arbitrária em uma larga distribuição de tempos de correlação, mas que os grupos laterais imóveis do PMMA estão travados nas temperaturas abaixo da sua $T_{\mathrm{g}}\left(105^{\circ} \mathrm{C}\right.$ de acordo com a Tabela II, Capítulo III). Por outro lado, os dados para o PEMA, Fig. 4.4(b), mostram um aumento significativo na fração de grupos que realizam o flip acima de $25^{\circ} \mathrm{C}$ mas ainda abaixo da sua $T_{\mathrm{g}}\left(66^{\circ} \mathrm{C}\right)$, ou seja, no seu estado vítreo. Para confirmar esse aumento inesperado na fração de grupos laterais móveis, foi medida uma segunda amostra de PEMA, agora enriquecido, Fig. 4.4(c), que indica a mesma dependência da fração de flip com a temperatura. Para o PiBMA, os dados da Figura 4.4(d) mostram um aumento similar 
na fração de flip mas sugere também um aumento mais significativo a partir de temperaturas mais baixas. Portanto, a Figura 4.4, indica um contraste muito grande entre o comportamento da fração de flip do PMMA e dos outros PRMAs acima da temperatura ambiente.

Também foi observado o efeito do tamanho do grupo $\alpha$ no movimento do grupo lateral ligado ao carbonil através de três polímeros. A Figura 4.5 apresenta os dados experimentais da intensidade do sinal CODEX em função de $N t_{\mathrm{r}}$ e as respectivas simulações. Na Figura 4.5(a) é mostrada novamente a curva do aPMMA para comparação com os resultados obtidos para os PMaAs. A estrutura do PMEA mostra que o seu grupo $\alpha$ é um pouco maior do que o do PMMA mas, apesar disso, as curvas CODEX indicam que ocorre um pequeno aumento na porcentagem de grupos laterias que realizam o flip (36\% para 41\%), Fig.4.5(b). Para grupos $\alpha$ maiores (PDMI e PM[TMS]A) as porcentagens de flip diminuem para aproximadamente $20 \%$, como indicam as Figuras 4.5(c) e 4.5(e). Portanto, grupos $\alpha$ muito grandes acabam limitando o movimento do $\mathrm{COOCH}_{3}$, responsável pela relaxação $\beta$ nesses polímeros. Isso ocorre porque os grupos $\alpha$ fazem parte da circunvizinhança dos grupos laterais responsáveis pelo mecanismo de relaxação, podendo assim, restringir ou favorecer o seu movimento. Para o PMEA este movimento parece estar sendo ligeiramente favorecido, apesar de seu grupo $\alpha$ ser maior que o do PMMA, o que indica que o tamanho do grupo $\alpha$ pode influenciar de uma maneira complexa a sua vizinhança.

Aproveitando-se da similaridade entre os dois grupos laterais no PDMI, observou-se o movimento do seu grupo lateral $\alpha$. A Figura 4.5(d) mostra os dados CODEX em função $N t_{\mathrm{r}}$ para o carbonil do grupo $\alpha$ do PDMI. O resultado é idêntico 
ao observado para o $\mathrm{COO}$ relacionado à relaxação $\beta$, Figura $4.5(\mathrm{c})$. Como os dois grupos laterais estão realizando o mesmo tipo de movimento nesse polímero, isso acaba modificando ligeiramente o comportamento global envolvido na sua relaxação $\beta$, podendo diferir daquele descrito na Figura 3.7.
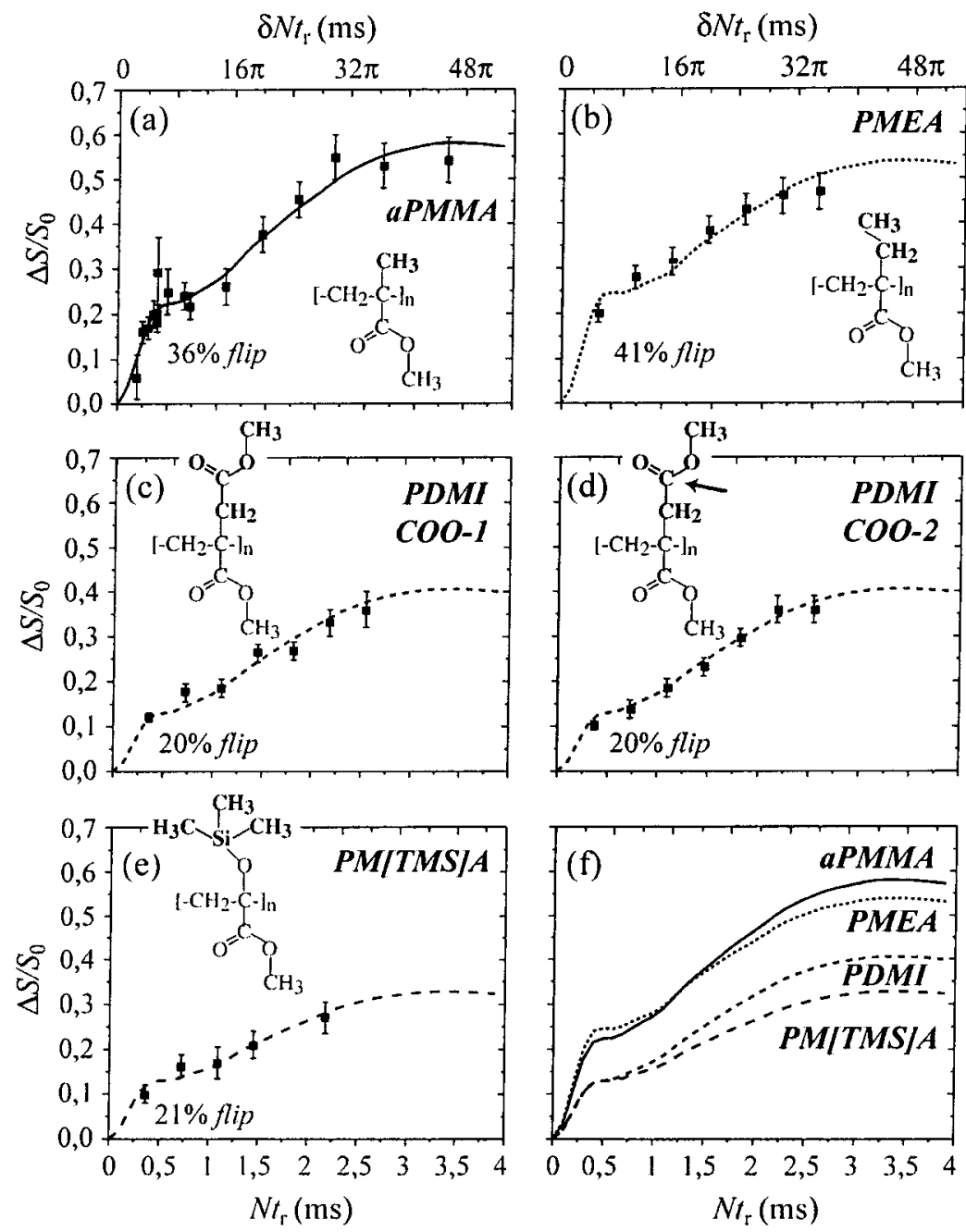

Figura 4.5: Curvas CODEX em função do tempo de reacoplamento $N t_{\mathrm{r}}$ para os poli(acrilatos $\alpha$-substituído)s: (a) aPMMA para comparação, (b) PMEA, (c) PDMI, (d) dados do COO do grupo $\alpha$ do PDMI e (e) PM[TMS]A. As simulações sobrepostas aos dados experimentais resultam na porcentagens de grupos laterais que estão realizando o flip como indicado. As condições experimentais utilizadas foram as mesmas que para os PRMAs. As curvas simuladas representam a somatória da contribuição dos dois movimentos discutidos acima como indicado na Figura 4.2(b). Em (f) é mostrada a superposição de todas as curvas simuladas. O grupo $\alpha$ de cada polimero está evidenciado nas fórmulas estruturais. $\mathrm{O}$ eixo $x$ superior está em unidades de $\delta N t_{\mathrm{r}}$ que será discutida posteriormente. 
Outro indício deste tipo diferenciado de influência do tamanho do grupo lateral $\alpha$ está nas porcentagens utilizadas para o twist de $6^{\circ}$ nas simulações da Figura 4.5. A Figura 4.5(f) mostra as quatro curvas simuladas em (a), (b), (c) =(d) e (e) superpostas. Nesta figura nota-se claramente (pela diminuição da altura da curva para altos valores de $N t_{\mathrm{r}}$ ) que a porcentagem do ângulo de twist teve que ser considerada menor que os $41 \%$ exigidos ao se considerar o modelo de movimentos acoplados descrito na Figura 3.7. Assim, enquanto que para o PMMA essa porcentagem acompanhou o flip (como realizado para todos os PRMAs na Figura 4.2), sendo $36 \%$, o PMEA ficou com uma porcentagem de apenas $30 \%$ para a contribuição do twist. Algo similar aconteceu para o PDMI e o PM[TMS]A. Os resultados CODEX destes dois polímeros exigem uma porcentagem similar para o movimento de flip, no entanto, a contribuição devido ao twist para o PDMI teve que ser $28 \%$ ao invés dos $20 \%$ exigidos pelo modelo. Já para o PM[TMS]A considerouse os $21 \%$ esperados. Concluindo, as restrições oferecidas ao movimento do COO, responsável pela relaxação $\beta$, devido ao grupo $\alpha$ fazem com que o seu movimento total possa, em alguns casos, não ser mais descrito pelos passos da Figura 3.7. Isso significa que o movimento do $\mathrm{COO}$, não está sendo influenciado apenas pelo aumento ou a diminuição do espaço entre as cadeias devido ao afastamento produzido pelos grupos laterais $\alpha$ o que, em princípio, não mudaria a forma do movimento. Como discutido no Capítulo III, quando o tamanho do grupo lateral aumenta as cadeias vizinhas são afastadas, apenas diminuindo os obstáculos aos movimentos da cadeia principal ou de outros grupos laterais. No caso dos PR $\alpha$ As, o movimento do COO deve estar relacionado não apenas aos mecanismos de relaxação que envolvem o próprio grupo lateral $\alpha$ e o espaço necessário para o seu movimento. 
Como exemplo, observa-se que os movimentos do grupo $\alpha$ no PMMA estão relacionados ao processo de relaxação $\gamma$, Fig. 3.4.

\subsubsection{Reavaliação dos Dados Obtidos para os PRMAs em Função de $N t_{\mathbf{r}}$}

Na Figura 4.2 foram mostradas as curvas CODEX em função de $N t_{\mathrm{r}}$, caracterizando o movimento dos grupos laterais nos poli(alquil metacrilato)s 10 relacionados com a relaxação $\beta$ nestes polímeros. Primeiramente, devido à excelência da técnica, foi possível avaliar melhor os resultados presentes na literatura que afirmavam que a relaxação $\beta$ no poli(metil metacrilato), PMMA, estava associada a uma rotação de $180^{\circ}$ (flip) do grupo lateral concomitantemente com uma rotação (de menor amplitude) em torno da cadeia principal (twist) - representados, respectivamente, pelos ângulos $\gamma$ e $\alpha$ na Figura 4.3. As simulações feitas para os dados CODEX corroboraram a afirmação de que estão ocorrendo esses dois movimentos e apresentaram, com grande precisão, que a pequena rotação em torno da cadeia principal é igual a um ângulo de $6^{\circ}$ para os PRMAs analisados. No entanto, esse modelo é muito simplista, sendo que o mais correto seria considerar-se distribuições para os ângulos de reorientação. Também foi a verificado que a porcentagem de elementos que realizam o flip é reduzida significativamente com o aumento da cadeia lateral destes polímeros.

Para complementar esse trabalho iniciou-se um estudo com a técnica PUREX nessas amostras que, em princípio, apresentavam uma incompatibilidade com os resultados observados pela técnica CODEX. Para efeito de comparação, a Figura 4.6(a) mostra o resultado obtido para a intensidade do sinal CODEX em função de $N t_{\mathrm{r}}$ para o PMMA, apresentado na Figura 4.2(a). A Figura 4.6(b) apresenta 
o resultado da intensidade do sinal PUREX para o PMMA em função de $2 \tau$, que é a curva (equivalentemente à de $N t_{\mathrm{r}}$ no experimento CODEX) que traz as informações sobre a geometria dos movimentos moleculares lentos.

As figuras apresentam também a simulação simplificada, como aquela mostrada na Figura 4.2(a), que considera apenas um valor discreto para o pequeno ângulo de rotação da cadeia principal $\left(\alpha=6^{\circ}\right)$ além do movimento de flip do grupo lateral. Junto com os resultados experimentais estão sendo mostradas as simulações para o flip do grupo lateral (ângulo $\gamma$ ) e para o twist da cadeia principal (ângulo $\alpha$ ). A soma destas duas contribuições, considerando-se que apenas $36 \%$ dos grupos laterais participam destes movimentos, se ajusta perfeitamente na curva CODEX, Fig. 4.6(a). No entanto, percebe-se claramente na Figura 4.6(b) que a curva PUREX não pode ser reproduzida com uma simulação que utiliza os mesmos parâmetros obtidos através do ajuste feito para a curva CODEX como descrito acima.

(a)

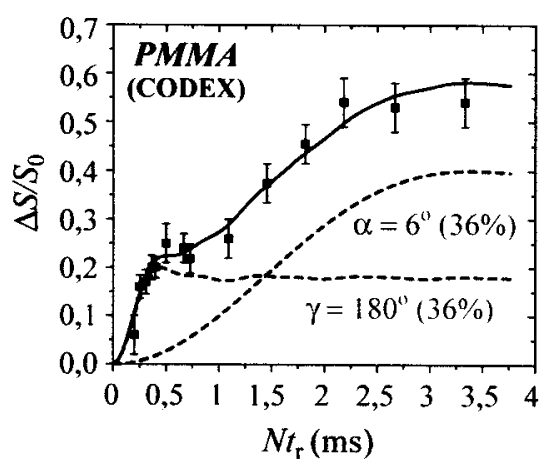

(b)

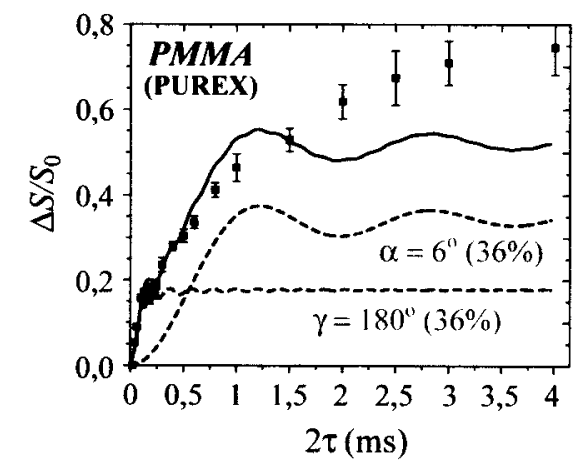

Figura 4.6: Simulações totais e suas duas componentes para curvas experimentais (a) CODEX em função de $N t_{\mathrm{r}}$ e (b) PUREX em função de $2 \tau$ para o PMMA - considerando-se apenas um ângulo de flip do grupo lateral $\left(\gamma=180^{\circ}\right)$ e um valor discreto para o ângulo de twist da cadeia principal $\left(\alpha=6^{\circ}\right)$. A porcentagem considerada de grupos laterais que realizam os dois movimentos é de $36 \%$. As simulações foram baseadas nos resultados obtidos pela técnica CODEX. Ao se aplicar os mesmos valores para a simulação PUREX esta não se ajusta aos dados experimentais obtidos. 
Como as medidas CODEX e PUREX foram feitas em equipamentos com campos magnéticos estáticos distintos (respectivamente $300 \mathrm{MHz}$ e $400 \mathrm{MHz}$ ) serão feitas algumas considerações sobre como tirar essa dependência das curvas observadas com $B_{0}$. As simulações são realizadas levando-se em consideração as respectivas freqüências do ${ }^{13} \mathrm{C}$ em cada equipamento utilizado $(75,5 \mathrm{MHz}$ e $100,5 \mathrm{MHz}$ ). Isso mostra que essa não é a causa da aparente incoerência entre os resultados dos experimentos CODEX e PUREX. Uma maneira simples de se eliminar a dependência com $B_{0}$ pode ser obtida multiplicando-se os eixos $x\left(N t_{\mathrm{r}}\right.$ ou $2 \tau$ ) por $2 \pi \delta$, onde $\delta$ é o parâmetro de anisotropia em ppm do núcleo ${ }^{13} \mathrm{C}$ da ligação COO. Neste caso, as curvas se tornam independentes da freqüência de ressonância do ${ }^{13} \mathrm{C}$, i.e., nessa nova forma a dependência do sinal CODEX ou PUREX tem que ser a mesma para qualquer campo $B_{0}$ considerado. Para ilustrar isso a Figura 4.7 mostra algumas simulações feitas para curvas CODEX em função de $N \mathrm{t}_{\mathbf{r}}$ (Fig. 4.7(a) e (c)) e $\delta N t_{\mathrm{r}}$ (Fig. 4.7(b) e (d) ) para as duas freqüências consideradas: 75,5 MHz (Fig. 4.7(a) e (b)) e 100,5 MHz (Fig. 4.7(b) e(d)). As curvas têm comportamentos diferentes para valores de $B_{0}$ distintos quando estas estão em função de $N t_{\mathrm{r}}$ como mostram as Figuras $4.7(\mathrm{a})$ e (c). Por outro lado, as simulações apresentam-se com o mesmo comportamento em função de $\delta N t_{\mathrm{r}}$, como aparece em 4.7(b) e (d). A mesma análise pode ser feita na Figura 4.8 que mostra algumas simulações feitas para curvas PUREX, em função de $2 \tau$ e $\delta 2 \tau$. 


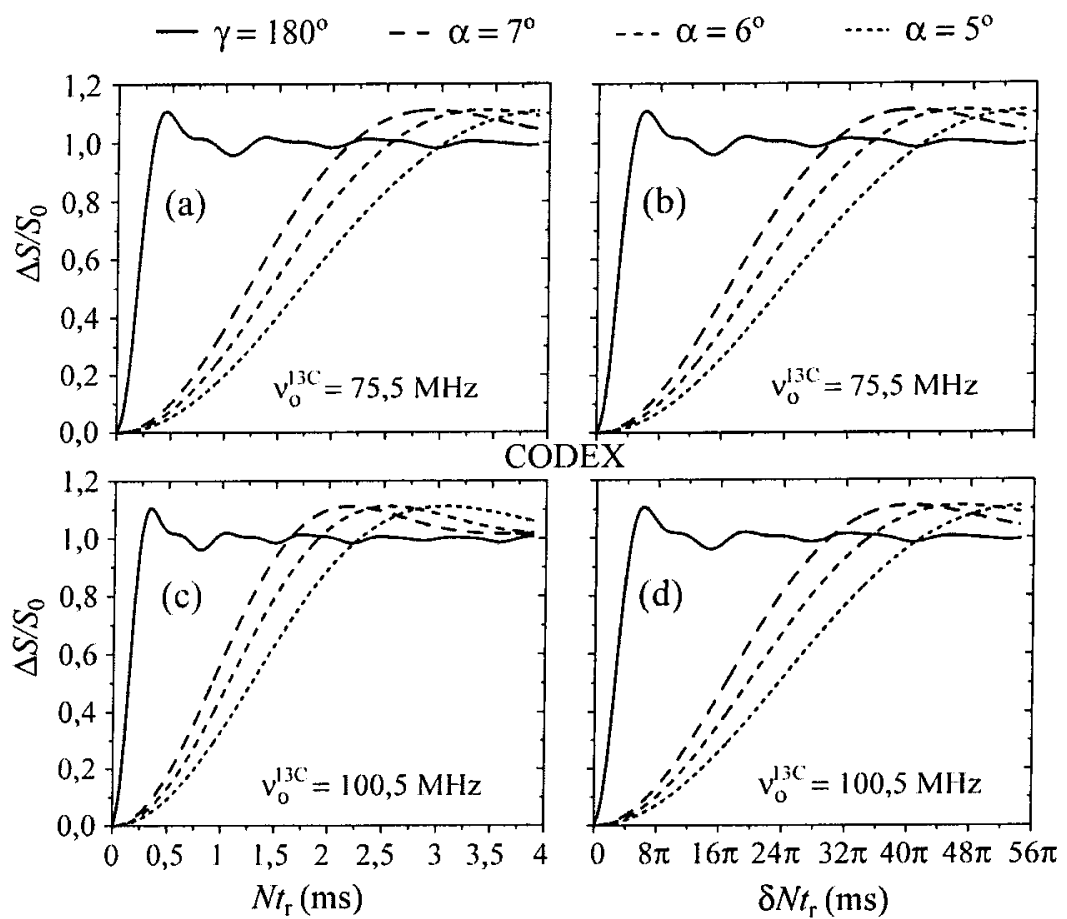

Figura 4.7: Simulações para a intensidade do sinal CODEX em função de $N t_{\mathrm{r}}$ e $\delta N t_{\mathrm{r}}$ para o PMMA para um ângulo de flip do grupo lateral igual a $180^{\circ}$ e para três ângulos de twist da cadeia principal $\left(\alpha=5^{\circ}, 6^{\circ}, 7^{\circ}\right)$. As simulações foram feitas para se estudar resultados obtidos tanto em um espectrômetro de $300 \mathrm{MHz}$ : (a) e (b), como em um de 400MHz: (c) e (d). Enquanto que as curvas são ligeiramente diferentes considerando-se dois campos $B_{\mathrm{o}}$ distintos quando estas estão em função de $N t_{\mathrm{r}}$ como em (a) e (c), observa-se que as simulações apresentam-se com o mesmo comportamento em função de $\delta N t_{\mathbf{r}}$.

O passo seguinte na identificação do problema da incompatibilidade dos resultados obtidos pelas duas técnicas seria a tentativa de modificar os valores para os ângulos propostos ou suas porcentagens. Uma análise mais acurada na Figura 4.6 mostra que a porcentagem, pelo menos no que se refere à contribuição devida ao ângulo de flip, não pode ser muito diferente da obtida (para o PMMA, 36\%) posto que o pequeno "ombro" que aparece em baixos valores de $N t_{\mathrm{r}}$ é exclusivamente devido a esse movimento, enquanto que o ângulo de twist é mais efetivo para altos valores de $N t_{\mathrm{r}}$. A solução poderia ser utilizar outro valor para o ângulo de flip ao invés de $180^{\circ}$. Mas diversas simulações realizadas mostraram que ambas as técnicas não são muito sensíveis à mudança deste parâmetro que pode variar em até $50^{\circ}$ sem 
mudanças significativas nas curvas.

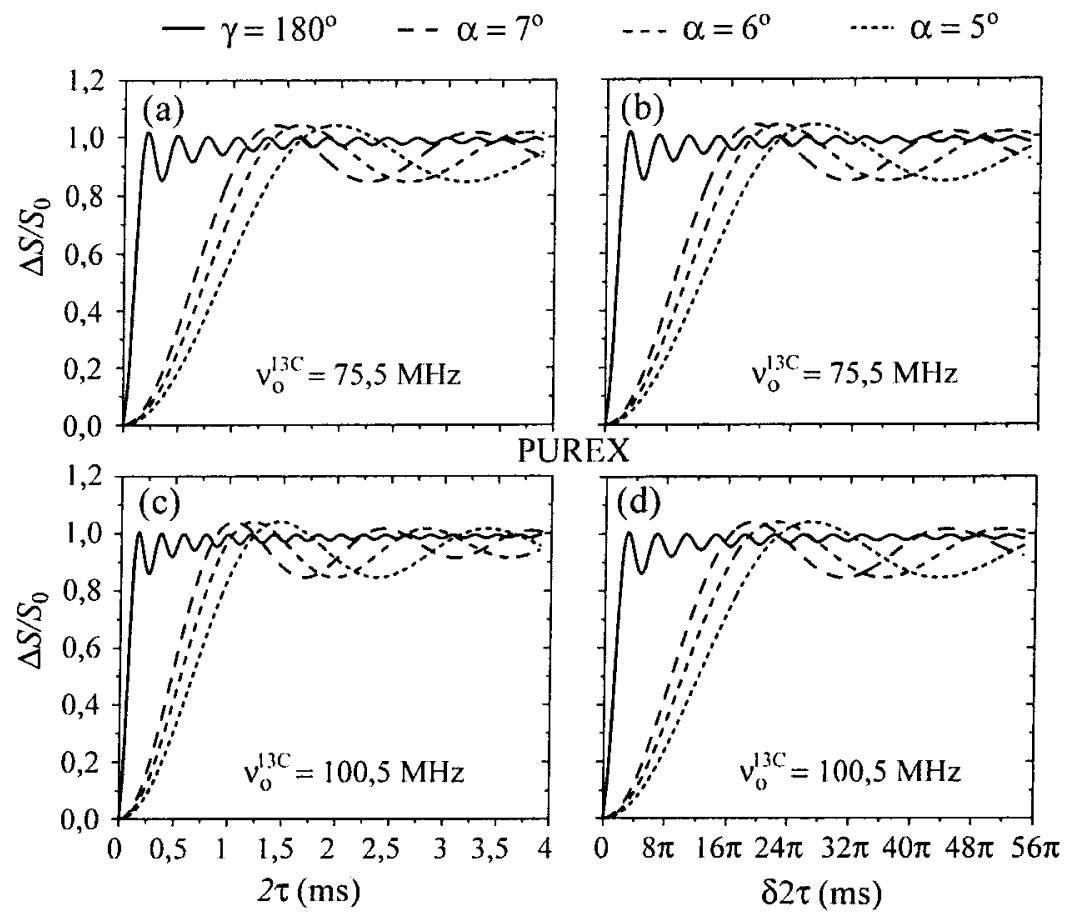

Figura 4.8: Simulações para a intensidade do sinal PUREX em função de $2 \tau$ e $\delta 2 \tau$ para o PMMA para um ângulo de flip do grupo lateral igual a $180^{\circ}$ e para três ângulos de twist da cadeia principal $\left(\alpha=5^{\circ}, 6^{\circ}, 7^{\circ}\right)$. As simulações foram feitas para se estudar resultados obtidos tanto em um espectrômetro de $300 \mathrm{MHz}$, (a) e (b), como em um de 400MHz: (c) e (d). Enquanto que as curvas são ligeiramente diferentes considerando-se dois campos $B_{0}$ distintos quando estas estão em função de $2 \tau$ como em (a) e (c), observa-se que as simulações apresentam-se com o mesmo comportamento em função de $\delta 2 \tau$.

Em contraposição, ambas as técnicas são muito sensíveis ao ângulo de twist, principalmente no que se refere àqueles com amplitudes não muito altas (ângulos pequenos), como podemos observar na diferença entre as curvas para $\alpha=5^{\circ}, 6^{\circ}, 7^{\circ}$ nas Figuras 4.7 e 4.8. Isso significa que uma mudança no valor de $\alpha$ só faz com que a simulação se afaste cada vez mais do que foi observado experimentalmente. Assim, tem-se que a porcentagem dos grupos laterais que realizam o movimento de flip não pode mudar muito e, conseqüentemente o mesmo também é válido para a quantidade de indivíduos que realizam o movimento de twist da cadeia principal, a qual, pela teoria já desenvolvida a respeito destes movimentos, deveria ser sempre relacionada 
ao primeiro. Juntamente com isso, os valores dos ângulos de twist e de flip não podem mudar muito para manter a coerência entre a simulação e o dados experimentais dos resultados CODEX para o PMMA.

Fica claro pela Figura 4.6(b) que está faltando uma contribuição para altos valores de $2 \tau$ de forma que a simulação PUREX reproduza os resultados experimentais. O tipo de movimento que poderia suprir essa deficiência seria justamente twist's para ângulos pequenos $\left(\alpha<5^{\circ}\right)$, como pode ser depreendido das curvas da Figura 4.8, que deveriam ser adicionados às simulações originais sem estarem necessariamente acoplados ao flip. Além disso, a Figura 4.6(b) mostra que a oscilação presente nas simulações PUREX para o movimento de twist tem grande responsabilidade na incompatibilidade entre simulação e dados experimentais observada. Para eliminar esse efeito é bom lembrar que na referência ${ }^{4}$ os autores revelam que uma distribuição gaussiana dos ângulos de flip em torno de $180^{\circ}$ com uma largura a meia altura de $20^{\circ}$ é uma proposta mais realista no que diz respeito à compostos como o PMMA. Pelas discussões acima sobre os ângulos de flip sabe-se que neste caso a presença ou não dessa distribuição não faz muita diferença. Por outro lado, como as variações nos ângulos de twist são altamente perceptíveis, as oscilações presentes devido a este movimento em torno da cadeia principal poderiam ficar mais suaves utilizando-se uma distribuição gaussiana em torno de $\left(\alpha=6^{\circ}\right)$ ao invés de apenas um valor discreto. Isso pode ser facilmente percebido ao se imaginar como seria a soma das simulações para os três distintos ângulos de twist da Figura 4.8: os vales e morros se tornariam cada vez mais suaves a medida que mais e mais ângulos distintos são somados. 
A discussão até agora mostrou que muitas vezes os dados podem ser simulados com um modelo simples, mas nem sempre a simplicidade condiz com o que está acontecendo, exigindo uma interpretação mais realista do que os experimentos CODEX e PUREX devem conseguir observar.

Os movimentos do grupo lateral (e da cadeia principal) relacionados com a relaxação $\beta$, baseados nos estudos de Spiess e colaboradores ${ }^{4}$ descritos pela Figura 3.8, são separados em três diferentes processos que podem ser observáveis por RMN, como mostra a Figura 4.9.

(a)

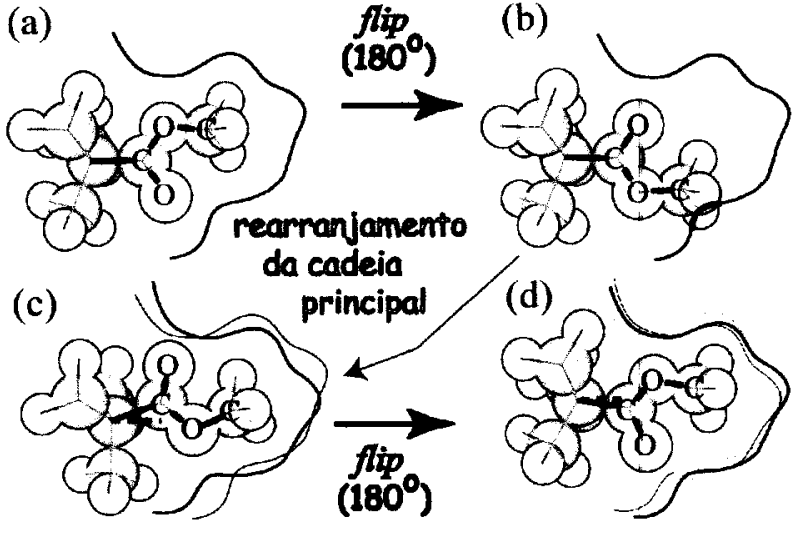

1 flip + twist $\left(\sigma_{\mathrm{a}}\right)$

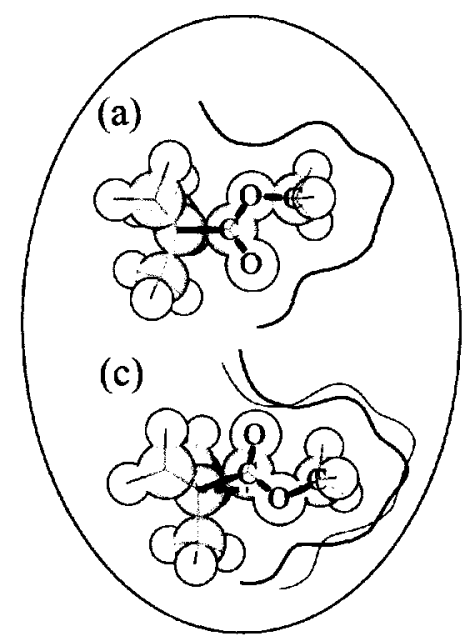

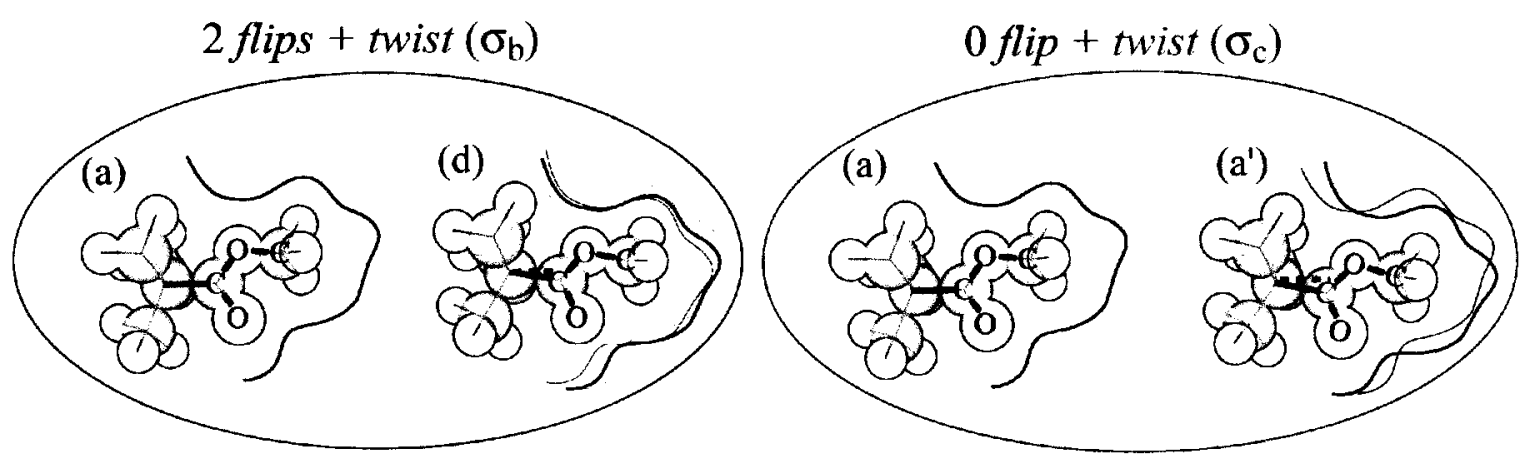

Figura 4.9: Os três diferentes processos que podem ser observáveis por RMN do ${ }^{13} \mathrm{COO}$, considerando-se os movimentos relacionados com a relaxação $\beta$ investigados por Spiess e colaboradores em $1994^{4}$. Os processos (flips e twists) que só são observados por RMN de maneira indireta estão escritos em preto, enquanto que os outros são diretamente observados. 
Não há como se observar a passagem de (a) para (b), posto que o processo (a) $\rightarrow$ (b) $\rightarrow$ (c) ocorre conjuntamente, isto é, o passo (b) apenas é mostrado para facilitar o entendimento do que está ocorrendo. Dessa forma, o primeiro processo é a passagem 1, da conformação (a) para a (c), na qual ocorre apenas 1 flip - ou um número ímpar de flips - e mais um twist com uma distribuição gaussiana de largura $\sigma_{a}$, que ocorre devido a reacomodação do grupo lateral no espaço deixado por ele antes do movimento. Apesar deste processo envolver um flip e um twist, quando analisa-se a situação antes e depois destes dois movimentos, que são acoplados, observa-se um efeito no sinal de exchange que é idêntico àquele observado considerando-se o movimento de flip apenas. Isso pode ser entendido pelo fato de que a mudança de (a) para (c) continua sendo uma mudança de grande amplitude, similar ao flip. Assim, para efeito do experimento de RMN e para as simulações, que consideram apenas a orientação relativa do SEP e do SM antes e depois do movimento como visto no Capítulo III, o resultado verificado é o mesmo. Isso significa que monitorando-se apenas o grupo lateral COO não se pode afirmar que o twist $\sigma_{\mathrm{a}}$ está ocorrendo ou não.

O segundo processo é a passagem 2 , da conformação (a) para a (d), na qual ocorrem 2 flips - ou um número par de flips - e mais um twist com uma distribuição gaussiana de largura $\sigma_{\mathrm{b}}$, que ocorre devido à ligeira mudança no posicionamento das cadeias vizinhas devido ao movimento do grupo lateral. Neste caso, o experimento de exchange apenas consegue perceber o twist $\sigma_{\mathrm{b}}$ já que ao realizar um número par de flips o grupo lateral volta à posição original. Aqui é interessante lembrar que se não estivesse ocorrendo o twist $\sigma_{b}$ esse movimento de 2 flips não poderia ser 
percebido - indiretamente, através do twist - pela técnica de exchange. Em outras palavras, a intensidade da curva de exchange normalizada, $\mathrm{S} / \mathrm{S}_{0}$, para os grupos $\mathrm{COO}$ que realizam o movimento de flip é igual à metade da porcentagem de grupos que realmente realizam este processo. A outra metade não contribui para o sinal de exchange posto que esta é a metade que realiza números pares de flips, como discutido para o caso de $\mathrm{N}=2$ sítios acessíveis em um movimento molecular no Capítulo I. Neste caso, a metade que está realizando números pares de flips não contribui para a intensidade de exchange na região de baixos tempos de evolução (região de contribuição típica do flip), mas o movimento de twist $\sigma_{b}$ é uma componente claramente observável nas curvas experimentais como será visto adiante.

O terceiro processo é a passagem 3 , da conformação (a) para a (a'), na qual não ocorre nenhum flip do grupo lateral mas apenas um twist com uma distribuição gaussiana de largura $\sigma_{\mathrm{c}}$, que pode ser explicado pelo movimento natural das cadeias vizinhas durante todo o processo de movimento molecular.

Na Figura 4.9, os processos (flips e twists) que só são observados por RMN de exchange de maneira indireta estão escritos em preto, enquanto que os outros são diretamente observados. Uma forma de se observar se movimentos relacionados à cadeia principal estão realmente ocorrendo, como o twist $\sigma_{\mathrm{a}}$ do processo 1 , é monitorar o sinal de exchange do carbono quaternário e do carbono do grupo $\mathrm{CH}_{2}$ da própria cadeia principal dos PRMAs. 
Neste caso, deveriam ser observados os processos descritos na Figura 4.10. As passagens 2 e 3, que são os processos de (a) para (d) e de (a) para (a'), se manifestam da mesma maneira que aquelas observadas para o caso do monitoramento do grupo COO descrito na Figura 4.9: apenas os twists continuam sendo observados, posto que os carbonos da cadeia principal, neste caso, também se movem. A mudança aparece no monitoramento da passagem 1, de (a) para (c). Neste caso o flip não pode mais ser observado pois este é um movimento estritamente relacionado ao grupo lateral. No entanto, com a insensibilidade dos carbonos da cadeia principal para a ocorrência do flip, este não "mascara" o twist $\sigma_{\mathrm{a}}$, que agora pode ser observado.

Além disso, como não existe contribuição para a intensidade de exchange para baixos tempos de evolução devido ao flip, é possível se observar a ocorrência da difusão de spins entre os carbonos do grupo $\mathrm{CH}_{2}$ e $\mathrm{COO}$, que devem ter uma pequena contribuição. Em outras palavras, com a difusão de spins entre estes dois sítios mudam-se os valores principais do tensor e trocam-se os respectivos sistemas de eixos principais, e o resultado final é como se estivesse ocorrendo um movimento de grande amplitude (com efeitos similares ao flip nas curvas de exchange). 

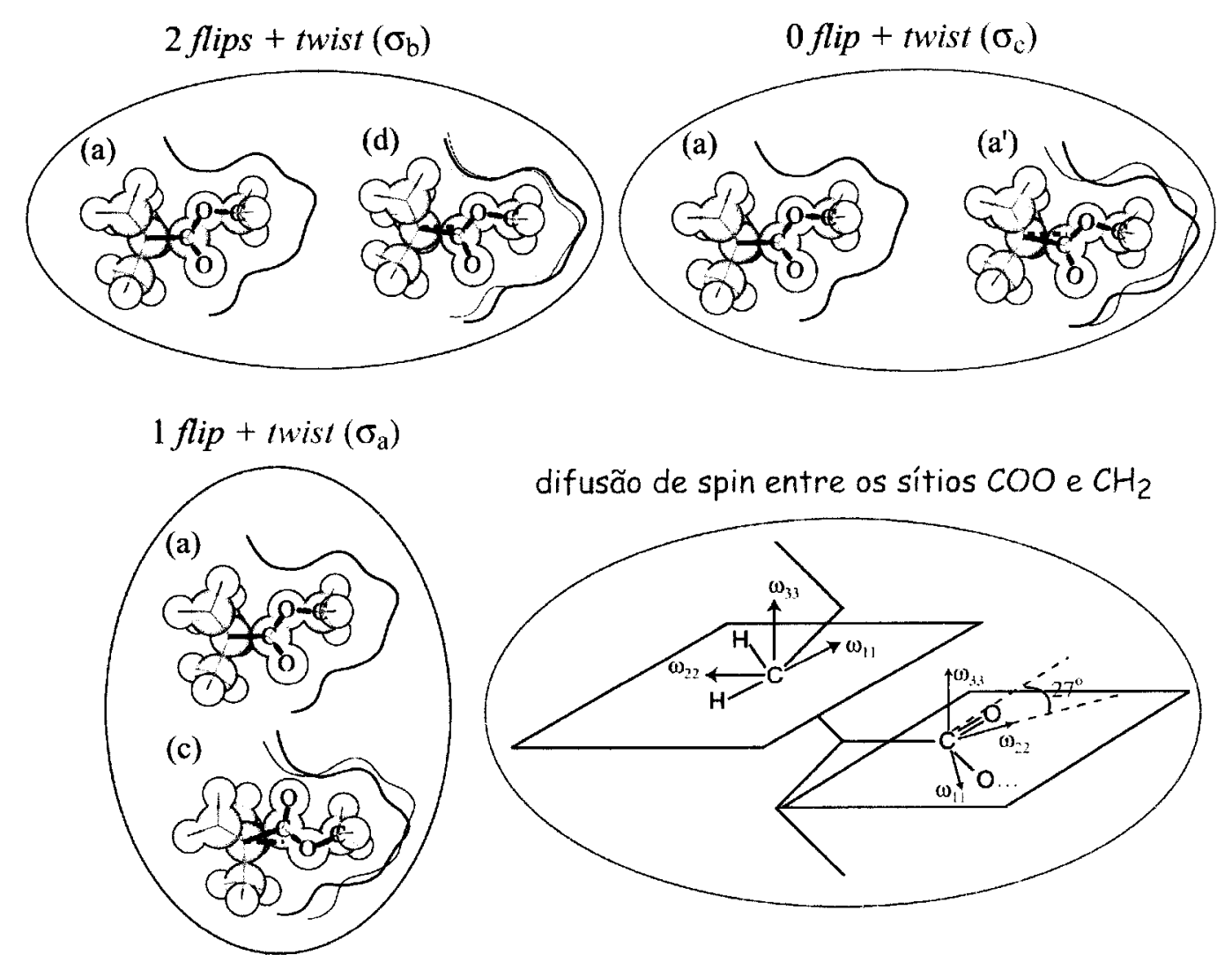

Figura 4.10: Os quatro diferentes processos que podem ser observáveis por RMN dos carbonos da cadeia principal do PRMAs, considerando-se os movimentos relacionados com a relaxação $\beta$ investigados por Spiess e colaboradores em 19944. Os processos (flips e twists) que só são observados por RMN de maneira indireta estão escritos em preto, enquanto que os outros são diretamente observados.

A Figura 4.11(a) mostra a curva experimental PUREX para o PMMA $\left({ }^{13} \mathrm{COO}\right)$ com a sua simulação e respectivas componentes, de acordo com as discussões da Figura 4.9. A Figura 4.11(b) mostra as distribuições de ângulos de twist individuais utilizadas e, em preto, a distribuição total de ângulos. Para se observar os carbonos da cadeia principal utilizou-se a técnica CODEX que permite uma melhor distinção entre linhas espectrais superpostas, como é o caso das linhas do espectro do PMMA excluindo-se o pico referente ao grupo COO. A Figura 4.11(c) mostra as curvas experimentais CODEX para o PMMA $\left({ }^{13} \mathrm{C}\right.$ quaternário e $\left.{ }^{13} \mathrm{CH}_{2}\right)$, com a sua simulação e respectivas componentes, de acordo com as discussões da Figura 4.10. A Figura 4.11(d) mostra as distribuições de ângulos de twist individuais e, em preto, a 
distribuição total de ângulos. As porcentagens e os valores para a raiz quadrática média das distribuições gaussianas, $\sigma$, estão indicadas na própria figura. Apesar dos dados referentes aos carbonos da cadeia principal serem um pouco ruidosos, as simulações destes permitem que se avalie melhor as suposições para a distribuição de componentes do movimento molecular dadas nas Figuras 4.9 e 4.10 .

(a) PMMA(PUREX)

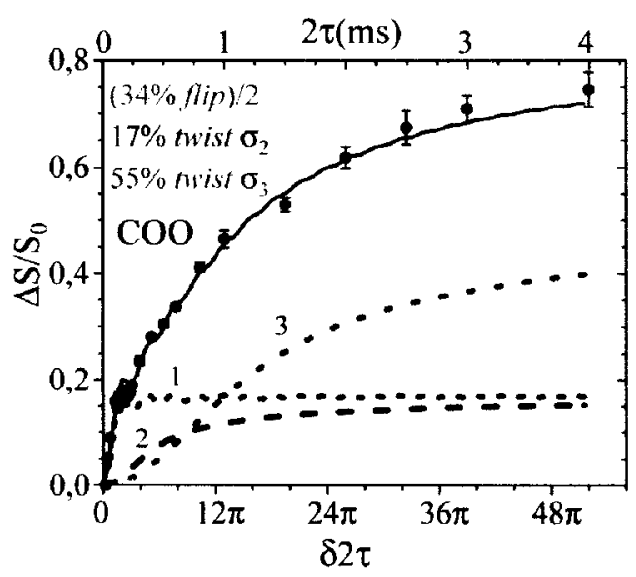

(c) PMMA(CODEX)

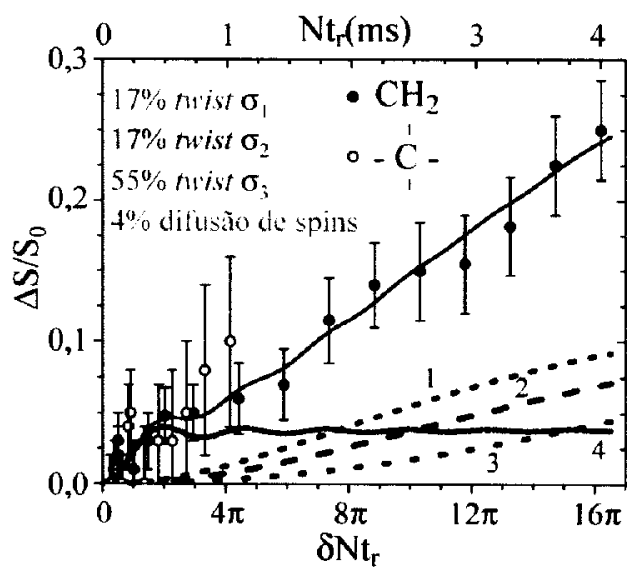

(b)

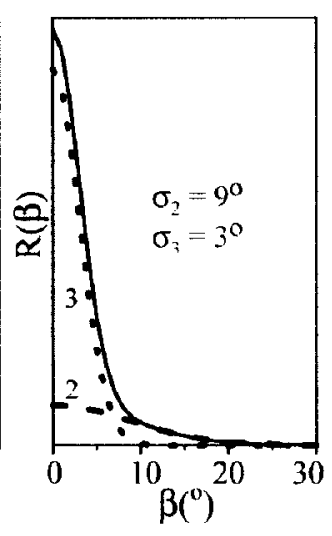

(d)

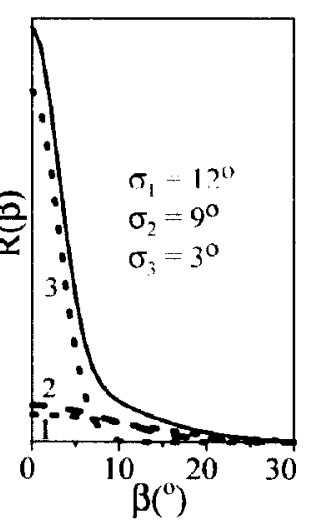

Figura 4.11: Curvas experimentais (a) PUREX $\left({ }^{13} \mathrm{COO}\right)$ e (c) $\operatorname{CODEX}\left({ }^{13} \mathrm{C}\right.$ quaternário e $\left.{ }^{13} \mathrm{CH}_{2}\right)$ em função dos respectivos tempos de evolução e curvas simuladas. Cada componente considerada nas simulações, como descrito no texto e nas Figuras 4.9 e 4.10, também são mostradas em (a) e (c) com as respectivas distribuições para os ângulos de twist em (b) e (d). As curvas pretas são a soma de todas as contribuições.

Para verificar que o problema da incompatibilidade entre as simulações dos dados CODEX e PUREX do COO (Fig. 4.6) não mais ocorre, a Figura 4.12 mostra a 
curva experimental CODEX $\left({ }^{13} \mathrm{COO}\right)$ para o PMMA e a respectiva simulação que leva em consideração as mesmas componentes utilizadas para simular os dados PUREX ( $\left.{ }^{13} \mathrm{COO}\right)$, Fig. 4.11(a) e (b). As Figuras 4.11(a) e 4.12 mostram que, considerando-se as componentes do movimento molecular adequadamente, não existe mais a incompatibilidade observada na Figura 4.6.

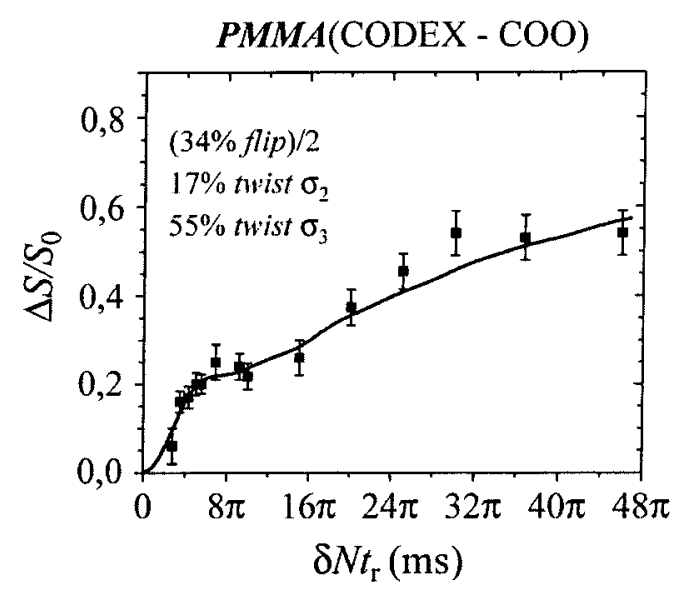

Figura 4.12: Curva experimental $\operatorname{CODEX}\left({ }^{13} \mathrm{COO}\right)$ e simulação que contém as mesmas componentes utilizadas para o caso PUREX da Figura 4.11(a) e (b). Neste caso, as simulações ajustam tanto os dados PUREX como CODEX, considerando as mesmas componentes do movimento.

Com essas novas distribuições as porcentagens de flip mudaram ligeiramente daquelas previamente obtidas pelas simulações da Figura 4.2, passando, no caso do PMMA, de 36\% para 34\%. Apesar da pequena mudança, os valores obtidos pelas simulações utilizadas na Figura 4.11 devem ser considerados como os mais acurados. Primeiramente, porque uma distribuição para o ângulo de twist, ao invés de um único valor discreto, é um comportamento esperado para estes sistemas $^{4}$. Em segundo lugar (e de maneira incontestável), porque apenas através dessas novas considerações é que os dados PUREX e CODEX concordam entre si.

Experimentos adicionais nas amostras PEMA, PiBMA e PcHMA mostram que o mesmo comportamento ocorre com elas, i.e., para ocorrer o acoplamento entre

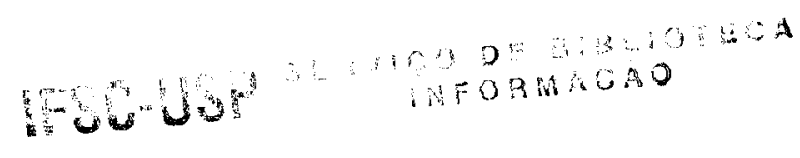


os resultados PUREX e CODEX as simulações devem ser feitas de forma análoga a representada na Figura 4.11 (a) e (b). A Figura 4.13 mostra os dados experimentais e as curvas simuladas com base neste procedimento para o PEMA - (a) e (b), o PiBMA - (c) (d) - e o PcHMA - (e) e (f), para dados PUREX $\left({ }^{13} \mathrm{COO}\right)$ e $\operatorname{CODEX}\left({ }^{13} \mathrm{C}\right.$ quaternário $\mathrm{e}^{13} \mathrm{CH}_{2}$ ), respectivamente. As simulações têm porcentagens e amplitudes ligeiramente diferentes daquelas encontradas para o PMMA, como mostra a Tabela III.

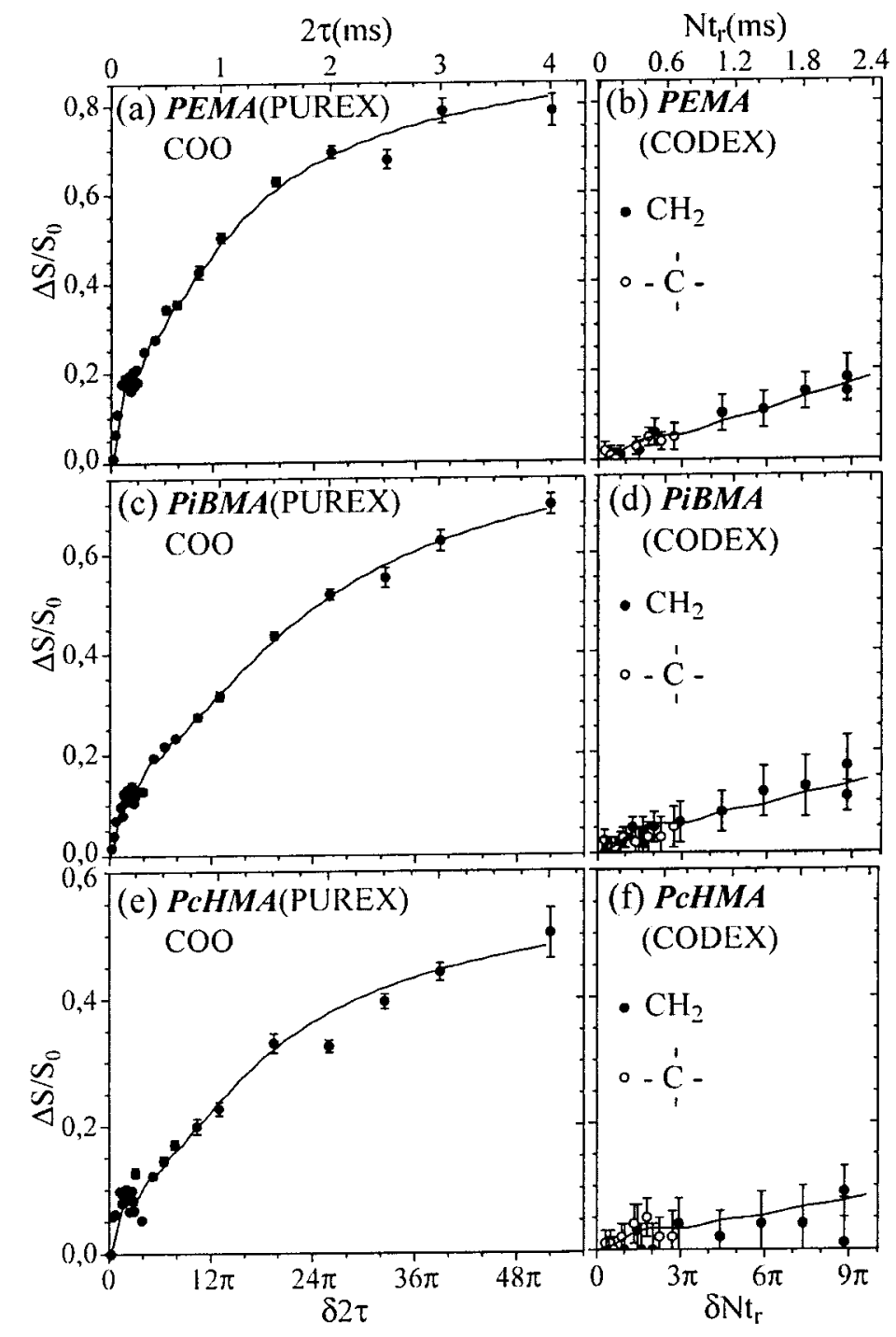

Figura 4.13: Curvas experimentais PUREX $\left({ }^{13} \mathrm{COO}\right)$ : (a), (c), (e) e (c); e CODEX $\left({ }^{13} \mathrm{C}\right.$ quaternário $\left.{ }^{13} \mathrm{CH}_{2}\right)$ : (b), (d) e (f) em função dos respectivos tempos de evolução e curvas simuladas, respectivamente para o PEMA, o PiBMA e o PcHMA. As simulações foram feitas com as mesmas componentes descritas para o PMMA na Figura 4.11, apenas com porcentagens e amplitudes ligeiramente diferentes (ver Tabela III). 
A Tabela III mostra a caracterização definitiva da amplitude e das porcentagens envolvidas nos movimentos moleculares lentos nos poli(alquil metacrilato)s com base nas distribuições utilizadas. A coluna $2 *$ flip apresenta $o$ dobro do valor, em porcentagem, utilizado na simulação para a contribuição do movimento de um único flip, isto é, os valores encontrados na coluna dão diretamente a porcentagem de grupos laterais que realizam oflip. As colunas $\% / \sigma_{1}$, $\% / \sigma_{2} \mathrm{e} \% / \sigma_{3}$ indicam as porcentagens respectivas e os valores rms $\sigma_{1}, \sigma_{2}$ e $\sigma_{3}$ das distribuições gaussianas, centradas em $0^{\circ}$, dos ângulos de twist para os movimentos 1,2 e 3 das Figuras 4.9 e 4.10. As porcentagens dos movimentos de flip, twist 1 e twist 2 para uma determinada amostra são sempre iguais, já que estes três movimentos estão acoplados da forma discutida acima. O movimento de twist 1 só pode ser observado através do acompanhamento de grupos da cadeia principal, o que não foi realizado para as amostras iPMMA e PEMA enriquecida $\left(20 \%\right.$ em $\left.{ }^{13} \mathrm{C}\right)$. Os movimentos de twist 2 e twist 3 foram simulados com os valores indicados tanto para os ajustes dos dados experimentais dos grupos da cadeia principal quanto do grupo COO.

A componente referente à difusão de spins obtida dos dados CODEX do ${ }^{13} \mathrm{CH}_{2}$ tem uma contribuição igual a $4 \%$ para todas as amostras. Isso dá uma idéia da imprecisão na determinação do flip dos dados experimentais PUREX do ${ }^{13} \mathrm{COO}$, onde não é incluído explicitamente nas simulações o efeito da difusão de spins (neste caso a contribuição para pequenos tempos de evolução é totalmente dominada pela contribuição dos números ímpares de flips). 
Tabela III. Porcentagem de cada componente conforme utilizada nas simulações do tipo indicado na Figura 4.11 (a) e (c) para todos os PRMAs à temperatura ambiente.

\begin{tabular}{ccccc}
\hline Polímero & $2^{*}$ flip & $\% / \sigma_{1}{ }^{*}$ & $\% / \sigma_{2}$ & $\% / \sigma_{3}$ \\
\hline aPMMA & $34 \%$ & $17 \% / 12^{\circ}$ & $17 \% / 9^{\circ}$ & $55 \% / 3^{\circ}$ \\
iPMMA & $26 \%$ & - & $14 \% / 9^{\circ}$ & $25 \% / 3^{\circ}$ \\
PEMA & $31 \%$ & $15 \% / 18^{\circ}$ & $15 \% / 12^{\circ}$ & $69 \% / 3^{\circ}$ \\
PEMA 20\% ${ }^{13} \mathrm{C}$ & $31 \%$ & -- & $14 \% / 12^{\circ}$ & $59 \% / 3^{\circ}$ \\
PiBMA & $22 \%$ & $11 \% / 18^{\circ}$ & $11 \% / 12^{\circ}$ & $72 \% / 2^{\circ}$ \\
PcHMA & $12 \%$ & $6 \% / 15^{\circ}$ & $6 \% / 11^{\circ}$ & $50 \% / 2,5^{\circ}$ \\
\hline
\end{tabular}

*Não foram realizados experimentos para acompanhamento dos carbonos da cadeia principal para $o$ iPMMA e o PEMA enriquecido.

A Figura 4.14 mostra os dados da intensidade do sinal CODEX como função de $N t_{\mathrm{r}}$ para todos os PRMAs da Tabela III e para o ácido poli(metacrílico) (PMAA). Desta vez, as curvas simuladas seguem as distribuições dadas na Tabela III, que valem tanto para os dados PUREX quanto CODEX do grupo COO (excetuando-se os valores da coluna $\% / \sigma_{1}$ que só podem ser obtidos diretamente através de experimentos CODEX de carbonos das cadeia principais - quaternário e $\mathrm{CH}_{2}$ ). 

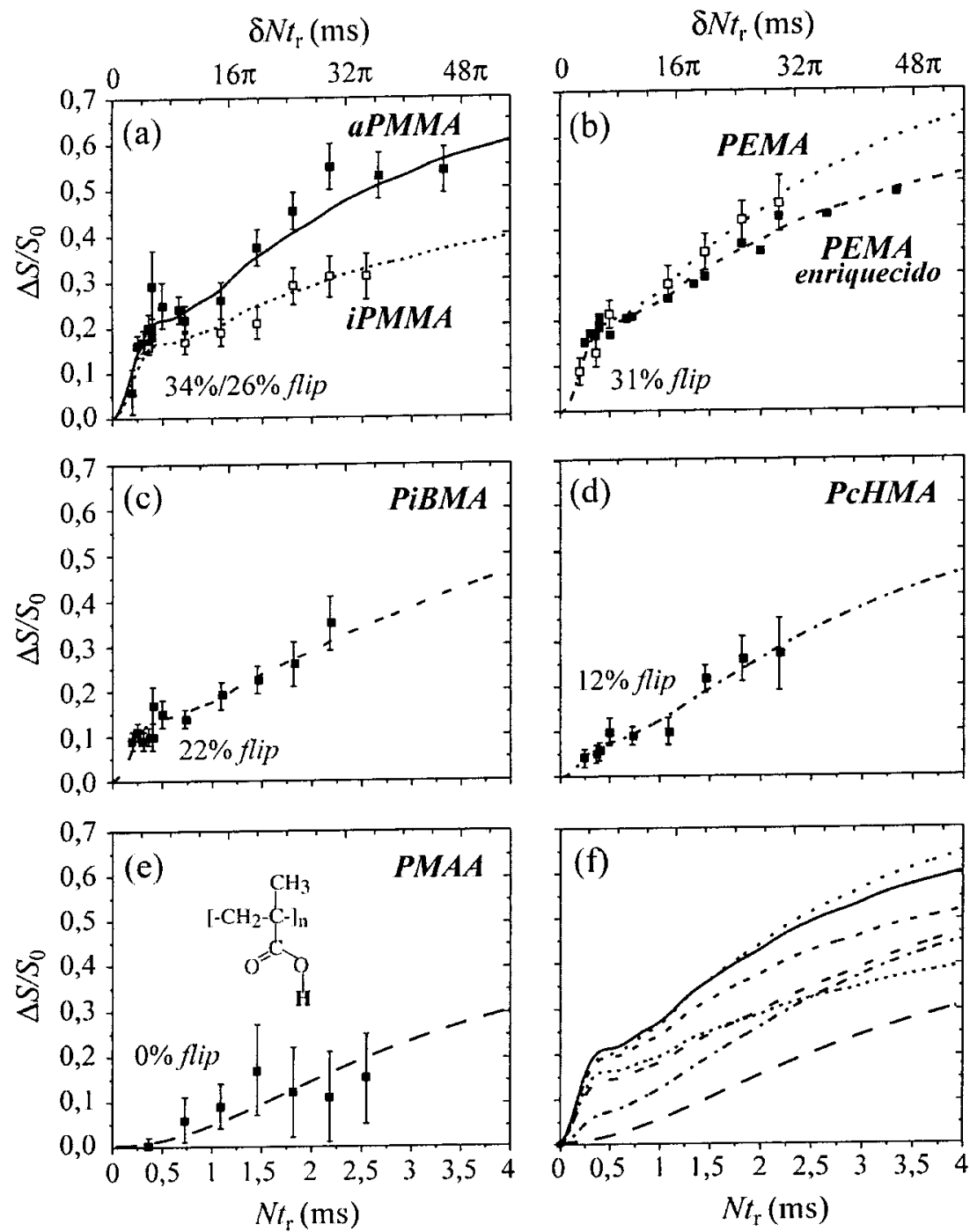

Figura 4.14: Curvas CODEX em função do tempo de reacoplamento $N t_{\mathrm{r}}$ com as simulações definidas na Tabela III: (a) aPMMA e iPMMA, (b) PEMA comum e PEMA enriquecido, (c) PiBMA, (d) PcHMA e (e) ácido poli(metacrílico) (PMAA) à $25^{\circ} \mathrm{C}$. O tempo de mistura utilizado foi $500 \mathrm{~ms}$, exceto para o PEMA $\left(t_{\mathrm{m}}=100 \mathrm{~ms}\right)$. As curvas simuladas representam a somatória das contribuições descritas na Figura 4.11 para o experimento PUREX. Todas as curvas foram obtidas dessa mesma maneira, com exceção feita para o PMAA que apresenta apenas um movimento de baixo ângulo com $\sigma=3,5^{\circ} \mathrm{com}$ uma porcentagem de $50 \%$. Em (f) estão colocadas, para comparação, todas as curvas simuladas na figura, onde pode-se perceber a influência relativa da porcentagem de cada componente dada na Tabela III para as curvas observadas. A porcentagem de flip que deve ser colocada na simulação para reprodução das curvas é igual a metade do valor indicado (para ficar de acordo com as discussões e a coluna $2 *$ flip da Tabela III).

Como pode ser observado nas simulações da Figura 4.7, a subida inicial das curvas na Figura 4.14 é atribuída ao movimento de flip de $180^{\circ}$, o que foi detectado previamente (para o PMMA e o PEMA enriquecidos com ${ }^{13} \mathrm{C}$ ) através de 
experimentos de exchange $2 \mathrm{D}^{4,5}$. O segundo aumento visto nas curvas da Figura 4.14 é devido aos movimentos lentos de pequenos ângulos, twist 2 e twist 3 como já discutido acima. O primeiro destes movimentos é uma distribuição gaussiana com valores de $\sigma_{2}$ da ordem de $10^{\circ}$. Essa componente está relacionada a números pares de flips, que fazem o grupo lateral retornar, aproximadamente mas não exatamente, a sua orientação original. O segundo movimento é a distribuição gaussiana com valores para $\sigma_{3}$ próximos a $3^{\circ}$. Essa componente é relacionada aos movimentos lentos de twist de pequena amplitude observada em grande parte dos grupos laterais que não realizam o flip.

À temperatura ambiente, com as novas simulações, a fração de flip é máxima para o aPMMA (34\%), Fig. 4.14(a). No iPMMA amorfo, essa fração é ligeiramente menor (26\%). Isso indica que a fração de grupos laterais que realizam o flip na forma isotática do PMMA é um pouco menor do que naquelas unidades em que predomina a forma sindiotática.

Sabe-se que, para o iPMMA, o pico de perda mecânica relacionado ao processo de relaxação $\alpha$ é deslocado em torno de $60^{\circ} \mathrm{C}$ abaixo da temperatura daquele observado para o polímero convencional (aPMMA) ${ }^{1}$. Isso faz com que ocorra uma superposição dos processos de relaxação $\alpha$ e $\beta$ no PMMA isotático. Por outro lado, as curvas de perda mecânica para o aPMMA, que sempre apresenta um alto grau de caráter sindiotático ( $76 \%$ neste caso), são em geral muito similares às do sPMMA. 
Enquanto que a altura do pico associado à relaxação $\beta$ no aPMMA é duas vezes aquela do pico $\alpha$, o oposto ocorre para o iPMMA Sendo assim, a amostra isotática sempre apresenta o pico $\alpha$ com maior magnitude e o pico $\beta$ com menor magnitude do que aquelas observadas para o aPMMA ou para o sPMMA. Adicionalmente, para uma determinada freqüência, o pico de relaxação $\beta$ é deslocado para temperaturas mais baixas na forma isotática do iPMMA.

Esse comportamento do PMMA frente a sua taticidade está de acordo com as diferenças nos valores das porcentagens de flip e do movimento de twist 3 obtidas para o aPMMA e o iPMMA na Figura 4.14. Enquanto que o processo de relaxação $\beta$ é menos efetivo para o iPMMA à temperatura ambiente (apenas 26\%), observa-se também uma redução considerável na porcentagem da componente 3 de ângulos pequenos de twist que passa de 55\%, no aPMMA, para apenas 25\%, no iPMMA.

No PEMA $31 \%$ e no PiBMA $22 \%$ dos grupos laterais realizam o movimento de flip, Fig.4.14(b) e (c), respectivamente. O degrau devido ao flip na curva do PcHMA, Fig.4.14(d), é pequeno mas claramente observável. A nova simulação, junto com os dados em função do tempo de mistura da Figura 4.14(d), mostra que em torno de $12 \%$ dos seus grupos laterais realizam o movimento de flip na escala de tempo de $1 \mathrm{~s}$. Neste caso, é confirmado que o efeito de difusão de spin não é o responsável pela pequena subida da curva para baixos valores de $N t_{\mathrm{r}}$, como esperado pela discussão feita sobre os dados da Figura 4.1.

Apesar da tendência indicada na Figura 4.14(f) de que a fração de grupos laterais que realizam o flip decresça com o tamanho do grupo lateral à temperatura ambiente, nenhuma fração de movimento de flip dos grupos laterais $(<5 \%)$ é detectada no PMAA na escala de tempo observada (1 s), Fig. 4.14(e). De acordo com 
a referência ${ }^{11}$, um grupo como o $\mathrm{COOH}$ é suficientemente assimétrico para evitar que o eixo principal $\sigma_{11}$ do SEP do tensor de deslocamento químico esteja ao longo da ligação C-C (o que faria o flip de $180^{\circ}$ invisível no experimento de RMN). Portanto, os dados da Figura 4.14(e) indicam que é improvável que flips lentos de $180^{\circ}$ do grupo $\mathrm{COOH}$ estejam ocorrendo. Ou os movimentos de flip são muito rápidos, de forma que o experimento detecta somente uma freqüência média invariante, ou, o que é mais provável, estes movimentos são muito lentos (podendo até não existir). Essa última hipótese pode ser explicada, por exemplo, pelas restrições impostas ao movimento devido às ligações de hidrogênio entre os grupos

\section{$\mathrm{COOH}$.}

As mesmas observações são válidas para o comportamento das curvas PUREX em função de $2 \tau$ na temperatura ambiente para todos os PRMAs, já que estas simulações também são feitas com base na Tabela III. Com isso, conclui-se que os resultados quantitativos obtidos com as técnicas CODEX e PUREX mostram que, no estado vítreo, somente uma fração dos grupos ésteres laterais dos poli(alquil metacrilato)s realizam flips de $180^{\circ}$. Mais especificamente, no PMMA apenas em torno de $1 / 3$ dos grupos laterais realizam este movimento. Antes do desenvolvimento das técnicas CODEX e PUREX, nenhuma técnica permitia a determinação da fração de flip com precisão. Portanto, estes experimentos revelam a fração de segmentos móveis como um terceiro aspecto fundamental da relaxação $\beta \mathrm{em}$ polímeros vítreos após a taxa e a amplitude dos movimentos dos segmentos envolvidos nesse processo.

Os dados também mostram que mesmo os grandes grupos laterais isobutil e ciclohexil podem realizar o movimento de flip à temperatura ambiente. 
Os resultados para a técnica CODEX em função da temperatura, Fig. 4.4, mostram uma surpreendente diferença no comportamento da fração de flip do PMMA em comparação com o PEMA e o PiBMA. Os dados mostram que a fração de flip (e também a amplitude do movimento) no PMMA é independente da temperatura entre $25^{\circ} \mathrm{C}$ e $80^{\circ} \mathrm{C}$, enquanto que um forte aumento é observado para o PEMA e o PiBMA. Como resultado, a $60^{\circ} \mathrm{C}$ a fração de flip para os grupos laterais do PEMA é aproximadamente duas vezes maior que a dos grupos laterais do PMMA que são menores. Era de se esperar que grupos laterais maiores apresentassem sempre uma maior restrição ao seu movimento, independente da faixa de temperatura.

Uma possível explicação para este efeito é indicada na Figura 4.15. O grupo lateral do PMMA tem menos graus de liberdade do que os que são disponíveis para os longos grupos laterais dos outros PRMAs. Com isso, sua forma assimétrica mostrada na Figura 4.15(a) é independente da temperatura e as constrições estéricas à conformação após o flip de $180^{\circ}$ permanecem iguais. No PEMA o grupo lateral é altamente assimétrico na conformação trans-trans, Fig. 4.15(b), que é a conformação dominante encontrada à temperatura ambiente ${ }^{12}$. No entanto, se a ligação C-O-C-C passa a ter uma conformação gauche em altas temperaturas, surge uma conformação de grupo lateral com uma maior simetria, Fig. 4.15(c). Isso acabaria por facilitar os flips, pois nesse momento o grupo $\mathrm{CH}_{2}$ "reserva" espaço para o grupo $\mathrm{CH}_{3}$ após o movimento, e vice-versa. Da mesma forma, uma conformação gauche da ligação CO-C-C no grupo lateral isobutil, leva a uma maior simetria do sistema, Fig. 4.15(d). 
(a)

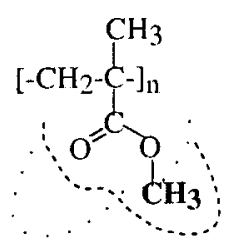

PMMA

qualquer temperatura (b)

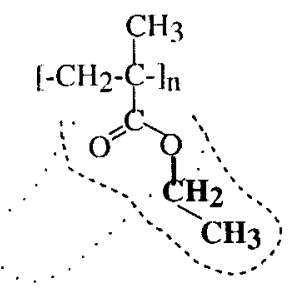

PEMA

baixas temperaturas (c)

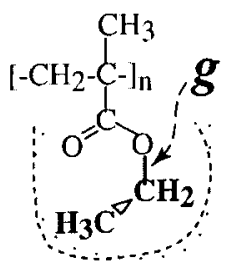

PEMA

altas

temperaturas (d)

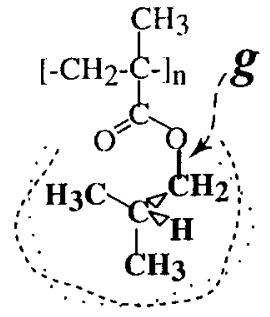

PiBMA

altas

temperaturas

Figura 4.15: Representação das conformações dos grupos laterais esquematizando uma possivel explicação para as diferentes dependências, com a temperatura, do PMMA em contraposição ao PEMA e o PiBMA (as linhas fracamente pontilhadas indicam o espaço necessário para o grupo lateral após realizar o flip). (a) PMMA. (b) PEMA na conformação trans-trans de baixas temperaturas. (c) PEMA em uma conformação hipotética transgauche em altas temperaturas, que faz o grupo lateral tornar-se mais simétrico e favorece os flips. (d) Grupos lateral do PiBMA em uma conformação hipotética mais simétrica em altas temperaturas. As ligações $\mathrm{C}-\mathrm{O}-\mathrm{C}-\mathrm{C}$ na conformação gauche estão marcadas pela letra $g$.

Essa hipótese, para a conformação em altas temperaturas, apresentada para tentar explicar o aumento da fração de grupos laterais que realizam o flip no PEMA pode ser testada experimentalmente através de uma extensão das medidas realizadas na referência 12 para temperaturas mais altas. No entanto, isso exige a utilização de uma amostra com enriquecimento múltiplo em ${ }^{13} \mathrm{C}$.

A ausência da dependência da fração de flip com a temperatura para o PMMA indica que essa fração não é uma quantidade arbitrária que resulta apenas dos movimentos que aparecem na janela de tempo do experimento (máximo $\sim 1 \mathrm{~s}$ ). $\mathrm{O}$ comportamento idêntico das curvas na Figura 4.4(a) sugere que a fração de flip no PMMA é uma quantidade fixa, estruturalmente determinada. 


\subsubsection{Estudo das Curvas PUREX em Função de $2 \tau$}

Considerando-se que o experimento PUREX mostrou-se mais sensível às distribuições de pequenos ângulos para o twist, realizou-se um estudo mais detalhado em função da temperatura para os PRMAs com essa técnica. A Figura 4.16 mostra as curvas da intensidade do sinal de exchange em função de $2 \tau$ obtidas até temperaturas próximas da $T_{\mathrm{g}}$ de cada polímero como indicadas.

Na Figura 4.16 também estão mostradas as regiões de baixos valores para $\tau$ que são aquelas responsáveis por definir as porcentagens de flip. Nas análises devese considerar, conforme a Tabela II do Capítulo III, que o PMMA e o PcHMA apresentam sua transição vítrea em temperaturas altas, $105^{\circ} \mathrm{C}$ e $104^{\circ} \mathrm{C}$, respectivamente. Enquanto que o PEMA e o PiBMA tem valores intermediários para a $T_{\mathrm{g}}: 66^{\circ} \mathrm{C}$ e $55^{\circ} \mathrm{C}$, respectivamente.

Inicialmente, observa-se a tendência, já apresentada pelos dados CODEX da Figura 4.4, de que o PMMA realmente não aumenta a sua porcentagem de flip com o acréscimo da temperatura. Esse comportamento fica evidenciado nos dados da Figura 4.16(a), principalmente no detalhe da região que sofre mais a contribuição do flip. As temperaturas utilizadas variaram entre $21^{\circ} \mathrm{C}$ e $96^{\circ} \mathrm{C}$, i.e., da temperatura ambiente até $9^{\circ} \mathrm{C}$ abaixo da sua $T_{\mathrm{g}}$. 


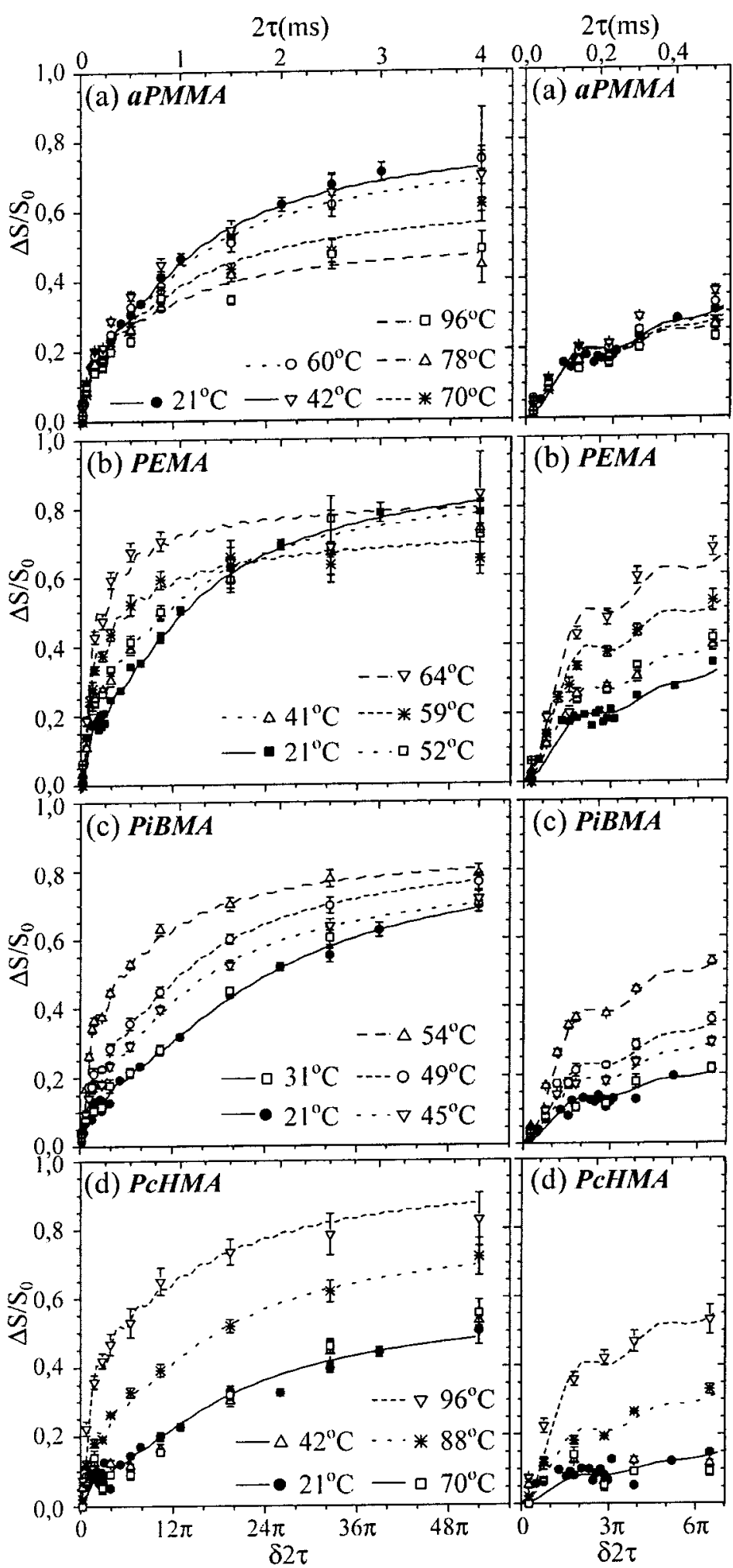

Figura 4.16: Curvas PUREX em função de $2 \tau$ mostrando a dependência dos movimentos lentos com a temperatura para os PRMAs: (a) PMMA, (b) PEMA, (c) o PiBMA e (d) PcHMA. A fração de grupos laterais que realizam o flip é constante no PMMA e aumenta com a temperatura para os outros polimeros. Para (b), (c) e (d) a amplitude da distribuição dos pequenos ângulos para a componente twist 2 também aumenta nas temperaturas altas. Para temperaturas próximas da $T_{\mathrm{g}}$, a porcentagem de elementos que realizam o twist 3 diminui em todos os casos, resultando na diminuição da intensidade da curva para altos valores de $\tau$. Este efeito está ligado aos movimentos muito rápidos que começam a promediar a anisotropia do espectro próximo da transição vítrea do polímero. No lado direito são apresentadas em detalhes as curvas para baixos tempos de evolução, aonde a contribuição do flip é mais efetiva. 
Assim como as outras três amostras, o PEMA tem um comportamento muito diferente. As curvas PUREX da Figura 4.16(b) mostram que a fração de grupos laterais que realizam o flip aumenta dos $31 \%$ a $21^{\circ} \mathrm{C}$, que é abaixo do valor encontrado para o PMMA nessa mesma temperatura, até $55 \%$ a $64^{\circ} \mathrm{C}\left(2^{\circ} \mathrm{C}\right.$ abaixo da sua $T_{\mathrm{g}}$ ). Para o PEMA mudanças na fração de flip já podem ser percebidas $25^{\circ} \mathrm{C}$ abaixo da sua $T_{\mathrm{g}}$, como se observa na curva de $41{ }^{\circ} \mathrm{C}$ na Figura $4.16(\mathrm{~b})$. Isso já indica que a falta de variação na porcentagem de flip no PMMA não é um efeito de se estar longe da sua $T_{\mathrm{g}}$ quando em temperaturas próximas da temperatura ambiente. Similarmente ao PEMA, os dados para o PiBMA mostrados nas Figuras 4.16(c) indicam um grande aumento da sua taxa de flip com a temperatura. A partir de $10^{\circ} \mathrm{C}$ abaixo da sua $T_{\mathrm{g}}$ pode-se perceber que a porcentagem de grupos laterais que realizam este movimento sobe vertiginosamente, indo dos $22 \%$ iniciais a $21^{\circ} \mathrm{C}$ até $54 \%$ para apenas um grau abaixo da sua $T_{\mathrm{g}}$. Estes resultados confirmam o que já era observado qualitativamente na Figura 4.4.

Nas Figuras 4.16(d) estão mostrados os dados PUREX para o PcHMA em cinco temperaturas diferentes. Em princípio surpreendentemente, por ter o maior grupo lateral de todos os PRMAs analisados, o PcHMA também apresenta um aumento na taxa de flip para temperaturas mais altas. Sua porcentagem de flip que é apenas $1 / 3(12 \%)$ da observada para o PMMA à temperatura ambiente, aumenta, similarmente ao PEMA e ao PiBMA, para $65 \%$ em temperaturas próximas da sua $T_{\mathrm{g}}$. Este resultado pode ser comparado mais diretamente ao observado para o PMMA já que suas temperaturas de transição vítrea são muito similares $\left(104^{\circ} \mathrm{C}, \mathrm{PcHMA}\right.$ e $105^{\circ} \mathrm{C}$, PMMA). A partir de $88^{\circ} \mathrm{C}\left(16^{\circ} \mathrm{C}\right.$ abaixo da $\left.T_{\mathrm{g}}\right)$ a fração de grupos laterais que realizam o flip já aumenta perceptivelmente, adquirindo um valor para a taxa de 
flip (35\%) próximo daquele observado para o PMMA em todas as temperaturas analisadas (34\%).

Como discutido no Capítulo III, quando o tamanho do grupo lateral aumenta as cadeias vizinhas são afastadas, diminuindo os obstáculos aos movimentos da cadeia principal ou até de outros grupos laterais 13,14 . No entanto, é observado que grupos laterais mais rígidos como o ciclohexil, apresentam altos valores de $T_{\mathrm{g}}$ com relação aqueles observados em grupos menores mas, que no entanto, são mais flexíveis. Essas discussões sobre a $T_{\mathrm{g}}$ baseiam-se apenas no afastamento entre as cadeias no polímero. Este raciocínio é válido para o comportamento da $T_{\mathrm{g}}$ dos PRMAs analisados. Partindo do PMMA $\left(T_{\mathrm{g}}=105^{\circ} \mathrm{C}\right)$, passando pelo PEMA $\left(T_{\mathrm{g}}=66^{\circ} \mathrm{C}\right)$ e indo até o PiBMA $\left(T_{\mathrm{g}}=55^{\circ} \mathrm{C}\right)$, observa-se uma diminuição nas temperaturas de transição vítrea devido ao maior espaçamento entre as cadeias poliméricas. Ao passar do PEMA para o PiBMA essa diminuição não é tão pronunciada como do PMMA para o PEMA por causa da maior rigidez do PiBMA, como discutido no Capítulo III com relação ao poli(n-butil metacrilato) (PnBMA). Por fim, esse último efeito passa a ser extremamente efetivo para o PcHMA com a sua alta temperatura de transição vítrea $\left(T_{\mathrm{g}}=104^{\circ} \mathrm{C}\right)$.

A discussão sobre o comportamento da taxa de flip, realizada na Figura 4.15 para o PMMA, o PEMA e o PiBMA, foi feita com base na possibilidade de mudança de conformação dos grupos laterais para justificar os resultados obtidos. No entanto, o PcHMA parece não apresentar a possibilidade de se rearranjar em uma outra conformação que o deixaria mais simétrico (ver detalhe da sua estrutura química nas Figuras 3.9 ou 4.2(d)). Os resultados observados para o PcHMA parecem confirmar a importância da simetria do sítio do grupo lateral antes e depois do flip, como 
indicado na Figura 4.14. Enquanto que o espaço ocupado pelo grupo lateral, antes e depois do flip, no PMMA (ou PEMA e PiBMA em conformações trans-trans) é altamente assimétrico, o sítio ocupado pelo PcHMA tem uma simetria relativa devido a própria forma do grupo ciclohexil, facilitando a realização do flip, como mostra a Figura 4.17.

Portanto, ao se considerar os diversos valores para a $T_{\mathrm{g}}$ (ou relaxação $\alpha$ ) nos PRMAs, as justificativas para essa variação podem ser embasadas apenas no maior (ou menor) espaçamento entre as cadeias devido à presença dos diferentes grupos laterais. Mas, no que diz respeito à relaxação $\beta$ (relacionada ao flip de $180^{\circ}$ dos grupos laterais), também tem que ser amplamente considerada a simetria do sítio ocupado pelo grupo lateral de cada PRMA.

(a)

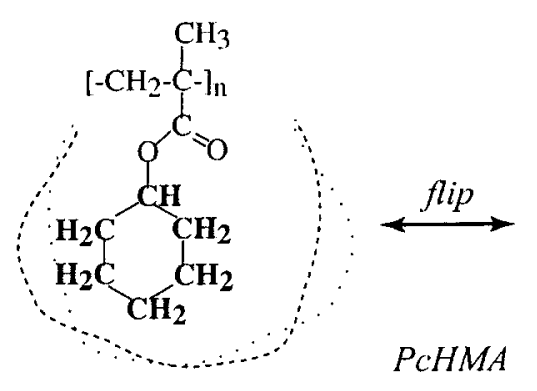

(b)

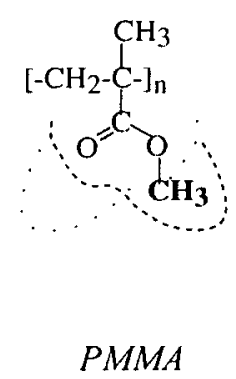

Figura 4.17: Espaço necessário para acomodar os grupos laterais do (a) PcHMA e do (b) PMMA antes e depois do flip. Apesar do grupo lateral do PcHMA ser muito maior, a região ocupada pelo ciclohexil é mais simétrica do que aquela ocupada pelo $\mathrm{CH}_{3}$, facilitando o movimento de flip.

Os dados utilizados para se realizar as simulações das Figuras 4.16 estão mostrados na Tabela IV. Da mesma forma que na Tabela III, a coluna $2 *$ flip apresenta o dobro do valor, em porcentagem, utilizado na simulação para a contribuição do movimento de um único flip. As colunas $\% / \sigma_{2} \mathrm{e} \% / \sigma_{3}$ indicam as porcentagens respectivas e os valores $\mathrm{rms} \sigma_{2}$ e $\sigma_{3}$ das distribuições gaussianas, centradas em $0^{\circ}$, dos ângulos de twist 2 e twist 3 das Figuras 4.9 e 4.10 . Os dados 
para o twist 1 não foram obtidos em função da temperatura devido ás limitações impostas pela baixa relação sinal/ruído dos espectros dos carbonos quaternários e dos grupos $\mathrm{CH}_{2}$ das cadeias principais.

Tabela IV. Porcentagem e amplitude de cada componente conforme utilizada nas simulações dos espectros PUREX dos PRMAs para cada temperatura.

\begin{tabular}{|c|c|c|c|c|c|}
\hline Polímero & $T^{*}$ & $T_{\mathrm{g}}-T$ & $2^{*}$ flip & $\% / \sigma_{2}$ & $\% / \sigma_{3}$ \\
\hline \multirow{5}{*}{$\begin{array}{c}\text { PMMA } \\
\left(T_{\mathrm{g}}=105^{\circ} \mathrm{C}\right)\end{array}$} & $21^{\circ} \mathrm{C}$ & $84^{\circ} \mathrm{C}$ & \multirow{2}{*}{$34 \%$} & \multirow{2}{*}{$34 \% / 9^{\circ}$} & \multirow{2}{*}{$55 \% / 3^{\circ}$} \\
\hline & $42^{\circ} \mathrm{C}$ & $63^{\circ} \mathrm{C}$ & & & \\
\hline & $60^{\circ} \mathrm{C}$ & $45^{\circ} \mathrm{C}$ & $34 \%$ & $34 \% / 9^{\circ}$ & $48 \% / 3^{\circ}$ \\
\hline & $70^{\circ} \mathrm{C}$ & $35^{\circ} \mathrm{C}$ & $34 \%$ & $34 \% / 9^{\circ}$ & $32 \% / 3^{\circ}$ \\
\hline & $\begin{array}{l}78^{\circ} \mathrm{C} \\
96^{\circ} \mathrm{C}\end{array}$ & $27^{\circ} \mathrm{C}$ & $34 \%$ & $34 \% / 9^{\circ}$ & $20 \% / 3^{\circ}$ \\
\hline \multirow{5}{*}{$\begin{array}{c}\text { PEMA } \\
\left(T_{\mathrm{g}}=66^{\circ} \mathrm{C}\right)\end{array}$} & $21^{\circ} \mathrm{C}$ & $45^{\circ} \mathrm{C}$ & $31 \%$ & $31 \% / 12^{\circ}$ & $69 \% / 3^{\circ}$ \\
\hline & $41^{\circ} \mathrm{C}$ & $25^{\circ} \mathrm{C}$ & \multirow[t]{2}{*}{$44 \%$} & \multirow[t]{2}{*}{$44 \% / 12^{\circ}$} & \multirow{2}{*}{$48 \% / 3^{\circ}$} \\
\hline & $52^{\circ} \mathrm{C}$ & $14^{\circ} \mathrm{C}$ & & & \\
\hline & $59^{\circ} \mathrm{C}$ & $7^{\circ} \mathrm{C}$ & $65 \%$ & $65 \% / 12^{\circ}$ & $10 \% / 3^{\circ}$ \\
\hline & $64^{\circ} \mathrm{C}$ & $2^{\circ} \mathrm{C}$ & $80 \%$ & $80 \% / 14^{\circ}$ & $4 \% / 3,5^{\circ}$ \\
\hline \multirow{4}{*}{$\begin{array}{c}\text { PiBMA } \\
\left(T_{\mathrm{g}}=55^{\circ} \mathrm{C}\right)\end{array}$} & $\begin{array}{l}21^{\circ} \mathrm{C} \\
31^{\circ} \mathrm{C} \\
\end{array}$ & $\begin{array}{l}34^{\circ} \mathrm{C} \\
24^{\circ} \mathrm{C} \\
\end{array}$ & $22 \%$ & $22 \% / 12^{\circ}$ & $72 \% / 2^{\circ}$ \\
\hline & $45^{\circ} \mathrm{C}$ & $10^{\circ} \mathrm{C}$ & $30 \%$ & $30 \% / 12^{\circ}$ & $55 \% / 3^{\circ}$ \\
\hline & $49^{\circ} \mathrm{C}$ & $6^{\circ} \mathrm{C}$ & $37 \%$ & $37 \% / 12^{\circ}$ & $55 \% / 3^{\circ}$ \\
\hline & $54^{\circ} \mathrm{C}$ & $1^{\circ} \mathrm{C}$ & $61 \%$ & $61 \% / 14^{\circ}$ & $28 \% / 3,5^{\circ}$ \\
\hline \multirow{5}{*}{$\begin{array}{c}\text { PcHMA } \\
\left(T_{\mathrm{g}}=104^{\circ} \mathrm{C}\right)\end{array}$} & $21^{\circ} \mathrm{C}$ & $83^{\circ} \mathrm{C}$ & \multirow{3}{*}{$12 \%$} & \multirow{3}{*}{$12 \% / 11^{\circ}$} & \multirow{3}{*}{$50 \% / 2,5^{\circ}$} \\
\hline & $42^{\circ} \mathrm{C}$ & $62^{\circ} \mathrm{C}$ & & & \\
\hline & $70^{\circ} \mathrm{C}$ & $34^{\circ} \mathrm{C}$ & & & \\
\hline & $88^{\circ} \mathrm{C}$ & $16^{\circ} \mathrm{C}$ & $35 \%$ & $35 \% / 11^{\circ}$ & $50 \% / 2,5^{\circ}$ \\
\hline & $96^{\circ} \mathrm{C}$ & $8^{\circ} \mathrm{C}$ & $65 \%$ & $65 \% / 14^{\circ}$ & $35 \% / 2,5^{\circ}$ \\
\hline
\end{tabular}

* Temperatura da amostra. 
Pelos dados da coluna $\% / \sigma_{2}$ da Tabela IV percebe-se que, para o PEMA, o PiBMA e o PcHMA, além do aumento da fração de grupos laterais que realizam o flip, é também observado um pequeno aumento na amplitude do movimento de twist 2 com o acréscimo da temperatura. Para estes três polímeros a amplitude desta componente aumenta por volta de $20 \%$ (até $\sigma_{2}=14^{\circ}$ ) ao se avançar da temperatura ambiente até próximo da $T_{\mathrm{g}}$. Isso significa que, em temperaturas elevadas, ângulos de twist maiores acompanham os movimentos de flip do grupo lateral.

As Figuras 4.16(b), (c) e (d) também mostram que, a despeito da subida inicial da intensidade do sinal de exchange devido ao aumento do flip com a temperatura, essa intensidade decresce para altos valores de $\tau$. Este fato pode ser observado também para o PMMA, Fig. 4.16(a). Isso ocorre porque, ao se aproximar da $T_{\mathrm{g}}$, os movimentos da cadeia polimérica tornam-se mais intensos, iniciando a promediação de parte da anisotropia dos sítios moleculares necessária para se caracterizar o processo de exchange (Capítulo I). Neste caso, começa a ficar mais difícil a observação dos movimentos de pequenos ângulos de twist $\left(\sigma \leq 3,5^{\circ}\right)$ do grupo lateral, como a componente twist 3. Assim, conforme a temperatura vai aumentando, o experimento não consegue mais fazer distinção entre os sítios envolvidos nestes movimentos. 
Esse efeito é comprovado pelas distorções observadas no espectro de pó do ${ }^{13} \mathrm{COO}$ devido à crescente promediação da anisotropia do deslocamento químico ${ }^{9}$, Figura 4.18. A Figura 4.18(a) mostra esse efeito de distorção do espectro de pó para altas temperaturas para o aPMMA. A Figura 4.18(b) mostra que o PcHMA, que tem uma temperatura para transição vítrea muito similar à do aPMMA, não sofre deformações observáveis no espectro até próximo da sua $T_{\mathrm{g}}$. Observando-se os espectros do PEMA, Figura 4.18(c), pode-se perceber o efeito da promediação nos espectros obtidos à temperaturas próximas da sua transição vítrea. $\mathrm{O}$ mesmo não é facilmente identificável com respeito ao PcHMA, Figura 4.18(d).

Concluindo, apenas o aPMMA e o PEMA apresentam mudanças significativas nos espectros de pó em temperaturas próximas da $T_{\mathrm{g}}$, que são devidas à promediação, por movimentos rápidos da cadeia polimérica, de parte da anisotropia dos sítios moleculares. Esse efeito está relacionado ao fato de que, nas simulações dos dados de altas temperaturas destas duas amostras, Figuras 4.16(a) e (b), porcentagens cada vez menores das contribuições descritas na coluna $\% / \sigma_{3}$ da Tabela IV devem ser utilizadas. Isso não significa que, repentinamente, os movimentos de twist 3 pararam de acontecer em vários sítios da amostra, mas sim que o tempo de correlação característico destes movimentos tornou-se muito baixo para ser observado pelos experimentos de exchange. 

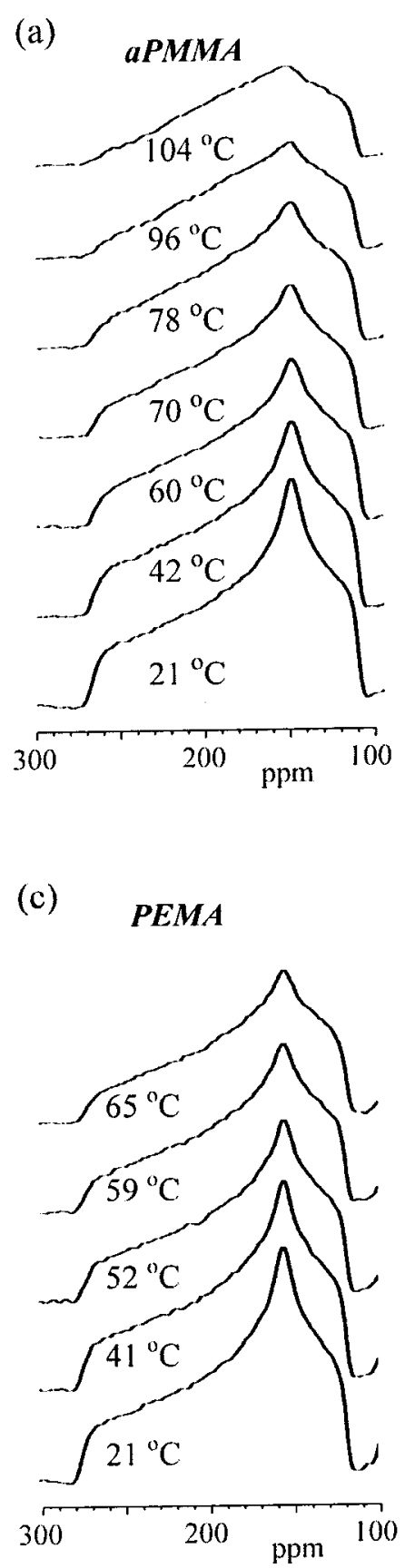
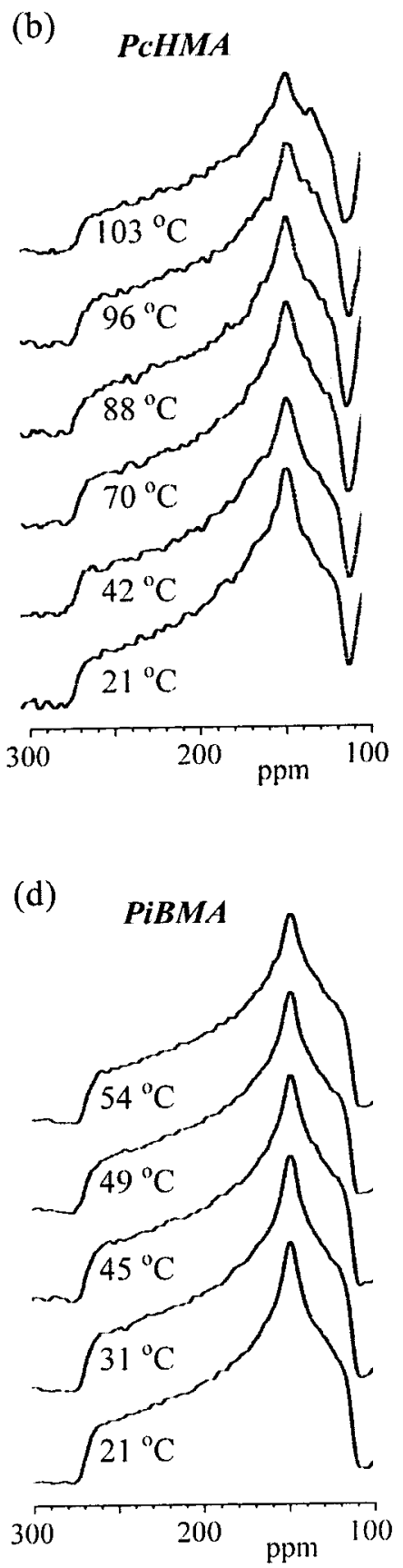

Figura 4.18: Espectros de pó do ${ }^{13} \mathrm{C}$ do grupo COO para: (a) o aPMMA; (b) o PcHMA; (c) o PEMA e (d) o PiBMA. Os espectros dos polímeros com $T_{\mathrm{g}}$ próximas foram colocados lado a lado. Para o aPMMA e o PEMA observa-se o efeito da promediação das interações que acaba deformando o espectro.

Através desse estudo, foram obtidas informações detalhadas e quantitativas sobre os movimentos lentos dos grupos laterais em poli(alquil metacrilato)s e poli(acrilatos $\alpha$-substituído)s com as técnicas de exchange CODEX e PUREX. Foram caracterizados movimentos de flip de grande amplitude e rotações lentas de 
pequena amplitude do grupo lateral. Somente uma fração dos grupos laterais, 34\% no PMMA, realiza os movimentos lentos de flip. Mesmo grandes grupos laterais realizam o flip, porém com uma fração reduzida (e.g., 12\% em grupos ciclohexil). Foram encontradas diferenças na dependência, com a temperatura, da fração de grupos laterais que realizam o flip no PMMA e no PEMA. Ainda que a fração de flip permaneça inalterada no PMMA, ela cresce continuamente entre $21^{\circ} \mathrm{C}$ e a $T_{\mathrm{g}}$ no PEMA, PiBMA e PcHMA. 


\subsection{Resultados Experimentais Obtidos no Estudo da Técnica Double Quantum}

Neste item são apresentados os resultados experimentais da implementação da técnica double quantum no espectrômetro Varian do IFSC. Para tanto, foram utilizadas as amostras POE/PNP e PET enriquecidas em pares ${ }^{13} \mathrm{C}^{13} \mathrm{C}$. Adicionalmente, são mostrados os resultados DQ (experimentos realizados em um espectrômetro Bruker DSX-300) do estudo da conformação do POE complexado em três sais de metais alcalinos.

\subsubsection{Experimentos de DQ no POE/PNP e no PET}

Para que fosse possível avaliar os resultados à medida que as seqüências de pulso fossem desenvolvidas no nosso laboratório foram escolhidas duas amostras enriquecidas com pares ${ }^{13} \mathrm{C}-{ }^{13} \mathrm{C}$ já estudadas com esta técnica: um complexo polimérico cristalino de poli(óxido etileno) e poli(para-nitrofenol) - POE/PNP15 e o polímero poli(etileno teraftalato) - $\mathrm{PET}^{16}$.

Os espectros foram adquiridos com uma sonda Doty de $7 \mathrm{~mm}$ à temperatura ambiente. Foram utilizados pulsos de $90^{\circ}$ para ${ }^{13} \mathrm{C}$ de $4,8 \mu$ s e para o ${ }^{1} \mathrm{H}$ de $3,7 \mu \mathrm{s}$, com desacoplamento de ${ }^{1} \mathrm{H}$ em $\gamma B_{1} / 2 \pi=70 \mathrm{kHz}$. O tempo de repetição utilizado foi de $3 \mathrm{~s}$. O tempo de polarização cruzada foi $0,5 \mathrm{~ms}$. O número total de médias foi 192 e, na segunda dimensão, foram realizados 28 incrementos em intervalos de $20 \mu$ s.

A seguir são apresentados os espectros DQ obtidos no espectrômetro Varian do IFSC. As Figuras 4.19(a) e (b) mostram os espectros para o PEO/PNP e as Figuras 4.19(c) e (d) para o PET, sem e com desacoplamento homonuclear, respectivamente. 
(a)
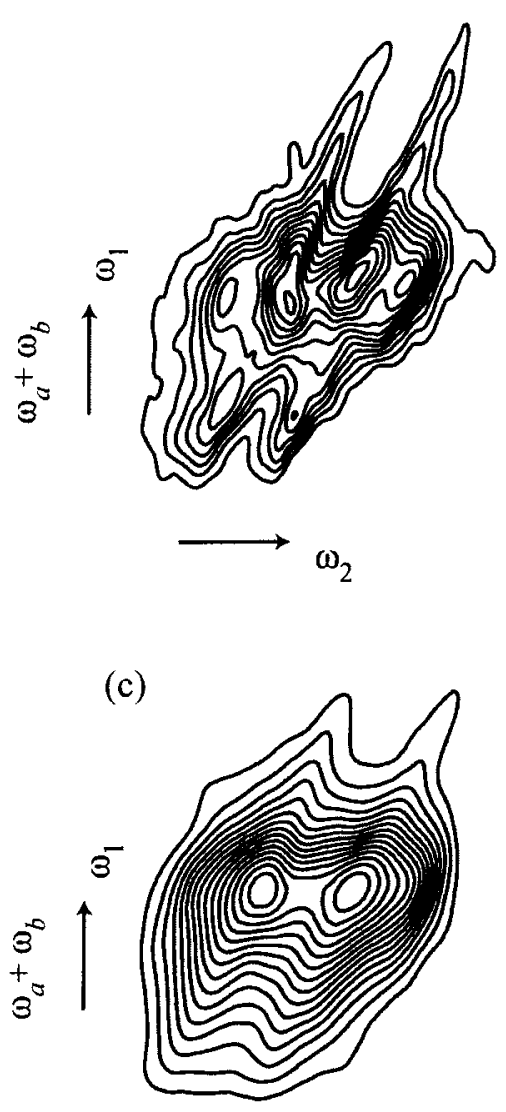

$\omega_{2}$

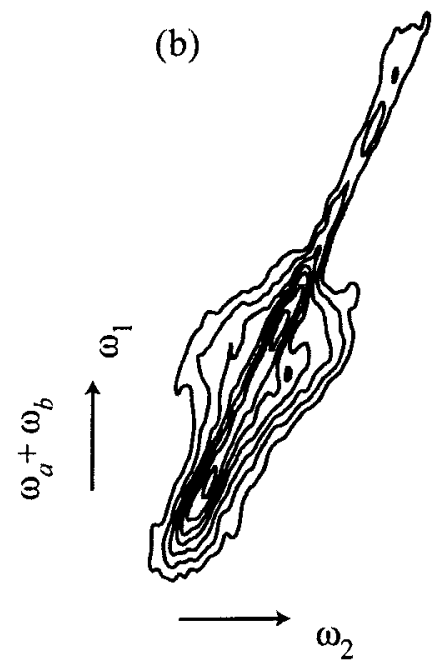

(d)

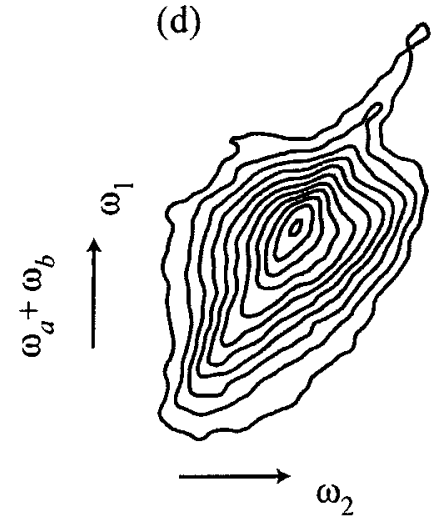

Figura 4.19: Espectros double quantum do POE no POE/PNP e do PET: (a) POE sem desacoplamento dipolar homonuclear; (b) POE com desacoplamento dipolar homonuclear; (c) PET sem desacoplamento dipolar homonuclear e (d) PET com desacoplamento dipolar homonuclear.

Os espectros sem e com desacoplamento dipolar homonuclear ${ }^{13} \mathrm{C}-{ }^{13} \mathrm{C}$ para o POE no POE/PNP mostram, de acordo com os padrões bidimensionais de double quantum vistos na Figura 2.17, que aproximadamente $67 \%$ dos ângulos de torção OC-CO são gauche.

Os espectros sem e com desacoplamento homonuclear para o PET permitem a observação de que a maior parte da sua conformação é gauche, com uma porcentagem trans $\approx 10 \%$. Isso pode ser observado pela pequena contribuição do sinal à parte superior dos espectros nas Figuras 4.19(a) e (b), de acordo com o obtido 
anteriormente $^{16}$.

\subsubsection{Experimentos DQ em Complexos de POE com Sais de Metais Alcalinos}

Como um exemplo de aplicação da técnica de double quantum para determinação de conformações moleculares utilizou-se compostos de poli(óxido etileno), POE, $\left[\left(-\mathrm{CH}_{2}-\mathrm{CH}_{2}-\mathrm{O}-\right)_{\mathrm{n}}\right]$, complexados com sais de metais alcalinos.

\section{Complexos de POE com Sais de Metais Alcalinos}

Eletrólitos poliméricos sólidos compostos de POE complexados com sais de metais alcalinos tem alta condutividade iônica fazendo-os muito úteis na fabricação de baterias de alta densidade de energia e em dispositivos eletrocrômicos. O transporte de íons nos eletrólitos poliméricos é altamente relacionado com as mudanças de comformação da cadeia de POE. Dessa forma, o conhecimento das características conformacionais do POE nestes complexos é importante para se entender os mecanismos de condução nesse tipo de material.

Sabe-se através de resultados de difração de raios-X, espectroscopia de infravermelho e espectroscopia Raman que a cadeia de POE no estado cristalino adota uma estrutura helicoidal que contém sete unidades que dão duas voltas ao longo do seu comprimento após $19.3 \AA^{[7]}$. Nessa hélice distorcida os ângulos de torção OC-CO são gauche, variando de $49^{\circ}$ a $92^{\circ}$, enquanto que os ângulos de torção CO-CC estão na conformação trans, em torno de $180^{\circ}$, como discutido nos Capítulo II.

No entanto, a conformação do POE complexado com metais alcalinos como os analisados aqui difere da estrutura helicoidal 72 . Os três compostos de POE investigados são: $(\mathrm{POE})_{3} \mathrm{NaI},(\mathrm{POE})_{3} \mathrm{LiCF}_{3} \mathrm{SO}_{3}$ e $(\mathrm{POE})_{3} \mathrm{LiClO}_{4}$. Encontra-se na 
literatura a caracterização destes três compostos através de outras técnicas. A estrutura cristalina do complexo (POE) $)_{3} \mathrm{NaI}$ foi determinada por $\mathrm{WAXD}^{17} \mathrm{e}$ espectroscopia vibracional (IR e Raman) ${ }^{18}$. A cadeia polimérica, na qual as unidades assimétricas consistem de três unidades monoméricas, tem uma conformação

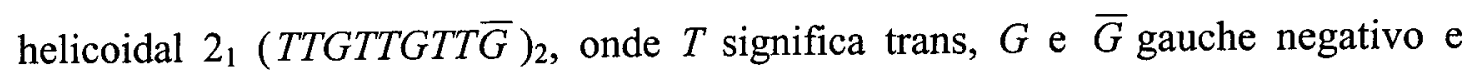
positivo, respectivamente. A cadeia helicoidal de POE tem uma periodicidade de $8.41 \AA$ com seis unidades repetidas de óxido etileno em cada cela unitária. Nessa hélice, os ângulos de torção gauche para OC-CO são $60^{\circ}, 92^{\circ}$ e $-62^{\circ}$; enquanto que os ângulos de torção trans CO-CC são $179^{\circ}, 180^{\circ}, 178^{\circ}, 180^{\circ}, 178^{\circ}$ e $177^{\circ}$. O arranjamento helicoidal da cadeia polimérica no complexo (POE) ${ }_{3} \mathrm{LiCF}_{3} \mathrm{SO}_{3}$ é similar ao $(\mathrm{POE})_{3} \mathrm{NaI}^{19}$. Já a estrutura cristalina do $(\mathrm{POE})_{3} \mathrm{LiClO}_{4}$ é mais complicada pois estudos de difração de raios-X indicaram que pelo menos três fases cristalinas distintas são formadas.

\section{Experimento $D Q$ e simulações}

Os espectros bidimensionais de double quantum foram adquiridos com um espectrômetro Bruker MSL 300 funcionando a $75,5 \mathrm{MHz}$ para ${ }^{13} \mathrm{C}$. A duração dos pulsos de ${ }^{13} \mathrm{C} \mathrm{e}{ }^{1} \mathrm{H}$ foi de $3,5 \mu$ s. Utilizou-se um tempo de contato igual a $500 \mu \mathrm{s}$, um tempo de aquisição de $3 \mathrm{~ms}$ e um tempo de repetição de $15 \mathrm{~s}$ para todos os experimentos. Na dimensão $t_{1}$ foram obtidas 18 incrementos espaçados por $20 \mu \mathrm{s}$. Utilizou-se um tempo de excitação e reconversão de double quantum definido por $2 \tau$ $=18 \mu \mathrm{s} . \mathrm{O}$ tempo de medida de cada espectro foi de aproximadamente 48 horas.

Os espectros simulados foram calculados diretamente no domínio das freqüências considerando-se $\boldsymbol{B}_{0}$ em todas as direções. Para cada orientação e para 
cada ângulo de torção específico o programa calcula a somatória do deslocamento químico anisotrópico do ${ }^{13} \mathrm{C}$ (dimensão de $\omega_{1}$ ), os deslocamentos químicos anisotrópicos individuais para ${ }^{13} \mathrm{C}$ e o acoplamento dipolar ${ }^{13} \mathrm{C}-{ }^{13} \mathrm{C}$ (dimensão de $\omega_{2}$ ). A geração de $\mathrm{DQ}$, as freqüências dipolares e de deslocamento químico e as intensidades dos espectros foram calculadas utilizando-se as fórmulas exatas dadas por Nakay et al. ${ }^{20}$. Para tornar as simulações mais próximas dos espectros reais foram adicionados alargamentos de linha pela convolução destas com gaussianas paralelas e perpendiculares à linha de coeficiente angular igual a dois no espectro 2D. Utilizou-se como valores do tensor de deslocamento químico $\sigma_{11}=93 \mathrm{ppm}, \sigma$ ${ }_{22}=84 \mathrm{ppm} \mathrm{e} \sigma_{33}=36 \mathrm{ppm}^{9}$. As coordenadas polares da ligação C-C no sistema de eixos principais do tensor de deslocamento químico foram $\alpha=-90^{\circ}, \beta=120^{\circ}$ e $\gamma$ = ângulo de torção, sendo a distância efetiva entre dois carbonos adjacentes igual a $1,56 \AA$.

As Figuras 4.20(a), (b) e (c) mostram os espectros double quantum do POE enriquecido com pares ${ }^{13} \mathrm{C}^{13} \mathrm{C}$ para as amostras $(\mathrm{POE})_{3} \mathrm{LiCF}_{3} \mathrm{SO}_{3}$, (POE) ${ }_{3} \mathrm{NaI}$ e $(\mathrm{POE})_{3} \mathrm{LiClO}_{4}$, respectivamente. Na Figura 4.20 também são apresentadas as simulações para cada espectro.

O contorno dos espectros mostra particularidades predominantemente gauche para as conformações. No entanto, algumas características do espectro trans também são observadas, especialmente na parte superior dos espectros. A fração estimada de ligações trans OC-CO foram: $(\mathrm{POE})_{3} \mathrm{LiCF}_{3} \mathrm{SO}_{3}<9 \%$, $(\mathrm{POE})_{3} \mathrm{NaI}<5 \%$ $\mathrm{e}(\mathrm{POE})_{3} \mathrm{LiClO}_{4}<2 \%$. 
Isso é obtido considerando-se a porcentagem utilizada nas simulações que melhor reproduziram os espectros, mostradas na Figura 4.20. Os ângulos gauche médios são iguais a $70^{\circ} \% \pm 15^{\circ} \%$ e os ângulos trans $\approx 180^{\circ}$. Devido à baixa porcentagem de conformações trans é difícil estimar a incerteza na determinação do seu ângulo de torção. Nas simulações foram usadas distribuições com larguras de $10^{\circ}$ em torno dos valores médios para os ângulos de torção de $70^{\circ}$ (gauche) e $180^{\circ}$ (trans).

A dispersão de deslocamentos químicos devido a efeitos conformacionais e de empacotamento não é uma razão provável para o alargamento observado. Nesse caso as larguras de linhas não seriam tão grandes e os alargamentos para os dois sítios ligados seriam menos correlacionados. Este alargamento é devido às fortes interações dipolares entre os núcleos ${ }^{13} \mathrm{C}$ e os núcleos dos sais que têm altas abundâncias naturais e momentos magnéticos relativamente intensos: ${ }^{7} \mathrm{Li}$ $\left(92.6 \%, 0,39 \gamma_{\mathrm{H}}\right),{ }^{23} \mathrm{Na}\left(100 \%, 0,26 \gamma_{\mathrm{H}}\right),{ }^{127} \mathrm{I}\left(100 \%, 0,20 \gamma_{\mathrm{H}}\right),{ }^{19} \mathrm{~F}\left(100 \%, 0,94 \gamma_{\mathrm{H}}\right),{ }^{35} \mathrm{Cl}$ $\left(75.4 \%, 0,10 \gamma_{\mathrm{H}}\right)$. A alta concentração de gauche obtida para todos os complexos através do experimento de double quantum corrobora a conformação proposta pela utilização de outros métodos experimentais encontrados na literatura. 
(a)

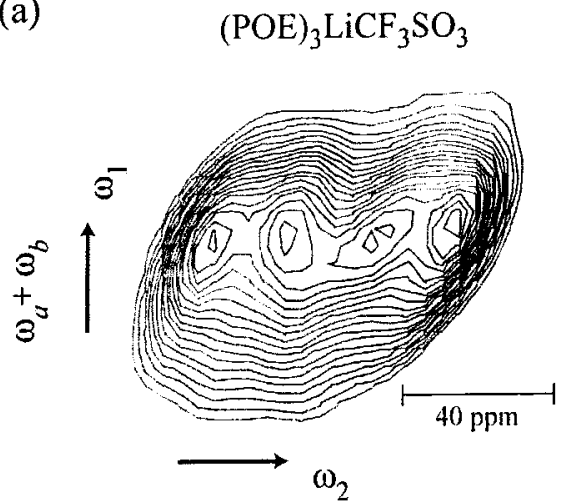

(b)

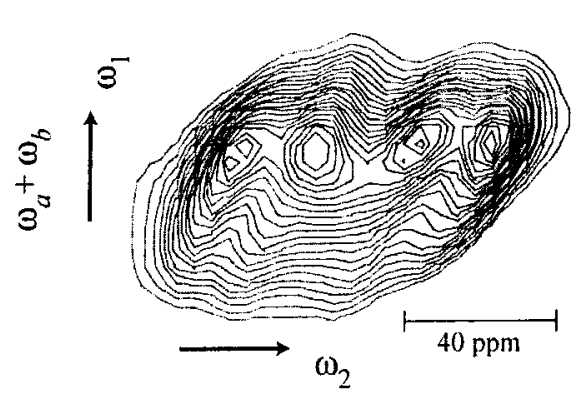

(c)

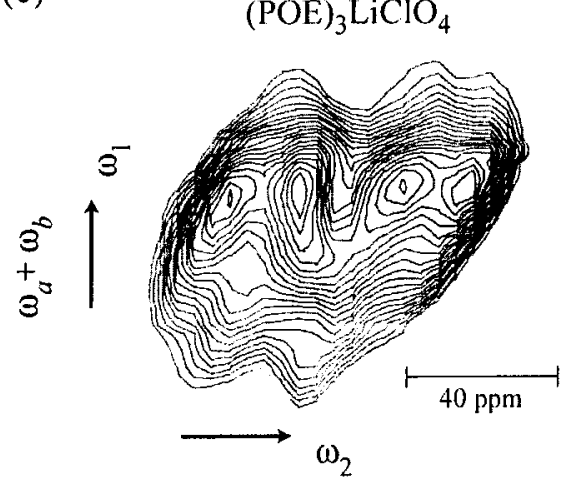

Simulação

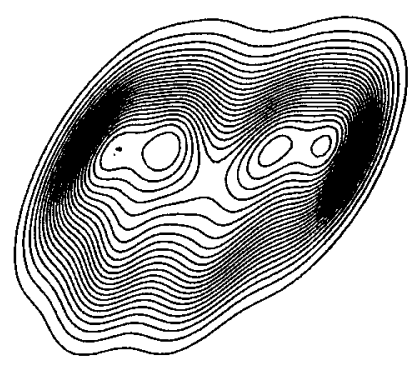

Simulação

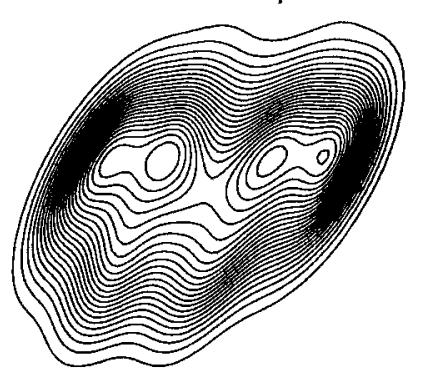

Simulação

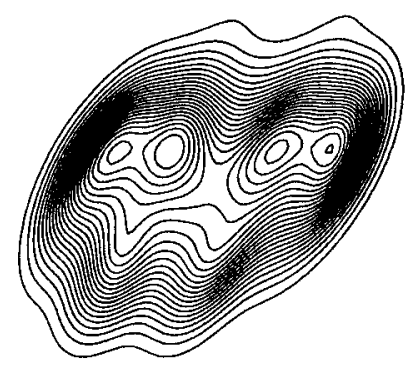

Figura 4.20: Espectros experimentais de double quantum sem desacoplamento homonuclear $\mathrm{e}$ as respectivas simulações para: (a) $(\mathrm{POE})_{3} \mathrm{LiCF}_{3} \mathrm{SO}_{3}$; (b) (POE) ${ }_{3} \mathrm{NaI}$ e (c) $(\mathrm{POE})_{3} \mathrm{LiClO}_{4}$. A porcentagem de conformações trans obtidas pelas simulações são iguais a $9 \%, 5 \%$ e $2 \%$ em (a), (b) e (c), respectivamente. 


\section{Conclusões e Perspectivas}

Com este trabalho, informações detalhadas e quantitativas sobre os movimentos lentos dos grupos laterais de cinco poli(alquil metacrilato)s e três poli(acrilatos $\alpha$-substituído)s foram obtidos por duas novas técnicas de RMN de exchange: centerband-only detection of exchange (CODEX) e pure exchange (PUREX). Até então, não haviam sido caracterizadas com tantos detalhes as rotações de $180^{\circ}$ (flip) dos grupos éster acopladas a movimentos de pequenos ângulos em torno da cadeia principal associados à relaxação $\beta$ nestes polímeros. A influência do tamanho do grupo lateral nestes movimentos moleculares foi caracterizada. Polímeros com grupos laterais maiores apresentam menos grupos participando deste processo à temperatura ambiente. Isso é válido, mesmo quando o grupo lateral acoplado ao carboxil (sob análise) mantém seu tamanho e o grupo $\left(\alpha-\mathrm{CH}_{3}\right)$ é mudado. Estudos em função da temperatura mostram que essa característica muda para altas temperaturas ainda que abaixo da $T_{\mathrm{g}}$ do polímero. $\mathrm{O}$ poli(metil metacrilato), que contém o menor grupo lateral, não aumenta a porcentagem de grupos laterais que realizam esses movimentos com o acréscimo da temperatura. No entanto, outros polímeros, com grupos laterais maiores, passam a ter uma porcentagem muito maior de grupos laterais realizando estes movimentos moleculares, passando dos valores encontrados para o PMMA. Isso mostrou que, 
com energia térmica suficiente, os grupos laterais maiores são capazes de encontrar conformações melhores no que diz respeito à simetria do espaço que eles ocupam antes e depois de realizar o movimento. Este estudo também mostrou que a técnica PUREX é mais sensível que a técnica CODEX aos movimentos de pequena amplitude, possibilitando a observação de detalhes da distribuição de ângulos necessária para se adequar as simulações às curvas experimentais. Essa característica tem que ser levada em consideração em estudos que podem ser feitos sem a rotação da amostra em torno do ângulo mágico.

Foi também realizado com sucesso um estudo da técnica double quantum, utilizada para a determinação de ângulos de torção entre pares ${ }^{13} \mathrm{C}-{ }^{13} \mathrm{C}$ na cadeia polimérica. Este estudo resultou na implementação desse experimento, com e sem desacoplamento homonuclear, no espectrômetro de RMN do IFSC-USP, permitindo sua utilização em trabalhos futuros.

Como visto nessa tese, muitos trabalhos de RMN(aplicando diversas técnicas de exchange) ${ }^{1}$, relaxação dielétrica e relaxação mecânica dinâmica $(\text { DMTA })^{2}$ já foram desenvolvidos para analisar a dinâmica dos grupos principais e laterais dos poli(alquil metacrilato)s e poli(acrilatos $\alpha$-substituído)s. No entanto, todos estes estudos não foram conclusivos, e nenhum dos que utilizaram RMN analisou os movimentos lentos $(0,1 / \mathrm{s}-1000 / \mathrm{s})$ com alta resolução empregando-se MAS como foi realizado para os oito compostos estudados nesse trabalho. As técnicas de RMN CODEX ${ }^{3-5}$ e PUREX $^{6}$ podem fornecer informações mais precisas que as técnicas acima citadas. Por exemplo, através delas a amplitude do movimento pôde ser estimada independentemente de qualquer modelo de relaxação. Portanto, a sua utilização é de fundamental importância para se analisar a dinâmica individual de 
cada grupo químico presente na cadeia polimérica e melhorar a compreensão da dinâmica de outros polímeros dessa família que também tenham um interesse de aplicação industrial.

Diversos polímeros constituem-se em potenciais candidatos para serem utilizados em futuros estudos similares aos desenvolvidos nesta tese.

Uma classe de polímeros de grande interesse são copolímeros acrílicos contendo cromóforos de azobenzenos ${ }^{7}$. Neste caso, os cromóforos de azobenzeno são inseridos em alguns ramos laterais do polímero acrílico (do tipo PMMA) conferindo ao material propriedades ópticas não lineares. Vários estudos utilizando relaxação dielétrica já foram realizados nesta classe de materiais no Grupo de Polímeros do IFSC. Os principais resultados indicam a presença dos processos de relaxação $\alpha$ e $\beta$. O processo que ocorre a mais baixa temperatura, a relaxação $\beta$, foi atribuído a movimentos do grupo $\mathrm{COOCH}_{3}$, na parte não funcionalizada do polímero (ramos sem a inserção do cromóforo). Já a relaxação $\alpha$ foi associada a movimentos moleculares nos grupos cromóforos. Portanto, ambos os processos de relaxação ( $\alpha \mathrm{e}$ ß) poderão ser estudados utilizando-se as novas técnica de exchange, com uma abordagem semelhante à dada neste trabalho, o que pode trazer informações valiosas sobre os detalhes dos movimentos moleculares envolvidos nestes materiais. Um dos tipos de movimentos moleculares que podem ser estudados são as transições entre as conformações cis e trans dos anéis benzênicos dos cromóforos. Estes movimentos são os responsáveis pelas propriedades ópticas não lineares desses materiais tornando-os, dessa forma, de grande interesse para a pesquisa. Outra possibilidade de estudo nesses polímeros são os efeitos da presença do cromóforo nos movimentos moleculares associados as relaxações $\alpha$ e $\beta$ do PMMA. 
Entre as perspectivas para futuros trabalhos também pode ser citado o estudo de polímeros industriais importantes como o poliestireno (PS), o policarbonato $(\mathrm{PC})$ e o poli(vinil acetato) (PVAC). Vários experimentos convencionais de RMN utilizando o padrão de bandas laterais em experimentos MAS e relaxação já foram realizados nesses polímeros com o objetivo de obter informações sobre a dinâmica molecular rápida $(\mathrm{kHz}-\mathrm{MHz})$ dos mesmos. Experimentos de $\mathrm{RMN}$ de ${ }^{2} \mathrm{H}$ mostraram que grande parte da mobilidade local no poliestireno tem origem em movimentos moleculares nos grupos aromáticos. Foi observado que os anéis aromáticos executam um movimento de flip de $180^{\circ}$ em torno do eixo do anel ${ }^{8}$. Espectros de ${ }^{13} \mathrm{C}$, obtidos com ecos rotacionais dipolares e de deslocamento químico, e medidas de $\mathrm{T}_{1}\left({ }^{13} \mathrm{C}\right)$ e $\mathrm{T}_{1 \rho}\left({ }^{13} \mathrm{C}\right)$ confirmaram o movimento de flip e sugeriram a possibilidade da presença de oscilações de pequenas amplitudes $\left(\sim 18^{\circ}\right)$ em torno do eixo do anel ${ }^{9}$. Estudos similares realizados tanto para o policarbonato quanto para o poli(vinil acetato) também confirmaram a presença deste tipo de movimento molecular ${ }^{8-11}$. Todavia esses trabalhos não foram conclusivos no que diz respeito a alguns detalhes desses movimentos como, por exemplo, a distribuição de ângulos de oscilação e de flip. Devido à alta sensibilidade das técnicas CODEX e PUREX à geometria e à escala de tempo de movimentos moleculares lentos, estas poderão ser utilizadas para confirmar a presença desses movimentos no intervalo de freqüência de $\mathrm{Hz}$ a $\mathrm{kHz}$, e também para obter informações sobre os detalhes do movimento molecular dos anéis aromáticos, que ainda não foram estudados por outras técnicas. Um estudo desse tipo pode ainda ser expandido para a análise dos movimentos moleculares lentos no policarbonato presente em blendas comerciais largamente utilizadas pela indústria como 
CYCOLOY $^{\circledR}$ - blenda de policarbonato com poli(acrilonitrila-co-butadieno-coestireno) (PC/ABS) e XENOY ${ }^{\circledR}$ - blenda polimérica de policarbonato com poliéster termoplástico (PC/PBT); ambas da GE Plastics.

Uma proposta de utilização futura e desenvolvimento dos estudos conformacionais por RMN abordados nesta tese é a sua aplicação em blendas contendo poli(óxido etileno). Uma possibilidade é realizar a polimerização do POE, enriquecido com pares de núcleos ${ }^{13} \mathrm{C}-{ }^{13} \mathrm{C}$, para sua utilização na formação de blendas deste polímero com o PMMA ou poli(4-vinil fenol) (PVF), por exemplo. Nas blendas obtidas pode-se suprimir completamente a fase cristalina do POE, utilizando-se porcentagens adequadas de POE e PMMA ou PVF. Deste modo, com a utilização da técnica de double quantum, poder-se-á determinar a conformação do PEO na fase amorfa e comparar esses resultados com os previstos pela teoria de Flory (Rotational Isomeric State Model of Polymers) 12,13 . Outros compostos também interessantes para serem estudados com esta metodologia são as ormolitas, nanocompostos mistos orgânico-inorgânicos (silica-POE). Neste caso, podem ser estudados os efeitos das interações físicas entre as fases orgânica e inorgânica do híbrido sobre a conformação do POE. Estes trabalhos já são temas de futuras dissertações de mestrado de alunos do grupo de RMN do IFSC. 


\section{Referências}

\section{Introdução}

1)Andrew, E. R.; Bradbury, A.; Eades, R. G. Nature 1958, 182, 1659.

2)Lowe, I. J. Phys. Rev. Lett. 1959, 2, 285-287.

3)Waug, J. S.; Huber, L. M.; Haeberlen, U. Phys. Rev. Lett. 1968, $20,180$.

4)Pines, A.; Gibby, M. G.; Waugh, J. S. J. Chem. Phys. 1972, 56, 1776.

5)Alla, M.; Lippmaa, E. Chem. Phys. Lett. 1976, 37, 260.

6)Schaefer, J.; Stejskal, E. O. J. Am. Chem. Soc. 1976, 98, 1031-1032.

7)Blümich, B.; Spiess, H. W. Angew. Chem. Int. Ed. Engl. 1988, 27, 1655.

8)Schmidt, C.; Wefing, S.; Blümich, B.; Spiess, H. W. Chem. Phys. Lett. 1986, 130, 84-90.

9)Schmidt, C.; Blümich, B.; Spiess, H. W. J. Magn. Reson. 1988, 79, 269-290.

10)Wefing, S.; Kaufmann, S.; Spiess, H. W. J. Chem. Phys. 1988, 89, 1234-1244.

11)Schmidt-Rohr, K.; Spiess, H. W. Multidimensional Solid-State NMR and Polymers; 1 st ed.; Academic Press: London, 1994; Vol. 1.

12)Henrichs, P. M.; Linder, M. J. Magn. Reson. 1984, 58, 458-461.

13)Edzes, H. T.; Bernards, J. P. C. J. Am. Chem. Soc. 1984, 106, 1515-1517.

14)Robyr, P.; Meier, B. H.; Ernst, R. R. Chem. Phys. Lett. 1991, 187, 471-478.

15)Robyr, P.; Tomaselli, M.; Straka, J.; Grob-Pisano, C.; Suter, U. W.; Meier, B. H.; Ernst, R. R. Mol. Phys. 1995, 84, 995-1020.

16)Mehring, M. High Resolution NMR in Solids; Springer-Verlag: Berlin, 1983.

17)Hagemeyer, A.; Schmidt-Rohr, K.; Spiess, H. W. Two-Dimensional Nuclear Magnetic Resonance Experiments for Studying Molecular Order and Dynamics in Static and in Rotating Solids; Warren, W. S., Ed.; Academic Press, Inc.: São Diego, 1989; Vol. 13, pp 85129.

18)deAzevedo, E. R.; Bonagamba, T. J.; Schmidt-Rohr, K. J. Mag. Reson. 2000, 142, 86-96. 19)deAzevedo, E. R.; Becker-Guedes, F.; Bonagamba, T. J.; Schmidt-Rohr, K. em preparação 2001.

20)Becker-Guedes, F.; deAzevedo, E. R.; Bonagamba, T. J.; Schmidt-Rohr, K. em preparação 2001.

21)deAzevedo, E. R.; Bonagamba, T. J.; Hu, W.-H.; Schmidt-Rohr, K. J. Am. Chem. Soc. $1999,121,8411-8412$.

22)Perepechko, I. I. An Introduction to Polymer Physics; Mir Publishers: Moscou, 1981.

23)Axelson, D. E. Carbon-13 Solid-State NMR of Semicrystalline Polymers; Komoroski, R. A., Ed.; VCH Publishers, Inc.: Deerfield Beach, 1986; Vol. 7.

24)Bailey, R. T.; North, A. M.; Pethrick, R. A. Molecular Motion in High Polymers; Oxford University Press: New York, 1981.

25)McCrum, N. G.; Buckley, C. P.; Bucknall, C. B. Principles of Polymer Engineering; 2nd ed.; Oxford University Press, Inc.: New York, 1997.

26)Boyd, R. H.; Robertsson, M. E.; Jansson, J. F. J. Polym. Sci.: Polym. Phys. Ed. 1982, 20, 73-81.

27)McCrum, N. G.; Read, B. E.; Williams, G. Anelastic and Dielectric Effects in Polymeric Solids; 2nd ed.; Dover: New York, 1991; Vol. 1.

28)Schmidt-Rohr, K.; Kulik, A. S.; Beckham, H. W.; Ohlemacher, A.; Pwelzik, U.; Spiess, H. W. Macromolecules 1994, 27, 4733 - 4745.

29)Nakai, T.; McDowell, C. A. Chem. Phys. Lett. 1994, 217, 234-238.

30)Nakai, T.; McDowell, C. A. J. Am. Chem. Soc. 1994, 116, 6373-6383.

31)Schmidt-Rohr, K. Macromolecules 1996, 29, 3975-3981. 
32)Schmidt-Rohr, K. J. Magn. Reson. 1998, 131, 209-217.

33)Schmidt-Rohr, K.; Hu, W.; Zumbulyadis, N. Science 1998, 280, 714-717.

34)Harris, D. J.; Bonagamba, T. J.; Hong, M.; Schmidt-Rohr, K. Macromolecules 2000, 33, 3375-3381.

\section{Capítulo I}

1)deAzevedo, E. R.; Bonagamba, T. J.; Schmidt-Rohr, K. J. Mag. Reson. 2000, 142, 86-96. 2)deAzevedo, E. R.; Bonagamba, T. J.; Hu, W.-H.; Schmidt-Rohr, K. J. Am. Chem. Soc. $1999,121,8411-8412$.

3)deAzevedo, E. R.; Hu, W.-H.; Bonagamba, T. J.; Schmidt-Rohr, K. J. Chem. Phys. 2000, 112,8988 .

4)Ernst, R. R.; Bodenhausen, G.; Wokaun, A. Principles of Nuclear Magnetic Resonance in One and Two Dimensions; 1st ed.; Clarendon Press: London / New York, 1987; Vol. 14.

5)Schmidt-Rohr, K.; Spiess, H. W. Multidimensional Solid-State NMR and Polymers; 1st ed.; Academic Press: London, 1994; Vol. 1.

6)McCrum, N. G.; Read, B. E.; Williams, G. Anelastic and Dielectric Effects in Polymeric Solids; 2nd ed.; Dover: New York, 1991; Vol. 1.

7)Slichter, C. P. Principles of Magnetic Resonance; 3rd ed.; Springer-Verlag: Heidelberg (Germany), 1990; Vol. 1.

8)Abragam, A. Principles of Nuclear Magnetism; Oxford Science Publications: Oxford, 1996.

9)Schmidt-Rohr, K.; Kulik, A. S.; Beckham, H. W.; Ohlemacher, A.; Pwelzik, U.; Spiess, H. W. Macromolecules 1994, 27, 4733 - 4745.

10)Spiess, H. W. Rotation of Molecules and Nuclear Spin Relaxation; 1st ed.; Diehl, P., Fluck, E. and Kosfeld, R., Ed.; Springer-Verlag: Berlin, 1978; Vol. 15, pp 59-214.

11)Szeverenyi, N. M.; Bax, A.; Maciel, G. E. J. Am. Chem. Soc. 1983, 105, 2579-2582.

12)Edzes, H. T.; Bernards, J. P. C. J. Am. Chem. Soc. 1984, 106, 1515-1517.

13)Hagemeyer, A.; Van Der Putten, D.; Spiess, H. W. J. Magn. Reson. 1991, 92, 628-630.

14)Schmidt, C.; Blümich, B.; Spiess, H. W. J. Magn. Reson. 1988, 79, 269-290.

15)Tekely, P.; Brondeau, J.; Elbayed, K.; Retournard, A.; Canet, D. J. Magn. Reson. 1988, 80,509 .

16)Bloembergen, N. Physica 1949, XV, 386.

17)Connor, T. M.; Read, B. E.; Willians, G. J. Appl. Chem. 1964, 14, 74-81.

18)McKenna, G. B. Comp. Mater. Sci. 1995, 4, 349-360.

19)Favre, D. E.; Schaefer, D. J.; Auerbach, S. M.; Chmelka, B. F. Phys. Rev. Lett. 1998, 81, 5852-5855.

20)Becker-Guedes, F.; deAzevedo, E. R.; Bonagamba, T. J.; Schmidt-Rohr, K. em preparação 2002.

21)Dixon, W. T. J. Chem. Phys. 1982, 77, 1800.

22)Gullion, T.; Schaefer, J. Adv. Magn. Reson. 1989, 13, 57-83.

\section{Capítulo II}

1)Schmidt-Rohr, K. Macromolecules 1996, 29, 3975-3981.

2)Schmidt-Rohr, K. J. Magn. Reson. 1998, 131, 209-217.

3)Henrichs, P. M.; Linder, M. J. Magn. Reson. 1984, 58, 458-461.

4)Edzes, H. T.; Bernards, J. P. C. J. Am. Chem. Soc. 1984, 106, 1515-1517.

5)Robyr, P.; Meier, B. H.; Ernst, R. R. Chem. Phys. Lett. 1991, 187, 471-478. 
6)Robyr, P.; Tomaselli, M.; Straka, J.; Grob-Pisano, C.; Suter, U. W.; Meier, B. H.; Ernst, R. R. Mol. Phys. 1995, 84, 995-1020.

7)Dabbagh, G.; Weliky, D. P.; Tycko, R. Macromolecules 1994, 27, 6183-6191.

8)Schmidt-Rohr, K.; Spiess, H. W. Multidimensional Solid-State NMR and Polymers; 1st ed.; Academic Press: London, 1994; Vol. 1.

9)Tomita, Y.; O'Connor, E. J.; McDermott, A. J. Am. Chem. Soc. 1994, 116, 8766-8771

10)Weliky, D. P.; Daggagh, G.; Tycko, R. J. Magn. Reson. 1993, 104, 10-16.

11)Nakai, T.; McDowell, C. A. Chem. Phys. Lett. 1994, 217, 234-238.

12)Nakai, T.; McDowell, C. A. J. Am. Chem. Soc. 1994, 116, 6373-6383.

13)Raleigh, D. P.; Creuzet, F.; Gupta, S. K. D.; Levitt , M. H.; Griffin, R. G. J. Am. Chem. Soc. $1989,111,4502-4503$.

14)Bennett, A. E.; Griffin, R. G.; Vega, S. , 1994; Vol. 33, pp 3.

15)Gullion, T.; Schaefer, J. Adv. Magn. Reson. 1989, 13, 57-83.

16)Pan, Y.; Gullion, T.; Schaefer, J. J. Magn. Reson. 1990, 90, 330-340.

17)Hing, A. W.; Vega, S.; Schaefer, J. J. Magn. Reson. 1992, 96, 205-209.

18)Gottwald, J.; Demco, D. E.; Graf, R.; Spiess, H. W. Chem. Phys. Lett. 1995, 243, $314-$ 323.

19)Jeener, J.; Meier, B. H.; Bachmann, P.; Ernst, R. R. J. Chem. Phys. 1979, 71, 4546-4553. 20)VanderHart, D. L. J. Chem. Phys. 1976, 64, 830-834.

21)Schmidt-Rohr, K.; Wilhelm, M.; Johansson, A.; Spiess, H. W. Magn. Reson. Chem. 1993, $31,352-356$

22)deAzevedo, E. R.; Bonagamba, T. J.; Schmidt-Rohr, K. J. Mag. Reson. 2000, 142, 86-96.

23)Nakai, T.; Mcdowell, C. A. Mol. Phys. 1993, 79, 965-983.

24)Nakai, T.; Mcdowell, C. A. J. Mag, Res. A 1993, 104, 146-153.

25)Sorensen, O. W.; Eich, G. W.; Levitt, M. H.; Bodenhausen, G.; Ernst, R. R. Prog. Nucl. Magn. Reson. Spectrosc. 1983, 16, 163-192.

26)Ernst, R. R.; Bodenhausen, G.; Wokaun, A. Principles of Nuclear Magnetic Resonance in One and Two Dimensions; 1st ed.; Clarendon Press: London / New York, 1987; Vol. 14.

27)Slichter, C. P. Principles of Magnetic Resonance; 3rd ed.; Springer-Verlag: Heidelberg (Germany), 1990; Vol. 1.

28)Banwell, C. N.; Primas, H. Mol. Phys. 1963, 6, 225-256.

29)Günther, H. NMR Spectroscopy; John Wiley \& Sons: Chichester, 1996.

30)Harris, D. J.; Bonagamba, T. J.; Schmidt-Rohr, K. Macromolecules 1999, 32, 6718-6724.

31)Schmidt-Rohr, K. Macromolecules 1996, 29, 3975-3981.

32)Schmidt-Rohr, K. J. Am. Chem. Soc. 1996, 118, 7601-7603.

33)Rhim, W.-K.; Pines A; S, W. J. Phys. Rev. B:Solid State 1971, 3, 684-695.

34)Haeberlen, U. High Resolution NMR in Solids; 1st ed.; Academic Press: London, 1976; Vol. supplement 1.

35)Harris, D. J.; Bonagamba, T. J.; Hong, M.; Schmidt-Rohr, K. Macromolecules 2000, 33, 3375-3381.

36)Tadokoro, H.; Chatani, Y.; Yoshihara, T.; Tahara, S.; Murahashi, S. Makromol. Chem. 1964, 74, 109.

37)Tadokoro, H.; Chatani, Y.; Kobayashi, M.; Yoshihara, T.; Murahashi, S.; amada, K. Rept. Prog. Polym. Phys. Japan 1963, 6, 303.

38)Flory, P. J. Statistical Mechanics of Chain Molecules; Wiley-Interscience: New York, 1969.

39)Tonelli, A. E. NMR Spectroscopy and Polymer Microstrucure: The Conformational Connection; VCH:, 1989.

40)Aranda, P.; Ruiz-Hitzky, E. Chem. Mater. 1992, 4, 1395-1403. 


\section{Capítulo III}

1)McCrum, N. G.; Read, B. E.; Williams, G. Anelastic and Dielectric Effects in Polymeric Solids; 2nd ed.; Dover: New York, 1991; Vol. 1.

2)Van-Brevelen, D. W.; Hoftyzer, P. J. Properties of Polymers; 1st ed.; Elsevier Scientific Publishing Company: Amsterdam, 1980.

3)Perepechko, I. I. An Introduction to Polymer Physics; Mir Publishers: Moscou, 1981.

4)Bailey, R. T.; North, A. M.; Pethrick, R. A. Molecular Motion in High Polymers; Oxford University Press: New York, 1981.

5)Helfand, E. Science 1984, 226, 647-650.

6)McCrum, N. G.; Buckley, C. P.; Bucknall, C. B. Principles of Polymer Engineering; 2nd ed.; Oxford University Press, Inc.: New York, 1997.

7)Bovey, F. A.; Tyers, G. V. D. J. Polym. Sci. 1960, 44, 173.

8)Fox, T. G.; Schnecko, H. W. Polymer 1962, 3, 575.

9)Baumann, V.; Schreiber, H.; Tessmar, K. Makromol. Chemie. 1959, 36, 81.

10)Komoroski, R. A. High Resolution NMR Spectroscopy of Synthetic Polymers in Bulk; VCH:, 1986; Vol. 7.

11)Kawai, T. J. Phys. Soc. (Japan) 1961, 16, 1220.

12)Powles, J. G.; Mansfield, P. Polymer 1962, 3, 336.

13)Schmidt-Rohr, K.; Kulik, A. S.; Beckham, H. W.; Ohlemacher, A.; Pwelzik, U.; Spiess, H. W. Macromolecules 1994, 27, 4733 - 4745.

14)Kulik, A. S.; Beckham, H. W.; Schmidt-Rohr, K.; Radloff, D.; Pawelzik, U.; Boeffel, C.; Spiess, H. W. Macromolecules 1994, 27, 4746-4754.

15)Penelle, J.; Collot, J.; Rufflard, G. J. Polym. Sci., Part A: Plym. Chem. 1993, 31, $2407-$ 2412.

16)Otsu, T.; Yamagishi, K.; Matsumoto, A.; Yoshioka, M.; Watanabe, H. Macromolecules 1993, 26, 3026-3029.

17)Penelle, J.; Verraver, S. Makromol. Chem., Rapid Commun. 1993, 14, 563-568.

18)Schmidt-Rohr, K.; Spiess, H. W. Multidimensional Solid-State NMR and Polymers; 1st ed.; Academic Press: London, 1994; Vol. 1.

19)deAzevedo, E. R. Novas Metodologias de RMN para o Estudo da Dinâmica Lenta em Materiais Orgânicos no Estado Sólido: Aplicações em Polímeros e Proteínas (Tese de Doutorado); Universidade de São Paulo: São Carlos, 2001.

20)Edzes, H. T. Polymer 1983, 24, 1425-1428.

21)Rose, M. E. Elementary Theory of Angular Momentum; USA:, 1957; Vol. 1.

22)Kulik, A. S.; Radloff, D.; Spiess, H. W. Macromolecules 1994, 27, 3111-3113.

23)Kuebler, S. C.; Schaefer, D. J.; Boeffel, C. Macromolecules 1997, 30, 6597-6609.

24)Mehring, M. High Resolution NMR in Solids; Springer-Verlag: Berlin, 1983.

\section{Capítulo IV}

1)McCrum, N. G.; Read, B. E.; Williams, G. Anelastic and Dielectric Effects in Polymeric Solids; 2nd ed.; Dover: New York, 1991; Vol. 1.

2)Lethersich, W. Brit. J. Appl. Phys. 1950, 1, 294-301.

3)Boyd, R. H.; Robertsson, M. E.; Jansson, J. F. J. Polym. Sci.: Polym. Phys. Ed. 1982, 20, 73-81.

4)Schmidt-Rohr, K.; Kulik, A. S.; Beckham, H. W.; Ohlemacher, A.; Pwelzik, U.; Spiess, H. W. Macromolecules 1994, 27, 4733 - 4745.

5)Kulik, A. S.; Beckham, H. W.; Schmidt-Rohr, K.; Radloff, D.; Pawelzik, U.; Boeffel, C.; Spiess, H. W. Macromolecules 1994, 27, 4746-4754.

6)deAzevedo, E. R.; Bonagamba, T. J.; Hu, W.-H.; Schmidt-Rohr, K. J. Am. Chem. Soc. 
$1999,121,8411-8412$.

7)deAzevedo, E. R.; Hu, W.-H.; Bonagamba, T. J.; Schmidt-Rohr, K. J. Chem. Phys. 2000, 112,8988 .

8)deAzevedo, E. R.; Bonagamba, T. J.; Schmidt-Rohr, K. J. Mag. Reson. 2000, 142, 86-96.

9)Schmidt-Rohr, K.; Spiess, H. W. Multidimensional Solid-State NMR and Polymers; ist ed.; Academic Press: London, 1994; Vol. 1.

10)Bonagamba, T. J.; Becker-Guedes, F.; deAzevedo, E. R.; Schmidt-Rohr, K. J. Polym. Sci. B: Polymer Physics 2001, 39, 2444-2453.

11)Veeman, W. S. Prog. Nucl. Magn. Reson. Spectrosc. 1984, 16, 193-235.

12)Dabbagh, G.; Weliky, D. P.; Tycko, R. Macromolecules 1994, 27, 6183-6191.

13)Bailey, R. T.; North, A. M.; Pethrick, R. A. Molecular Motion in High Polymers; Oxford University Press: New York, 1981.

14)Perepechko, I. I. An Introduction to Polymer Physics; Mir Publishers: Moscou, 1981.

15)Harris, D. J.; Bonagamba, T. J.; Hong, M.; Schmidt-Rohr, K. Macromolecules 2000, 33, 3375-3381.

16)Schmidt-Rohr, K.; Hu, W.; Zumbulyadis, N. Science 1998, 280, 714-717.

17)Chatani, Y.; Okamura, S. Polymer 1987, 28, 1815-1820.

18)Papke, B. L.; Ratner, M. A.; Shriver, D. F. J. Phys. Chem. Solids 1981, 42, 493-500.

19)Lightfoot, P.; Mehta, M. A.; Bruce, P. G. Science 1993, 262, 883-885.

20)Nakai, T.; Mcdowell, C. A. J. Mag, Res. A 1993, 104, 146-153.

\section{Capítulo V}

1)Schmidt-Rohr, K.; Kulik, A. S.; Beckham, H. W.; Ohlemacher, A.; Pwelzik, U.; Spiess, H. W. Macromolecules 1994, 27, 4733 - 4745.

2)McCrum, N. G.; Read, B. E.; Williams, G. Anelastic and Dielectric Effects in Polymeric Solids; 2nd ed.; Dover: New York, 1991; Vol. 1.

3)Bonagamba, T. J.; Becker-Guedes, F.; deAzevedo, E. R.; Schmidt-Rohr, K. J. Polym. Sci. B: Polymer Physics 2001, 39, 2444-2453.

4)deAzevedo, E. R.; Hu, W.-H.; Bonagamba, T. J.; Schmidt-Rohr, K. J. Chem. Phys. 2000, 112,8988 .

5)deAzevedo, E. R.; Bonagamba, T. J.; Hu, W.-H.; Schmidt-Rohr, K. J. Am. Chem. Soc. $1999,121,8411-8412$.

6)deAzevedo, E. R.; Bonagamba, T. J.; Schmidt-Rohr, K. J. Mag. Reson. 2000, 142, 86-96.

7)Ribeiro, P. A.; Balogh, D. T.; Giacometti, J. A. IEEE Trans. Dielet. Elect. Insul. 2000, 7, 572-577.

8)Spiess, H. W. Colloid Polym. Sci. 1983, 5, 446 - 453.

9)Schaefer, J.; Stejskal, E. O.; McKay, R. A.; Dixon, W. T. Macromolecules 1984, 17, 1107. 10)Wehrle, M.; Hellmann, G. P.; Spiess, H. W. Colloid Polym. Sci. 1987, 9, 815-822.

11)Schaefer, J.; Stejskal, E. O.; Perchak, D.; Skolnick, J.; Yaris, R. Macromolecules 1985, 18,368 .

12)Tonelli, A. E. NMR Spectroscopy and Polymer Microstrucure: The Conformational Connection; VCH:, 1989.

13)Flory, P. J. Statistical Mechanics of Chain Molecules; Wiley-Interscience: New York, 1969. 